\title{
The universal periodic review mechanism of the United Nations Human Rights Council : transforming the human rights discourse
}

Citation for published version (APA):

Lewis, T. N. (2013). The universal periodic review mechanism of the United Nations Human Rights Council : transforming the human rights discourse. [Doctoral Thesis, Maastricht University]. Maastricht University. https://doi.org/10.26481/dis.20131128tl

Document status and date:

Published: 01/01/2013

DOI:

10.26481/dis.20131128t|

Document Version:

Publisher's PDF, also known as Version of record

Please check the document version of this publication:

- A submitted manuscript is the version of the article upon submission and before peer-review. There can be important differences between the submitted version and the official published version of record.

People interested in the research are advised to contact the author for the final version of the publication, or visit the DOI to the publisher's website.

- The final author version and the galley proof are versions of the publication after peer review.

- The final published version features the final layout of the paper including the volume, issue and page numbers.

Link to publication

\footnotetext{
General rights rights.

- You may freely distribute the URL identifying the publication in the public portal. please follow below link for the End User Agreement:

www.umlib.nl/taverne-license

Take down policy

If you believe that this document breaches copyright please contact us at:

repository@maastrichtuniversity.nl

providing details and we will investigate your claim.
}

Copyright and moral rights for the publications made accessible in the public portal are retained by the authors and/or other copyright owners and it is a condition of accessing publications that users recognise and abide by the legal requirements associated with these

- Users may download and print one copy of any publication from the public portal for the purpose of private study or research.

- You may not further distribute the material or use it for any profit-making activity or commercial gain

If the publication is distributed under the terms of Article 25fa of the Dutch Copyright Act, indicated by the "Taverne" license above, 


\title{
THE UNIVERSAL PERIODIC REVIEW MECHANISM OF THE UNITED NATIONS HUMAN RIGHTS COUNCIL: TRANSFORMING THE HUMAN RIGHTS DISCOURSE
}

\author{
to obtain the degree of Doctor at \\ Maastricht University, \\ on the authority of the Rector Magnificus, Prof. Dr. L.L. G. Soete \\ in accordance with the decision of the Board of Deans, \\ to be defended in public \\ on Thursday, November 28, 2013 at 14.00 hours \\ by Tamara Nicolle Lewis Arredondo
}

Prof. Dr. L.L. G. Soete, Rector Magnificus 


\section{Supervisors:}

Prof.dr. Menno Kamminga

Prof.dr Fons Coomans

Assessment Committee:

Prof.dr. Theo van Boven

Prof.dr. Thomas Conzelmann

Prof.dr. Cees Flinterman

Dr. Elvira Dominguez Redondo, Middlesex University

Dr. Theodor Rathgeber, University of Kassel 
Table of Contents. . iii

List of Abbreviations.

\section{Preface}

Chapter One - New Beginnings: Replacement of the Human Rights Commission with the UN Human Rights Council........3

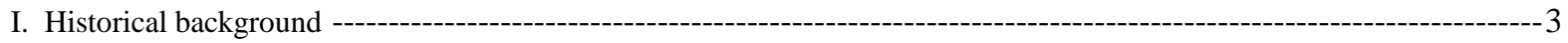

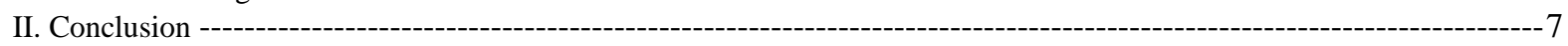

Chapter Two - Research Design, Methodology and Structure ..................................................................................8

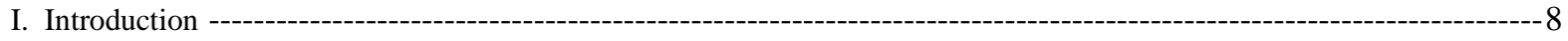

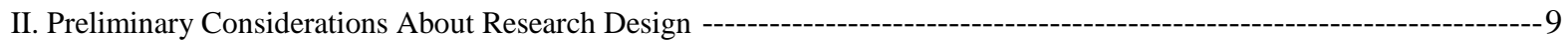

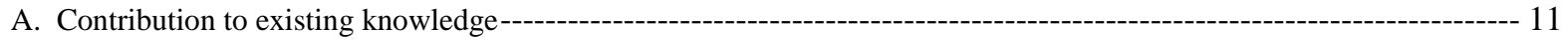

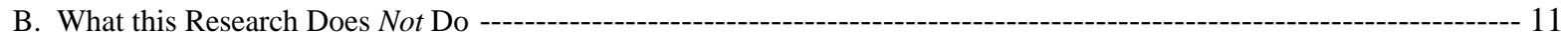

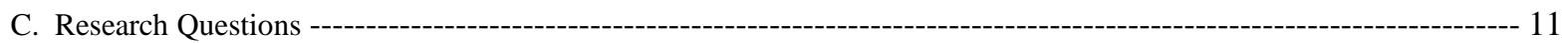

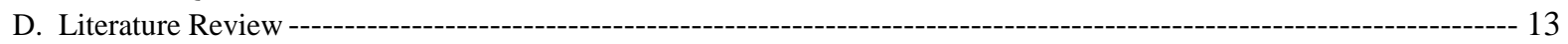

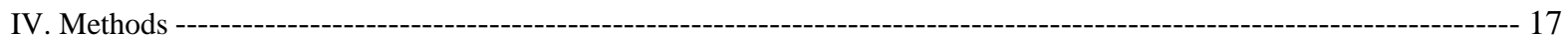

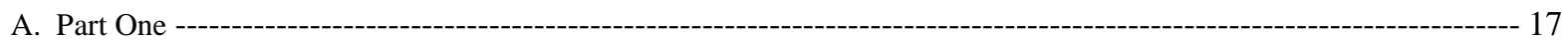

B. Part Two --------------------------------------------------------------------------------------------------------------------------------- 17

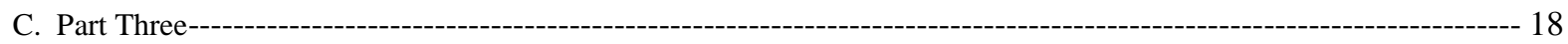

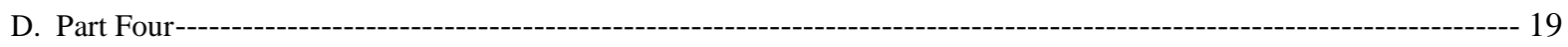

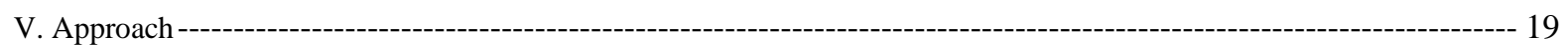

VI. Observations -------------------------------------------------------------------------------------------------------------------------- 20

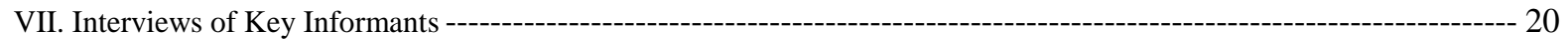

VIII. Text and Discourse Analysis --------------------------------------------------------------------------------------- 23

IX. Writing Up the Results and Findings ---

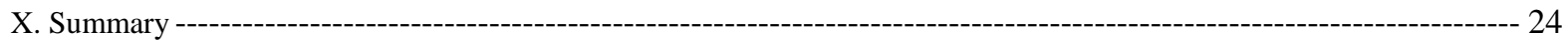

\section{PART TWO:}

THE CONCEPT OF ACCOUNTABILITY AND ACCOUNTABILITY MECHANISMS IN INTERNATIONAL LAW 25

Chapter Three - Defining Accountability and Accountability Mechanisms ..............................................................................26

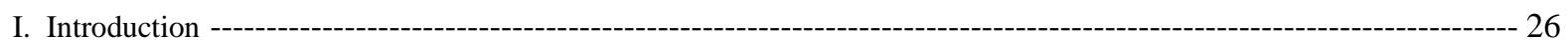

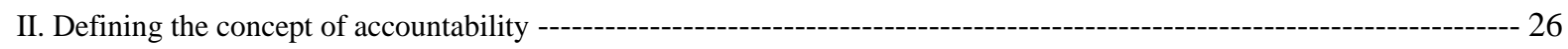

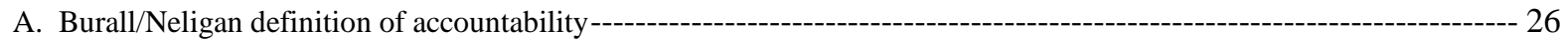

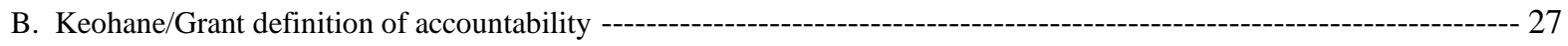

C. Similar terminology in the literature ------------------------------------------------------------------------------- 28

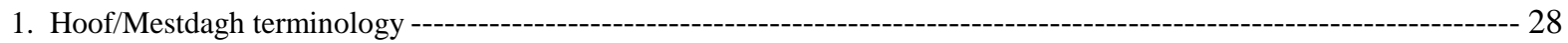

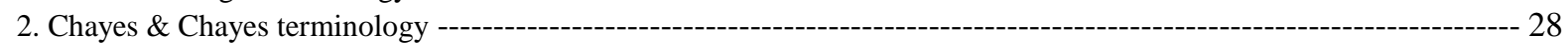

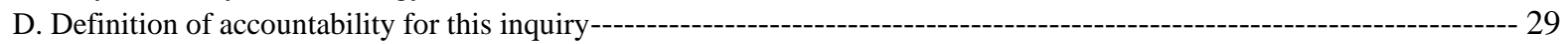

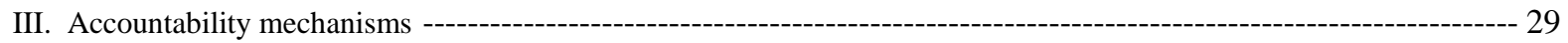

A. National accountability mechanisms ----------------------------------------------------------------------------------------- 31

1. The New York City Police Department and the Civilian Complaint Review Board---------------------------------- 31

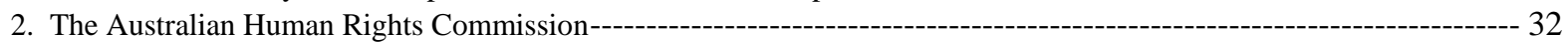

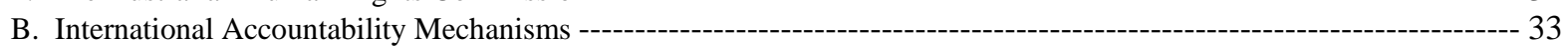

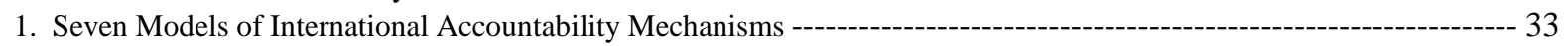

2. Distinguishing Judicial and Non-Judicial Accountability Mechanisms ----------------------------------------------- 35 
3. Periodic Reporting as the Mainstay of Non-Judicial Accountability Mechanisms-------------------------------------- 36

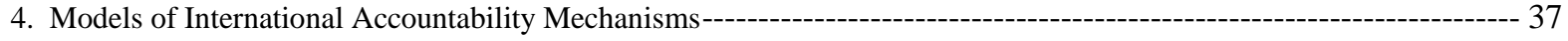

a. The International Labour Organization --------------------------------------------------------------------------------------- 37

b. The International Monetary Fund: Bilateral and Multilateral Surveillance ------------------------------------------------ 40

c. The UN Human Rights System as an international accountability mechanism --------------------------------------------- 43

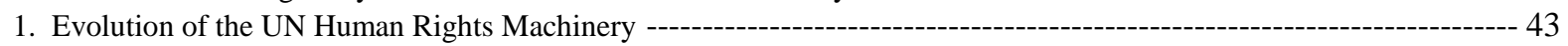

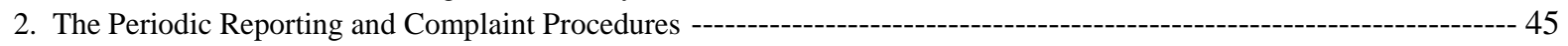

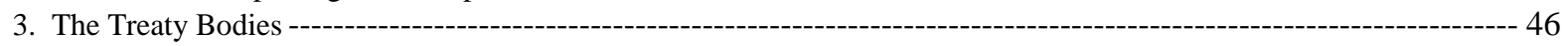

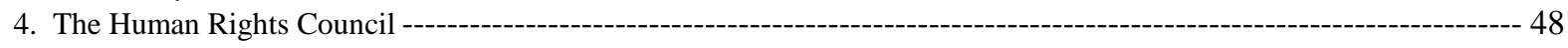

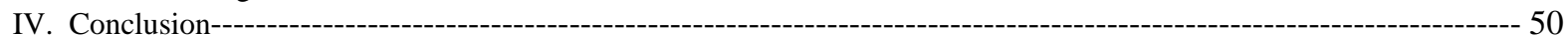

Chapter Four - Unique Characteristics of the Peer Review Accountability Mechanism ........................................................52

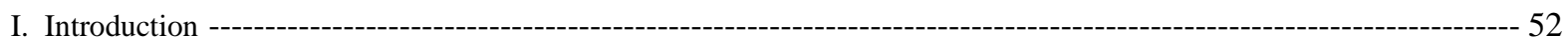

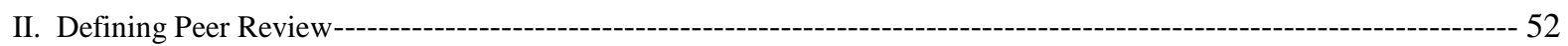

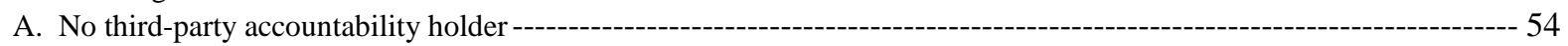

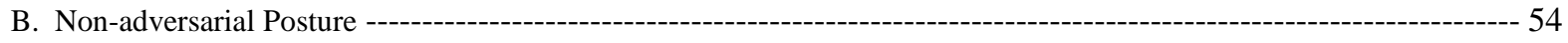

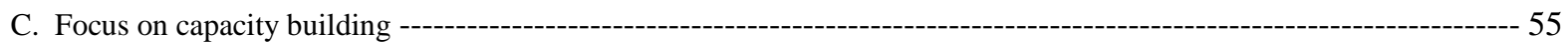

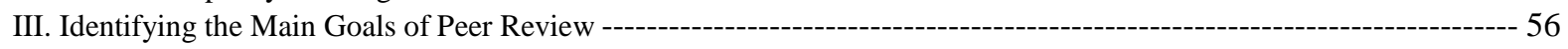

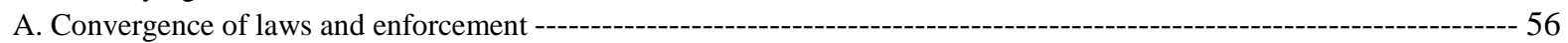

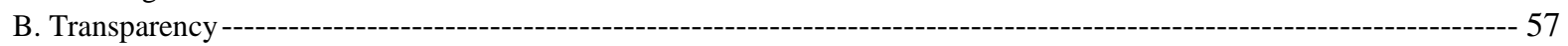

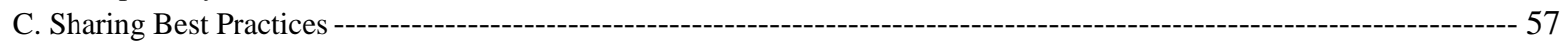

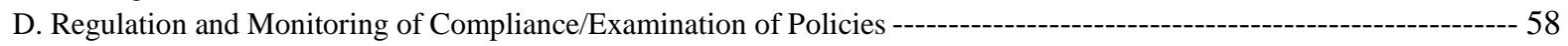

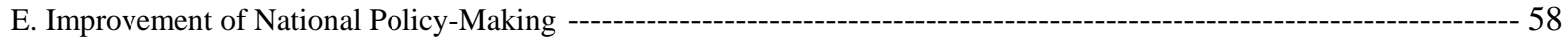

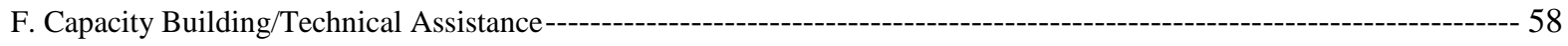

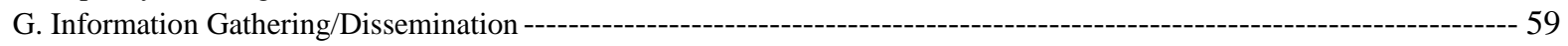

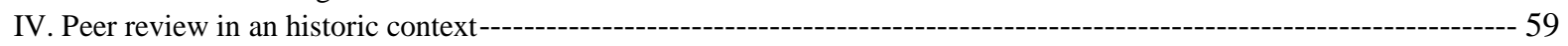

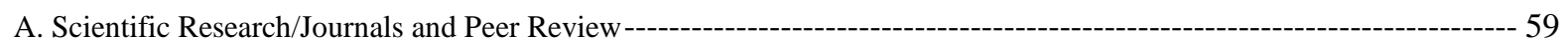

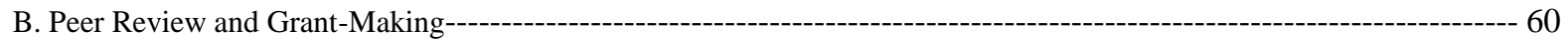

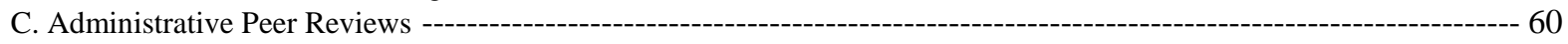

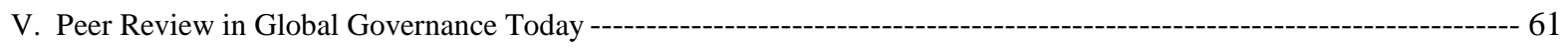

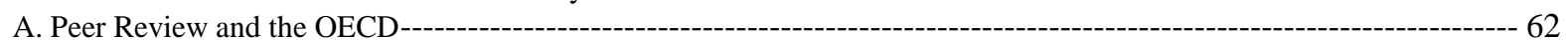

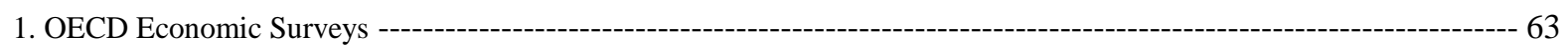

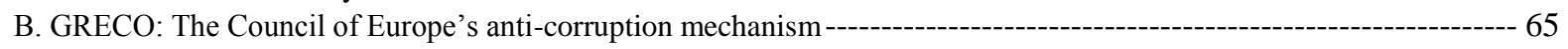

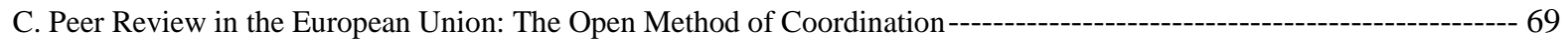

D. The African Peer Review Mechanism ------------------------------------------------------------------------------------ 70

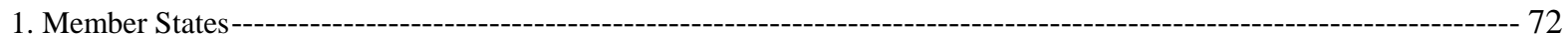

2. Secretariat-------------------------------------------------------------------------------------------------------------------------------- 72

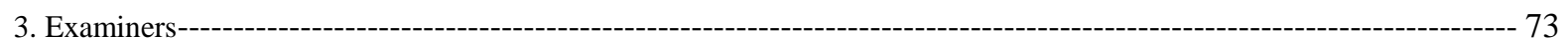

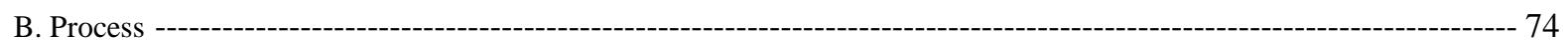

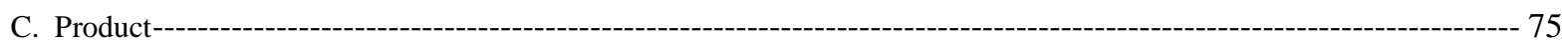

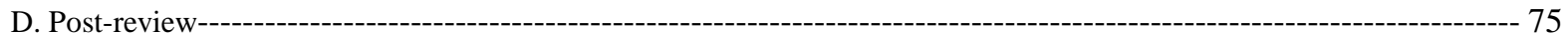

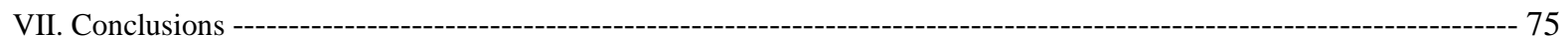

Chapter Five - Peer Review and Universal Periodic Review ...................................................................................................77

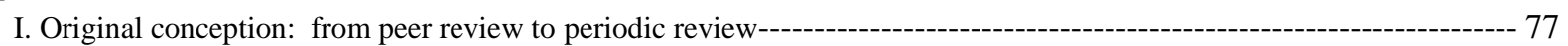

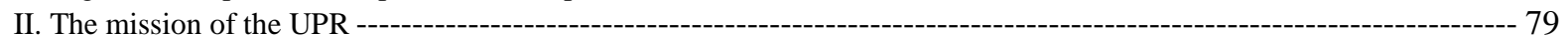

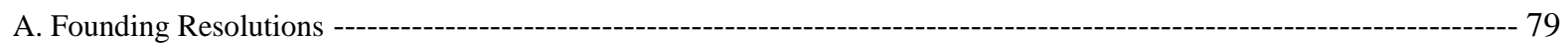

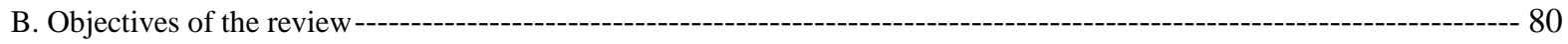

C. Standards for the review----------------------------------------------------------------------------------------------------- 80

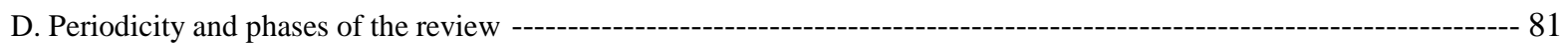

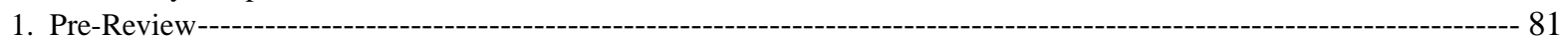

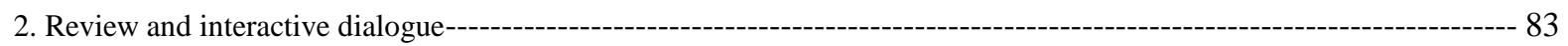

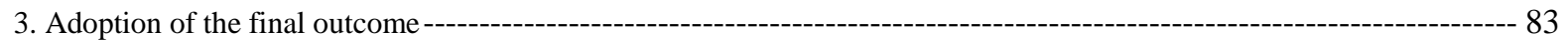

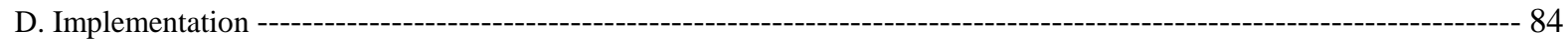

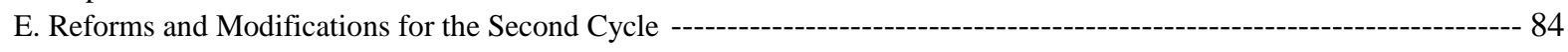

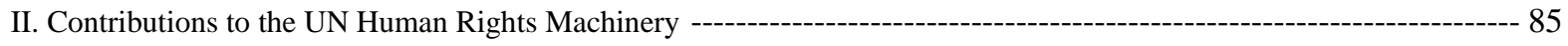




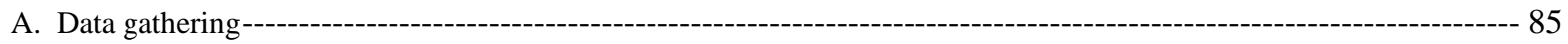

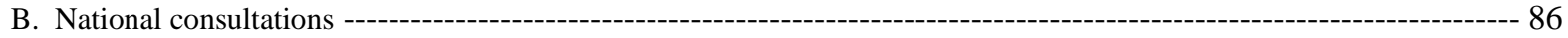

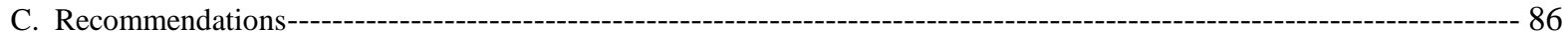

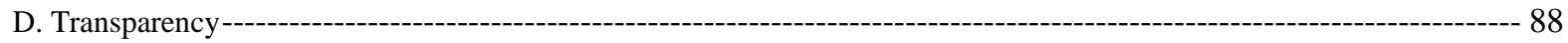

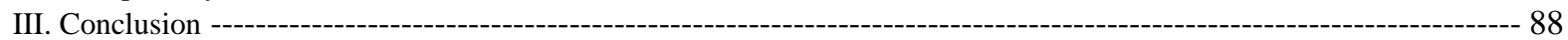

\section{PART THREE: CASE STUDIES OF GOVERNMENTS, NATIONAL HUMAN RIGHTS INSTITUTIONS AND CIVIL}

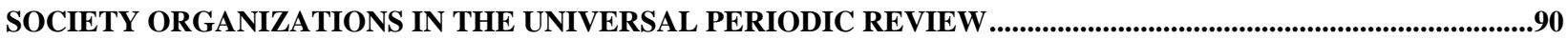

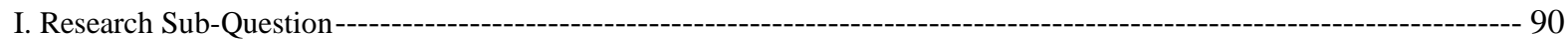

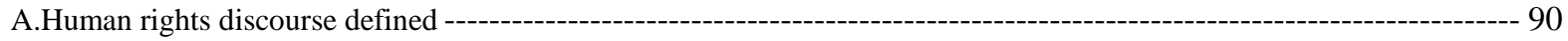

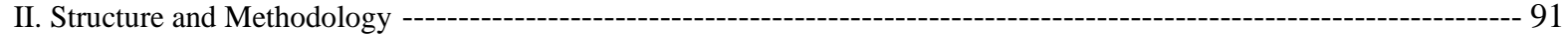

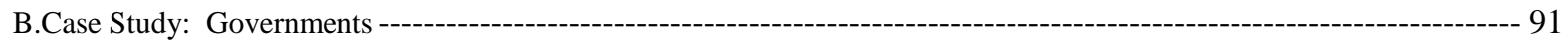

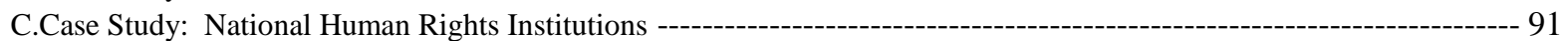

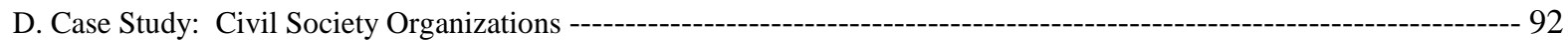

Chapter Six - Case Study of the Role of Governments in the Universal Periodic Review: The Netherlands .........................93

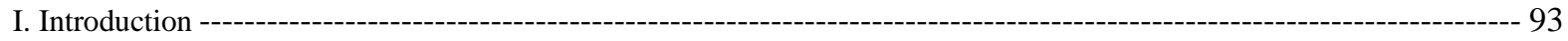

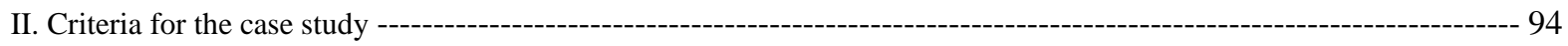

III. The Dutch Universal Periodic Reviews of 2008 and 2012 ------------------------------------------------------------------ 95

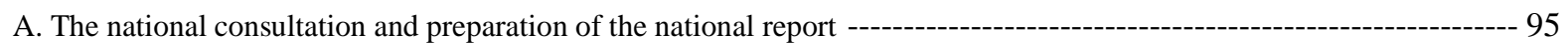

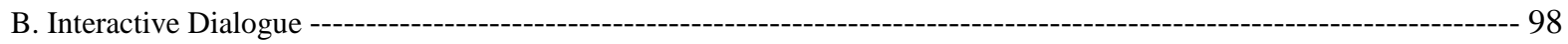

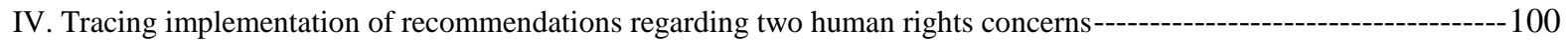

V. Best Practices -------------------------------------------------------------------------------------------------------103

A. Readiness to dialogue and form partnerships with civil society and NHRIs --------------------------------------------103

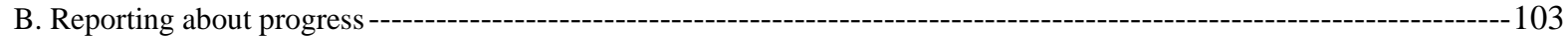

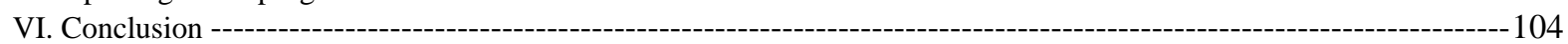

Chapter Seven - Case studies of the Role of the National Human Rights Institutions in the Universal Periodic Review: Denmark

and Kenya

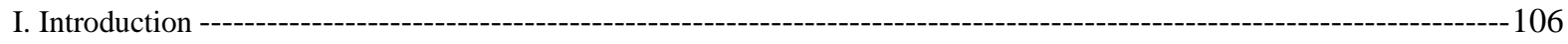

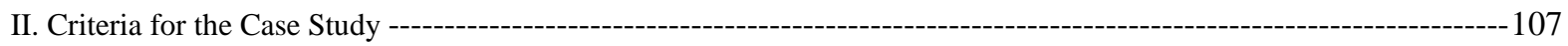

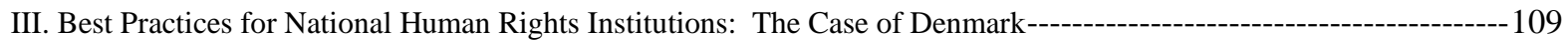

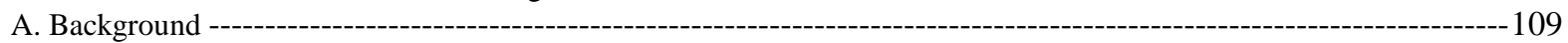

B. NHRIs Stimulate Stakeholder Participation ------------------------------------------------------------------------------------- 109

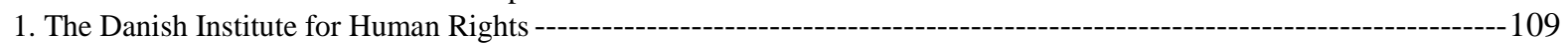

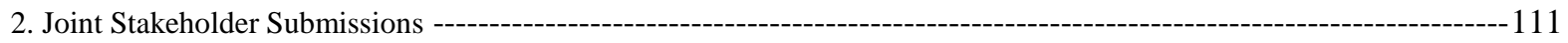

3. DIHR's Submission ----------------------------------------------------------------------------------------------------------------111

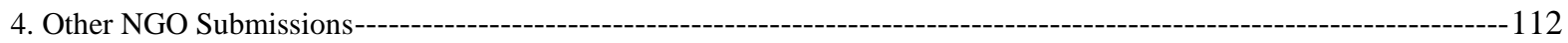

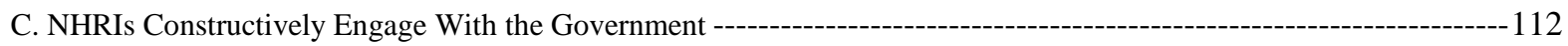

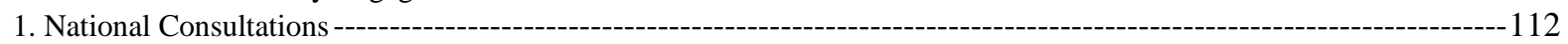

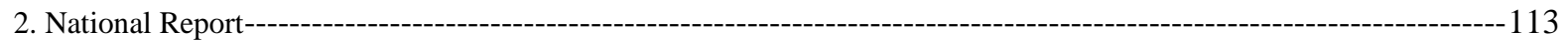

D. Compilation and Summary from the OHCHR Offers Alternative Viewpoint----------------------------------115

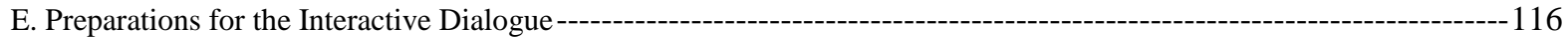

F. The Interactive Dialogue ---------------------------------117

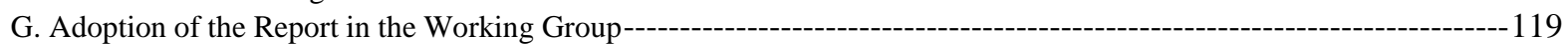

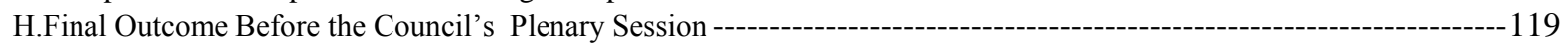

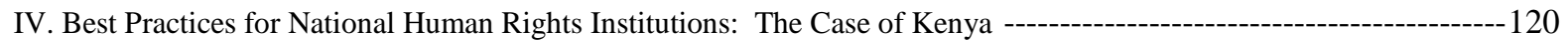

A. Background ----------------------------------------------------------------------------------------------------------------------120

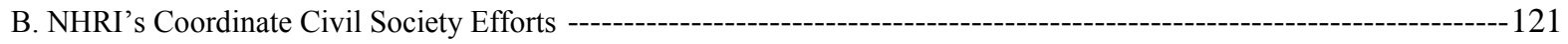

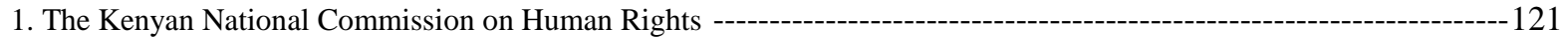

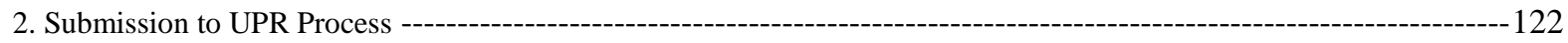

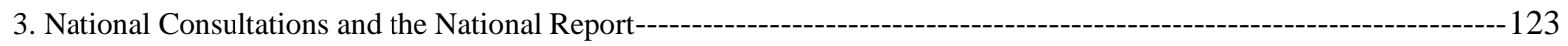

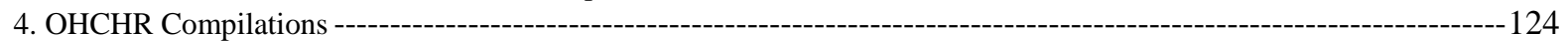


5. Media and Advocacy Campaigning in Preparation for the Interactive Dialogue -----------------125

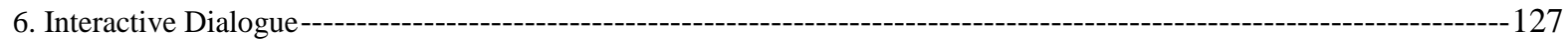

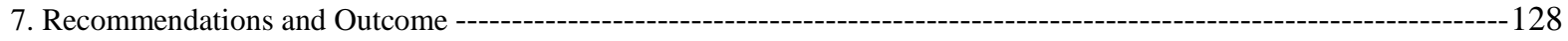

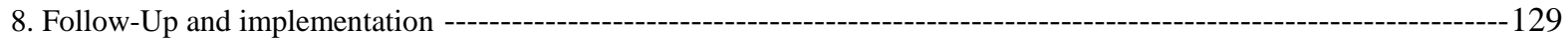

V. Best Practices from the Danish and Kenyan UPRs -------------------------------------------------------------------------129

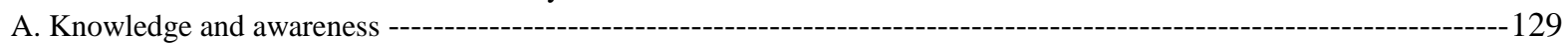

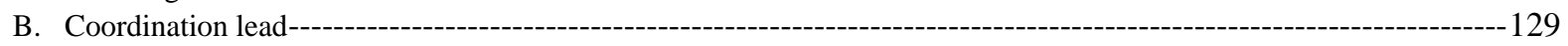

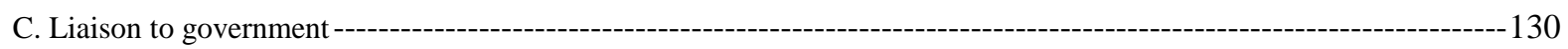

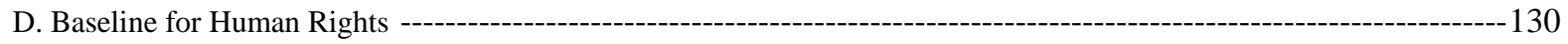

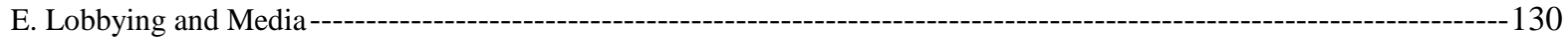

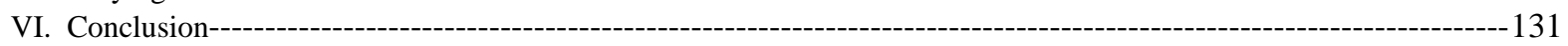

Chapter Eight - The Role of Civil Society in the Universal Periodic Review .......................................................................132

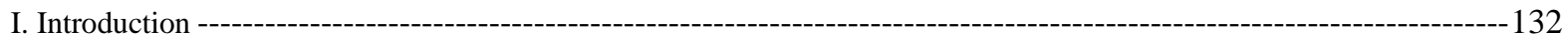

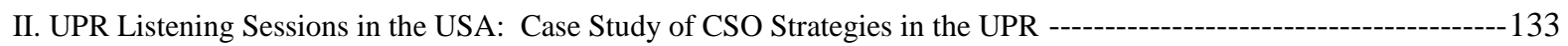

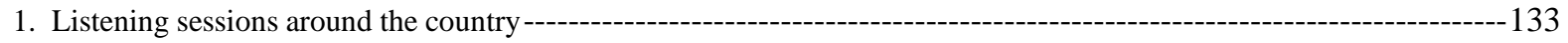

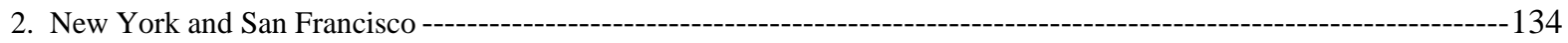

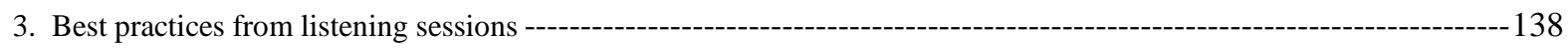

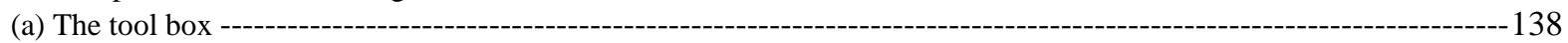

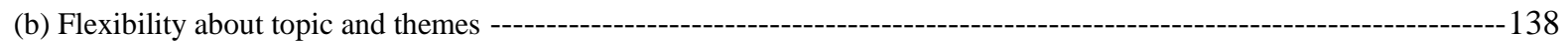

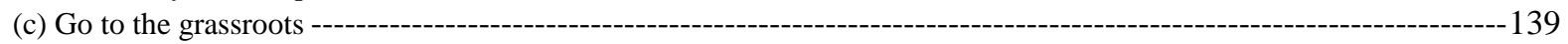

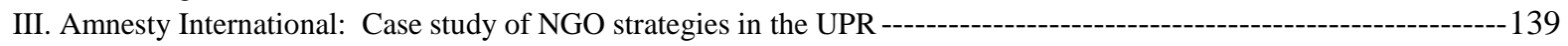

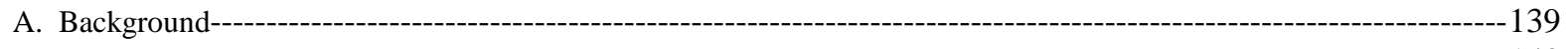

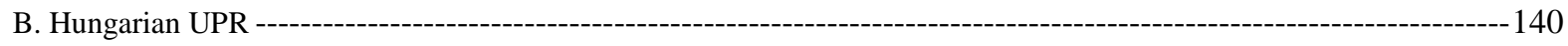

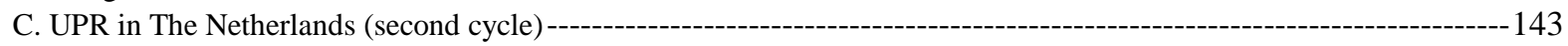

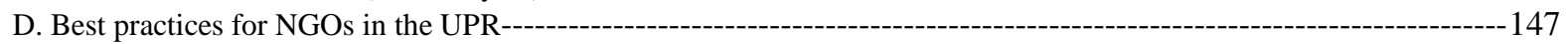

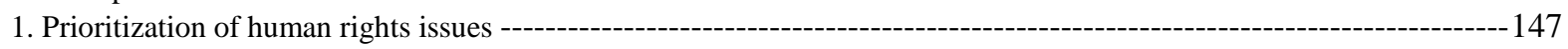

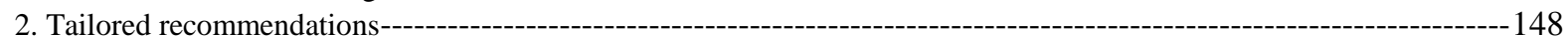

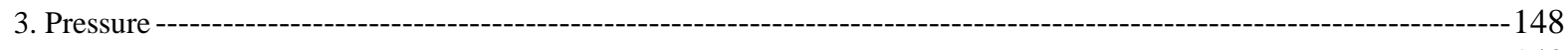

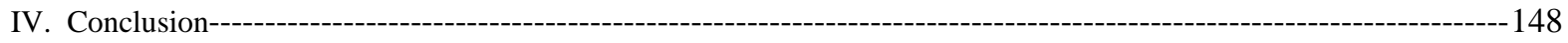

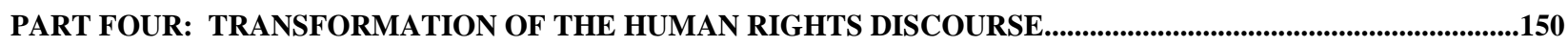

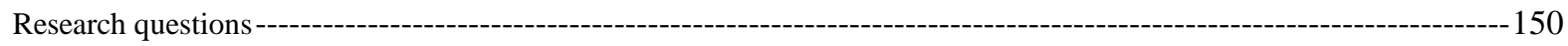

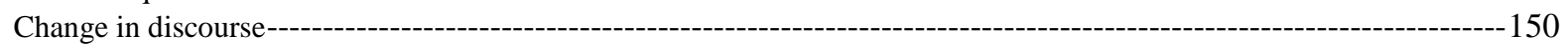

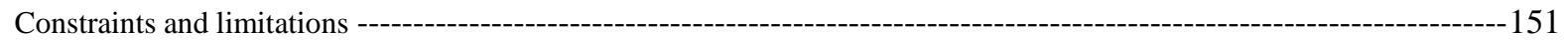

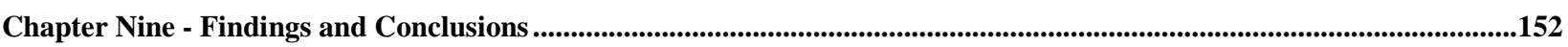

I.The Creation of a Peer Review Mechanism Transforms Human Rights Discourse ----------------------------152

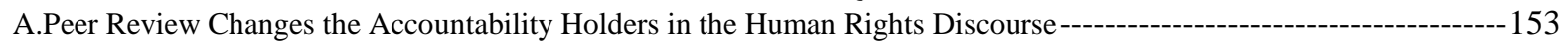

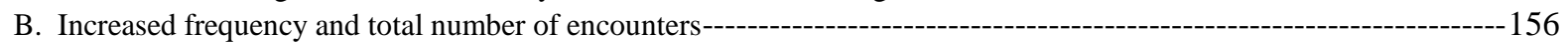

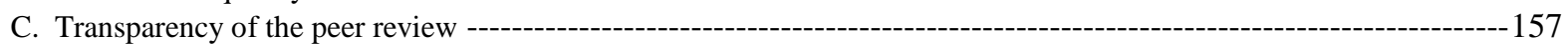

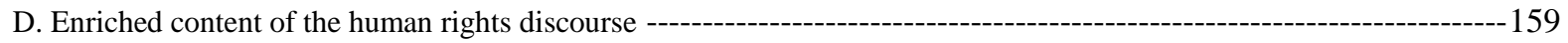

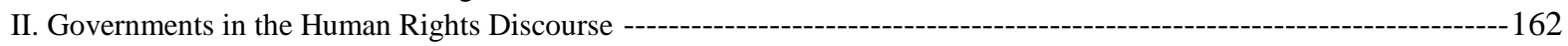

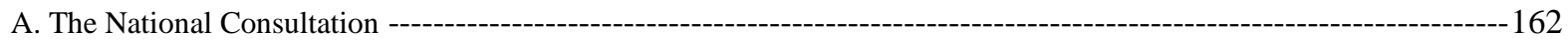

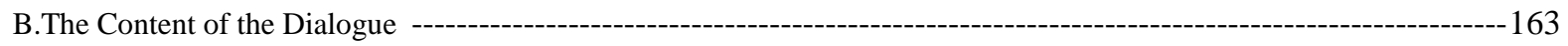

C.One Challenge: Will Cooperation by Government Continue to be the Norm?-------------------------------------------165

III. National Human Rights Institutions in the Human Rights Discourse ----------------------------------------------165

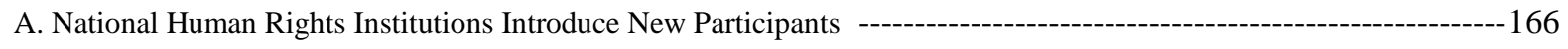

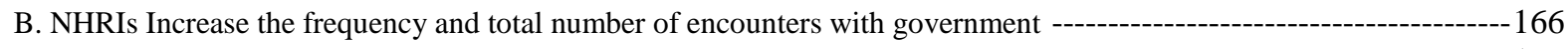

C. NHRIs Influence the Manner in Which Participants Take Part in the UPR-----------------------------------167

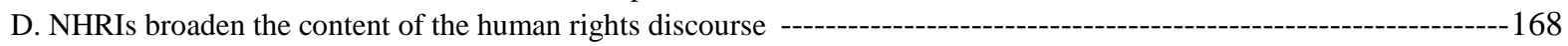

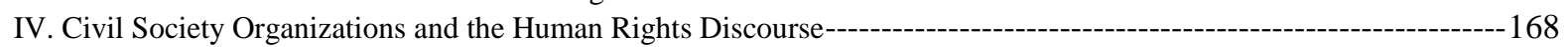

A. Participation among civil society organizations has the potential to multiply in the UPR-------------------------169

B. Increased contact and coordination among CSOs and other CSOs, government ---------------------------------169 
C. Carrying out the discourse through pressure, media campaigns and lobbying ------------------170

D. Influencing the content of the discourse through agenda-setting ---

V. Summary of Findings ------------------------------------------------------------------------------------------------173

VI. Improving the UPR process -------------------------------------------------------------------------------------------------- 173

A. Using the expert human rights mechanisms to inform the interactive dialogue-------------------------------------------174

B. Sharing best practices in the interactive dialogue -------------------------------------------------------------------------174

C. Recommendations to visit and exchange best practices and transfer knowledge and policies ---------------------------175

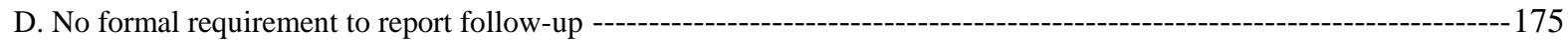

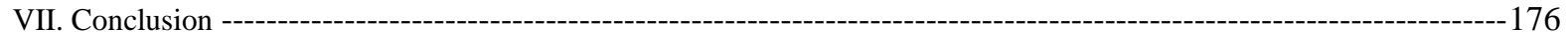

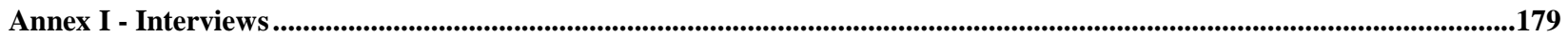

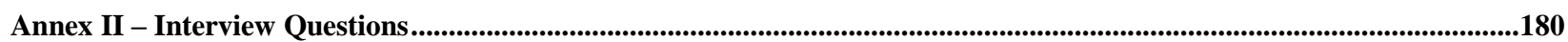

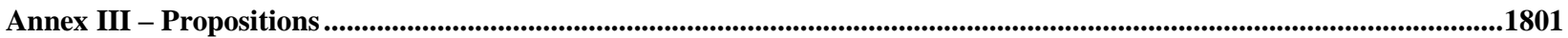

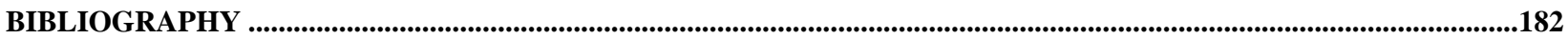

CURRICULUM VITAE 


\section{List of Abbreviations}

AI

APRM

CAT

CEDAW

CERD

CESCR

CIA

CMW

COE (CoE)

CPED

CRC

CRC-OP

CRPD

CSO

DIHR

DOS

ECOSOC

EDRC

EU

GRECO

ICC

ICCPR

ICCPR-OP2

ICERD

ICESCR

ICRMW

ICTR

ICTY

viii
Amnesty International

African Peer Review Mechanism

Committee Against Torture

Committee for the Elimination of Discrimination Against Women

Committee for the Elimination of Racial Discrimination

Committee on Economic, Social and Cultural Rights

(United States) Central Intelligence Agency

Committee on Migrant Workers

Council of Europe

International Convention for the Protection of All Persons from Enforced Disappearance

Committee on the Rights of the Child

Optional Protocol to the CRC

International Covenant on the Protection and Promotion of the Rights of Persons with Disabilities

Civil Society Organization

Danish Institute for Human Rights

(United States) Department of State

United Nations Economic and Social Council

Economic Development and Review Committee

European Union

Group of States Against Corruption

International Coordinating Committee of National Institution for the Promotion and Protection of Human Rights

International Covenant on Civil and Political Rights

ICCPR Optional Protocol 2

International Convention on the Elimination of All Forms of Racial Discrimination

International Covenant on Economic Social and Cultural Rights

International Covenant on the Rights of All Migrant Workers

International Criminal Tribunal for Rwanda

International Criminal Tribunal for the Former Yugoslavia 


\begin{tabular}{|c|c|}
\hline $\mathrm{IO}$ & International Organization \\
\hline ILO & International Labour Organization \\
\hline IMF & International Monetary Fund \\
\hline KNCHR & Kenyan National Commission for Human Rights \\
\hline KSC-UPR & Kenya Stakeholders' Coalition for the Universal Periodic Review \\
\hline NEPAD & New Partnership for Africa's Development \\
\hline NGO & Non-Governmental Organization \\
\hline NHRI & National Human Rights Institution \\
\hline OECD & Organization of Economic Cooperation and Development \\
\hline OEEC & Organization for European Economic Cooperation \\
\hline $\mathrm{OHCHR}$ & Office of the High Commissioner for Human Rights \\
\hline $\mathrm{OMC}$ & Open Method of Coordination \\
\hline OP-CAT & Optional Protocol to the CAT \\
\hline UDHR & Universal Declaration of Human Rights \\
\hline $\mathrm{UN}$ & United Nations \\
\hline UPR & Universal Periodic Review \\
\hline US or USA & United States of America \\
\hline WTO & World Trade Organization \\
\hline
\end{tabular}




\section{Preface}

In August 2009, I pulled up stakes for the third time in less than two years, this time to settle in Maastricht, the Netherlands. There were many people who (and organizations that) helped me in one way or another during this four-year venture. Some of them are acknowledged here.

The Maaastricht University Faculty of Law welcomed me to the International and European Law Department after a Skype interview. I found it remarkable that the interview focused on my research plan and credentials, a refreshing change from my experiences in my own country where job talks often centered on gaps in resumes or career trajectory changes and where Skype interviews are never used. My two thesis supervisors ensured that I was promptly received into the Netherlands School of Human Rights so I could begin sharing my research with fellow doctoral candidates. Colleagues at the faculty helped me to find my way around the department, university and the city. Thanks to Nishara Mendis, Viorelia Gasca, Katarina Eisele, Mark Kawakami and Andrea Broderick for hours of stimulating conversation, tea and tasty desserts. Others who helped with my perspective on human rights topics of the day: Ana María Torres, Gustavo Arosemena and Jasper Krommendijk.

Life as an expatriate can be a challenge, particularly to form friendships. Two Dutch women tried to ease that burden. Nanda Spanjer made sure I visited one new Dutch city a year. Edith Rameckers patiently coached me in verbal Dutch so I could converse more comfortably and gave me a grand tour of Limburg province. I was surrounded by a very caring (Belgian) church community: Liège's Eglise Protestante Reformée, Lambert-Le Begue - je vous remercie de tout mon coeur l'encouragement pendant toutes ses années.

Back home in the United States, I am grateful to the people at Little Prairie United Methodist Church, under the pastorships of Gordon Deuel and Shawna Horn, who prayed for all of my trips throughout Europe and for the development of this manuscript. Friends and relatives checked in to ask about my research and progress. Thanks Stacey Mae Olson, Kendra Lewis, Gabriel Bangoura, Angela Lewis, Sharleen Goldberg, Joan Osborne and Rosemarie Coleman. A special thanks to my favorite Uncle Aaron and Aunt Inga for the prayer bubble.

My parents, Ira and Lillie Lewis, have always supported me in my career choices. When I decided to return to school to seek higher degrees in International Human Rights Law, my mother was very supportive, understanding my belief that the "civil rights" discourse in the United States was too restrictive and that there was a need for a broader discourse encompassing "human rights." I am most appreciative of their indulgence throughout my life of my need to experiment and embark on new adventures.

After finalizing my manuscript, I was privileged to have a distinguished panel of readers. The stellar work by Professors van Boven and Flinterman in the field of human rights is acknowledged world wide. Professor Conzelmann is leading an invaluable project on peer review mechanisms. Both Professors Redondo and Rathgeber have made significant contributions to the understanding of the Universal Periodic Review (UPR). I am both humbled to know that they have approved this manuscript and honored to have them on my defense panel.

This research is only a beginning. There are many more angles from which to study the UPR. I hope that more work will be published regarding the roles of civil society, national human rights institutions and governments. My conclusions regarding a potential for transforming the human rights discourse can only be proved or disproved by further research on upcoming UPR cycles. While I plan to do further research on the topic, I hope that other scholars will study the issue and produce additional data for additional debate and analysis.

Tamara Nicolle Lewis Arredondo

October 2013

Shieldsville, Minnesota

United States of America 


\section{THE UNIVERSAL PERIODIC REVIEW MECHANISM OF THE UNITED NATIONS HUMAN RIGHTS COUNCIL: TRANSFORMING THE HUMAN RIGHTS DISCOURSE}

\section{PART ONE}

\section{HIGH HOPES FOR A NEW ACCOUNTABILITY MECHANISM IN HUMAN RIGHTS}

When the Universal Periodic Review burst onto the international scene in 2008, the historical significance of the event was recognized by participants at all levels. The sitting High Commissioner for Human Rights at that time, Louise Arbour, had declared in the $6^{\text {th }}$ session of the newly-minted United Nations Human Rights Council, that " $[\mathrm{t}]$ he Universal Periodic Review process ... represents potentially the first universal and comprehensive tool for overseeing the application of the principles of the Universal Declaration of Human Rights in a consistent, comprehensive and meaningful manner." 1 Arbour added, "We are acutely aware that the credibility of the United Nations human rights system hinges upon satisfactory implementation of the review, since the UPR has the potential to greatly influence and address human rights situations on the ground." 2

On April 7, 2008 the Working Group of the United Nations Human Rights Council (the Council) convened the first session of the Universal Periodic Review (UPR). ${ }^{3}$ The distinguished Romanian Ambassador Doru Romulus Costea, President of the Council, opened the session by announcing that the UPR was "an historic process" and by emphasizing that a long journey had come to an end, a journey started two years prior with the adoption of Resolution 60/251, calling for a universal periodic review. ${ }^{4}$

Ambassador Costea's words were echoed by the Bahrain delegation which was the first country to be reviewed in the UPR process. The delegation stated that human rights are about dignity and respect and that the UPR was the first human rights innovation of the new millennium, calling to mind the efforts of the former UN Secretary General Kofi Annan to bring attention to human rights and the reform the UN mechanisms. ${ }^{5}$

These statements reflected the optimism found in the Council, the Office of the High Commissioner for Human Rights and within the larger UN membership. The UPR was being hailed as an effort to hold all countries accountable for their human rights records. At its inception, the international community had high hopes for its success. Five years on, one must ask what the UPR has changed in the domain of human rights.

This inquiry is concerned with the UPR and its ability to change the way nations view, discuss, defend, promote and protect human rights. That is to say, how the UPR has changed the human rights discourse? The human rights discourse takes place at national, regional and international fora. Immediately prior to the establishment of the UPR, the human rights discourse at the international level occurred largely within the UN

${ }^{1}$ OfFice of THe High COMmissioner For Human Rights OfFice, First Session of the Universal Periodic Review, at http://www.ohchr.org/EN/NEWSEVENTS/Pages/UPR_1stSsession.aspx.

${ }^{2} \mathrm{Id}$.

${ }^{3}$ Office of the High COMmissioner for Human Rights, Universal Periodic Review, Media Information for the $1^{\text {st }}$ Session, 7-18 April 2008 , http://www.ohchr.org/EN/HRBodies/UPR/Pages/MeetingsHighlightsSession1.aspx

${ }^{4}$ The statements by Ambassador Costea and by the Bahrain delegation are available in the archived webcast of Bahrain's review before the Council. See http://www.un.org/webcast/unhrc/archive.asp?go=080407.

${ }^{5}$ Id. 
Human Rights machinery - the Commission, the OHCHR, the Treaty Body process, and the Special Procedures. The replacement of the Commission by the new Human Rights Council was an attempt to change the human rights discourse, particularly the atmosphere in which human rights were discussed and debated and the manner in which states were required to address human rights violations. Therefore, when the UPR was established, it was created within the auspices of the new Human Rights Council.

As noted, the decision to replace the Commission reflected a dissatisfaction with the human rights discourse that is to say, with how human rights were being discussed, verbally and in writing, and how violations were being addressed within the UN Human Rights machinery. As will be explained in more detail, below, the Commission was rife with politicized debates. Some felt that certain nations were always criticized for poor human rights records, while others completed escaped scrutiny. Therefore, I am interested in knowing the ways in which the UPR changed the human rights and the way that the UPR promotes and protects human rights as compared to what happened under the machinery of the old Commission. This inquiry will look at the UPR and the way it has affected how governments converse with citizens about human rights; namely, how governments converse with other governments about human rights; how civil society engages with governments regarding human rights; how human rights institutions interface with government and civil society concerning human rights. This inquiry is particularly concerned with whether the introduction of the UPR modified the ways in which all of these actors discussed and interacted concerning human rights. To examine the ways in which the UPR has transformed the human rights discourse and how it is carried out in domestic and international jurisdictions, ${ }^{6}$ this dissertation begins, in Part One, with the brief look at the events leading to the establishment of the UPR, then turns to the methodology and structure of this dissertation.

${ }^{6}$ This dissertation does not study the human rights discourse that takes place in the regional arena (such as the InterAmerican Court or the European Court of Human Rights) nor does it study supranational human rights discourse (that is found in institutions like the European Union). 


\section{Chapter One}

\section{New Beginnings: Replacement of the Human Rights Commission with the UN Human Rights Council}

\section{Historical background}

Following the Second World War at the establishment of the United Nations, the promotion of human rights was among the principle goals of the organization. ${ }^{7}$ The Charter of the United Nations (the Charter) and the Universal Declaration of Human Rights (UDHR) became the hallmark instruments of human rights in the immediate post-war era. ${ }^{8}$ During the ensuing decades there arose a plethora of conventions to protect individual freedoms and economic and social rights. Today, in addition to the Charter and UDHR, there are additional treaties that seek to protect the rights of individuals. ${ }^{9}$ These treaties together with the regional instruments form the ensemble of human rights instruments in the realm of public international law. ${ }^{10}$ The committees created by the treaties have served to monitor whether states parties are living up to the obligations set forth within the instrument. The monitoring is done through both periodic reporting, and in some cases, through filing of individual complaints that are acted on by the individual treaty bodies. These treaties and declarations, together with the recommendations, views and general comments arising from the treaty body process, form a human rights discourse understood by nations both within their borders and in the international arena.

At the behest of Eleanor Roosevelt and others, the UN had also established the UN Human Rights Commission (the Commission), a body that existed from 1945 until its replacement by the UN Human Rights Council in 2006. ${ }^{11}$ The Commission had originally taken the stance that it would not entertain individual complaints regarding the human rights violations committed by UN Member States. ${ }^{12}$ However, in the ensuing decades, the Commission's views evolved. In 1946, a sub-commission was created to study country situations and draft conventions on diverse issues in human rights. ${ }^{13}$ In 1959, the Economic and Social Council (ECOSOC) adopted a resolution directing the UN Secretary General to create a list of communications regarding human

\footnotetext{
7 The UN Charter did not define the term "human right" nor did it enumerate those rights. HENRY J. STEINER, ET AL, International Human Rights in Context: Law, Politics, Morals, Texts and Materials, 138-139 (2008).

${ }^{8}$ Id. at $134-136$.

${ }^{9}$ The following core human rights instruments exist as of the writing of this inquiry (1) the International Covenant on Economic, Social and Cultural Rights, Dec. 16, 1966, 993 U.N.T.S. 3; (2) the International Covenant on Civil and Political Rights, Dec. 16, 1966, 999 U.N.T.S.171; (3) the International Convention on the Elimination of All Forms of Racial Discrimination, Dec. 21, 1965, 660 U.N.T.S. 195, 212; (4) the Convention on the Elimination of All Forms of Discrimination Against Women, Dec. 18, 1979, 1249 U.N.T.S. 13; (5) the Convention Against Torture and Other Cruel, Inhuman and Degrading Treatment or Punishment, Dec. 10, 1984, 1465 U.N.T.S. 85, 113; (6) the Convention on the Rights of the Child, Nov. 20, 1989, 1577 U.N.T.S. 3; (7) the International Convention on the Protection of the Rights of All Migrant Workers and Members of their Families, Dec. 18, 1990, 2220 U.N.T.S. 93; (8) the International Convention on the Protection and Promotion of the Rights and Dignity of Persons with Disabilities, G.A. Res. 61/106, Annex I, U.N. GAOR, 61st Sess., Supp. No. 49, U.N. Doc. A/61/49, at 65 (Dec. 13, 2006); and (9) the International Convention for the Protection of All Persons from Enforced Disappearance, G.A. Res. 61/177, U.N. Doc. A/RES/61/177 (Jan. 12, 2007).

${ }^{10}$ The regional instruments currently in force are: (1) the African (Banjul) Charter on Human and Peoples' Rights, June 27, 1981, 1520 U.N.T.S. 217; (2) the American Convention on Human Rights, Nov. 21, 1969, 1144 U.N.T.S. 143; and (3) the Convention for the Protection of Human Rights and Fundamental Freedoms, Nov. 4, 1950, 213 U.N.T.S. 221.

11 The establishment of the Commission was explicitly called for in Article 68 of the Charter (" $\mathrm{t}$ ] ]he Economic and Social Council shall set up commissions in economic and social fields and for the promotion of human rights, and such other commissions as may be required for the performance of its functions.") U.N. Charter, art.68; DAVID WEISSBRODT \& CONSTANCE DE LA VEGA, International Human Rights Law, An Introduction, 24-26 (2007)..

${ }^{12}$ COnStance De La Vega \& TAmara Lewis, Peer Review in the Mix: How the UPR Transforms Human Rights Discourse, in New Challenges for the UN Human Rights Machinery: What Future for the UN Treaty Body System and the Human Rights Council Procedures?, (M. Cherif \& Schabas Bassiouni, William A. ed., 2011), at 354.; WEISSBRODT \& DE LA VEGA, supra note 11 at 257.

${ }^{13}$ Id. at 355.
} 
rights violations. ${ }^{14}$ These communications and the responses by the governments (both also available to the Commission and to the relevant governments) represented the first time the Commission would gather information about human rights situations in domestic jurisdictions. ${ }^{15}$ In 1967, ECOSOC resolution $1235^{16}$ granted the Commission and the Sub-commission the powers to debate situations within countries, and to assign special rapporteurs to study country situations or themes. ${ }^{17}$ Additionally, the Commission could consider gross violations reported in the list of communications. A final innovation in 1970 established the Commission's authority to hear individual or group complaints under the 1503 procedure. ${ }^{18}$ The 1503 procedure, still in existence in a modified form, is a confidential mechanism in which complaints relating to patterns of gross violations of human rights are heard. ${ }^{19}$ The Commission would publicly announce the countries involved, but never disclosed the actions taken by the Commission. ${ }^{20}$

The Commission also established a periodic review mechanism; however, it did not see widespread use by member states. ${ }^{21}$ The earlier attempt to establish a mechanism for periodic reporting regarding human rights commitments was in the 1950s. ${ }^{22}$ Both France and Yugoslavia made proposals- France wanting a system to examine states and their obligations under the UDHR, while Yugoslavia proposed that states receive capacitybuilding assistance to help implement human rights obligations. ${ }^{23}$ In 1953 the United States suggested annual voluntary state reports on human rights issues, including " fact-finding, information-sharing, and the role of administrative staff and States in providing peer-led practical advice and guidance on implementing human rights standards." 24 In 1956 the proposals came to fruition, but in a diluted form. ${ }^{25}$ The reporting procedure lasted 25 years, but was eventually suppressed in 1981.26

By 2006, the nations of the world had deemed that the Commission, which had fallen into disrepute after years of infighting and hostilities among UN member states, no longer enjoyed the independence, neutrality and good reputation deserving of its mandate mainly due to the politicization that had grown up in the Commission where it appeared that some states were constantly under scrutiny for their human rights violations while others with similarly poor records escaped scrutiny. ${ }^{27}$ That same year, the United Nations (UN) General Assembly

${ }^{14}$ Id.; Economic and Social Council Resolution 728 F (XXVIII) of 30 July 1959; 28 U.N. ESCOR Supp. (No. 1) at 19, U.N. Doc. E/3290 (1959). The resolution empowered the Secretary General to compile a "confidential list containing a brief indication of the substance of other communications concerning human rights, however addressed, and to furnish this list to members of the Commission [and Sub-Commission], in private, without divulging the identity of the authors of communications ...."

${ }^{15}$ DE LA VEGA \& LEWIS, supra, note 12 at 355; WEISSBRODT \& DE LA VEGA, supra note 11 at 257.

${ }^{16}$ Economic and Social Council Resolution 1235 (XLII) of 6 June 1967, 42 U.N. ESCOR Supp. (No. 1) at 17, U.N. Doc. E/4393 (1967); Scholar Nadia Bernaz considers the 1235 procedure to be the historical predecessor of the Universal Periodic Review. See Nadia Bernaz, Reforming the UN Human Rights Protection Procedures: A Legal Perspective on the Establishment of the Universal Periodic Review Mechanism, in New Institutions for Human Rights Protection: The Collected Courses of the Academy of European Law 86 (Kevin Boyle ed., 2009).

17 DE LA VEGA \& LEWIS, supra, note 12 at 355; WeISSBRODT \& DE LA VEGA, supra note 11 at 257-258.

${ }^{18}$ Economic and Social Council Resolution 1503 (XLVIII) of 27 May 1970, 48 U.N. ESCOR (No. 1A) at 8, U.N. Doc. E/4832/ Add.1 (1970).

${ }^{19} \mathrm{Id}$. at 356; WEISSBRODT \& DE LA VEGA, supra note 11 at 260.

${ }^{20}$ ECONOMIC AND SOCIAL COUNCIL RESOLUTION 1503, supra note 15, at paras. 7-8.

${ }^{21}$ See PHILIP ALSTON, Reconceiving the UN Human Rights Regime: Challenges Confronting the New UN Human Rights Council, 7 Melbourne Journal of International Law 185, 207-213 (2006) (outlining the complete evolution of the historical parallel to the UPR).

${ }^{22}$ FREEDMAN, New Mechanisms of the UN Human Rights Council, 29 Netherlands Quarterly of Human Rights (2011), at 292.

${ }^{23}$ Id., citing 'Yugoslavia: Amendments to the Draft Resolution on Annual Reports (E/CN.4/L.266) Submitted by the United States of

America,' UN Doc. E/CN.4/L.305/Rev.1 (1953) in 'Report of the Ninth Session of the Commission on Human Rights,' UN Doc. E/2447 (30

May 1953), at. 266; ALSTON, supra note 21, at 207.

${ }^{24}$ FREEDMAN, supra note 22, at 293, citing Commission on Human Rights, 'Report of the Sixth Session of the Commission on Human Rights', 19 May 1950, UN Doc. E/1681, at 8; ALSTON, supra note 21, at 208.

${ }^{25}$ ALSTON, supra note 21, at 211 (stating additionally that the "proposals are of particular relevance today given the growing recognition that one of the principal potential achievements of a reporting procedure is the stimulation of an authentic national dialogue over domestic human rights policies.") $I d$.

${ }^{26} \mathrm{Id}$. at 213 (noting that at its height, the reporting procedure received 67 reports, but that number dropped to as low as 47 in later years and furthing noting "it is doubtful whether it made any significant contribution to the promotion of respect for human rights. It did, however, succeed in giving the appearance that all governments were making themselves accountable to the Commission, and it gave NGOs and UN specialized agencies an excuse to submit written comments.").

${ }^{27}$ Alston notes that although the "tasks of fostering cooperation and building capacity were uncontroversial," the further mandate to "promote global respect for human rights and to respond to rights violations was intrinsically controversial because it required that it monitor and call to account many of the countries that sat as members of the Commission." Id. at 187. Alston concludes that "these controversies plagued the operations of the Commission and resulted in a rancorous debate among governments, often reflecting a North-South split. Accusations of politicization, double standards and unprofessionalism led many commentators to conclude that the Commission had lost its credibility and 
created a new body to consider the performance of UN member states in the area of human rights. The new body, called the UN Human Rights Council (the Council), replaced the beleaguered UN Human Rights Commission. ${ }^{28}$

The creation of the Council followed a series of proposals to reform the UN institutions. More specifically, the General Assembly (UNGA) had held a World Summit in 2005 in New York City, in part to review the "status of implementation" of the 2000 Millennium goals articulated in a declaration adopted at the summit. ${ }^{29}$ The Millennium Summit had resulted in an ambitious set of goals for development, together with a set of practical steps invented by experts in the field of development to achieve those goals. ${ }^{30}$ In preparation for the World Summit, the UNGA was also guided by the report of Kofi Annan, then Secretary-General of the UN, entitled In Larger Freedom: Towards Development, Security and Human Rights for All ${ }^{31}$ in which he recommended the establishment of a Human Rights Council. ${ }^{32}$ The World Summit would also result in a UN General Assembly resolution to, among other things, "reaffirm that all human rights are universal, indivisible, interrelated, interdependent and mutually reinforcing" and declare that while "national and regional particularities" must be "borne in mind," all States were under a duty to "promote and protect all human rights and fundamental freedoms." 33 The Secretary-General advocated for an additional peer review component for the proposed Human Rights Council. ${ }^{34}$ Significantly, the World Summit resolution echoed the call for the creation of a "Human Rights Council" in conjunction with its commitment to "strengthen the United Nations human rights machinery." 35

The debates leading to the formation of the Council were polemic. At the time the founding resolution of the Council was adopted March 15, 2006 at a plenary meeting of the UNGA, the president of the assembly hailed the creation of the Council as a "significant improvement" over the predecessor Commission, arguing that the Council would be elevated to a "subsidiary body of the General Assembly" and would have more meetings throughout the year. ${ }^{36}$ Again, in an effort to highlight the desire to avoid the politicization that had led to the downfall of its predecessor, the president also pointed to the universal periodic review as a "mechanism whereby each State's fulfillment of its human rights obligations would ensure equal treatment with respect to all Member States and would prevent double standards and selectivity." 37 However, the bitter nature of the debates was even evident in the plenary meeting when the Cuban and Venezuelan delegations took the opportunity to voice their dissatisfaction with the resolution. ${ }^{38}$ Prior to the vote, Cuba voiced its view that the resolution made the "punitive and sanctions approach" prevail, rather than bring about genuine cooperation. ${ }^{39}$ Cuba voted in favor of the resolution, but Venezuela abstained. Venezuela expressed doubts about the United States' motives in opposing the resolution (as had Cuba) and explicitly rejected a preambular paragraph that it viewed could allow

prompted calls for far-reaching reforms of its operation." Id. at 187-188 [citation omitted]. Alston further reflects that "the diagnosis that [the Commission] had lost credibility was motivated by radically divergent perceptions of what it should have been doing and what it had done or failed to do. While many of the critics called for a conciliatory approach that would avoid confrontation with governments, others impugned its credibility precisely because it had failed to condemn governments that they considered to be responsible for egregious cases of human rights violations." Id. at 188 [citations omitted.]

States had also been dissatisfied with Item 9 of the old Human Rights Commission agenda under which country situations were discussed. As the Council began its deliberations, the question of which body or procedure should address country situations was hotly disputed. Scannella and Splinter highlight the divide concerning the treatment of country situations, stating, "Many delegations have argued that there is little place for country resolutions, and some have gone as far as asserting that the universal periodic reviewshould be the only means of addressing country situations." PATRIZIA SCANnella \& PETER SPLINTER, The United Nations Human Rights Council: A Promise to be Fulfilled, 7 Human Rights Law Review 41, 60-61, 63 (2007). To date, the country situations remain the purview of the Council, special procedures and the UPR process.

${ }_{28}^{28}$ See generally REPORT OF THE U.N. SECRETARY GENERAL, In Larger Freedom: Towards Development, Security and Human Rights for All, U.N. Doc. A/59/2005 (Mar. 21, 2005) (detailing the events leading to the Commission's replacement).

${ }^{29}$ Yearbook of the United Nations 2005: Sixtieth Anniversary Edition - Towards Development, Security and Human Rights for All at 47 (UN

Dep't of Public Information ed., 2008) [hereinafter UN YEARBOOK 2005].

${ }^{30} I d$. at $49-79$.

31 REPORT OF THE SECRETARY GENERAL, supra note 28.

32 UN YEARBOOK 2005, supra note 29 , at $47,67-70$.

${ }^{33}$ Id. at 48, 711-712; G.A. Res. 60/1, ๆ 4, 121-131, U.N. Doc. A/RES/60/1 (Sept. 16, 2005).

${ }^{34}$ UN Yearbook 2005, supra note 29, at 69-70, 711-712.

${ }_{35}$ G.A. Res. 60/1, supra notes 33, ๆ ๆ 157-160.

${ }^{36}$ Statement by the President of the United Nations General Assembly, http://www.un.org/ga/president/60/speeches/060315.pdf .

${ }^{37} \mathrm{Id}$.

${ }^{38}$ UN Webcast Archives, 15 March 06, http:/ /www.un.org/webcast/ga2006.html.

${ }^{39} \mathrm{Id}$. at $15^{\prime}$. 
interference in internal affairs of nations under the pretext of humanitarian intervention. ${ }^{40}$ Venezuela also explained that it did not believe that certain paragraphs were binding on the Bolivarian state. ${ }^{41}$ The result of the vote establishing the Council: 170 votes in favor, 4 against (Israel, US, Palau and Marshall Islands) and 3 abstentions (Belarus, Iran and Venezuela). ${ }^{42}$

It is equally important to consider the larger context of the founding of the new Council. Indeed, the Council was being formulated even as the Office of the High Commissioner for Human Rights (OHCHR) was strengthening its capacity to promote and protect human rights at the country level. ${ }^{43}$ On an even grander scale, the UN was itself entering a period of renovation and reform to encourage multilateral cooperation in tackling the problems of development, peace and collective security, human rights and rule of law and the strengthening of the machinery of the UN itself. ${ }^{44}$ The effort to renew and strengthen the United Nations and its machinery is, therefore, the context in which the new UN Human Rights Council was born.

Because of the new zeal to combat gross human rights violations, the new Council was viewed as the vehicle to monitor each UN Member State's compliance with its individual human rights obligations. The process would become known as the Universal Periodic Review (UPR) and would be a four-year cycle of peer review by the members of the Council. The first four-year cycle, which began in 2008, is the subject of this inquiry. This inquiry will also consider reforms and modification made to the UPR following the completion of the first cycle and will assess the early reviews of the second cycle.

Immediately before the establishment of the UPR, the human rights discourse had as its main participants the OHCHR Secretariat, thematic and special rapporteurs, experts sitting on the Treaty Bodies and the national governments, with a limited participation by NGOs who offered shadow reports. The main accountability holders were the experts, rapporteurs and treaty committees. With the UPR, the main accountability holders are the states themselves. (The 1503 procedure and its successor are carried out by states, but the procedure is not a periodic review as it is triggered by complaints.)

Prior to the establishment of the UPR, the human rights discourse at the national and international levels was influenced by certain factors which varied widely in different regions of the world and with different types of political systems. Prior to the UPR, these factors influenced the breadth and content of human rights discourse within a nation:

- whether a country's political structure was democratic or autocratic in nature;

- the legal framework for the protection of human rights; membership in organizations protecting human rights;

- whether the country ratified or acceded to human rights treaties and which protocols it ratified; and

- whether the country came under scrutiny of a UN special procedure or by the Commission.

In democratic countries, human rights are more often subject to scrutiny, criticism and debate by citizens, whereas in autocratic regime, the discourse regarding human rights is likely truncated. Some countries have constitutional and legislative guarantees to protect human rights and institutions to punish those who violate those rights. For example, in the United States of America, the U.S. Constitution provides for protections against searches and seizures in the Fourth Amendment. Those police who carry out a search without a warrant can be barred from using the evidenced seized in the search against a suspect at trial. Such protections and discussions about police searches would not be the topic of the day in a country where the legislation or Constitution does not afford such a protection. The 47 members of the Council of Europe have also ratified the European Convention for the Promotion and Protection of Human Rights; therefore, European countries have additional duties and

${ }^{40} \mathrm{Id}$ at $21^{\prime}$

${ }^{41} I d$ at $28^{\prime}$.

42 Id at 31:30'; NANA YeBOAH, The Establishment of the Human Rights Council, in Managing Change at the United Nations, 83 (Center for UN

Reform Education 2008), available at http://www.centerforunreform.org/node/308.

${ }^{43}$ UN YeARBOOK 2005, supra note 29, at Part Two 711-883.

${ }^{44} \mathrm{Id}$. at Introduction 41-79. 
obligations under the ECHR and citizens have wider protections and remedies for human rights violations than in other parts of the world where regional treaties do not exist. Accordingly, prior to the beginnings of the UPR, human rights discourse was determined by which treaties you ratified and the protocols you signed. Therefore, if a nation did not sign or ratify the ICESCR, the human rights discourse regarding economic, social and cultural rights may not be as broad unless those rights were found elsewhere in the legal or constitutional framework. Finally, the human rights discourse was also influenced by whether your nation was the target of UN Special Procedure or a Commission debate; often such considerations were political in nature and countries with similar problems may not face the same level of criticism and scrutiny.

\section{Conclusion}

This inquiry studies the UPR and the way it transforms the human rights discourse both nationally and internationally. The UPR has the potential to transform the human rights discourse. Firstly, the UPR introduces a new type accountability mechanism into the UN Human Rights machinery - a mechanism based on peer review. Secondly, it creates a national consultation with potential to increase the number of participants in the human rights discourse and broaden the scope and content of the discourse.

At the international level, the introduction of the UPR does have potential to transform the discourse, in large part due to the fact that the, during its peer review in Geneva, the UPR critiques nations using the same set of criteria. The criteria covers the entire human rights picture, regardless of the type of regime or the treaties ratified and the regional groups to which one belongs. Because every UN Member State gives an accounting of its performance on the same set of criteria, the discourse is broadened in many countries where certain human rights were not the subject of discussion simply because the country had few legal obligations in the form of treaties or national legislation or because the country had an autocratic regime. (In Part Four, this author looks at North Korea, a country that is a state party to four of the core human rights treaties, but which is largely autocratic, but whose human rights record was duly considered in the first cycle of the UPR.) The second factor where transformation could potentially occur lies in the requirement to hold a national consultation. In some cases, the consultation could present a second transformative element wherein the grassroots public may contribute to the UPR process and in which governments are confronted by the people when seeking to accurately portray the human rights conditions in the country. (This will be discussed in detail in Parts Three and Four with the consultations in the United States and in Denmark.) Finally, the actors taking part have new ways to interact with each other; therefore, the roles of governments, national human rights institutions and civil society organizations in the human rights discourse are also transformed due to the national consultations and the interactive dialogue in Geneva. (Again, Parts Three and Four will reveal the transformation in case studies.)

This author notes that with respect to my choice to use the word "transformation," scholars may be less accepting of such terminology. The term "transformation" denotes a dramatic change that many observers have not perceived in the UPR process. Nevertheless, the case study of the United States, Denmark, and Kenya, as well as Hungary present a new way to dialogue about human rights, whether driven by an NHRI or by civil socity. These consultations are not as visible to scholars and other observers as is the interactive dialogue; however, it potential for transformation of human rights discourse is highlighted bythe way in which grassroots participants were able to directly present their complaints to high-level government officials. In addition, civil society groups are also apparently empowered to broach the totality of human rights violations with the government, no longer being restricted to the rights within the treaties to which a member state is a party. This author further posits that, internationally, the transformation is found in the way in which the process is easily accessed and made public. In addition, all states that have participated and felt obligated to provide some type of defense for their postures on human rights issues both during the interactive dialogue and in the response to which recommendations they accepted or rejected. Therefore, thus far, they have accepted the authority of the mechanism to call them into subjection regarding weaknesses and violations and have also felt compelled to explain their failures or refusals to accept recommendations. This need to justify and rationalize also shows a change from some postures in the treaty bodies where states simply never fulfill their reporting obligations. 


\section{Chapter Two}

\section{Research Design, Methodology and Structure}

\section{Introduction}

The new UN Human Rights Council (Council) was created on March 15, 2006. Among the mandates given the Council was to undertake a universal periodic review of the fulfillment by each UN Member State of its human rights obligations and commitments. Beginning in 2008, the Council initiated the Universal Periodic Review mechanism (UPR), which is a three-hour interactive dialogue in which the human rights record of a member state is discussed before the 47-member Council, The substance of the interactive dialogue is based on three written reports - one submitted by the national government under review and two compiled by the Office of the High Commissioner for Human Rights (OHCHR) on the basis of stakeholder input and the member states' human rights record in treaty bodies and special procedures.

The UPR, the process of review of state compliance with human rights norms, is understood as a cooperative and interactive dialogue with the full participation of the member state under review. The mechanism is designed not to supplant, but to complement the work of other UN treaty bodies. Following a period of national consultations with civil society and the submission of the national report, the process moves to Geneva and commences with the selection of the Troika - a three-member body to carry out an interactive dialogue with the state under review, with the assistance of the OHCHR and the preparation of an outcome paper. Credible, reliable information regarding the compliance by the member state with human rights standards is also taken from other stakeholders, including NGOs. The review process, itself very streamlined, permits a mere 20-page submission by the state party, a 10-page compilation by the UNHCHR and is subject to strict time constraints- a review cannot exceed three hours. The report of the working group, voted on by the Working Group of the Council, provides a summary of the conclusions of the working group sessions, recommendations, and voluntary commitments of the Member State. The process then moves back to the state, where recommendations and voluntary commitments are to be implemented before the next review.

My research examines the UPR's first full cycle, which ended in October 2011 (the plenary sessions for those reviews were held in April 2012). Some discussion will also be dedicated to the reforms made to the process for the second cycle, together with the earliest reviews of the second cycle. First, in Chapter One, the research looks at the background events leading to the establishment of the UPR, including the demise of the UN Human Rights Commission, the creation of the Council and the call by the then UN Secretary General, Kofi Annan for a mechanism that objectively and reliably assessed the overall human rights picture of all UN Member States. This Chapter Two is the methodology explanation. Next, in Part Two of the dissertation, I explore the concept of peer review, which is the method by which all states are reviewed in the UPR. Peer review was first used in academic journals and scientific research, but more recently has been the method of choice for monitoring compliance with obligations in international organizations such as the OECD, World Trade Organization or European Union. I trace the history of peer review and also describe its use in international organizations and regional bodies. In Part Three, I look at the UPR itself and describe the role of each of the actors in the UPR process. I use interviews with NGOs, civil society organizations, National Human Rights Institutions (NHRIs) and government officials to create case studies for how the UPR was carried out in a select group of UN Member States. Part Four -- the latter part of this dissertation -- discusses the findings and conclusions of the empirical research. In addition, I make recommendations for improvements to the UPR mechanism, draw conclusions and mention future challenges.

This chapter lays out the research design undertaken for this inquiry. In this chapter, I consider the goals of my research, the conceptual framework, the research questions, and methods. This methodology chapter also provides an outline of the remainder of this dissertation. 


\section{Preliminary Considerations About Research Design}

Before beginning this dissertation, I set out to understand how to design my research, how to structure a research question, how to devise a research plan and how to choose the proper methods to carry out my research. To achieve these ends, I read literature explaining social science research methodology, including qualitative and quantitative research. ${ }^{45}$ Furthermore, I consulted other writings that explained how to build a research question, and the steps to explain the exact query to be answered through investigation and study. ${ }^{46} \mathrm{I}$ also enrolled in methodology seminars and courses to assist me in using the proper tools. ${ }^{47}$ The courses were completed over the entire period of my doctoral research.

In the early months of my research used the following research guide, though the actual textbook that adopts a similar process was not made known to me until later:

- Prepare the research

- Collect the material

- $\quad$ Assess the material

- Structure the report

- Structure the reasoning

- $\quad$ Report the research 48

After formulating my research question and sub-questions, I also began an outline of the dissertation's content and a timeline for completion of research and writing. My research question and sub-questions, the outline and the research timetable have been reviewed and commented upon by my two thesis advisors as well as by peer researchers during conferences and seminars. They have been revised on several occasions in an effort to fine-tune them to the goals of my research.

One of my primary considerations was what research methods to employ. While I am a lawyer and law is considered to be among the social sciences, relying solely on texts that explain legal research did not seem appropriate for the type of research questions I envisioned. Instead, there are other methodologies employed in other disciplines that utilize important methods and techniques that can be beneficial for my own research. Therefore, in addition to the texts discussing social science methodology and because my topic falls within the specialized area of human rights research, I also consulted the body of scholarship dedicated to the subject of human rights research. ${ }^{49}$

Researchers use a variety of methods when collecting data. ${ }^{50}$ Then, the research employs "multiple methods to cross-check and verify the reliability of a particular research tool and the validity of the data collected." 51 After consulting the texts on social science and human rights research, I determined that qualitative research methods

\footnotetext{
45 TOdD LANDMAN, Studying Human Rights (2006); JOSEPH A. MAXWELL, Designing a Qualitative Study, in The Handbook of Applied Social Research Methods (Leonard Bickman \& Debra Rog, eds., 2008).

${ }^{46}$ The Curry-Sumner text came to my attention several months into my research. It has a very comprehensive treatment of legal research, devising research questions and how to develop a research plan. IAN CURRY-SUMNER, ET AL., Research Skills Instruction for Lawyers (2010). ${ }^{47}$ Methods of Human Rights Research, Faculty of Law, Maastricht University, Fall 2009; Workshop on Interviewing Skills; Faculty of Law, Maastricht University, June 7, 2011; Nordic Research Training Course on Methods in Human Rights Research, Institute for Human Rights Abo Akademi University, March 19-23, 2012.

${ }^{48}$ CURRY-SUMNER, supra note 46, at 13-60. McNeill and Chapman offer an even more detailed process for what they call "social surveys" - (1) choosing the topic to be studied; (2) reviewing the literature; (3) forming of hunches and hypotheses; (4) identifying the population to be surveyed; (5) carrying out preparatory investigations and interviews; (6) drafting the questionnaire or interview schedule; (7) conducting a pilot survey; (8) finalizing the questionnaire; (9) selecting a sample of the population; (10) selecting and training interviewers (if necessary); (11) collecting the data; (12) processing the data and analyzing the results; (13) writing the research report... (14) publication of the report. PATRICK MCNEIL \& STEVE CHAPMAN, Research Methods at 29-30 (2005).

49 FONS COOMANS, FRED GRUNFELD \& MENNO KAMMINGA, Methods of Human Rights Research(2009).

${ }^{50}$ MCNEILL, supra note 48 , at 22-23.

${ }^{51} \mathrm{Id}$. at 23 . 
were the most apt for my research question; namely, interviews, text and discourse analysis, together with case studies. I began to consult additional texts explaining these methods.

\section{Goals of the Research}

Joseph Maxwell, a research methods scholar, notes that when designing a qualitative study, it is important to explicitly state the goals of your study because "[w]ithout a clear sense of the goals of your research, you are apt to lose your focus and spend your time and effort doing things that won't contribute to these goals." Maxwell further specifies that goals have these functions:

First, they help guide your other design decision to ensure that your study is worth doing, that you get out of it what you want. Second, they are essential to justifying your study, a key task of a funding or dissertation proposal. In addition, your goals inevitably shape the descriptions, interpretations, and theories you create in your research. They therefore constitute not only important resources that you can draw on in planning, conducting, and justifying the research, but also potential validity threats, or sources of bias, that you will need to deal with.52

Awareness that the goals for research can be personal, practical and intellectual should be foremost for the researcher so that she is conscious of how those goals are shaping her research. ${ }^{53}$ Prior to beginning this dissertation, I had a personal goal to obtain a doctoral degree in International Human Rights Law. I wanted to focus on an issue or topic that was of immediate interest in the human rights arena. While completing my LL.M., I became aware of the newly-formed UN Human Rights Council and of its mandate to have a periodic review of the human rights records of all UN Member States. I drafted a research proposal regarding the UPR process. While the awareness of my personal goals has not led me to find a bias or other issue that could invalidate my conclusions, it has let me see that choosing this topic so early in the life of the UPR has other pitfalls, namely that my research could become too much of a descriptive look at the process rather than a critical research study. I have struggled to avoid this pitfall by formulating research questions that can be answered with the data available from the first four years of the UPR process.

Knowing that doing research individually was not within my financial means, I employed the practical goal of finding funding for my proposal. When I submitted my proposal to the hiring process for the Maastricht University (UM) Faculty of Law, I was hired to carry out the research on behalf of the law faculty. Therefore, I was in the rather enviable position of being able to simultaneously research a topic of interest to me and to be placed on a university staff with all of the resources and privileges that come with such a PhD position. However, this also meant being subject to the time constraints of the faculty and the additional teaching obligations that accompany such a position. This practical goal is also not incompatible with the research because it behooves both the faculty and me to find ways to broaden the understanding of the UPR process among academics and international human rights practitioners.

Intellectually, one of my overall goals is to contribute to the literature available regarding the UPR process both in the national and international context. I believe scholars and practitioners could also consult my research when seeking to critique or even improve the existing UPR mechanism. This goal is particularly amenable to qualitative research because the data collected would be useful for two things: to understand the meaning and to understand the process. In discovering the meaning of the Universal Periodic Review, I reasoned that by studying the participants in the process, I would be able to better understand their behavior during the reviews through an interpretive approach to their behavior and actions. ${ }^{54}$ Qualitative research is also particularly helpful when one focuses on process. ${ }^{55} \mathrm{I}$ knew that I would need to look at the UPR process from start to finish and determine whether the peer review process provides the environment to induce nations to improve their human rights systems. In addition, my research outcomes should be interesting to practitioners, particularly to National

52 MAXWELL, supra note 45, at 219.

${ }^{53} \mathrm{Id}$. at $219-220$.

${ }^{54} \mathrm{Id}$. at, 221.

${ }^{55} \mathrm{Id}$. at, 221 ("it is more important to understand the process by which things happen in a particular situation than to measure outcomes rigorously or to compare a given situation with others.")Id.at 222. 
Human Rights Institutions and to civil society organizations that engage with the UPR mechanism. The qualitative research will give context and inspire practitioners to find ways to collaborate in the process. ${ }^{56}$

\section{A. Contribution to existing knowledge}

There are several areas in which this dissertation contributes new knowledge regarding the UPR process. First, this inquiry gathers data regarding the national consultations and the process of preparing the national reports. The national consultations have not been studied or written about in scholarly literature; therefore, this inquiry fills that gap in knowledge by giving information about consultations in three countries - the United States of America, Denmark, Kenya, Hungary and the Netherlands. Additionally, this research is likely the first to provide a comprehensive description and assessment of how the UPR has been carried out in national jurisdictions around the world through interviews and description of how the UPR has been implemented in distinct nations. The research provides a way of sharing best practices and challenges for assessing human rights in domestic jurisdictions. These best practices show innovations in interaction with the human rights machinery. My conclusions involve not just the UPR in isolation, but its relationship to the Special Procedures and to the Treaty Bodies. I hope that this inquiry will be brought to the attention of those who seek reform in the UN human rights system. ${ }^{57}$

I have tapped the knowledge of people who directly participated in the UPR in their nations whether in the form of a national consultation or in the preparation of a stakeholder report or national government report. These interviews and their resulting picture of the process provide an insider's view of the process.

Because this study also examines the roles that NGOs, Civil Society Organizations (CSOs) and NHRIs have played in pressuring governments to incorporate certain information in the national report, influencing the content of the interactive dialogue through lobbying efforts and coordinating efforts for implementation or pressuring progress on accepted recommendations, this study also provides a look into the strategies of civil society in influencing both national and international processes. Again, there is little in the current literature regarding how civil society has interacted with governments in the national consultation and the strategies used to bring issues to the interactive dialogue.

One final contribution to existing literature is the description of the structure of the UPR as a peer review mechanism. While there is a significant amount of literature regarding international accountability mechanisms and soft governance techniques, there is less focus on peer review. ${ }^{8}$ This study places peer review under scrutiny at the international level as a means of soft governance in human rights monitoring and supervision. By providing a comparative analysis, I hope this will lead to more literature on the subject in the future, particularly with regard to how peer review can be used to share best practices and transfer knowledge to other countries.

\section{B. What this Research Does Not Do}

Sometimes it is useful to clarify what a study does not seek to do. In the field of human rights, legal researchers are often confronted with the issue of whether an obligation is implemented at the national level. In addition, human rights practitioners and scholars are interested in how effective certain mechanisms are at encouraging such implementation. This inquiry does not undertake to assess the impact or effectiveness of the mechanism.

\section{Research Questions}

The research question is the "heart of the research design" and describes what you "specifically want to learn or understand." 59 Maxwell emphasizes that in qualitative research, the research question should not be

\footnotetext{
${ }^{56} \mathrm{Id}$. at 222.

57 The High Commissioner for Human Rights has appealed to scholars and human rights practitioners for ideas for reform. The author's recommendations were included in a book presented to the High Commissioner for Human Rights on ways to strengthen the UN Human Rights machinery. DE LA VEGA \& LEWIS, supra note 12, at 377-384.

58 One notable exception is the work of Thomas Conzelmann, discussed in the literature review below.

${ }^{59}$ MAXWELL, supra note 45, at 228-229. UWE FLICK, Designing Qualitative Research 16-23 (2007).
} 
"formulated in detail until the goals and conceptual framework...of the design are clarified, and should remain sensitive and adaptable to the implications of other parts of the design." 60 Research questions may be descriptive, comparative, design-oriented, evaluative, explanatory or predictive in nature. ${ }^{61}$ The research question used for my study has been reformulated on several occasions due to the data I collected from discourse and text studies, as well as from interviews and observations. ${ }^{62} \mathrm{It}$ is both descriptive and explanatory because it requires a discussion of the features and properties of the UPR mechanism, but it also requires an explanation of the source and reasons for its creation.

As noted in the introductory portion of this chapter, the research focuses on the Universal Periodic Review (UPR) mechanism. While the UPR is concerned with human rights and how they are realized in United Nations Member States, this inquiry focuses on the ways in which the mechanism has modified the human rights discourse at the domestic and international levels. Therefore, this inquiry is necessarily concerned with both the theoretical as well as the real world aspects of the UPR.

The main research question is: Does the Universal Periodic Review change the human rights discourse at the national and/or international level?

The term "change" can refer to any modifications in how civil society, governments, national human rights institutions and UN human rights actors communicate, interact and cooperate on human rights issues. These modifications may be changes in the frequency of contact, deepening of subject matter discussed, or resistance to pressure to address issues. The phrase "human rights discourse" refers to the way in which human rights are "discussed" at the domestic and international level. The discourse can be both verbal and written. Therefore, it includes the way in which human rights are talked about, debated and discussed in national and international forums. The study of the human rights discourse also includes how human rights are described, portrayed and explained in written texts and how they are invoked by civil society, national human rights institutions against and in concert with goverments to press for changes to human rights situations on the ground in national settings. Among the elements to be considered in this inquiry are the topics evoked in texts and during the interactive dialogue as well as the way in which governments interact with civil society, national human rights institutions and other relevant participants when dealing with issues that impact human rights. Similarly the human rights discourse can include the way in which governments interface with each other in the international arena.

A research question delineates a subject, determines what needs to be researched and what doesn't need to be done. ${ }^{63}$ In addition, the research question will often lead to a number of smaller inquiries - sub-questions. ${ }^{64} \mathrm{My}$ research has the following sub-questions:

- Does a peer review mechanism change the human rights discourse at the international level?

- Does government participation in the UPR change human rights discourse nationally and/or internationally?

- Does the participation of National Human Rights Institutions in the UPR change human rights discourse nationally and/or internationally?

- Does the participation of civil society in the UPR change the human rights discourse nationally and/or internationally?

\section{I am specifically interested in establishing all of the following:}

\footnotetext{
${ }^{60}$ MAXWELL, supra note 45, at 229.

${ }^{61}$ CURRY-SUMNER, supra note 46, at 18-19.

62 FLICK, supra note 59, at 22. (describing two ways to formulate research: "One way is to start with defining and formulating your research and then to pursue it through your empirical work in order to find an answer to it. The other way is to start with a general observation and to make the research question more focused under way." Id.) I tended to follow the latter model when approaching my research.

${ }^{63}$ CURRY-SuMnER, supra note 46, at 13.

${ }^{64} I d$.
} 
- the ways in which human rights were monitored prior to the establishment of the UPR;

- other mechanisms upon which the UPR was modeled;

- the significance of peer review as a mechanism for encouraging fulfillment of obligations;

- the main phases of the UPR;

- the main actors of the UPR and what are their roles; and

- How the UPR been carried out in individual UN member states.

My approach was to begin with the presumption that something should change if a new mechanism or process is introduced. It was my task to discover if there were changes and what those changes were through interviews, textual analysis and observation. Therefore it was a semi-open question in which I gathered evidence to test whether or not a change had occurred in the human rights discourse. My conclusions were based on the qualitative evidence gathered in the course of the interviews, in observing the webcasts, in reading the documents from civil society and the OHCHR, and by listening to audio recordings of the national consultations.

This dissertation is structured in the following way:

Part One - Introduction, Methodology, Historical background to UN Human Rights machinery, the need for a new start.

Part Two - The concept of International Accountability Mechanisms, including Peer review mechanisms and expert-based human rights mechanisms.

Part Three - How National Human Rights Institutions and Civil Society Organizations have approached the UPR, using the examples of the Dutch government, the Danish Institute for Human Rights, the Kenyan National Commission for Human Rights, the Listening Sessions in the United States' national consultation and the approach of Amnesty International in its national chapters in Hungary and the Netherlands.

Part Four - The summary of findings and conclusions regarding the research questions, based on the empirical data gathered. Presentation of recommendations to strengthen the mechanism.

\section{Literature Review}

Reading the literature on your research topic is a crucial point of departure. "Every researcher...should spend time reading what other people have written about the area in which they are interested." 65 The literature review is "a systematic search through library catalogues and perhaps online journals...." 66 The historical background of the UN Human Rights machinery is primarily discussed in secondary literature and on the Internet on the official website of the United Nations. By reading books and scholarly articles and internet accounts of the history of the establishment of the United Nations and the human rights system, I was able to understand the historical context for the UN Human Rights machinery. My first inquiries were done at the electronic catalogue of the Maastricht University library. I gathered those books that covered human rights as well as the post- World War II creation of the United Nations. I also used the Peace Palace Library in The Hague as a second source for books. When searching the catalogues, I used subject searches such as "UN Human Rights system." I also checked the syllabi of introductory human rights courses of major universities online to get the authors and titles of other human rights textbooks. Finally, I read and analyzed the texts to determine the main

${ }^{65}$ MCNEILL, supra note 48, at 31; See generally, CHRIS HART, Doing a Literature Search: A Comprehensive Guide for the Social Sciences (2003).. ${ }^{66}$ MCNEILL, supra note 48. 
trends and events from history that led to the UN human rights system as it existed immediately prior to the establishment of the UPR.

To collect scholarly articles, I used electronic databases such as Hein Online, Westlaw and EBSCO to find articles that discussed the UN Human Rights machinery. Again, I read the articles and summarized their content in Part One's discussion of the historical background to the UPR. I included scholarly articles that relied on credible and well-known experts' or academicians' books and articles on the subject found through desk-based and library-based research methods.

Once I had read the scholarship on the history of the UN Human Rights machinery, I needed to digest it and make sense of it. I used historical and chronological (timeline) perspectives when engaging in text analysis. ${ }^{67}$ I looked for trends and key events in the establishment of the special procedures, committees and other parts of the human rights machinery found at the United Nations. I wrote about those trends and tried to provide an explanation of key events leading to the establishment of the UPR.

The second part of this dissertation was also undertaken by data gathering and data analysis; however, a comparative approach was used to make sense of the information gathered about accountability mechanisms in International Organizations and one semi-structured interview was conducted to give context to information about the International Labour Organization. In this second part, I undertook to answer one sub-question: Does a peer review mechanism change the human rights discourse at the international level?

This research sub-question took as a point of departure the fact that the UPR is a peer-review, rather than an expert-based mechanism. I queried whether peer review structures differ from other forms of global governance or from the expert-based UN Human Rights machinery such as special procedures and treaty bodies. The inquiry explains theoretical concepts that are crucial to understanding the way in which organizations keep members accountable for meeting their obligations. Because the UPR is a relative latecomer to the international stage, there were already several peer review systems and expert review systems that monitored whether member states fulfilled their obligations under treaties and combinations of soft and hard law obligations. Therefore, I undertook to evaluate these other mechanisms to draw comparisons and contrasts with the UPR. I conducted desk studies of secondary literature and I compared the processes of different International Organizations, such as the OECD, the EU peer processes and the African Peer Review mechanism (APRM). ${ }^{68}$ These were the same peer review and periodic review processes considered when the UPR mechanism was being created and structured. I chose not to include descriptions of the environmental treaty compliance mechanism or the nuclear weapons inspection regimes. These mechanisms were not among the ones considered when drawing up a model for the UPR. While they provide interesting contrasts to international accountability and global governance regimes, the data and scholarship available on the ILO, OECD, the EU and the APRM were sufficient for the discussion of accountability mechanisms in Part Two.

The methodological tool that I used, comparative law, entailed a micro-comparison. ${ }^{69}$ By micro-comparison, I refer to the scrutiny of the peer review and/or supervisory or monitoring features of a small number of international organizations. This undertaking included a comparative look at both the functional and structural elements of the organizations. In other words, my analysis comprised a discussion of the roles and functions of the organizations, as well as the way that monitoring mechanisms are structured and designed.

The library research yielded the conclusion that there is ample literature on international accountability mechanisms, but little information in the way of peer review. I faced significant challenges in finding texts that treated the rise of peer review in scientific settings. There were a few scholarly articles with scant details about

\footnotetext{
${ }^{67}$ Lecture by Markku Suksi at Nordic Research Training Course on Methods in Human Rights Research, March 21, 2012. (Notes and Power Point Presentation on file with the author.)

${ }^{68}$ These mechanisms were chosen because they were also studied by the founders of the UPR and therefore parts of each mechanism are present in the UPR process. I did not include mechanisms that were not also considered by the group that designed the UPR.

${ }^{69}$ Lecture by Markku Suksi, supra note 67.
} 
peer review in science research, journal writing and in scientific grant-making. ${ }^{70}$ I pieced together information from several journal articles to try to paint a picture of what peer review looked like in past decades. However, no detailed textbooks appear to have been written on the subject.

In contrast, there is a wide variety of discussions regarding accountability mechanisms. I look at how International Organizations have held their member states responsible for fulfilling treaty and soft law obligations. This has been done for decades in the International Labour Organization, the Organization for Cooperation and Economic Development and in certain European Union bodies.

As in the case of historical background, to inform myself about the international accountability and global governance mechanisms, I consulted the UM library and Peace Palace library catalogues as well as electronic databases for scholarly articles and books. In addition, I used sources derived from my participation in a seminar in Bremen, Germany on April 9 and 10, 2010 where scholars discussed global governance and ways to evaluate whether an international organization is effectively monitoring its member states' progress toward fulfilling obligations. This conference (arranged by UM Professor Thomas Conzelmann and University of Bremen Professor Kirsten Martens) was attended by political scientists who have studied European Union institutions and International Organizations in the context of peer review. The conference was entitled, "Peer Review as an Instrument of Global Governance." The conference was crucial in introducing me to the idea of peer review as a form of governance. I began to look for discussions of peer review mechanisms and comparisons with expertbased governance tools. The papers discussed at the conference also provided a framework for examining reviews and I used those discussions to examine the texts of the structure of the UPR mechanism as well as the structure of the EU, African Peer Review Mechanism and International Organizations discussed in this dissertation.

The literature regarding the Universal Periodic Review mechanism itself has been growing over the period of my research. The mechanism began in 2008; therefore, when I began my research, in 2009, there were several scholars who had looked at the reform of the UN Human Rights Council and the resolutions establishing and structuring the UPR process. As the UPR continued, more scholars cast a critical eye toward the mechanism and began to study the recommendations and outcomes of the UPR process. As a result, there are three trends in the literature: articles dedicated to an explanation of the process and structure, based on the description of the UPR in its founding resolutions; articles or studies that look at the mechanism in practice, as evidenced in the interactive dialogue and the final recommendations; and articles that rely on case studies of UPRs carried out in individual or groups of states.

Regarding the first trend, this author notes that the scholarly literature discussing the review mechanism and its structure tended to precede the actual start of the UPR; ${ }^{71}$ therefore, the weakness of these articles is that they are largely descriptive -- relying on the founding resolutions -- and sometimes do not reflect the modifications in the structure and content of reports and modalities for the interactive dialogue that occurred after the actual reviews began. This literature also offers critiques of the UPR without having seen the mechanism in action; ${ }^{72}$ those critiques focus on the political nature of the process and the lack of expert participation. The strength of these studies is their contribution to the knowledge regarding the process leading up to the establishment of the mechanism, including the founding dialogues and papers. The Alston paper is a very good example of the

\footnotetext{
${ }^{70}$ Neil W. Hamilton, The Ethics of Peer Review in the Academic and Legal Professions, South Texas Law Review 227 (2001); LOUIS J. VIRELLI, Scientific Peer Review and Administrative Legitimacy, 61 Administrative Law Review 723 (2009); ALISTER SCOTT, Peer Review and the Relevance of Science, 39 Futures 827 (2007).; J.B. RuHL \& JAMES SALZMAN, In Defense of Regulatory Peer Review, 38 Environmental Law Reporter News and Analysis 10553 (2008).

${ }^{71}$ Scholars relied on the formative documents describing the mechanisms. These documents do not always reflect the way the mechanism operates today. ALSTON, supra note 21 at 185-224; FELICE D. GAER, A Voice Not an Echo: Universal Periodic Review and the UN Treaty Body System, 7 Hum. Rts. L. Rev. 109; Claire CALLEJON, Developments at the Human Rights Council in 2007: A Reflection of its Ambivalence, 8 Hum. Rts. L. Rev. 323; FELIX KIRCHMEIER, Inaugural Session of the United Nations Human Rights Council Geneva 19 to 30 June 2006 , Friedrich Ebert Stiftung, July 2006; GISELA VON KEYSERLINGK, Fifth Session of the UN Human Rights Council, Friedrich Ebert Stiftung, June 2007 No. 6; THEODOR RATHGeBer, The HRC Universal Periodic Review: A Preliminary Assessment, Friedrich Ebert Stiftung, July 2008.

${ }^{72}$ One notable exception is the scholarship of Dominguez focusing on the reviews of the first session of the first cycle. ELVIRA DOMINGUEZ REDONDO, The Universal Periodic Review of the UN Human Rights Council: An Assessment of the First Session, 7 Chinese Journal of International Law 726 (2008).
} 
tendency in the early writing on the UPR to focus on what must be avoided in order to be successful. ${ }^{73}$ Alston looks at the UPR founding documents and discusses the predecessor albeit short-lived review mechanism and lists several potential pitfalls that will need to be avoided in order for the UPR to escape the fate of its predecessor. Gaer's study of the mechanism emphasizes the founding documents and the discussions and work (travaux préparatoires) to establish the UPR, again offering a list of pitfalls to be avoided. ${ }^{74}$ Both of these scholars are heavily influenced by the political failings of the Commission and the politicized nature of human rights debates thereunder. Both seek to offer ways for the UPR to avoid politicization of its processes.

One notable exception in the tendency of the early writing to rely solely on the formative resolutions is a study by Dominguez of the first session of the first cycle of the UPR. ${ }^{75}$ Dominguez looks at how delegations were composed and the number of states taking the floor during the interactive dialogue to conclude that nations were taking the UPR process seriously. ${ }^{76}$ She also briefly considers the roles of NHRIs and CSOs in the process by mentioning lobbying efforts and side events organized to get certain items on the agenda during the interactive dialogue. ${ }^{77}$ Another look at the first cycle, first session by Juliana Vengoechea-Barrios gave a brief summary of troika members and issues raised for Brazil, South Africa and Poland. ${ }^{78}$ The Friedrich Ebert Stiftung research should also be mentioned for its unique perspective regarding the role of civil society in the UPR. ${ }^{79}$

The early scholarship highlights the significance of the UPR for paving the way to a process where all countries are responsible for reporting on their human rights situations. These scholars also emphasize the UPR's broad mandate to scrutinize virtually every area of human rights within a nation.

Later scholarship examines the UPR and its actual practices, including the interactive dialogues and the final reports and recommendations. Prof. Edward R. McMahon of the University of Vermont has conducted studies of the Universal Periodic Review, in collaboration with the Friedrich Ebert Stiftung, focusing on the policy recommendations and the responses by the states thereto. ${ }^{80}$ Others have looked at the UPR within the larger context of the UN Human Rights Council and the other existing human rights monitoring mechanisms. ${ }^{81}$ The Friedrich Ebert Stiftung offered new insights from other stakeholders, including the role of national parliaments. ${ }^{82}$ Preckel and Willi survey the role of civil society in the UPR, highlighting the use of information, symbolic, leverage and accountability politics. ${ }^{83}$ They also conduct a case study of the Austrian UPR. ${ }^{84}$ Again, Dominguez offers a different perspective for the remaining reviews in the first cycle by considering the potential contribution of the UPR to state practice and opinio juris. ${ }^{85}$ Among the more novel approaches is the one taken by Antonio Cisneros de Alencar, who looks at the cooperation between the Inter-American regional system for the protection of human rights and the UPR and identifies ways to increase and enhance cooperation in future UPR cycles. ${ }^{86}$

\footnotetext{
73 ALSTON, supra note 21.

${ }^{74}$ GAER, supra note 71.

${ }^{75}$ DOMINGUEZ REDONDO, supra note 72.

${ }^{76} \mathrm{Id}$. , at 729 .

77 Id. at 731-732.

${ }^{78}$ Juliana VengoecheA-BARRIOS, The Universal Periodic Review: A New Hope for International Human Rights Law or A Reformulation of Errors of the Past? 12 Revista Colombiana de Derecho Internacional (2008), at 101-116.

${ }^{79}$ KIRCHMEIER, supra note 71; RATHGEBER, supra note 71.

${ }^{80}$ See EDWARD MCMAHON \& MARTA ASCHERIO, Analysis of Recommendations of the Universal Periodic Review Sessions I-VI, Friedrich Ebert Stiftung, October 2010 and EDWARD MCMAHON, The Universal Periodic Review: A Work in Progress, An Evaluation of the First Cycle of the New UPR Mechanism of the United Nations Human Rights Council, Friedrich Ebert Stiftung, September 2012.

FREEDMAN, supra note 22, at 292; BERNAZ, Reforming the UN Human Rights Protection Procedures:,supra note 16, at 87 et seq.

${ }^{82}$ FELIX KIRCHMEIER, The Role of Parliaments in the Universal Periodic Review, Friedrich Ebert Stiftung, April 2009.

${ }^{83}$ KIRA PRECKEL \& ROSALINE WILLI, The Role of Civil Society in the Universal Periodic Review: Human Dignity, in Your Hands? in European Yearbook on Human Rights, (Wolfgang Benedek, Florence Benoit-Rohmer, Wolfram Karl, Manfred Nowak, eds., 2012 ), at 417-432.

$84 \mathrm{Id}$. at $428-430$.

${ }^{85}$ Elvira Dominguez Redondo, The Universal Periodic Review - Is There Life Beyond Naming and Shaming in Human Rights Implementation?, available at http:// papers.ssrn.com/sol3/papers.cfm?abstract_id=2111607.

${ }^{86}$ ANTONIO M. CISNEROS DE ALENCAR, Cooperation Between the Universal and Inter-American Human Rights Systems in the Framework of the Universal Periodic Review Mechanism 7 Sur International Journal on Human Rights 13 (2010), at 171-183.
} 
Some literature gives insight into specific UPR reviews. Verrest and Dopheide look at the Netherlands' second cycle review. ${ }^{87}$ Rhona Smith studies Asian-Pacific nations' experiences in the first cycle, drawing conclusions about whether the size and resources of a nation result in disparate treatment in the mechanism..$^{88}$ Smith does a second study of Pacific Island States. ${ }^{89}$ Cochrane and McNeilly conduct a case study of the United Kingdom's first and second reviews. ${ }^{90}$ Harrington summarizes the history leading to the UPR and outlines the Canadian experience in the first cycle. ${ }^{91}$

Books about the UPR are not yet proliferating, but Purna Sen has written two regarding the Commonwealth nations' experiences in the UPR in the first cycle. ${ }^{92}$ Many new textbooks also reference the UPR. The author has not read all of them, but will mention one notable textbook: David Forsythe's Human Rights in International Relations. ${ }^{93}$

The vast majority of scholarship regarding the UPR focuses solely on the events in Geneva; that is to say, the interactive dialogue. There is little written to date regarding how the national consultations are approached. ${ }^{94}$ In addition, little is known about how the civil society groups and national human rights institutions have contributed to the UPR process during the national consultation and in the period of implementation of recommendations. This inquiry seeks to fill those voids.

\section{Methods}

\section{A. Part One}

For Part One, I employed library research and desk studies to gather texts on the historical background to my thesis. In this portion of my research, I conducted a review of the existing scholarship regarding the reform of the UN human rights machinery - namely, the events leading to the creation of the UN Human Rights Council and the establishment of the Universal Periodic Review mechanism. After that first data-gathering stage, I then moved to analysis of the texts that I collected before writing the results.

\section{B. Part Two}

In Part Two, I applied comparative techniques by examining the phases of review used in other International Organizations such as the OECD and the ILO. These comparisons are done horizontally, looking at the way processes are carried out in International Organizations (IOs). These comparisons are useful for drawing conclusions about the UPR structure and its potential for encouraging the fulfillment of human rights obligations by member states.

Additionally, I looked at the structures of the IOs as a type of legal plurality. Legal pluralism is a paradigm that challenges the traditional view that there is but one legal order. Legal pluralists recognize a myriad of legal orders, particularly the "plurality of decision-making institutions, distributive criteria and cultural traditions." 95

\footnotetext{
87 P.A.M. VerRest \& T. DOPHEIDE, De evaluatie van Nederland in het kader van de Universal Periodic Review, 6 Justiele Verkenningen (Oct. 2012), at 11-21. See also the 2008 review summary T. DOPHEIDE, Universal Periodic Review, Het grote mensenrechtenexamen van de VN, 33 NJCM-Bulletin 6 (2008), at 891-901.

${ }^{88}$ RHONA K.M. SMITH, Equality of 'Nations Large and Small': Testing the Theory of the Universal Periodic Review in the Asia-Pacific, 2 AsiaPacific Journal on Human Rights and the Law (2011), at 36-54.

${ }^{89}$ RHONA K.M. SMITH, The Pacific Island States: Themes Emerging from the United Nations Human Rights Council's Inaugural Universal Periodic Review? 13 Melbourne Journal of International Law 1 (2012), at 1-26.

${ }^{90}$ Leanne Cochrane \& Kathryn McNeilly, The United Kingdom, the United Nations Human Rights Council and the First Cycle of the Universal Periodic Review, 17 International Journal of Human Rights 1 (2012), at 152-177.

${ }^{91}$ JOANnA HARRINGTON, Canada, the United Nations Human Rights Council, and Universal Periodic Review, 18 Constitutional Forum 79 (2009) at 79-93.

92 Perna Sen, Universal Periodic Review of Human Rights: Towards Best Practice (Commonwealth Secretariat, 2009); PERNA SEN, Universal Periodic Review: Lessons, Hopes and Expectations (Commonwealth Secretariat, 2011).

${ }^{93}$ DAVID FORSYTHE, Human Rights in International Relations (Cambridge University Press, 2012).

${ }^{94}$ Preckel and Willi's scholarship does look at how CSIs use information, symbolic, leverage and accountability politics to impact the UPR both nationally during the preparation phase and internationally in the interactive dialogue and other Geneva-based phases.

${ }^{95}$ RodericK A. MACDONALD, Metaphors of Multiplicity: Civil Society, Regimes, and Legal Pluralism, 15 Arizona Journal of International \& Comparative Law 69, 77 (1998).
} 
They recognize that while "state-sponsored normative standards" exist, there are also equally important informal orders that exist independently of each other and are created by citizens and customs found in "families, cultural communities, workplaces, neighbourhoods, bureaucratic organizations, commercial enterprises." 96 International Organizations do not have one rigid way of assessing how well member states live up to their obligations. I wanted to look at the plurality of approaches to aiding member states in fulfilling their obligations; for example purely expert or state-driven mechanisms or hybrid structures involves state and expert review.

Part Two also required text analysis. This was due to one particularly valuable tool: the Internet. Many international organizations have an official website that describes the internal processes of the organization. The "democratic character" of the Internet means that "anyone can post something up on their own web-site." 97 I consider these sites to be "official voices," but I also seek to verify and corroborate the validity of the information with other sources through the process of triangulation..$^{98}$

In addition to the literature review regarding IOs, I also consulted the websites of the various organizations and the UN High Commissioner for Human Rights (OHCHR). There, I found public relations materials explaining the mission and mandate of the organization. The websites have text as well as images. I examined these websites and conducted text analysis to see what the main discourses were, the language employed by the organization and the messages these organizations were conveying to website visitors. I use this analysis in my writing to describe the messages and impressions communicated by the organizations over their websites.

In addition, there were scholarly studies of the organizations that were made available to explain the monitoring and supervision roles of the organization. I also analyzed these texts, taking into account their purpose and author. These texts were useful for seeing how the organization wants to be viewed by outsiders. The documents are invaluable for providing an alternative view to those written by scholars and academicians in journal articles and books. Both are necessary for providing a balanced view of what the organization does and how it is structured.

One final method was employed to gather data for Part Two - the semi-structured interview ${ }^{99}$ of a key informant. 100 Beth Leech points out that in an interview "what you already know is an important as what you want to know. What you want to know determines which questions you will ask." 101

I needed information about how the ILO mechanism functioned with its tri-partite structure involving civil society, experts and states. While I knew the theory on paper, I suspected that the every-day functions could be different. Therefore, interviewing a key official would be helpful to discern what occurs in real life. This key informant was a legal adviser and had knowledge of how member states were pressured to adopt key ILO standards and implement them in their domestic legislation.

\section{Part Three}

Part Three of my inquiry focuses on how the UPR was carried out in practice in the first full cycle and in the early stages of the second cycle.

I used semi-structured interviews of key officials who had been involved in the planning of the government, CSO and NHRI participation in the UPR. I also used text and discourse analysis to derive findings regarding the

\footnotetext{
${ }^{96} I d$.

${ }^{97}$ MCNeILL, supra note 48, at 167.

${ }_{98}$ Id. 23. ("triangulation refers to the use of multiple methods to cross-check and verify the reliability of a particular research tool and the validity of the data collected.") Id.; HART, supra note 64 at 205; CLIVE SEALE, the Quality of qualitative Research 52-72 (1999).

${ }^{99} \mathrm{Id}$. at 56-67(discussing the use of interviews in social science research).

${ }^{100}$ Some might also consider this key informant to be an "elite" as that term is understood in political science interview methods. He held a key position in the ILO, at the time of the interview. BETH L. LEECH, Interview Methods in Political Science, 35 Political Science \& Politics 663, 665-666 (2002).

${ }^{101} I d$. at 665 .
} 
changes in the human rights discourse. Finally, I chose to look at the roles of governments, national human rights institutions and civil society organizations in the UPR for my principle case studies.

The sub-questions that I seek to answer in Part Three are:

- Does government participation in the UPR change human rights discourse nationally and/or internationally?

- Does the participation of National Human Rights Institutions in the UPR change human rights discourse nationally and/or internationally?

- Does the participation of civil society in the UPR change the human rights discourse nationally and/or internationally?

\section{Part Four}

Part Four of this inquiry presents the findings and conclusions by assessing the changes in the human rights discourse brought about by the UPR.

Four considerations are examined when determining how the UPR has changed the human rights discourse:

Participants in the human rights discourse;

The frequency and total number of encounters between the participants;

The manner in which the human rights discourse is carried out; and

The content of the human rights discourse.

The inquiry is not limited to findings and conclusions, but also makes policy recommendations regarding ways to strengthen the process.

\section{Approach}

I employed new legal realism as my approach to the UPRs achievements. ${ }^{102}$ New legal realism in the human rights context is a way to analyze local rights consciousness and how intermediaries, such as governments, CSOs or NHRIs, translate the documents and outcomes of human rights bodies into terms that are relevant to local individuals. ${ }^{103}$ The research coming from socio-legal origins have highlighted the failure to translate articulated rights into realized rights at the local level.104

I am particularly persuaded by this approach to research because some parts of the UPR occur in a transnational environment in Geneva. All actors, from civil society, to government permanent missions are brought together with a broad spectrum of issues and complaints. During the UPR, documents are created and disseminated and placed on the Internet. Using the new legal realism approach, I see how the UPR works in practice by looking at the CSOs and NHRIs and the way they construe the UPR and its significance in their societies and how they press governments to implement the recommendations and outcomes of the process. I also look at governments and how they carry out their own mandate to conduct a national consultation and implement recommendations from the process. All of this is done by interviewing the actors and looking at the discourse and the documents that are disseminated locally.

102 SALLy ENGLE MERRY, New Legal Realism and the Ethnography of Transnational Law, 31 Law \& Social Inquiry 974 (2006).

${ }^{103} \mathrm{Id}$. at 978

${ }^{104}$ Id. at 979 . 


\section{Observations}

One source of information for Part Three involved data gained from observation. Non-participatory observation is an "unobtrusive form of observation" that focuses on behavior or activity and is carried out by a person that is a "detached onlooker." 105 I decided to be a non-participatory observer of the UPR process. The decision not to participate had one very significant consequence: I would not be admitted to the floor of the UN Human Rights Council. The only persons permitted on the floor are accredited NGOs, along with members of the permanent missions in Geneva, the delegations that are under scrutiny before the Working Group, the members of the Working Group and the staff of the OHCHR Secretariat. My decisions to be a non-participant were made on an ethical basis. I made a conscious choice not to ask an NGO to permit me to tag along with them into the UN Human Rights Council Working Group sessions because that necessarily meant viewing the process through the lens of an NGO. 106 NGOs are not independent, neutral bodies. They have interests, agenda and advocacy duties that color their worldviews and could influence mine.

In a similar vein, I discounted the possibility of gaining access through contacts in the OHCHR Secretariat. Again, the Secretariat is the UN representative, with its own political interests and biases. My choice to observe from the public gallery meant that my information would not go through the filter of any interested party, but it also necessarily imposed a distance between me and the UPR participants that I was observing. I needed to bridge that gap by going downstairs and standing among the delegates as they stood outside of the doors of the UN Human Rights Council meetings and talked, negotiated, made telephone calls and defended and drew up their positions and statements. I also attended side events sponsored by NGOs and by the OHCHR Secretariat. This tradeoff was worth it in order to maintain a semblance of neutrality.

There were three processes of the UPR that I would observe as a non-participant: (1) the initial review of a UN Member State before the UN Human Rights Council Working Group in a session known as the "interactive dialogue; "(2) the adoption of the working group report, a 30-minute meeting that takes place 48 hours after a country has been reviewed in the interactive dialogue ; and (3) the adoption of the final recommendations in the Plenary Session of the UN Human Rights Council three months after the interactive dialogue. I observed the interactive dialogue/review for the following countries in October 2011: Ireland, Togo and Syria; the adoption of the Working Group report for Antigua and Barbuda and Trinidad and Tobago; and the adoption of the final outcome in the plenary session in March 2012 for the following countries: Haiti, Timor Leste, Moldova. These sessions were live at the Palais de Nations in Geneva, Switzerland. However, my experience in observing the processes was not limited to my live observations. The OHCHR maintains an archive of all UPRs and plenary sessions. I have observed the following webcasts of country UPRs and adoptions of final reports: Bahrain, Switzerland, Gabon, Chile, the United States of America, Denmark, Kenya, Hungary, Indonesia, Timor Leste, Uganda, Haiti, Morocco (second cycle), Netherlands (first cycle and second cycle), Ecuador (first and second cycle). I have also seen portions of the interactive dialogues of countless other reviews.

\section{Interviews of Key Informants}

A second source of information was through semi-structured interviews. ${ }^{107}$ I interviewed a total of seventeen officials who came from international organizations, national governments, NHRIs and CSOs. ${ }^{108}$ Each of the officials has some role in an aspect of the UPR. All interviews were semi-structured interviews where I used an interview guide tailored to the country and the role that the informant played in the UPR. Generally, there isn't a fixed rule about how many interviews must be conducted except that "you will need enough data to explore and document a range of themes." 109 Two interviews were conducted in person in Geneva. One face-to-face interview was conducted in Maastricht and another in Turku, Finland. Three interviews were conducted using video and

\footnotetext{
${ }^{105}$ MCNeILL, supra note 48, at 92.

106 SAlly ENGLE Merry, Anthropology and Activism: Researching Human Rights Across Porous Boundaries, 28 PoLAR 240, 245 (2005).

${ }_{107}$ Basing case studies on interviews is a theme touched upon by Max Travers. MAX TRAVERS, Qualitative Research Through Case Studies 37 (2001).

108 See Annex I for a list of each of the interviewees.

109 TRAVERS, supra note 107.
} 
voice over Internet protocol (Skype). Six interviews were conducted using a landline telephone. The remaining interviews were conducted by me using Skype to call a landline telephone.

I chose the officials based on their participation in the process. In each case I interviewed the individual who had the main responsibility for coordinating the UPR efforts within the organization. In the cases of the civil society organizations, the informant was the only one or only one of a very small team of less than two full-time staff who worked on the UPR. (Annex II contains a sample list of possible interview questions. Each interview was conducted independently.) This was also the case with the government of the Netherlands, where the first cycle of the UPR was carried out by just one person. The second cycle team was larger; in that case, I interviewed three informants. Therefore, the information given in my interviews was authoritative because it was supplied by the individual with the sole responsibility for the process within the government or civil society organization.

Some ethical considerations did arise as I interviewed key informants. One key informant initially agreed to go on the record. However, in the course of the interview the informant stated that I should not quote one particular statement that he made. Then, when explaining the relationship between civil society organizations and the government, it became clear that members of civil society were reluctant to approach government officials to press them on certain human rights issues to be included in the government's national report. Furthermore, civil society members could face reprisals if they broached certain human rights topics with government employees. Out of concern for this civil society organization informant's safety, I opted not to identify the informant (confidentiality is typically the case for ethnographic research).

My interview with government officials was limited to the Kingdom of the Netherlands. I was not able to make fruitful contact with other governments despite my best efforts to interview government officials from Ecuador, the United States of America and Burkina Faso. Accordingly, the case study for governments consists of my contacts with the key informants from the Dutch government UPR. I chose to speak with the Dutch officials because:

(1) The key informants indicated that they could speak willingly regarding their assessments of the Dutch participation in the UPR without getting approval or prior authorization for their responses;

(2) The Dutch government's initiative to inform the OHCHR of its implementation efforts during the first could be more closely scrutinized during interviews to see how the government met its commitments ; and

(3) The Netherlands case presented interesting issues and challenges to governments due to the creation of an NHRI and the demise of the government (cabinet) in the midst of a UPR cycle.

The fact that my government case study is limited to one western government does have some larger repercussions for my research which is discussed in depth in the findings and conclusions. First, the research is based on the experiences of a democratic country with a largely independent civil society; therefore, the experiences are not likely to be duplicated in societies where civil society is not independent or where the government is autocratic. In my findings and conclusions, I mention this limitation and explain how it affects the usefulness of my data.

I interviewed individuals from National Human Rights Institutions (NHRIs) in Kenya and Denmark to determine how NHRIs engaged in the UPR process.

I chose the Danish and Kenyan NHRIs because:

(1) Both NHRIs had been mentioned in conferences and scholarly articles regarding unique approaches to national consultations in the UPR;

(2) They were from different regional blocs and were of differing geographical size and economic resources; and

(3) NHRI officials in both organizations were able to speak about the process without seeking prior approval of the organization concerning statements made during the interview. 
I made my contacts with the NHRIs after attending a conference in Copenhagen Denmark in May 2011. This was a Cost Action Working Group conference held for two days at the Danish Institute for Human Rights. ${ }^{110}$ During the conference, Jonas Christoffersen, the director of the Danish Institute spoke candidly about the challenges the institute had in arranging the UPR consultations with the government. Other members of UPR teams were introduced. I networked with these individuals and told them of my interest in interviewing them for this dissertation. They were more than willing to cooperate and later provided invaluable contacts (the snowballing technique) used for future interviews with other participants in other countries such as Kenya. My interviews were based on an interview guide. (I had developed interview guides according to the role that the individual played. Therefore, I had separate interview guides for NGOs, government officials, OHCHR officials and NHRIs. The interviews were always semi-structured. I used a combination of open-ended and closed-ended questions.) The data that I collected from the interviews with NHRIs would help me analyze how the UPR had changed the human rights discourse at the domestic level. Much of the data confirmed my original thesis that the interaction between NHRIs and civil society organizations and other grassroots participants had been enriched by the new way in which NHRIs were capacitating and interaction with these groups. In addition, new roles and participation was being forged with the NHRI and government agencies and officials. I also saw that the NHRIs were asserting themselves in new ways in the international arena with interaction with permanent missions and diplomats. The NHRIs were also developing baseline reports and other benchmarks for future assessment of government progress on recommendations and goals coming out the UPR.

My case studies of civil society organizations and the UPR focus on the United States review because when I reviewed the US Department of State website, the information suggested that the US used a unique approach, arranging for listening sessions and sending high-level government officials to each event to record and keep a record of what was expressed by civil society in the events. My impressions about the unique approach were borne out when my interviews demonstrated that the US government permitted the events to be arranged by civil society, giving wide latitude to the ways in which information was presented. Several formats were used, including video clips, site visits, panel discussions and question/answer sessions.

An American law professor with whom I co-authored an article about the UPR was involved in the listening session held by the United States Department of State at the University of San Francisco in the state of California as part of the government's national consultation. This professor put me in contact with the person who arranged many of the important aspects of the event. I conducted a semi-structured interview via Skype (with video) to ascertain important aspects of the structure and content of the listening session. I also contacted the Human Rights Institute at Columbia University School of Law who was actively involved in a listening session in New York City. Relying on the fact that I was an alumna of the law school, I wrote an e-mail asking to interview the key informant about the content and structure of the listening session. Again, the interview was a semi-structured telephone interview using a combination of open-ended and closed-ended questions. Both interviews permitted me to form a thick narrative about the listening session experiences and the role of civil society in these sessions. I was also able to obtain an audio copy of the New York listening session. I employed discourse analysis to the panel discussions that occurred during that listening session. The data I collected from the interviews has also been important in conceiving how civil society organization have changed the human rights discourse at the international and domestic level through the ways in which they participate in the UPR. This data allowed me to make findings that the universality of human rights covered in the UPR permits civil society organizations that never before interacted with treaty bodies (because their topics were not part of a treaty body to which the country was accountable) were empowered to participate in the UPR process. Additionally, the civil society organizations' key informant interviews indicate a potential for the UPR national consultations to encourage a level of participation and contact heretofore unseen by many national officials with their citizens.

I chose to use the Amnesty International model as an example of how national civil society organizations can impact the UPR process. I chose Amnesty International's strategies in Hungary and the Netherlands because they are case studies in how prioritizing issues can result in significant amounts of recommendations surrounding

${ }^{110}$ COST Action IS0702 The Role of the EU in UN Human Rights Reform hosted by the Danish Institute for Human Rights in Copenhagen, Denmark on May 23 and May 24, 2011. Members of the Danish Institute for Human Rights reported about the role of the institute in the Danish UPR, particularly the national consultation. 
topics of importance in human rights. Amnesty International's approach first became evident to me in a seminar that I organized, together with Jasper Krommendijk, a fellow PhD candidate at Maastricht University Faculty of Law. The seminar took place on November 25, 2011 and was organized under the auspices of the Maastricht Centre for Human Rights. ${ }^{111}$ Marianne Lilliebjerg, Interim Programme Director International Advocacy, Amnesty International, explained how the organization approached advocacy in the UPR. Ms. Lilliebjerg later put me in contact with national chapters, permitting me to arrange to interview the key AI officials for this dissertation.

The Office of the High Commissioner for Human Rights also plays an important role in the entire UPR process. I interviewed the head UPR official to ascertain certain aspects of the role of the OHCHR in the process. I chose this official because he had been with the UPR process from the beginning and was therefore able to offer perspective to how the process evolved and why certain decisions were made regarding the structure of the reviews and the resources within the Secretariat. The informant was interviewed with a semi-structured approach after having e-mailed him my interview guide. The information gathered will assist me in giving context to the managerial aspects of the OHCHR as well as the financial and resource constraints faced by the Secretariat. This served as a way to bolster my understanding of what is going on in the background during the UPR process.

\section{Text and Discourse Analysis}

A third source of information came from the reports submitted to the UPR process and interactive dialogue held during the review of each nation as well as the adoption of the working group report and the adoption of the final report in the Plenary Session. One can learn a lot from the documents. ${ }^{112}$ Each UPR offers three-and-a-half hours of verbal discourse and over 100 pages of text for analysis. In Part Three I chose to study a few nations up close to see how the UPR was carried out in the country. This involved looking at the national report, all stakeholder reports, the final outcome report, and watching the interactive dialogue over an Internet webcast. I employed text analysis to look at the documents that were submitted by the national government, stakeholders and the OHCHR itself. I was able to identify recurring themes that were raised in reports from each of the stakeholders, governments, NHRIs and OHCHR, suggesting that the actors were learning a common discourse with understood themes and issues. ${ }^{113}$ This was true no matter what regional group or block the country adhered to and no matter what economic conditions or size. Similarly, the analysis of the interactive dialogues showed a convergence of ideas and themes among the participating states.

\section{Writing Up the Results and Findings}

The most difficult of my tasks was to determine how to present my information. "[T]here is a difference between simply reporting your observations, or present extracts from interviews, and developing a coherent analysis informed by a particular theoretical tradition or perspective." 114 After gathering my empirical data from the interviews, after applying text analysis to the UPR documents and after analyzing the discourse in the interactive dialogues, I determined that the best way to present my findings would be through the use of case studies highlighting the transformation in human rights discourse that I observed at the domestic and international levels. Research aims, methods, findings, discussion and conclusions are all important considerations when writing up the report. ${ }^{115}$

This portion of the research findings are discussed in case studies. Case studies in social science research are generally understood as the "intensive study of a single case where the purpose of that study is - at least in part-

\footnotetext{
111 Full report on the outcome of the seminar at http://www.maastrichtuniversity.nl/web/institutes/maastrichtcentreforhumanrights/pastnewsandevents/pastevents.htmhttp://www.maa strichtuniversity.nl/web/Institutes/MaastrichtCentreForHumanRights/NewsAndEvents/PastEvents.htm.

112 TRAVERS, supra note 107, at 5.

113 Norman Fairclough is credited with galvanizing this approach to research. NORMAN FAIRCLOUGH, Language and Power (1989).

114 TRAVERS, supra note 107 , at 38.

115 MARTin BRETt DAVIES, Doing a Successful Research Project, 209-228 (2007).
} 
to shed light on a larger class of cases.... ${ }^{116}$ I have chosen certain country UPRs for closer study. In addition, I chose certain governments, organizations and national consultations to observe and study, with the understanding that they are not representative of all periodic reviews, ${ }^{117}$ but that there are certain practices that can be extracted from each experience for the good of the entire process. I have chosen those countries and organizations on the basis of several considerations. First, I made an effort to include countries from the six regional blocks of the United Nations. Those blocks represent the way in which many countries vote and view issues, including issues of human rights, within the UN setting. It was important to me that countries from each of the blocks be present in my case studies because many scholars posit the theory that human rights are viewed differently within these regional blocks. If this theory is true, then to have a representative sampling, I would need to ensure that I looked at UPRs across the regional blocks.

A second consideration was size and economic resources. Many scholars and human rights practitioners also point out that economic power can affect the way human rights are implemented locally. Therefore, I tried to ensure that my case studies cover the gamut in size - from the smaller nations like the Netherlands and Denmark to the large country of the United States of America. I tried to ensure that the nations with less economic power, such as Kenya, and those with greater economic power were present, as it would be important to see whether best practices for UPR interaction could be found in each country.

My choices in case studies were also influenced by what I heard and read when conducting background information on the UPR, when watching UPR webcasts or observing live UPR sessions in Geneva, by what certain UPR actors were saying about who was providing good governance or best practices in the UPR. Certain countries have been mentioned in literature or by anecdotal information given at conferences as countries that have used innovative methods in the UPR. I tried to include those countries in my case studies. Finally, certain organizations and civil society members were pointed out as examples of good practice and innovative approaches to advocacy. These organizations were also chosen for more careful study.

\section{Summary}

In summary, this study is a qualitative study that uses literature studies, interviews, non-participatory observation, text and discourse analysis to examine whether the UPR has changed the human rights discourse in the domestic and international arena. This study further examines whether the use of peer review has changed the way that fulfillment of human rights obligations are discussed between UN Member States during the UPR through comparative analysis with other international organizations. The study reports the data collected in the form of case studies to give the reader a better idea of how the UPR works in practice. This research is strategic in nature because it sets out to give policy recommendations for ways to strengthen the UPR mechanism. In addition, it lays out some best practices for national governments, national human rights institutions and civil society groups as they continue to interact with the UPR mechanism.

116 JOHN GERRING, Case Study Research: Principles and Practices, 20 (2007).

117 Gerring notes that "[a]n additional implication of the term "case study" is that the unit(s) under special focus is not perfectly representative of the opopulation...."Id. 


\section{PART TWO:}

\section{THE CONCEPT OF ACCOUNTABILITY AND ACCOUNTABILITY MECHANISMS IN INTERNATIONAL LAW}

The Universal Periodic Review (UPR) is a mechanism that relies on peers to assess compliance by other member states with human rights obligations. In this Part Two, the focus is on the research sub-question: Does a peer review mechanism change the human rights discourse at the national and/or international level?

In the parlance of modern international law, the UPR can be described as an accountability mechanism. The concept of accountability is currently being widely debated in public international law. ${ }^{118}$ What does the term mean? Who holds who accountable for what? What are the consequences for failure to be accountable? These are the questions that are posed when debating the responsibility of states.

This portion of the inquiry, first looks at accountability in its general sense. Accountability, as a concept, is not unique to the realm of international law. Indeed, it is also evident in national systems, where governments are held to the standards and expectations of the people they govern. National institutions are often designed to keep governments and elected officials cognizant that they have a duty to act responsibly and to carry out the mandate given them by the electorate. Accordingly, this chapter considers definitions of accountability and how the concept is understood in national and international settings by drawing on examples from national and international institutions to further develop the concept.

Following the explanation of the term accountability, the inquiry moves to the related question of accountability mechanisms. Again, like the concept of accountability, these mechanisms can be found in the national context as well as within the context of international law. There are many types of accountability mechanisms. Some are comprised of experts who assess compliance with obligations. Others rely on peers to evaluate each other. We will look at accountability mechanisms, in general and how they have evolved, their characteristics and their goals. Then, we will look at some specific examples of accountability mechanisms found in the national and international context. First, in the national context, we examine the New York Police Department's Civilian Complaint Review Board and the Australian Commission for Human Rights, the International Labour Organization (ILO), and the World Bank. This section will also include a detailed look at the United Nations Human Rights system as the foremost accountability mechanism for human rights at the international level.

Finally, Peer review in and of itself is a unique type of accountability mechanism. The UPR is a peer review mechanism. Therefore, Part Two also examines the theory behind peer review and the nature of the peer review process. We will take a closer look at other peer review mechanisms found in international bodies such as the Organization of Economic Cooperation and Development (OECD), the EU Open Methods of Cooperation, and the African Peer Review. This section will also compare the structures of those peer review frameworks to that of the UPR. ${ }^{119}$

At the end of the discussion about peer review and the UPR, this inquiry looks at the contributions that UPR makes to the UN Human Rights machinery. Four major contributions will be discussed: data gathering, national consultations, final recommendations and transparency.

\footnotetext{
118 Simon Burall \& CAROline Neligan, The Accountability of International Organizations, GPPi Research Paper Series No.2, available at http://www.gppi.net/fileadmin/gppi/IO_Acct_Burall_05012005.pdf

119 The reader should note that this portion of the inquiry relies on secondary documents to describe the accountability mechanisms in International Organizations.
} 


\section{Chapter Three}

\section{Defining Accountability and Accountability Mechanisms}

\section{Introduction}

If the goal of the UPR is to hold UN Member States accountable for the ensemble of their human rights obligations, then the notion of accountability is important in assessing whether peer review transforms the human rights discourse. Indeed, accountability has become an important underlying concept in the human rights discourse. More and more, the UN human rights machinery focuses on whether states are meeting their obligations. Of equal interest is how to address failures to fully comply with one's engagements in the area of human rights.

This chapter is divided into two parts. In the first part of the chapter, we will examine the idea of accountability and will create a definition of accountability that will be used throughout this dissertation. To arrive at a working definition for accountability, we first look at an ordinary dictionary definition for accountability, then at the Black Law dictionary's definition and finally at two scholarly concepts of the term. We then will devise our own definition of accountability for use in this inquiry.

In the second half of the chapter, we turn to the concept of an accountability mechanism. This part of the discussion will answer some key questions about accountability mechanisms: What is an accountability mechanism? What are the characteristics of an accountability mechanism? Where are some examples of accountability mechanisms found in both national and international settings? When looking at national and international accountability mechanisms, we will examine mechanisms that are outside of the field of human rights, together with accountability mechanisms that are specifically designed to protect individual freedoms and human rights. In this latter portion, it is instructive to study some models of accountability mechanism. Therefore, the inquiry looks at the New York Police Department's Civilian Complaint Review Board and the Australian Human Rights Commission as examples of national accountability mechanisms. The International Labour Organization, the International Monetary Fund's Country Surveillance procedures and the United Nation's Human Rights System round out the discussion of international accountability mechanisms.

\section{Defining the concept of accountability}

The term accountable is defined in the Oxford online dictionary as "required to justify actions or decisions" 120 while Black's Law dictionary states that to be accountable means to be "[r]esponsible; answerable." 121 Therefore, accountability, both in its ordinary sense and in a legal context can be generally understood to involve responsibility and answerability to another.

Accountability can be seen in both judicial and non-judicial contexts. In judicial settings, accountability can mean answering before a judge or jury or before a panel of experts for conduct or for failure to live up to one's obligations. In non-judicial settings, accountability can include appearing before peers to give an explanation for behavior or it could mean facing an angry electorate or responding to the questions of constituents. In its most basic form, accountability means facing the music by justifying your actions or inaction.

\section{A. Burall/Neligan definition of accountability}

Scholars do not always concur in their definitions of accountability. Some scholars conceive accountability in its broadest possible scope. For example, the concept of accountability has been described by Burall and Neligan as both "the way in which individuals and organizations are held responsible for their actions," as well as "the

120 OXFORD DICTIONARIES, http:/ / oxforddictionaries.com/.

121 BLACK'S LAW DiCtionARY (9th ed, 2009). 
way in which organizations and individuals take responsibility for developing policies and procedures for shaping mission and values, and for assessing performance in relation to goals."122

This definition by Burall and Neligan is quite comprehensive in scope. It looks at accountability from two very different standpoints. The first part of the Burall/Neligan definition looks at the manner in which entities are held responsible. I refer to this as the "how" of accountability. The second part of the definition looks at the policymaking, procedures and assessment of goal formulation in accountability. This can be referred to as the "process." At first blush, these two distinctions may seem unimportant; however, upon further consideration, the two represent diametrically distinct avenues of viewing accountability.

As stated, the first instance is a view to the "how" of the question. To use the UPR as an example, the "how" of accountability would be answered: through peer review by member states. Therefore, in the UPR accountability is achieved (at least at the international level in Geneva) through a peer review.

Nonetheless, the "how" of the UPR is strikingly different than the "process" of the second part of the Burall/Neligan definition. This second part necessarily involves an awareness that the procedures, policies and assessment that makes up the process are just as imperative to accountability as is the fact that the mechanism exists. Therefore, in the UPR process, accountability is not simply the existence of a process in which one assesses state compliance with human rights, but of equal importance is the fact that there is a reporting requirement that involves gathering pertinent information from civil society within a country, a compilation of outside human rights reports by the Secretariat, an interactive dialogue with peer states, and a session before the Council to justify and clarify the positions of the nation under review. All of these elements have their own individual accountability holders, as will be discussed in Part Four.

The Burall/Neligan definition is expansive. By contrast, some scholars have chosen to advocate for a narrow view of the term accountability. This is the case with Keohane and Grant. Their definition is more restrictive because it focuses on a top-down relationship between the party being held accountable and the individuals holding the party accountable:

Accountability [...] implies that some actors have the right to hold other actors to a set of standards, to judge whether they have fulfilled their responsibilities in light of these standards, and to impose sanctions if they determine that these responsibilities have not been met. Accountability presupposes a relationship between power-wielders and those holding them accountable where there is a general recognition of the legitimacy of (1) the operative standards for accountability and (2) the authority of the parties to the relationship (one to exercise particular powers and the other to hold them to account). The concept of accountability implies that the actors being held accountable have obligations to act in ways that are consistent with accepted standards of behavior and that they will be sanctioned for failures to do so. ${ }^{123}$

\section{B. Keohane/Grant definition of accountability}

The Keohane/Grant definition carries a hierarchical view of accountability. It is vertical (while, arguably Burall/Neligan is more horizontal in focus) ${ }^{124}$ in that it recognizes a higher authority that wields the power to impose standards and simultaneously demand that actor being held accountable comply with those standards. When we look at the UPR at the international level during the interactive dialogue and apply the Keohane/Grant definition, it is less clear whether the UPR would be considered a mechanism that serves to impose accountability among its members. This is because the UPR fails to have a group of true group of actors from a higher authority (as understood in the Keohane/Grant definition) holding another group of subordinate actors accountable. The UPR actors are all the same level (there is no vertical relationship) and they are all holding each other accountable, therefore, in a sense, they are merely holding themselves accountable (self-assessment/self-accountability). In addition, the UPR has no sanctioning mechanism; therefore, does the UPR process then fail the definition of

\footnotetext{
122 SiMON BURALl \& CAROLINE NELIGAN, supra note 118 at 7.

${ }^{123}$ Robert O. KeOHANe \& Ruth W. GRANT, Accountability and Abuses of Power in World Politics, 99 American Political Science Review 29, 29--30 (2005).

${ }^{124}$ The Burall/Neligan definition is rather neutral. It doesn't have either a vertical or a horizontal view of accountability. It seems to work in either structure because it looks at the process rather than at who and what are exercising power.
} 
accountability? This author thinks the answer is no. Accountability is a broad term and for this inquiry we will employ the wider definition that encompasses the process as well as the policy-making, assessment and other phases that define the mechanism as a whole.

\section{Similar terminology in the literature}

This inquiry employs the word "accountability" by choice. However, this is not a term used by all scholars when conducting research on compliance with international obligations. Scholars are not united in defining the term or even agreeing that accountability is the right term. In fact, some prefer the use of other terminology. Those terms include the following concepts: monitoring, supervision, oversight or auditing. However, these terms appear to only encompass a small aspect of the concept of accountability. In fact, one can make a compelling argument that monitoring, supervision, oversight or auditing are essentially the same concepts. Van Hoof has defined supervision as:

The function of an international body or its designee that permits it to identify, sanction or modify the behavior of its members that runs counter to norms or regulations established by that body for its members. ${ }^{125}$

This concept is closely related to and may even be considered identical to the concept of monitoring, auditing or oversight, but it is not synonymous with the concept of accountability as it is used in this inquiry. As Burall and Neligan rightfully observe, accountability "involves some element of control, exposure and potential sanction. It is different from oversight, monitoring, or auditing which do not involve this element of control." 126

\section{Hoof/Mestdagh terminology}

Scholars G.J.H. van Hoof and K. de Vey Mestdagh use the term "mechanisms of international supervision" to describe the various forms of accountability mechanisms found in diverse international organizations such as the ILO, IMF and others. ${ }^{127}$ These two scholars use the working definition of Kaasik for supervision as the point of departure for their explanation of the supervisory function of international organizations. Kaasik's definition states:

The supervisory function is an essential part of the legal technique. It performs a function which is absolutely necessary to the existence and progress of any society, of any social organization. The main object of this function is to ensure respect for the law and the realization of rules of law as well as the regular functioning of public service within the limits laid down in these rules of law. Supervision is an organic function which makes it possible for errors (either in the assessment of a situation or in taking action) which might jeopardize the stability and security of social existence to be rectified. It therefore serves to ensure public order. ${ }^{128}$

\section{Chayes \& Chayes terminology}

By contrast, Chayes and Chayes have described a management strategy. ${ }^{129}$ According to these scholars, organizations charged with holding a state accountable employs certain strategies to improve a states' compliance. This management strategy includes removing obstacles to compliance, clarifying issues and convincing parties to change their behavior. ${ }^{130}$ Non-compliance is to be resolved by solving problems and withholding benefits rather than punishing. ${ }^{131}$

To conclude this section on the definition of accountability, it is important to emphasize that the definition of accountability differs according to your choice of scholar. However, accountability according to any scholar must include at least two elements: (1) defined standards for what is desired behavior and (2) the ability to hold a party

${ }^{125}$ G.J.H. VAN HoOF \& K. DE Vey MeStDagh, Mechanisms of International Supervision 7 (P. Van Dijk ed., 1984).

${ }^{126}$ BURALL, supra note 118 , at 8.

127 VAN HOOF \& MESTDAGH, supra note 125, at 4.

$128 \mathrm{Id}$. at 7.

129 ABram ChAyes \&ANTONIA HANDLER CHAYES, The New Sovereignty 109-134 (1995).

${ }^{130} \mathrm{Id}$. at 109.

${ }^{131} \mathrm{Id}$. at 110 
to those standards. Some scholars also argue that accountability includes the ability to sanction for failure to meet predetermined standards.

\title{
D. Definition of accountability for this inquiry
}

We will use the following definition of accountability:

\begin{abstract}
Accountability refers to the answerability or responsibility to another. That answerability exists because of norms, standards, laws or rules that demand a certain type of behavior or prohibit specified acts. The party to whom an answer is owed can demand answerability or responsibility through both judicial and/or non-judicial means.
\end{abstract}

In the case of the UPR, accountability is evident because the state under review is answerable to all other UN Member States. The state is answerable to those other UN Member States because it is part of the UN system and because it has contracted obligations pursuant to treaties and other international obligations. Those treaties demand certain behavior from the state and they also prohibit the state from engaging in other behavior. The state under review may also be answerable to other international organizations and courts such as the International Court of Justice, the International Criminal Court or the World Trade Organization, International Monetary Fund, etc. Therefore, the state would be answerable in both judicial and non-judicial contexts. ${ }^{132}$ Finally, and most importantly, the state is answerable in its domestic context to its own citizens and to the civil society within its borders. As will be shown in this inquiry, it is the civil society and the national human rights institutions that will play a significant role in the UPR and in holding the national government accountable for meeting its human rights engagements.

\section{Accountability mechanisms}

Although we have provided a definition of accountability, as well as two elements most important in the concept of accountability, that term is still vague as it relates to mechanisms. This part of the discussion will answer some key questions about accountability mechanisms: What is an accountability mechanism? What are the characteristics of an accountability mechanism? Where accountability mechanisms can be found in national and international settings?

Accountability mechanisms are processes that are specifically designed to disseminate policies, share best practices, monitor, supervise, evaluate and even punish. In the best of circumstances, they are formal bodies and they often employ uniform practices when engaging in their tasks. Societies commonly recognize the need for members of the society to conform to certain prescribed, desirable norms of behavior or codes of conduct. These codes and norms may be written or unwritten, explicit or tacit. Nonetheless, the task of verifying that these codes and norms are adhered to is often left to a body, agency or commission and these mechanisms are not always forthcoming and transparent in carrying out their tasks. Sometimes, it is not even possible to identify the body that is charged with holding others accountable.

What, then, will be the definition of an accountability mechanism in this inquiry? What are the typical characteristics of such a mechanism?

An accountability mechanism is a body charged with evaluation, supervision, monitoring or sanctioning. These tasks must be carried out in connection with a given set of rules, regulations or duties assigned to another party. The mechanism usually involves a reporting or accounting phase in which the body looks at the behavior of the party under review. Then, the body must draw conclusions regarding that party's compliance with the rules, regulations, or duties owed. Those conclusions must be made known to the party under review as well as to other interested parties. Generally, the conclusions are also published and made available to the general public. In some accountability mechanisms, the party under review can challenge

${ }^{132}$ As will be explained below, international accountability mechanisms can be found in both judicial and non-judicial settings. 
the findings. There are also cases in which mechanisms can punish the party under review for failure to meet obligations. Those sanctions, punishments or disincentives range in severity and can include monetary fines, suspension from membership, probation and temporary loss of membership rights, damage to reputation or public humiliation through naming and shaming tactics.

What is important to note is that accountability mechanisms exist both on the national and international level. Internationally speaking, however, the community has fewer norms and/or mechanisms for monitoring compliance with international norms. This is due to the fact that individuals entrust the State with regulation of nations, while the international community relies on individual Member States to self-regulate. ${ }^{133}$

There are distinctions between global and national models of accountability. Nevertheless, while accountability mechanisms have distinct roles in national and international governance, there are three common elements identified by Keohane:

1. Standards that those who are held accountable are expected to meet.

2. Information available to accountability-holders, who can then apply the standards in question to the performance of those who are held to account.

3. The ability of these accountability-holders to impose sanctions: to attach costs to the failure to meet the standards. ${ }^{134}$

One way to depict the dynamic relationships within an accountability mechanism is as follows:

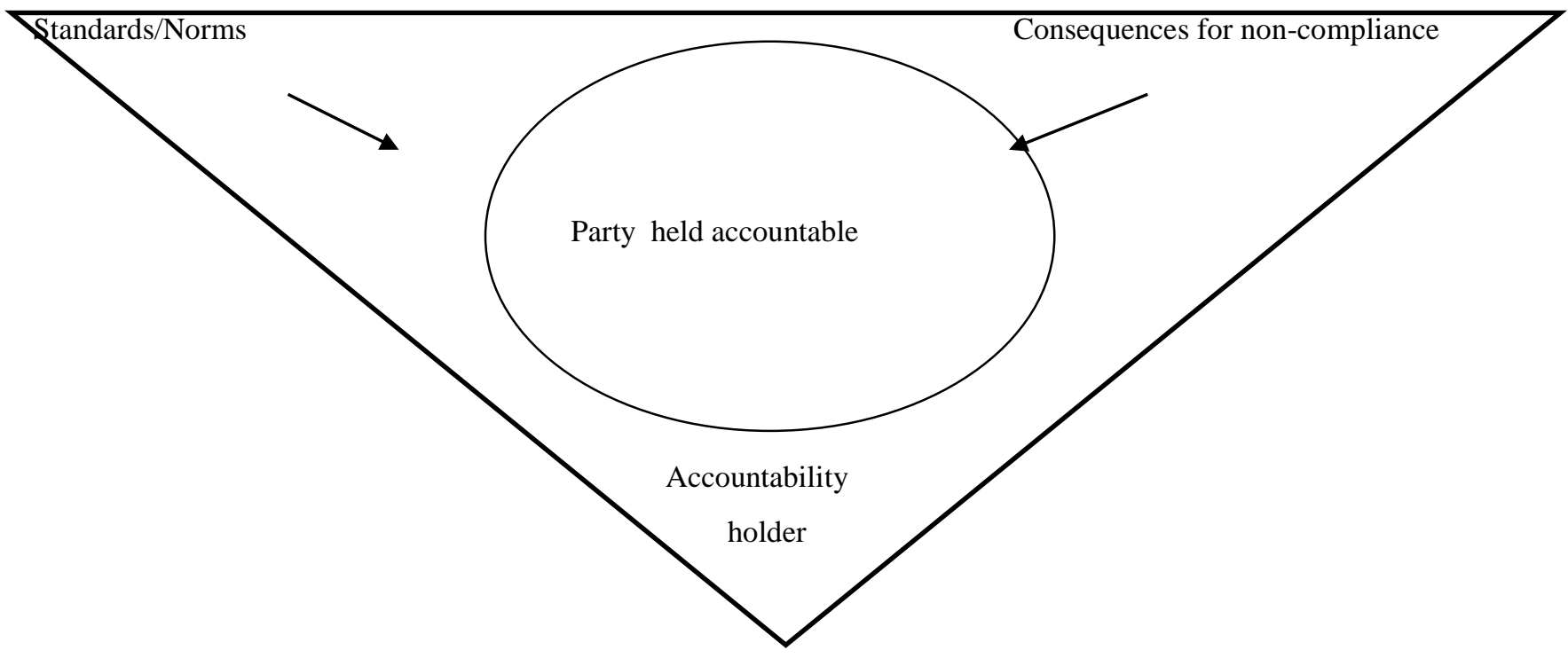

ACCOUNTABILITY MECHANISM

FIGURE 1

This diagram depicts that the party being held accountable is at the center of the mechanism. That is because the process of accountability is the main reason for which the mechanism exists and that process is the center of the mechanism's mission. The accountability holder is at the bottom of the triangle because the holder is not a

133 VAN HOOF \& MESTDAGH supra note 125, at 4.

134 Robert O. KeOHANe, Exploring the Governance Agenda of Corporate Reponsibility: Complex Accountability and Power in Global Governance: Issues for Global Business, 8 Corporate Governance 361, 362 (2008). 
superior (or inferior); instead the accountability holder is the actor that makes the decision as to whether the standards are met and whether consequences must ensue where non-compliance is uncovered. Standards and consequences are at the top because the norms are what create responsibility and the consequences are what enforces or ensures that the party being held accountable will live up to the standards.

\section{A. National accountability mechanisms}

Models of accountability mechanisms can be found in domestic jurisdictions as well as in international fora. At the national level, we will examine two accountability mechanisms, one in the United States of America, the other in Australia. The US example is a local accountability mechanism which operates in New York City - the New York City Police Department's Civilian Complaint Review Board. The Australian example is an agency with a nation-wide mandate - the Australian Commission for Human Rights.

\section{The New York City Police Department and the Civilian Complaint Review Board}

In the city of New York, police conduct is subject to review under certain cases, including excessive use of force or even discourteous language. The review is conducted by a panel or board and the results are made available to the complainants and to the police force, often with a recommendation as to disciplinary action against the police officer. This type of procedure is an accountability mechanism. There is a specified code of conduct that is applicable to all police officers (the standard). When that code is violated, complainants can enter into a defined procedure through the civilian review board (the accountability holder). The review board can recommend sanctions or disciplinary action (consequences).

In the case of civilian review board in the city of New York, the review board is comprised of a panel of people who serve for a four-year period and are appointed by the major and city council. When a complaint is brought to the civilian review board to interview complainants regarding the alleged misconduct, investigate regarding the circumstances, review the events in a panel or board and make a final determination together with a recommendation for discipline, suspension, etc. ${ }^{135}$ Although the New York City Police Department has ultimate say over whether or not it will pursue the recommendation of the review board in each case, the website of the Civilian Complaint Review Board demonstrates that in some cases, its recommendations have been followed and police officers have been punished; however, in most of the cases listed on the website of the review board, officers have forfeited vacation days. ${ }^{136}$

The New York City Police Department's Civilian Complaint Review Board constitutes a type of accountability mechanism because it possesses all of the characteristics of an accountability mechanism, having standards that must be met by all officers, possessing the ability to apply those standards to officers who are alleged to have failed to meet them, and being able to command sanctions or punishments when finding the standards have been violated. The board is the accountability holder. All of the board's operations revolve around the behavior of police officers; thus the latter are parties being held accountable. The board has a mandate to hear only the following certain types of complaints: (1) excessive or unnecessary use of force; (2) abuse of authority; (3) discourtesy; (4) offensive language (including, but not limited to, slurs relating to sexual orientation, race, ethnicity, religion, gender or disability). ${ }^{137}$ Therefore, the types of complaints within the board's mandate set the standards that the police officers are held accountable for. The board can recommend certain types of disciplinary measures to be taken against an officer found to have violated the established standards.

\footnotetext{
135 New York City Civilian Complaint Review BoARD, City of New York Police Department, http://www.nyc.gov/html/ccrb/pdf/English.pdf.

136 NEW YORK CITY CiviLIAN COMPLAINT Review BOARD, CCRB Case Profiles, http://www.nyc.gov/html/ccrb/html/profiles.html.

137 REPORT NEW YORK CITY CIVILIAN COMPLAINT REVIEW BOARD, http://www.icac.nsw.gov.au/documents/doc_download/2213-new-yorkpolice-department-preventing-crime-and-corruption\#P345_52509.
} 


\section{The Australian Human Rights Commission}

There are also national accountability mechanisms whose broad mandate includes the protection of human rights throughout the entire country. Such is the case of the Australian Human Rights Commission. The Commission has a broad mandate in that it is authorized to both receive individual complaints of discrimination and to educate the general public in issues regarding human rights. ${ }^{138}$ The Commission describes its mission as follows:

- education and public awareness;

- discrimination and human rights complaints;

- human rights compliance; and

- $\quad$ policy and legislative development. ${ }^{139}$

The Commission is independent and receives its statutory powers from the Australian Parliament. It carries out its mandate by:

- resolving complaints of discrimination or breaches of human rights under federal laws;

- holding public inquiries into human rights issues of national importance;

- developing human rights education programs and resources for schools, workplaces and the community;

- providing independent legal advice to assist courts in cases that involve human rights principles;

- providing advice and submissions to parliaments and governments to develop laws, policies and programs; and

- undertaking and coordinating research into human rights and discrimination issues. ${ }^{140}$

It has the power to hear complaints based on race, age, disability and gender discrimination. ${ }^{141}$ The Commission has other related mandates, including a general mandate to monitor human rights issues. Among the human rights agreements that the Commission is responsible for are:

- International Covenant on Civil and Political Rights

- Convention Concerning Discrimination in Respect of Employment and Occupation

- Convention on the Rights of the Child

- Declaration of the Rights of the Child

- Declaration on the Rights of Disabled Persons

- Declaration on the Rights of Mentally Retarded Persons

- Declaration on the Elimination of All Forms of Intolerance and of Discrimination Based on Religion or Belief. 142

The Commission has a complaint process for individuals. This process represents an example of a national accountability mechanism for human rights. In the Australian Human Rights Commission, individuals must begin the complaint process by submitting a written complaint detailing the circumstances of the alleged discriminatory treatment after which the Commission will begin an investigation, contacting both the complainant and the party against whom the complaint has been alleged, and makes as decision as to whether it

\footnotetext{
138 Australian Human Rights COMmission, About The Australian Human Rights Commission, http://www.hreoc.gov.au/about/index.html. ${ }^{139} \mathrm{Id}$.

${ }^{140} \mathrm{Id}$.

${ }^{141}$ Australian Human Rights COMmission, The Australian Human Rights Commission's Complaint Process http://www.hreoc.gov.au/complaints_information/complaints_flyers/complaints_process_flyer.html. 142 AUSTRALIAN Human Rights COMMISSION, Annual Report 2009-2010,

http://www.hreoc.gov.au/pdf/about/publications/annual_reports/2009_2010/AHRC2009_2010_complete.pdf.
} 
can entertain the complaint. ${ }^{143}$ In the case of an unfavorable decision, the Commission will explain to the complainant why the complaint cannot be handled by the Commission, but if the case is taken up, the Commission will guide the complainant and the party against whom the complaint is filed through the conciliation process in an effort to settle the matter between the parties through amicable arrangements such as: "an apology, policy changes, compensation and/or staff training." 144

The complaint process of the Commission has the main three characteristics of an accountability mechanism. Again, as with the New York City Civilian Complaint Review Board, the Australian Human Rights Commission has standards against which behavior must be measured. In the case of the Commission, these standards have been set regarding non-discrimination in age, gender, race and disability in the form of laws enacted by the Australian Parliament. ${ }^{145}$ Those standards are applied to various parties. Those parties include employers, caretakers, educational institutions and others. These parties are the ones held accountable to provide nondiscriminatory settings. Failure to do so will result in a finding by the Commission that those norms have been violated and will also result in a punishment. In summary, the Australian Human Rights Commission is another example of an accountability mechanism. In this case, we are speaking of a national accountability mechanism with a broad mandate in the area of human rights.

While the New York Civilian Complaint Review Board is a local accountability mechanism, the Australian Human Rights Commission interacts with regional human rights institutions and also recognizes international human rights norms and standards. This connectivity is a good example of the interplay between international and national accountability mechanisms. It is also an example of the way in which accountability for human rights obligations is a fluid topic which entangles national and international actors.

\section{B. International Accountability Mechanisms}

The international arena also boasts accountability mechanisms. Scholars have chosen to categorize the models in different ways. Keohane and Grant identify seven different types of mechanisms found in global governance. ${ }^{146}$ Other scholars have simply distinguished between judicial and non-judicial accountability mechanisms.

\section{Seven Models of International Accountability Mechanisms}

In the international arena, accountability mechanisms are evident in several forms. Keohane and Grant have identified seven types of structures, as evidenced in the following chart:

\footnotetext{
${ }^{143}$ Australian Human Rights Commission, The Australian Human Rights Commission's Complaint Process, http://www.hreoc.gov.au/complaints_information/lodging.html.

${ }^{144} \mathrm{Id}$. .

145 Australia's laws include the Sex Discrimination Act of 1984; Race Discrimination Act; Disability Discrimination Act of 1992; Age

Discrimination Act of 2004.

146 KEOHANE \& GRANT, supra note 123 at 36.
} 


\begin{tabular}{|c|c|c|c|c|}
\hline \multicolumn{5}{|c|}{$\begin{array}{c}\text { Keohane/Grant's } \\
\text { SEVEN MECHANISMS OF ACCOUNTABILITY IN WORLD POLITICS } 147\end{array}$} \\
\hline Mechanism & $\begin{array}{l}\text { Accountability } \\
\text { holder }\end{array}$ & Power wielder & $\begin{array}{l}\text { Cost to power- } \\
\text { wielder }\end{array}$ & Example \\
\hline Hierarchical & $\begin{array}{l}\text { Leaders of } \\
\text { organization }\end{array}$ & $\begin{array}{l}\text { Subordinate } \\
\text { official }\end{array}$ & $\begin{array}{l}\text { Loss of career } \\
\text { opportunities }\end{array}$ & $\begin{array}{l}\text { Authority of UN } \\
\text { Secretary-General }\end{array}$ \\
\hline Supervisory & States & $\begin{array}{l}\text { Multilateral } \\
\text { organization and } \\
\text { its executive head }\end{array}$ & $\begin{array}{l}\text { Restraints on } \\
\text { ability to act, loss } \\
\text { of office }\end{array}$ & $\begin{array}{l}\text { World Bank and IMF } \\
\text { governance by their } \\
\text { executive boards }\end{array}$ \\
\hline Fiscal/Legal & $\begin{array}{l}\text { Funding agencies } \\
\text { and Courts }\end{array}$ & $\begin{array}{l}\text { Funded agency } \\
\text { Individual official } \\
\text { or agency }\end{array}$ & $\begin{array}{l}\text { Budget restrictions } \\
\text { Restriction of } \\
\text { authority to } \\
\text { criminal penalties }\end{array}$ & $\begin{array}{l}\text { Withholding of UN } \\
\text { dues } \\
\text { International Criminal } \\
\text { Court }\end{array}$ \\
\hline Market & $\begin{array}{l}\text { Equity- and } \\
\text { bond-holders and } \\
\text { consumers }\end{array}$ & $\begin{array}{l}\text { Firm or } \\
\text { government }\end{array}$ & $\begin{array}{l}\text { Loss of access to, } \\
\text { or higher cost of, } \\
\text { capital }\end{array}$ & $\begin{array}{l}\text { Refusal of capital } \\
\text { markets to finance } \\
\text { developing country } \\
\text { government during } \\
\text { world financial crises }\end{array}$ \\
\hline Peer & $\begin{array}{l}\text { Peer } \\
\text { organizations }\end{array}$ & $\begin{array}{l}\text { Organizations } \\
\text { and their leaders }\end{array}$ & $\begin{array}{l}\text { Effects on network } \\
\text { ties and therefore } \\
\text { on others' support }\end{array}$ & $\begin{array}{l}\text { Independent marine } \\
\text { certification body's } \\
\text { evaluation of the } \\
\text { Greenpeace-Shell } \\
\text { controversy }\end{array}$ \\
\hline $\begin{array}{l}\text { Public } \\
\text { reputationala }\end{array}$ & $\begin{array}{l}\text { Peer and diffuse } \\
\text { public }\end{array}$ & $\begin{array}{l}\text { Individual or } \\
\text { agency }\end{array}$ & $\begin{array}{l}\text { Diffuse effects on } \\
\text { reputation, } \\
\text { prestige self- } \\
\text { esteem }\end{array}$ & $\begin{array}{l}\text { Effects on US "soft } \\
\text { power" of } \\
\text { unilateralism }\end{array}$ \\
\hline
\end{tabular}

${ }^{147} \mathrm{Id}$. 
The chart depicts the way in which the structure of the mechanism can vary from hierarchical to horizontal. The accountability holders vary in each model. For the purposes of this inquiry, it is important to note that many of the international organizations ( IOs) could be considered to be in more than one of the categories in the chart.

\section{Distinguishing Judicial and Non-Judicial Accountability Mechanisms}

There is another way to view accountability mechanisms in the international context. To distinguish the mechanism based on whether it is judicial or non-judicial in nature. This distinction is more practical because it also helps to understand the structure of non-judicial accountability mechanisms. The non-judicial mechanisms tend to include periodic reporting requirements, a feature found in several accountability mechanisms within the major international organizations and within the UN Human Rights machinery. Consider the following diagram:

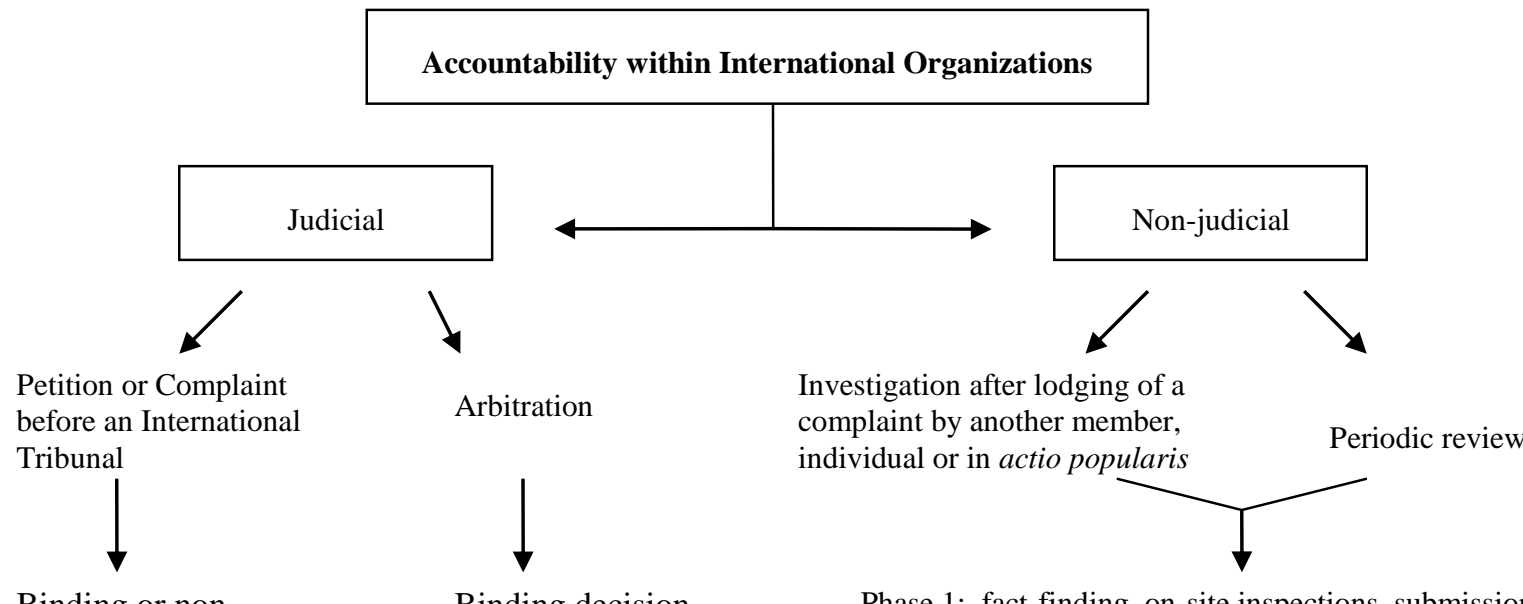

Binding or nonbinding decision on a

Binding decision In a particular case

\section{of reports}

Phase 2: Assessment of facts and formal outcome

Phase 3: Follow-up to outcome

\section{FIGURE 2}

The judicial accountability mechanisms are not the subject of this inquiry. These mechanisms include the International Court of Justice, the European Court of Human Rights and the Court of Justice of the European Communities. These mechanisms generally do not provide a forum for comprehensive and periodic evaluation of state compliance. The judicial accountability mechanisms are triggered by a violation that is then brought before the body.

Non-judicial supervision, taking place outside of a judicial context is also widely used in international contexts. This form of accountability mechanisms differs from judicial accountability mechanisms in that there is no need for a violation to occur in order to trigger the mechanism. Non-judicial accountability mechanisms can be a preventive tool or a monitoring tool that assesses the progress of States in meeting their obligations. Most IOs have a non-judicial form of supervision. Therefore, this chapter and our inquiry as a whole are concerned with the forms of non-judicial accountability mechanisms (depicted on the right-hand side of the chart) and how they are structured in the various IOs that have adopted a monitoring system.

Non-judicial supervision is marked by an atmosphere of cooperation and problem-solving as a means of achieving compliance. Chayes and Chayes refer to such a regime as a "managerial model" (as opposed to the 
coercive "enforcement model"). ${ }^{148}$ In the managerial model, the focus is to offer an alternative to sanctions. This model accepts the general axiom that states have a general propensity to comply with treaty obligations. ${ }^{149}$ This model also recognizes that non-compliance with treaty obligations is often not deliberate; instead, states are faced with ambiguity in the language of the treaty itself, limitations on the capacity to carry out obligations and social, economic or political changes. ${ }^{150}$ These factors can lead to non-compliance.

\section{Periodic Reporting as the Mainstay of Non-Judicial Accountability Mechanisms}

These accountability mechanisms use periodic reporting as their mainstay, evaluating whether a member state is meeting its obligations. The structure of the periodic reporting is generally the same, as are the participants.

Organs that opt for non-judicial supervision usually have a technical supervisory organ (secretariat) that is comprised of representatives from all member states which may take one of three forms: expert national officials under instruction from their respective governments, independent experts, appointed by international organizations, or a mixed group of both governmental representatives and independent experts. ${ }^{151}$

Most non-judicial supervisory mechanisms do not have formal complaint procedures or other procedural rules like due process or locus standi, which are usually present in judicial contexts. ${ }^{152}$ Instead, procedures are adopted by the IO itself.

In non-judicial contexts where a body seeks to merely review, it will exchange of information through some form of reporting. Exchange of information can be very informal and take place along diplomatic lines, or it can be in the form of a strict reporting requirement. Periodic reporting is often employed and involves a degree of uniformity in that questionnaires are often devised to guide the member state with its submissions. The reports are then disseminated to a plenary organ or, in some cases, to a more public forum.

Three identifiable phases are usually present in non-judicial accountability mechanisms: data gathering, verification/monitoring and assessment of performance. The first phase involves the collection of materials through investigations, fact-finding missions, reporting requirements and may be carried out by the Secretariat of the International Organization, by independent experts, or by the States themselves. Scholar Conzelmann notes that the secretarial "plays a crucial role" because it is viewed by the states as a neutral or disinterested party. ${ }^{153}$ The most important feature of this phase is that data is gathered regarding the situation in a state. ${ }^{154}$

The data gathered is usually presented in a report that may originate from various sources. For example, the report may be completed generated by the member state itself. (Such is the case for the UPR). Self-reporting, however, is often viewed as suspect. Therefore, in many contexts, including in the area of human rights, a parallel, independently drafted report may also provide an alternative view to the report of the member state. 155 In other contexts, such as the OECD, a member state may not have a chance to draw up its own report, instead it must respond to questions from the Secretariat in the form of a questionnaire. ${ }^{156}$ The WTO Trade Policy Review mechanism provides for information from NGOs, research institutes and other stakeholders to be included in the national report. ${ }^{157}$ Chayes and Chayes also point out that self-reporting is only the beginning of data gathering

${ }_{148}$ CHAYES, supra note 129 , at 3.

${ }^{149} \mathrm{Id}$. at 4.

${ }^{150} \mathrm{Id}$. at 9-17.

$151 \mathrm{Id}$. at 19.

$152 \mathrm{Id}$. at 20.

153 Thomas ConZELmann, Reporting and Peer Review in the Implementation of International Rules: What Role for Non-State Actors?, in The Ashgate Research Companion to Non-State Actors, at 325 (Bob Reinalda, ed. 2011).

${ }^{154}$ CHAYES, supra note 129 , at 110.

${ }^{155}$ CONZELMANN, supra note 153 , at 323.

${ }^{156} \mathrm{Id}$.

$157 \mathrm{Id}$. 
because certain treaty regimes, such as that of the International Atomic Energy Agency, have the right to carry out inspections on-site as a way of verifying what a state has reported. 158

Following the collection of information, that information is normally also subjected to evaluation. The evaluation may be carried out in a number of different ways: by selected peers (other Member States), by independent experts, policy experts, rapporteurs or members of a Secretariat. The evaluation may even be done by members of the diplomatic corps of a country. The purpose of the evaluation is to identify any "behavior that raises significant compliance questions." 159 In this phase, the member states participate in decisions about the outcome of the first phase. Generally, this will be done through debates, dialogue, direct confrontation or negotiations. This second phase frequently culminates in some type of outcome. That outcome may take the form of sanctions for violations, non-binding recommendations for changes in member state policy, law, etc., or even requirements that the state report back within a certain time to show what measures have been taken to correct the violations in question.

Conzelmann notes that the structure of the evaluation phase depends on the role of the Secretariat. ${ }^{160}$ In organizations such as the WTO where the Secretariat is largely silent, the weaknesses of the member state are not clearly stated in the report. In contrast, the OECD Secretariat impacts the format of the evaluation phase by clearly setting forth in its report the weaknesses and problems in a member state policy. ${ }^{161}$

The final phase of accountability mechanisms involves an assessment of a state's performance. In other words, has the state passed the test? Again, in practice, the way in which assessments are carried out varies by organization. However, in general, the Secretariat makes no judgments regarding compliance. ${ }^{162}$ Instead, states negotiate over the final document and what type of recommendations will appear therein. Most outcome documents must include praise for the member state. The recommendations are carefully worded to avoid punitive language or accusatory tones.

In many non-judicial mechanisms, a fourth very important phase is also identifiable (but not always a formally-recognized element) - that of follow-up. Additional on-site inspections after a period of time to verify that the violation has been corrected or a deadline for the state to return to the body and explain how it has addressed certain recommendations emanating from the review are two examples of follow-up seen in international organizations.

\section{Models of International Accountability Mechanisms}

\section{a. The International Labour Organization}

The International Labour Organization (ILO) model provides a particularly useful study because, as with the UPR, its founders sought to include all nations in its body and wished that each member state accept the conventions and recommendations that it adopted. ${ }^{163}$ By making universal membership a priority and by promoting ratification of labor treaties early in its existence, the ILO was able to create an international supervisory model unrivaled even today in its scope.

\footnotetext{
158 CHAYES, supra note 129 , at 163.

${ }^{159} \mathrm{Id}$.

160 CONZELMANN, supra note 153 at 329-330 [“It is particularly with regard to the credibility of reporting and peer reviewing procedures that the secretaries of IGOs play a role in peer reviews. They can shape conceptions of sound policies (for example through influencing the choice of indicators and through compiling information in a particular manner, safeguard the quality of the reviewing work through using common templates or through preparing an independent third actor perspective in the performance of particular states) and help to legitimize and coordinate peer pressure...."]

${ }^{161}$ CONZELMANN, supra note 153 , at 325.

$162 \mathrm{Id}$.

${ }^{163}$ LAURENCE R. HELFER, Understanding Change in International Organizations: Globalization and Innovation in the ILO, 59 Vanderbilt Law Review 652, 681 (April 2006).
} 
By far the oldest institution, the ILO, was created in 1919 by the International Labour Commission in connection with the Versailles Treaty at the end of World War I. ${ }^{164}$ Over the ensuing decades, the ILO has universalized labor standards in 176 conventions and 183 recommendations in approximately 170 member states. 165 The three organ components of the ILO are its Conference, Governing Body and the International Labour Office (under control of the Governing Body). ${ }^{166}$ The Governing Body of the ILO is comprised of a three-part structure involving governments, employers and labor representatives in a social dialogue. ${ }^{167}$ The ILO Constitution provides, in Article 7, which the Governing Body must consist of 58 members 28 of whom represent governments, 14 of whom represent employers and 14 of whom belong to labor groups. ${ }^{168}$ The ILO process is unique in that it is one of the few international organizations that regularly engages non-state actors in its process. Both laborers and employers are involved in the process. The ILO has also expanded the role of international civil society in its process. ${ }^{169}$

The ILO provides a forum for both complaints (brought through a labor organization by employees or by employers or government) and for periodic reporting. ${ }^{170}$ It is the latter that is of interest for this inquiry.

\section{Article 22 of the ILO Constitution provides that}

Each of the Members agrees to make an annual report to the International Labour Office on the measures which it has taken to give effect to the provisions of Conventions to which it is a party. These reports shall be made in such form and shall contain such particulars as the Governing Body may request. ${ }^{171}$

The reporting process described in Art. 22 applies to obligations arising from two types of instruments: conventions and recommendations. ${ }^{172}$ The International Labour Conference adopts these instruments, as set forth in Art. 19 of the ILO Constitution. ${ }^{173}$ Conventions create legal obligations upon ratification, whereas recommendations give "guidance as to policy, legislation and practice." 174 One unique feature of the ILO is the mandatory requirement that any and all conventions and recommendations must be submitted to the competent authorities of a member state (usually the legislature) in a timely manner. ${ }^{175}$ The reporting procedures are directly linked to the conventions ratified by member states. As of 2003, a new reporting system began and required reporting every two years for "fundamental and priority

\footnotetext{
164 INTERNATIONAL LABOUR ORGANIZATION, About the ILO: Origins \& History, http://www.ilo.org/global/About_the_ILO/Origins_and_history/lang--en/index.htm. period of several months in which governments must consult relevant members of civil society and complete questionnaires from the Labour Office describing the current practice in their country. The Labour Office drafts the recommendation or convention and submits it to member states who in turn consult with the same civil society actors, seeking appropriate recommendations for modifications and amendments to the draft. Often, the conventions and recommendations have flexibility clauses built in to provide for derogations.

173 INTERNATIONAL LABOUR OFFICE, Handbook of Procedures Relating to International Labour Conventions and Recommendations [hereinafter ILO Handbook], http://www.ilo.org/wcmsp5/groups/public/---ed_norm/---normes/documents/publication/wcms_087791.pdf.

$174 \mathrm{Id}$. at 2.

175 Id. at 9-10; Art. 19, ILO CONSTITUTION, supra note 166.
} 


\section{conventions" ${ }^{176}$ or every five years for other conventions, unless a shorter interval is requested. ${ }^{177}$}

The reporting process involves submission by member states of either a detailed or simplified report. The detailed report is required for the first report following the entry into force of a convention, or by request of the Committee of Experts or the Conference Committee. ${ }^{178}$ The simplified report is generally for the nonfundamental and non- priority conventions. The simplified reports generally contain responses to the comments by the supervisory bodies (Committee of Experts), explanations on any major changes in legislation and observations of employers' and workers' organizations. ${ }^{179}$

The governments are responsible for writing their own reports, once they have received a letter requesting reports (usually sent each February) with questionnaires and instructions regarding which reports must be submitted; the government report - which may also include contributions of employers and workers - is submitted for consideration by the Committee of Experts and must conform to the format approved by the Governing Body for each convention, usually the following:

(a) Laws, regulations, etc. All relevant legislation or similar provisions should be listed and, unless this has already been done, copies supplied.

(b) Permitted exclusions, exceptions or other limitations. Several Conventions allow given categories of people, economic activities or geographical areas to be exempted from application, but require a ratifying State which intends to make use of such limitations to indicate in its first article 22 report the extent to which it has recourse to them. It is therefore essential for the first report to include indications in this respect, since, if it does not, the limitations will no longer be possible. The same Conventions may call for information to be included in subsequent article 22 reports indicating the extent to which effect is nevertheless given to the Convention in respect of the excluded persons, activities or areas.

(c) Implementation of the Convention. Detailed information should be given for each Article on the provisions of legislation or other measures applying it. Some Conventions ask for particular information to be included in reports (as to the practical application of the Convention or certain Articles or as to application in cases of exclusion).

(d) Effect of ratification. Information is asked for as to any constitutional provisions giving the ratified Convention the force of national law and any additional measures taken to make the Convention effective.

(e) Comments by the supervisory bodies. Where the Committee of Experts or the Conference Committee on the Application of Standards have made comments or asked for information, the report should indicate the action taken and supply the information wanted.

(f) Enforcement. Governments are asked to indicate the authorities responsible for administration and enforcement of the relevant laws, regulations, etc., and to supply information on their activities. Copies of the authorities own reports may be appended or, if they have already been supplied, referred to.

(g) Judicial or administrative decisions. Governments are asked to supply either a copy or a summary of relevant decisions.

(h) Technical cooperation. Governments are asked to indicate the measures taken as a result of the assistance or advice provided in the context of ILO technical cooperation projects.

\footnotetext{
176 Twelve conventions are considered "fundamental and priority." These convention involve such topics as freedom of association and collective bargaining, child labor, and labor inspections.

177 ILO Handbook, supra note 172, at 20.

178 The Committee of Experts on the Application of Conventions and Recommendations was established in the mid-1920s when it became evident that the Director General could not efficiently process state reports. The Committee is a standing Committee that enjoys expansive powers including the ability to follow up with governments for the "evaluation of the problems that they had encountered in giving domestic effect to the treaties." The Committee can "engage in pointed exchanges with state representatives and offer specific recommendations for remedial action." HELFER, supra note 163, at 687-688.

${ }^{179}$ ILO Handbook, supra note 173, at 25.
} 
(i) General appreciation. Governments are asked to give a general assessment of how the Convention is applied, with extracts from any official reports, statistics of workers covered by the legislation or collective agreements, details of contraventions of the legislation, prosecutions, etc.

(j) Observations by employers, and workers, organizations. Full information should be provided with any government response. 10

(k) Communication of copies of reports to employers, and workers, organizations. The names of the organizations to which copies are sent should be given. ${ }^{180}$

The second phase of the ILO reporting involves the review of the government report by the Committee of Experts. The committee may make a direct request soliciting more information from a country (this request is generally not published) and the Committee of Experts may also give observations on more serious implementation and compliance issues, such observations are published and direct the government to take certain steps. ${ }^{181}$

Following the review by the Committee of Experts, a country may be called before the Conference Committee - a group composed of representatives from unions and confederations and heads of workers' groups from national jurisdictions and employer groups - which, during the Annual Conference, examines the governments recommended to it by the Committee of Experts to be further questioned about areas of non-compliance. ${ }^{182}$

Like many international bodies, reporting in the ILO is undertaken periodically by member countries. However, the ILO Constitution is unique in its requirement (in Article $19.5 \mathrm{e}$ ) that reports include non-ratified conventions. 183 As of 1998, the ILO implemented an annual performance review of states that had not ratified all fundamental conventions, requiring the state to report what obstacles exist to ratification. ${ }^{184}$ By requiring the yearly reporting, pressure is placed on non-ratifying states to ratify instruments in order to be on the "good list". ${ }^{185}$

In summary, the ILO is an accountability mechanism in which the Committee of Experts and the tri-partite Conference Committee holds member countries accountable for a myriad of obligations under both ratified and non-ratified instruments. Those member countries with continual non-compliance issues are subject to closer scrutiny and more frequent explanations.

\section{b. The International Monetary Fund: Bilateral and Multilateral Surveillance}

The IMF is a second example of an international accountability mechanism. Monetary stability and economic growth are two of the main goals of the IMF. ${ }^{186}$ The two core activities of the IMF involve bilateral and multilateral surveillance of the economic situations of member countries as well as the world economy. ${ }^{187}$ Following the crash of the stock market in 1929 and the Great Depression of the 1930s, countries began to indulge in protectionism by erecting trade barriers and devaluating their currencies. ${ }^{188}$ This behavior led to a decline in world trade and further impacted employment and living standards in a negative manner during a time when there was no international monetary cooperation. At the end of World War II, some nations envisioned an

\footnotetext{
${ }^{180} I d$. at $24-26$.

${ }^{181}$ Interview with ILO Official, June 28, 2011

$182 \mathrm{Id}$.

183 HELFER. supra note 142, at 709-710.

$184 \mathrm{Id}$. at 710 .

185 Interview with ILO Official, June 28, 2011

186 INTERNATIONAL MONETARY FUND, About the IMF: Cooperation and Reconstruction (1944-71), http://www.imf.org/external/about/histcoop.htm.

187 IMF INDEPENDENT EVALUATION OFFICE, The IMF's Multilateral Surveillance: Issues Paper for an Evaluation by the Independent Evaluation Office (IEO) 2, http://www.imf.org/External/NP/ieo/2005/ms/eng/092305.pdf.; LOUIS W. PAULY, IMF Surveillance and the Legacy of Bretton Woods (2006). ; IMF Surveillance -- The 2007 Decision on Bilateral Surveillance(2011), http://www.imf.org/external/np/exr/facts/surv07.htm. ${ }^{188}$ FUND, About the IMF, supra note 186.
} 
institution that would ensure exchange rate stability and eliminate trade barriers; that institution came into being in December of 1945, when 29 member countries signed the Articles of Agreement for the International Monetary Fund (IMF). ${ }^{189}$ In 2007, the bilateral surveillance policies were revised and updated by the Decision on Bilateral Surveillance over Members' Policies, which "clarifie[d] that country surveillance should be focused on assessing whether countries' policies promote domestic and external stability." 190

The heart of the IMF's accountability operation lies in a process known as surveillance. Surveillance is conducted on the national, regional and global level. ${ }^{191}$ The country surveillance involves a check of a nation's economy. ${ }^{192}$ Currently, there are 187 IMF member countries who undertake, under Article IV of the IMF Articles of Agreement, to "collaborate with the IMF and with one another to promote stability." 193 Article IV establishes that "domestic policies, including financial sector policies, can have an important impact on the stability of the overall system of exchange rates, and, accordingly are a subject of international concern." 194 The Fund is charged with the oversight of each member country's compliance with its obligations under Article IV. ${ }^{195}$

The Fund's surveillance under Article IV is referred to as Article IV consultations. While the word "consultation" gives the image of voluntary undertakings, in fact, the obligations under Article IV are mandatory in nature. ${ }^{196}$ This surveillance is explicitly agreed to by each member country when it joins the IMF; in addition, the country also commits to the following:

To pursue policies that are conducive to orderly economic growth and reasonable price stability;

To avoid manipulating exchange rate for unfair competitive advantage; and

To provide the IMF with data about its economy. ${ }^{197}$

During the surveillance process the IMF identifies "weaknesses that are causing or could lead to financial or economic instability." 198 According to Section 3 of Article IV of the IMF's Articles of Agreement:

(a) The Fund shall oversee the international monetary system in order to ensure its effective operation, and shall oversee the compliance of each member with its obligations under Section 1 of this Article.

(b) In order to fulfill its functions under (a) above, the Fund shall exercise firm surveillance over the exchange rate policies of members, and shall adopt specific principles for the guidance of all members with respect to those policies. Each member shall provide the Fund with the information necessary for such surveillance, and, when requested by the Fund, shall consult with it on the member's exchange rate policies. The principles adopted by the Fund shall be consistent with cooperative arrangements by which members maintain the value of their currencies in relation to the value of the currency or currencies of other members, as well as with other exchange arrangements of a member's choice consistent with the purposes of the Fund and Section 1 of this Article. These principles shall respect the domestic social and political policies of members, and in applying these principles the Fund shall pay due regard to the circumstances of members. ${ }^{199}$

\footnotetext{
${ }^{189} \mathrm{Id}$.

${ }^{190}$ INTERNATIONAL MONETARY FUND, IMF Surveillance(2011), http://www.imf.org/external/np/exr/facts/surv.htm.

${ }^{191}$ INTERNATIONAL MONETARY FUND, Surveillance at http://www.imf.org/external/about/econsurv.htm.

${ }^{192} I d$.

${ }^{193}$ FUND, IMF Surveillance, supra note 187; FUND, Surveillance, supra notes 190, 191.

194 IMF LEGAL DEPARTMENT, The Fund's Mandate -- The Legal Framework(2010), 4 , http://www.imf.org/external/np/pp/eng/2010/022210.pdf. $195 \mathrm{Id}$. at 5.

196 BESSMA MOMANI, Assessing the Utility of, and Measuring Learning from, Canada's IMF Article IV Consultations, 39 Canadian Journal of Political Science 249 (2006). ("The fund also conducts bilateral surveillance of all of its members by meeting with member-state officials on an annual basis. These Article IV consultations are mandatory exercises, during which members accept the IMF's Articles of Agreement. The Article IV consultation reports offer detailed external assessments conducted by highly regarded Fund economists, and address exchange rates as well as fiscal, monetary, financial-sector and structural policies. Ideally, the Fund's bilateral meetings and reports would contribute to the domestic policy debate on formulating economic policies and, in addition to other actors and stakeholders, would influence government policy decisions....")Id. at 249-250.

${ }_{197}^{19 U N D}$, Surveillance, supra note 191.

198 Id.

199 INTERNATIONAL MONETARY FUnd, Articles of Agreement of the IMF.
} 
Lombardi and Woods state that the first step in bilateral surveillance is a "technical briefing prepared by the staff or management which serves as an agenda for the subsequent bilateral consultations." 200 Then, the IMF sends economists to the member country to consult with government officials. ${ }^{201}$ The Fund describes the consultations as a mission in which IMF economists "exchange views with the government and central bank and focus on whether there are risks to domestic and external stability that argue for adjustment in economic or financial policies." 202 The IMF team of economists "assess economic and financial developments and discuss the country's economic and financial policies with government and central bank officials." 203 The country visit also includes meetings with "other stakeholders, such as parliamentarians and representatives of business, labor unions, and civil society." 204

Momani writes about seven years of Article IV consultation reports on Canada. ${ }^{205}$ Momani explains that the Article IV consultation take place in Ottawa "mainly with Department of Finance officials", but stresses that other agencies, including the "Bank of Canada, the Superintendent of Financial Institutions, Health Canada and Human Resources Canada" may also be included in consultations. 206

Following the country visit, the team of economists must report all finding to the IMF management and to the Executive Board. 207 The team "writes a back-to-office report to management, outlining the main findings, from which, following an extensive inter-departmental review, the staff report is finalized and finally circulated to the Board, normally within three months after the end of the mission itself." 208

The IMF's Executive Board (the body that represents all IMF member countries) transmits its views to the country's authorities. ${ }^{209}$ Those views are also summarized and published in a Public Information Notice, available on the IMF website. ${ }^{210}$ In addition, most staff reports and analysis are published on the IMF website. 211

The view from the Executive Board can be very frank, as is evident in the summary of the country report for the Kingdom of the Netherlands which noted that:

While the mortgage and housing markets appear relatively stable, banks have suffered major declines in asset quality, profits, and capital, and lending conditions have tightened. The fiscal position has weakened considerably because of the cyclical downturn, sizable stimulus to buoy economic activity, and massive financial sector bailout. Against this background, real GDP is expected to suffer an unprecedented fall in 2009, with a rather modest recovery expected in 2010.212

Subsequently, the Executive Board also advised the Netherlands that "additional bank capital, particularly equity, might be required because of the likely losses associated with the ongoing recession, the need to augment existing capital buffers, and an expected increase in lending when the crisis subsides." 213 The Executive Board made suggestions for structural changes, stating:

the financial system should be bolstered by regulatory and supervisory reform to strengthen capital standards for securitizations, resecuritizations, and high-LTV-ratio mortgages. A reduction of incentives for high LTV loans, such as mortgage interest deductibility, is desirable. Directors also considered that cross-country supervision and

\footnotetext{
${ }^{200}$ DOMEnico Lombardi \& NGaIRe WoOdS, The Politics of Influence: An Analysis of IMF Surveillance, 15 Review of International Political Economy 711,719 (2008).

${ }^{201} I d$. at 719.

202 FUND, IMF Surveillance, supra note 143.

${ }^{203} \mathrm{Id}$.

$204 \mathrm{Id}$.

${ }^{205}$ MOMANI, supra note 196.

206 Id. at 256.

${ }^{207}$ FUND, Surveillance, supra note 191.

208 LOMBARDI, supra note 200, at 719.

${ }^{209}$ FUND, IMF Surveillance, supra note 143.

${ }^{210} \mathrm{Id}$.

${ }^{211} \mathrm{Id}$.

${ }^{212}$ INTERNATIONAL MONETARy Fund, IMF Executive Board Concludes 2009 Article IV Consultation with the Kingdom of the Netherlands - Netherlands Public Information Notice (PIN) No. 10/17; February 2, 2010 at http://www.imf.org/external/np/sec/pn/2010/pn1017.htm.

${ }^{213} \mathrm{Id}$.
} 
resolution, as well as deposit insurance and fiscal burden-sharing, should be strengthened together with EU regulators. ${ }^{214}$

To conclude, this section has examined the IMF's country surveillance pursuant to Article 4 of its Articles of Agreement, which is another example of an international accountability mechanism. The standards for economic stability are set by the IMF team of economists. Each country is held accountable by the Executive Board with the help of a team of economists. In this case the consequences for failure to comply with standards can be a severe downturn or a worsening of the economic situation in the country and can negatively impact trade.

\section{c. The UN Human Rights System as an international accountability mechanism}

This thesis revolves around the Universal Periodic Review Mechanism which is, in and of itself, a type of accountability mechanism. However, the UPR is an accountability mechanism that functions within other larger accountability mechanisms - those of the United Nations. The machinery to monitor human rights has evolved following World War II with the UN Charter and the advent of international conventions. These accountability regimes run the gamut from judicial bodies such as the International Court of Justice and the International Criminal Court to treaty bodies like the Committee for the Elimination of Discrimination Against Women (CEDAW) to the UPR itself. This thesis will pause to take a brief look at the UN Human Rights monitoring system as a whole to unravel the way in which states are held accountable within the UN Human Rights machinery.

Generally, monitoring of human rights in the international context has been carried in either a charter-based or treaty-based mechanism. ${ }^{215}$ The charter-based mechanisms derive their authority from the UN Charter. Today, the main charter-based mechanisms are the UN Human Rights Council (Council), the UPR (the subject of this inquiry), the special procedures and the complaints mechanism (formerly 1503 procedure). The treaty bodies monitor the fulfillment of obligations by states parties to the major human rights conventions. The monitoring is generally through state reporting, individual complaints, inquiries and site visits by independent experts, or consideration either in closed sessions or open sessions before the Council or within its working groups. Specific attention will be given to the charter-based organs, including the Human Rights Council, as well as to the treatybased mechanisms.

\section{Evolution of the UN Human Rights Machinery}

The United Nations Human Rights System is a complex set of bodies that form part of a larger UN charterand treaty-based system to promote and encourage human rights. The United Nations Charter mandates, in Chapter 1, Article 1 that:

The Purposes of the United Nations are:

1. To maintain international peace and security, and to that end: to take effective collective measures for the prevention and removal of threats to the peace, and for the suppression of acts of aggression or other breaches of the peace, and to bring about by peaceful means, and in conformity with the principles of justice and international law, adjustment or settlement of international disputes or situations which might lead to a breach of the peace;

2. To develop friendly relations among nations based on respect for the principle of equal rights and selfdetermination of peoples, and to take other appropriate measures to strengthen universal peace;

3. To achieve international co-operation in solving international problems of an economic, social, cultural, or humanitarian character, and in promoting and encouraging respect for human rights and for fundamental freedoms for all without distinction as to race, sex, language, or religion; and

4. To be a centre for harmonizing the actions of nations in the attainment of these common ends. 216

\footnotetext{
${ }^{214} I d$.

215 See OfFice of the High COMmissioner for Human Rights, Working With the United Nations Human Rights Programme: A Handbook for Civil Society (2008) [hereinafter OHCHR Handbook], available at http://www.ohchr.org/EN/AboutUs/CivilSociety/Documents/Handbook_en.pdf (overview of the treaty-based and charter-based mechanisms) .

${ }^{216}$ Charter Of THE United NAtions, Chapter 1 (Article 1) 59 Stat. 1031; T.S. No. 99; Id.
} 
Paragraph 3 of Chapter 1, Article 1 of the United Nations Charter is the genesis of the human rights system. Indeed, the charter mandates members of the organization to promote and encourage respect for human rights and fundamental freedoms. Because of the broad language used in Chapter 1, Article 1 of the UN Charter, it can be used to justify many types of methods to encourage respect for human rights. In fact, this part of the charter is the basis for the United Nations Human Rights System. The system is designed to hold States accountable for obligations through different procedures that are open to individuals, groups and organizations that are familiar with violations. These complaint procedures are available under three different mechanisms which will be further elaborated below.

The UN began to fulfill the mandate to promote and encourage respect for human rights by adopting conventions, treaties and declarations in the domain of human rights. The first, and arguably most significant document, was the Universal Declaration of Human Rights, adopted on December 10, 1948.217 The Universal Declaration embodies the concept of universality of human rights by declaring that "all human beings are born free and equal in dignity and rights." 218 The adoption of the Universal Declaration of Human Rights started the metaphorical ball rolling for the adoption of other important treaties and conventions, including two very important covenants: the International Covenant on Civil and Political Rights ${ }^{219}$ and the International Covenant on Economic, Social, and Cultural Rights ${ }^{220}$ which, together with the Universal Declaration of Human Rights, are known as the International Bill of Human Rights. ${ }^{221}$

The ensuing decades saw several new international covenants that covered racial discrimination, torture, discrimination against women, the rights of children, and rights for migrant workers. Currently, most of these treaties have a related treaty body that oversees the performance of the states signatories to the treaty. The human rights treaty body system has played a central role in the development of human rights standard setting and monitoring.

217 UN OfFice Of THE High COMMISSIONER FOR Human RigHTS, The United Nations Human Rights System: How to Make It Work for You [hereinafter OHCHR Make it Work] at http://www.un-ngls.org/IMG/pdf/Final_logo.pdf.

218 Universal Declaration of Human RightS, Article 1, G.A. Res. 217A (III), U.N. Doc. A/810 at 71 (1948) .

${ }^{219}$ INTERNATIONAL COVENANT ON CIVIL AND POLITICAL RIGHTS, supra note 5, available at http://www2.ohchr.org/english/law/ccpr.htm. 220 INTERNATIONAL COVENANT ON ECONOMIC SOCIAL AND CULTURAL RIGHTS, supra note 5, available at http://www2.ohchr.org/english/law/cescr.htm.

${ }^{221}$ OHCHR Make it Work, supra note 217. 
The whole UN Human Rights system has been depicted in a chart by the United Nations Office of the High Commissioner for Human Rights 222 as:

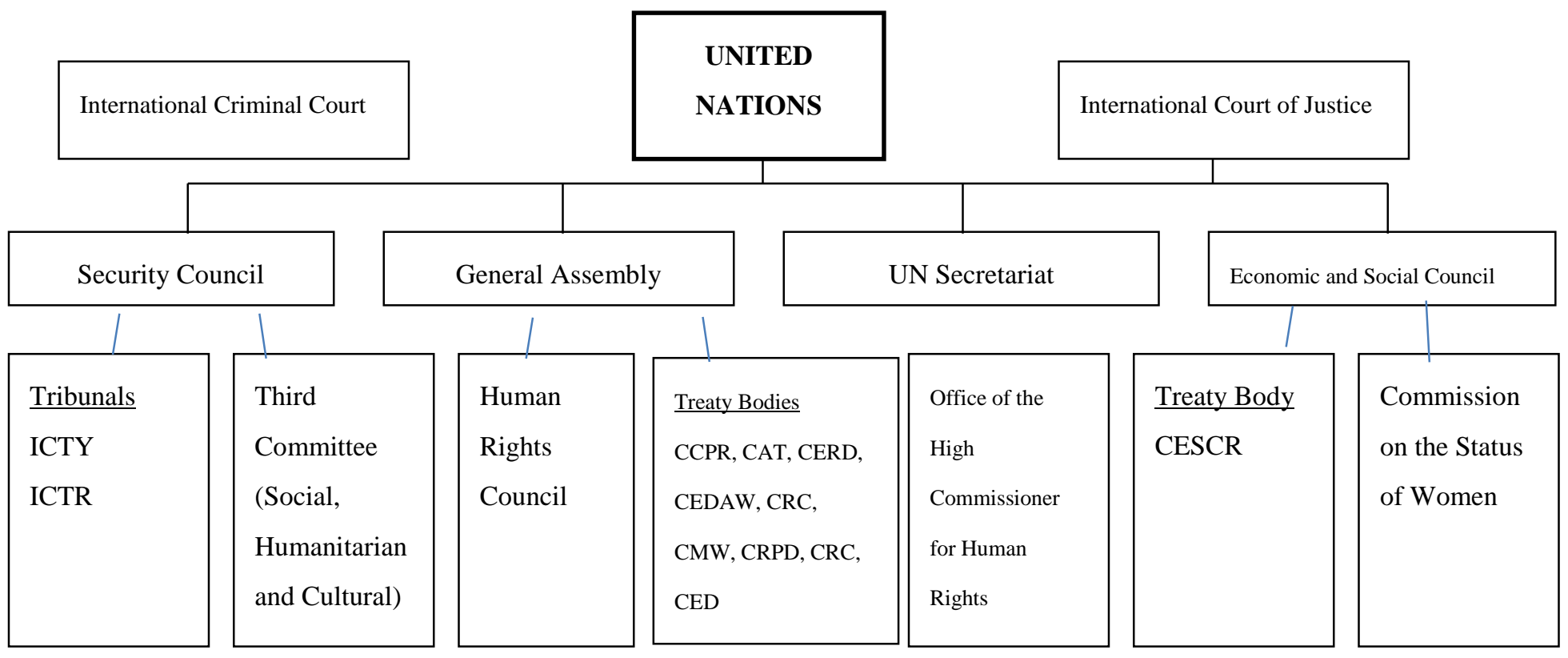

Key to abbreviations: ICTY - International Criminal Tribunal for the Former Yugoslavia; ICTR - International Criminal Tribunal for Rwanda; CCPR- Human Rights Committee; CAT - Committee Against Torture; CERD - Committee on the Elimination of Racial Discrimination; CEDAW- Committee on the Elimination of Discrimination Against Women; CRC - Committee on the Rights of the Child; CMW - Committee on Migrant Workers; CRPD - Committee on the Rights of Persons with Disabilities: CESCR - Committee on Economic, Social and Cultural Rights; CRC - Committee on the Rights of the Child; CED - Committee on Enforced Disappearances

As is evidenced by the chart, the UN disposes of several types of bodies to enforce, monitor, supervise and even create human rights obligations. The chart identifies both judicial and non-judicial mechanisms. For example, the International Criminal Court as well as the ICTY and ICTR, are all criminal tribunals with the power to punish and imprison those individuals found guilty of violating human rights norms. These forums are examples of the way in which international law has evolved over the decades following the Second World War Following the Nuremberg and Tokyo Tribunals and the other related trials, there were no tribunals that held individuals responsible for war crimes and crimes against humanity until the early 1990s and the massacres in the former Yugoslavia and the genocide in the African country of Rwanda. The creation of the ICTY and ICTR were watersheds in international criminal justice. However, these were tribunals for the gross and widespread violation of human rights by states during times of war or internal conflict. They are not fora for complaints against individual states for human rights violations during peace time. Instead, peace-time violations of human rights are brought before the Human Rights Council and its special procedures or before the Treaty Bodies.

\section{The Periodic Reporting and Complaint Procedures}

The UN Human Rights System has three main ways of monitoring human rights:

- The Treaty Bodies (periodic reporting, inquiries and individual petitions that come before the body based on an alleged violation of one of the treaties); 
- The special procedures mechanism of the Human Rights Council (inquiries, site visits, reports); and

- The complaint procedure mechanisms of the UN Human Rights Council (UPR, modified 1503 procedure).

The reporting and complaint procedures within the Human Rights system are depicted in this chart:

\section{UN Human Rights Machinery}

\section{International Human Rights Treaties}

Periodic reporting by states parties

Recommendations regarding individual states parties

Individual complaints against State party after domestic remedies are exhausted, permitted by state (optional protocol)

Urgent interim measures can be taken

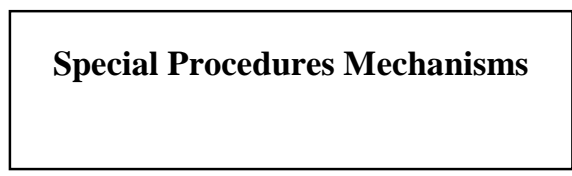

Individual complaint or general pattern of human rights abuse;

Can be alleged by civil society organization;

Cases can be brought against ANY state;

Case can be brought both in special procedures and before a treaty body

The special procedure must cover the specific human rights issue or that specific country

Non-binding outcome
UN Human Rights Council

Individual or group complaint;

Violation can be alleged by any person or group with direct or reliable knowledge;

Case can be brought for violations of all human rights and fundamental freedoms;

Case may be brought against ANY state;

Confidential and lengthy process, where no urgent interim measures can be taken;

Must not be pending before a treaty body, or regional/international adjudicative body

FIGURE 3

\section{The Treaty Bodies}

Treaty bodies are equipped to receive periodic state reports and to consider individual complaints brought by the individual or by a third-party. The Treaty Bodies or committees evolved from decades of progress in the UN Human Rights system. Over the decades following the creation of the UN, many treaties were signed involving the elimination of discrimination against women, the elimination of racism and the rights for children, among others. These treaties also had bodies to monitor their implementation and compliance with their provisions. Some treaties also had optional protocols that give rights to individuals to lodge complaints.

The treaty-based mechanisms are concerned with fulfillment of treaty obligations by the parties to the treaty. The subject matter of the treaties themselves are limited, therefore the monitoring body is concerned only with the 
obligations enumerated in the treaty - e.g. migrant workers' rights or enforced disappearance. As of 2012 there were nine treaty committees, plus the Subcommittee on the Prevention of Torture. ${ }^{223}$

The treaty body committees receive periodic reports ${ }^{224}$ from each state party regarding its fulfillment of treaty obligations. The frequency of reporting varies with each committee. Those reports are considered by the experts that sit on the committee. The experts are individuals who have been chosen by their countries to sit on the treaty body; however, they sit in their own individual capacity and do not represent their government. The experts write concluding observations regarding each country's performance. Those observations must be implemented by the state under review.

In some cases, treaty bodies can also take individual complaints. The following treaty bodies have the authority to consider individual complaints:

(1) the Human Rights Committee;

(2) the Committee on the Elimination of Racial Discrimination;

(3) the Committee against Torture; and

(4) the Committee on the Elimination of Discrimination Against Women.

If complaints are permitted by the treaty and a country has opted to permit individual complaints by ratifying the option protocol (or the other relevant provisions), then individuals who have exhausted all domestic remedies can bring complaints before the treaty body and await a response. Treaty bodies may give remedies to deserving complainants.

Some treaties (CAT and CEDAW) also permit inquiries. ${ }^{225}$ During the inquiries, a state will be asked to comment to a well-founded allegation, and in the case that it does not sufficiently refute the accusation; the Committee may make a confidential inquiry on site. ${ }^{226}$ The Committee will send a confidential report to the government indicated its finding and giving recommendations about what should be done. ${ }^{227}$

The treaty body monitoring system has been the subject of criticism and is now under reform at the behest of the High Commissioner for Human Rights. ${ }^{228}$ Much of the criticism is aimed at the impotence of the committee in the face of states who do not comply with reporting requirements. In addition, many consider the outcomes of the committee to be non-binding and believe that states largely ignore recommendations coming from the treaty body committees. The treaty body system is also very limited in its reach as there are many UN member states

\footnotetext{
${ }^{223}$ There are nine human rights treaty bodies and the Subcommittee on Prevention of Torture (SPT):The Human Rights Committee (CCPR) monitors implementation of the International Covenant on Civil and Political Rights (1966) and its optional protocols; The Committee on Economic, Social and Cultural Rights (CESCR) monitors implementation of the International Covenant on Economic, Social and Cultural Rights (1966); The Committee on the Elimination of Racial Discrimination (CERD) monitors implementation of the International Convention on the Elimination of All Forms of Racial Discrimination (1965); The Committee on the Elimination of Discrimination Against Women (CEDAW) monitors implementation of the Convention on the Elimination of All Forms of Discrimination against Women (1979) and its optional protocol (1999); The Committee Against Torture (CAT) monitors implementation of the Convention against Torture and Other Cruel, Inhuman or Degrading Treatment (1984); The Committee on the Rights of the Child (CRC) monitors implementation of the Convention on the Rights of the Child (1989) and its optional protocols (2000); The Committee on Migrant Workers (CMW) monitors implementation of the International Convention on the Protection of the Rights of All Migrant Workers and Members of Their Families (1990); The Committee on the Right of Persons with Disabilities (CRPD) monitors implementation of the International Convention on the Rights of Persons with Disabilities (2006); The Committee on Enforced Disappearance (CED) monitors implementation of the International Convention for the Protection of All Persons from Enforced Disappearance (2006).

224 See Michael O'Flaherty \& Pei-Lun Tsai, Periodic Reporting: The Backbone of the UN Treaty Body Review Procedures, in New Challenges for the UN Human Rights Machinery: What Future for the UN Treaty Body System and the Human Rights Council Procedures? (M. Cherif Bassiouni \& William A. Schabas,eds 2011). See also INEKE BoEREFIJN, The Reporting Procedure Under the Covenant on Civil and Political Rights (1999); MANFRED NOWAK, Introduction to the International Human Rights Regime (2003).

${ }^{225}$ NOWAK, supra note 223 , at 103

${ }^{226} \mathrm{Id}$.

$227 \mathrm{Id}$.

228 See the website of the OHCHR, at http://www2.ohchr.org/english/bodies/treaty/reform.htm.
} 
which are not parties to the core human rights treaties and therefore fall outside of the reach of the treaty committees.

Despite the criticisms, the Treaty Body system is a form of accountability mechanism. The experts sitting on the committee are the accountability holders. The standards by which the states parties are measured are found in the treaty and in the jurisprudence that is issued by the Treaty Body itself.

\section{The Human Rights Council}

For many decades the UN Human Rights Commission played a role in human rights monitoring. The Commission operated from the inception of the United Nations until its dissolution and replacement by the UN Human Rights Council in 2006. The Council is now considered the "principle UN intergovernmental body responsible for human rights." 229 The Council meets in three regular sessions each year for a duration of no less than ten weeks. ${ }^{230}$ The Council may also hold special sessions at the request of a member state. ${ }^{231}$ The Council examines the reports of the Working Group on Situations (a confidential procedure that considers gross violations of human rights). The Council provides the seat of the UPR and its four-year review cycle of the human rights obligations of all UN Member States. The UPR is an accountability mechanism, as will be demonstrated by Part Three of this thesis.

\section{(a) Human Rights Council complaint procedure ${ }^{232}$}

The complaint procedure within the Council (formerly the 1503 procedure) is another type of accountability mechanism for human rights. The procedure is designed to take individual submissions detailing violations by a UN Member State or complaints from a group claiming to be a victim of human rights violations. The Council's complaint procedure considers gross violations of human rights in any part of the world. These complaints can be made by the victim or by an organization having "direct, reliability knowledge" of the violation.

The procedure begins with the written submission. That submission must be in English, French, Russian or Spanish and should not exceed 15 pages. The submission is subject to an initial screening by the High Commissioner for Human Rights' secretariat and the Chairperson of the Working Group on Communications. The screening checks to ensure that the complaint complies with admissibility criteria. ${ }^{233}$ The complaints that pass the criteria are acknowledged and sent to the government (Member State against which the complaint is lodged.)

The Working Group on Communications is a five-member working group whose members also sit on the Human Rights Council Advisory Committee. If a particular complaint constitutes a "consistent pattern of gross and reliably attested violations of human rights and fundamental freedoms," the group is required to pass the complaint along to the Working Group on Situations.

The Working Group on Situations is also made up of five members who sit on the Human Rights Council. The group meets at least twice per year for five days. The five-member Working Group on Situations examines the individual complaints (together with state replies) sent to its attention by the Working Group on Communications twice a year for five working days. ${ }^{234}$ The Working Group on Situations reports to the Council on "consistent patterns of gross and reliably attested violations of human rights and fundamental freedoms" and

\footnotetext{
229 OHCHR Make it Work, supra note 217, at 7.

${ }^{230}$ OHCHR Handbook, supra note 215.

${ }^{231} \mathrm{Id}$.

232 Unless otherwise indicated, the information in this subsection (a) is based on OHCHR Handbook, supra note 215, Chapters V and VIII.

233 The admissibility criteria are stringent. For a complaint to be admissible, the following content must not be present: manifestly political motivations; objects inconsistent with the UN Charter, the Universal Declaration of Human Rights or other relevant human rights documents; no factual description of the alleged violation; abusive language; submitted by a person or entity without knowledge of the facts; exclusively based on media reports; facts are being dealt with by special procedures, treaty body or a regional body in the field of human rights; or domestic remedies are not exhausted. OFFICE OF THE HigH COMMISSIONER FOR HUMAN RigHTS UnitED NATIONS HuMAN RigHTS, Complaint Procedure, http://www.ohchr.org/EN/HRBodies/HRC/Pages/Complaint.aspx.

${ }^{234} \mathrm{Id}$.
} 
recommends action to be undertaken. ${ }^{235}$ The group evaluates each case before it and drafts a report for the Human Rights Council with specific recommendations for the case, if there is a pattern of gross violations of human rights. The group can also dismiss a case or keep the situation under review.

The last stage of the complaint procedure is the plenary session before the Human Rights Council. The Council must consider situations brought to its attention by the Working Group on Situations. The Council must meet at least once a year. The Council can take action on a situation in the form of a resolution or decision. It also has the following options:

- To discontinue considering the situation when further consideration or action is not warranted;

- To keep the situation under review and request the State concerned to provide further information within a reasonable period of time;

- To keep the situation under review and appoint an independent and highly qualified expert to monitor the situation and report back to it;

- To discontinue reviewing the matter under the confidential complaint procedure in order to take up public consideration of the same;

- To recommend that OHCHR should provide technical cooperation, capacity-building assistance or advisory services to the State concerned.

The inner workings of the complaint procedure include the three essential elements for accountability mechanisms. The standards applied to the Member States are the human rights norms subscribed to by the Member State, such as treaties and conventions. The accountability holder is the Human Rights Council, which consists of $47 \mathrm{UN}$ Member States elected for a specific term to sit on the Council. The accountability mechanisms permits for consequences for gross violations that include being brought before the plenary Council. However, the situations always remain confidential; therefore, there is no reporting requirement or press release.

\section{(b) Special Procedures 236}

Special Procedures is the term given to mechanisms created by the Commission of Human Rights (now the Human Rights Council) to examine and report on situations in specific countries or on thematic issues surrounding patterns of human rights violations around the world. As of April 1, 2013, there were 36 thematic and 13 country mandates to examine, monitor, advise and report to the Council. The mandates are held by independent experts or by working groups that respond to individual complaints, conduct studies, or provide advice on technical cooperation. A number of special procedures are authorized to receive communications. Such communications may involve a violation that has already occurred, continues to occur or will occur. ${ }^{237}$ The communications may concern "individual cases, general trends and patterns of human rights violations occurring in a particular country, cases affecting a particular group or community, or the content of draft or existing legislation considered to be not fully compatible with international human rights standards." 238

The people involved in special procedures are independent experts who are also called special rapporteurs or special representatives. These experts are given logistical support, including research assistance or personnel by the Office of the High Commissioner for Human Rights. The mandate of a special rapporteur is set forth in the UN General Assembly Resolution creating the special procedure. The Office of the High Commissioner for Human Rights has described the mandate-holders' duties:

\footnotetext{
${ }^{235} \mathrm{Id}$.

${ }^{236}$ Unless otherwise indicated, the information in this discussion of Special procedures is based on OFFICE OF THE HIGH COMMISSIONER FOR HumAN Rights UNITED NATIONS HumAN RIGHTS, Special Procedures of the Human Rights Council: Introduction, http://www.ohchr.org/EN/HRBodies/SP/Pages/Welcomepage.aspx.

237 OfFice OF THE High COMMISSIONER FOR HumAn RightS United NATIONS HuMAN Rights, Communications, http://www.ohchr.org/EN/HRBodies/SP/Pages/Communications.aspx.

${ }^{238} \mathrm{Id}$.
} 
- Receive and analyse information on human rights situations provided by various sources on an ongoing basis;

- Network and share information with partners, both governmental and non-governmental, within and outside the United Nations;

- Seek - often urgently - clarification from Governments on alleged violations and, where required, request Governments to implement protection measures to guarantee or restore the enjoyment of human rights;

- Raise awareness about specific human rights situations and phenomena, and threats to and violations of human rights;

- When specific circumstances so warrant, communicate their concerns through the media and other public statements;

- Undertake country visits to assess human rights situations pertaining to their respective mandates, and make recommendations to Governments with a view to improving those situations;

- Report and make recommendations to the Human Rights Council and, where relevant to their mandates, to the General Assembly (and in some cases to the Security Council) on: regular activities under their mandate; field visits; and specific thematic trends and phenomena;

- Contribute thematic studies to the development of authoritative norms and standards for the subject area of the mandate, and may provide legal expertise on specific issues.

The thematic special procedures mechanism just described is an accountability mechanism in the area of human rights where the UN Member State is held responsible for its performance in a certain area of human rights, in this example - minority issues. The accountability holder is the UN itself, represented by the independent expert. The consequence for non-compliance is a published report with specific findings about the strengths and weaknesses of a government's policies. In addition, the government is pressured to accept technical assistance from the UN to improve conditions for minority group. Finally, the independent expert will follow up on recommendations to see how well the government is doing with its implementation. ${ }^{239}$

\section{Conclusion}

In this chapter, we have examined the definition of accountability and we have looked at accountability mechanisms at the national and international level. Accountability is answerability or responsibility to another that exists because of standards that demand certain behavior. Consequences for failure to meet standards are achieved both through judicial and/or non-judicial means.

The way in which states are held accountable can take place in the context of several types of accountability mechanisms. Accountability mechanisms have three main elements: standards against which parties are measured; accountability-holders who determine whether standards are met; and consequences for failure to comply with standards. Mechanisms are seen nationally and internationally. Nationally, accountability mechanisms may monitor the particular behavior of public officials, as is the case of the New York City Civil Review Board. National accountability mechanisms may also assess compliance with treaties and other obligations or receive individual complaints of human rights violations, as is the case with the Australian Human Rights Commission. Internationally, the ILO evaluates compliance by states parties with international labor standards. The IMF conducts yearly country surveillance to ensure the stability of internal and global markets.

In the field of human rights, the United Nations has several accountability mechanisms for human rights: the Treaty Bodies, the Human Rights Council complaint procedure; and the Special Procedures, in addition to the UPR. States that are members of the UN may be subject to visits or inquiries from thematic or country rapporteurs. They can also be the subject of a communication or complaint that is then considered by the UN Human Rights Council and/or its Working Groups. States may also be subject to reporting requirements if they have ratified certain core human rights conventions. In some cases, states have permitted their individual citizens

${ }^{239}$ One severe limitation to the special procedures is that the mechanism is not legally binding; therefore, Member States comply at their own discretion. 
to lodge complaints under those conventions. The UN Human Rights Council also holds states accountable for patterns of gross human rights violations. The UN Human Rights System constitutes an accountability mechanism because it has an elaborate set of standards enshrined in international conventions and treaties. The Member States that are parties to the treaties are held accountable for their actions by other Member States or by individual experts. In all, the UN machinery has several tools for holding states responsible for their human rights obligations. The introduction of the UPR creates a completely different forum for examining states and their commitments to human rights. As we will see, its reporting and dialogue are before other states, rather than rapporteurs and experts. This inquiry will continue to consider how such a forum can change the way states talk about human rights. 


\section{Chapter Four}

\section{Unique Characteristics of the Peer Review Accountability Mechanism}

As has been discussed in the previous chapter, scholars identify different types of accountability mechanisms, among them mechanisms that are driven by experts and those that are led by the states participating in the mechanism itself. The ILO and IMF mechanisms, together with the majority of the human rights machinery examined in the previous chapter are accountability mechanisms that are made up primarily of expert examiners. The OECD and other international and supranational bodies have created mechanisms that monitor performance and implementation of policies through peer pressure and mutual scrutiny. These IOs engage in peer review. When the UPR was being formulated, several different international organizations were studied and used as models to design the UPR, including expert and peer-based mechanisms. The ultimate model used to shape the UPR was a peer review model, rather than an expert model. The addition of the UPR to the ensemble of human rights monitoring processes meant that the new UN Human Rights monitoring system would now have a process that would occur among Member States. This use of peer review in the surveillance of states' implementation of human rights obligations has important ramifications for the way in which human rights are discussed, the way policies are created, diffused and transferred and for the way in which information is gathered and data regarding national human rights situations are gathered. Because the choice of peer review influences the way in which countries implement their obligations, it is important to understand how peer review came about and how peer review mechanisms are structured. We do this by first reviewing the history and goals of peer review.

This chapter will look at the theory and history of peer review as an accountability mechanism. Additionally, this chapter examines the peer review mechanisms found in the OECD, the Council of Europe, the EU and the New African Partnership for Development (commonly referred to as the African Peer Review Mechanism). The peer review structures in these international organizations help to demonstrate the structure of peer review mechanisms.

\section{Introduction}

The peer review process has only recently begun to get attention in the literature, particularly in regard to peer reviews within international organizations. Previously, literature discussing peer review focused on medical, academic, legal and regulatory peer review within a national context. ${ }^{240}$ In the past decade, however, some literature has arisen in the context of OECD peer reviews ${ }^{241}$ and with regard to the establishment of the African Peer Review Mechanism (APRM).242 Peer review has also been studied in the larger framework of global governance. $^{243}$

\section{Defining Peer Review}

In this first part of the chapter, we look at how peer review has been defined in international contexts, specifically in the context of the Organization of Economic and Cooperative Development (OECD). From these

\footnotetext{
${ }^{240}$ HAMILTON, The Ethics of Peer Review, supra note 70, at 231-233.

${ }^{241}$ See FABRIZIO PAGANI, Peer Review: A Tool for Co-operation and Change, An Analysis of an OECD Working Method, 11 African Security Review 15 (2002) and Peer Review: Merits and Approaches in a Trade and Competition Context. (2002). See also THOMAS CONZELMANN, Beyond the Carrot and the Stick: State Reporting Procedures in the World Trade Organization and the Organization for Economic Cooperation and Development, in International Organizations and Implementation (Jutta Joachim, ed. 2008) and MARTIN MARCUSSEN, OECD Governance Through Soft Law, in Soft Law in Governance and Regulation (Ulrika Morth, ed. 2004).

242 See Allehone Mulugeta Abebe, Of Shaming and Bargaining: African States and the Universal Periodic Review of the United Nations Human Rights Council, 9 Human Rights Law Review 1 (2009); MAGNUS KILLANDER, The African Peer Review Mechanism and Human Rights: The First Reviews and the Way Forward, 30 Human Rights Quarterly 41 (2008); RAVI KANBUR, The African Peer Review Mechanism (APRM): An Assessment of Concept and Design (2004), http:/ / www.arts.cornell.edu/poverty/kanbur/APRM.pdf

http://www.arts.cornell.edu/poverty/kanbur/APRM.pdf.

${ }^{243}$ CONZELMANN, Carrot and Stick, supra note 241; THOMAS CONZELMANN, Reporting and Peer Review in the Implementation of International Rules: What Role for Non-State Actors?, in The Ashgate Research Companion to Non-State Actors (Bob Reinalda ed. 2011); KEOHANE, Exploring the Governance Agenda, supra note 134.
} 
definitions, we extract three principal characteristics of all peer review processes: lack of a third-party accountability holder, non-adversarial posture, and a focus on capacity-building through cooperation and sharing of best practices.

Although peer review has been utilized for centuries in medical and scientific fields, the term peer review has not been widely defined in the medical and scientific review or grant-making literature; however, definitions of the term "peer review" are employed in the context of international peer review. Most notably, the term has been widely discussed by scholars of the OECD peer review mechanisms. ${ }^{244}$

Fabrizio Pagani has defined the term in the practice of the OECD as:

The systematic examination and assessment of the performance of a State by other State, with the ultimate goal of helping the reviewed State improve its policy making, adopt best practices and comply with established standards and principles. ${ }^{245}$

The OECD Joint Global Forum on Trade and Competition used the following working definition:

Peer review is a method by which countries can assess the quality and effectiveness of their policies, legislation, policy environments and key institutions. It provides a forum where policies can be explained and discussed, where information can be sought and concerns expressed, on a nonconfrontational and non-adversarial basis. The feedback provides the reviewee with a yardstick for measuring its system against those of other peers while also informing the reviewing countries. ${ }^{246}$

While citing Pagani's definition, Professor Nico Groenendijk states that international peer review is a "systematic examination of a policy of a certain state by other states, with the goal of helping the examined state to improve its performance within that policy field." 247 Again, citing the Pagani and the OECD understanding of peer review, scholar Markku Lehtonen notes that "peer reviews can be seen as a mechanism attempting to combine the functions of learning and accountability with a single evaluation framework." 248 Groenendijk further notes that in peer review processes, participation is voluntary and the process relies on "mutual trust of the participating countries." 249 Additionally, peer review results in peer pressure because peer countries make recommendations, engage in informal dialogue and subject each other to public scrutiny, comparison and "in some cases even ranking among countries." 250 Martens and Jakobi, scholars who study the OECD peer review mechanism, explain that peer review, in the context of the OECD, is "a mechanism of development and diffusion of knowledge between member states on the success of failure of specific national policies." 251 Lehtonen notes that "peer reviews can be seen as a mechanism attempting to combine the functions of learning and accountability within a single evaluation framework." 252

We can identify a common thread running through these explanations of peer review. From these definitions, we can derive three characteristics that are unique to peer review - (i) the lack of a third-party accountability holder; (ii) non adversariality of the procedures; and (iii) a focus on learning, assistance and collaboration through dialogue rather than sanctions. We explore these three characteristics in turn.

\footnotetext{
${ }^{244}$ MARKKU LeHTONEn, Deliberative Democracy, Participation, and OECD Peer Reviews of Environmental Policies, 27 American Journal of Evaluation, 189 (2006); MARKKU LEHTONEN, OECD Environmental Performance Review Programme: Accountability (f)or Learning?, 11 Evaluation, 177 (2005); ORGANIZATION FOR ECONOMIC COOPERATION AND DEVELOPMENT, Issues for Trade and Competition in the Global Context: A Synthesis (2004), http:/ / www.oecd-ilibrary.org/governance/issues-for-trade-and-competition-in-the-global-context_clp-v5-art10-en. The OECD has adopted peer review as its method of choice in its country reviews and economic surveys.

${ }^{245}$ FABRIZIO PAGANI, Peer Review: A Tool for Co-operation and Change, supra note 241, at 15.

${ }^{246}$ ORGANizATION OF ECONOMic COOPERATION AND DeVElopment, Peer Review Merits and Approaches 4 (2002), http://www.oecd.org/officialdocuments/publicdisplaydocumentpdf/?cote=COM/TD/DAFFE/COMP(2002)4/FINAL\&docLanguage=En.

${ }_{247}^{24}$ Nico GROENENDIJK, The EU and OECD Benchmarking and Peer Review Compared (European Union Centre of Excellence 2009).

${ }^{248}$ LEHTONEN, OECD Environmental Performance, supra note 244, at 177.

${ }^{249}$ GROENENDIJK, The EU and OECD Benchmarking, supra note 247, at. 7.

${ }^{250} \mathrm{Id}$. at 7, citing Fabrizio Pagani, Peer Review: A tool for co-operation and Change, OECD 2002.

${ }^{251}$ KERSTIN MARTENS, ET AL., Introduction: The OECD as an Actor in International Politics, in Mechanisms of OECD Governance 10, (Kerstin Martens ed. 2011).

${ }^{252}$ LEHTONEN, OECD Environmental Performance, supra note 244, at 177.
} 


\section{A. No third-party accountability holder}

In earlier discussions of accountability, we stated that among the parties to accountability mechanisms are accountability holders. In many cases, particularly in the case of expert-based accountability mechanisms, the accountability holders are third parties. In peer reviews, there is no third-party accountability holder.

International organizations holding peer reviews are comprised of member countries. The peer review takes place between member countries. As Armin Schafer remarks, “[m]ultilateral surveillance rests on peer review, i.e. on the mutual monitoring and evaluation of national policies by other governments." 253 In this regard, the peer review model differs from the accountability mechanism paradigm in that the accountability holders are the states themselves. Moreover, at some point during the review process, the states change roles, and the reviewee becomes the accountability holder. This is collaborative process where the roles are fluid. All members will sit both as reviewer and reviewee.

In contrast, the expert mechanisms (ILO and IMF) have a third party who is holding the countries accountable. For example, the Executive Board of the IMF or the Committee of Experts on the Application of Conventions and Recommendations of the ILO have a role in determining whether a Member State complies with applicable standards and law.

The lack of a third-party accountability holder has a further ramification for the peer review process: the atmosphere of peer review is generally non-adversarial. States are reluctant to directly confront other states with threats of punishment or sanctions, knowing they will soon come before the same states for their own review process. The non-adversarial posture of peer reviews is discussed next.

\section{B. Non-adversarial Posture}

A second unique characteristic relates to the non-adversarial nature of the process. ${ }^{254}$ Non-adversariality is generally not found in other types of national and international accountability mechanisms. Most compliance and monitoring processes are adversarial because they pit the state under review against the accountability holder. ${ }^{255}$ The state under review can be sanctioned by the accountability holder. In other accountability mechanisms, the accountability holder is not another state, instead a member state could be held accountable by an adjudicative body, a review panel made up of experts or a court or administrative judge. In each such case, the body, panel or judge can impose sanctions on the party under review. The peer review process, on the other hand, pits the member state against nobody.

The lack of adversarial proceedings, however, does not necessarily translate into a lack of ability to effect change in member state policies. While peer reviews strive to maintain a collegial environment, peer pressure and group scrutiny are, nonetheless, applied. ${ }^{256}$ Washington enumerates two essential functions in the peer review model:

First, a group of equals is delineated, and second, the cost of noncompliance or nonconformism is raised through peer pressure and public scrutiny. Thus, peer review operates as a mechanism of accountability within an institutionalized social system..$^{257}$

\footnotetext{
${ }^{253}$ ARMIN SCHAFER, A New Form of Governance? Comparing the Open Method of Co-ordination to Multilateral Surveillance by the IMF and the OECD, 13 Journal of European Public Policy 80 (2006) (emphasis added).

${ }^{254}$ OrganiZATION FOR ECONOMic CoOperation And Development, Practical Modalities of Peer Review in a Multilateral Framework on Competition (2003),

http:// www.oecd.org/officialdocuments/publicdisplaydocumentpdf/?cote=COM/DAFFE/TD(2002)82/FINAL\&docLanguage=En.

255 This is true of the mechanisms described by Keohane -- the hierarchical, supervisory, legal/fiscal and others.

${ }^{256}$ Organization for ECONOMic COOPERATION AND Development, Practical Modalities of Peer Review in a Multilateral Framework on Competition, supra note 254, at 7,17, 24.

${ }^{257}$ MOniCA J. WASHIngton, The Practice of Peer Review in the International Nuclear Safety Regime, 72 New York University Law Review, 446 (1997).
} 
Peer pressure can be effective in inducing states to adopt policies that make them look more like their neighbors in order to be accepted in a wider group of member states. In addition, group scrutiny is also conducive to policy diffusion and knowledge sharing, both of which are helpful in changing national policies.

Pagani references "soft persuasion." He contrasts that strategy with the acts characterized in other fora- acts such as legally binding outcomes, sanctions or other enforcement tactics. ${ }^{258}$ The effectiveness of peer pressure depends on the "influence and persuasion exercised by the peers during the process." 259 Pagani states that peer pressure arises through:

(i) a mix of formal recommendations and informal dialogue by the peer countries: (ii) public scrutiny, comparisons, and, in some cases, even ranking among countries; and (iii) the impact of all the above on domestic public opinion, national administrations and policy makers. The impact will be greatest when the outcome of the peer review is made available to the public.... When the press is actively engages with the story, peer pressure is most effective. Public scrutiny often arises from media involvement. 260

Pagani further notes that peer pressure thrives:

when it is possible to provide both qualitative and quantitative assessments of performance. The quantitative assessment might take the form of a ranking of countries according to their performance, and the drawing of real scoreboards reflecting such rankings. An example is the OECD Jobs Strategy, a programme which sets out principles and benchmarks, carries out quantitative analysis and ranks country [sic] according to their performances in reducing unemployment. Another example, outside the OECD, of a very effective scoreboard is the Internal Market Scoreboard, maintained by the European Commission, which ranks the EU Members States according to their performance in the completion of the internal market. A variation of this system is the "naming and shaming" technique, which singles out poor performers. However, these methods are appropriate and produce positive results only when the "rules of the game" are clear and the countries accept them. ${ }^{261}$

\section{Focus on capacity building}

A final singularity of the peer process is its focus on collaborative ways to aid a state in adopting best practices or policies. Peer review does not have as its main goal sanction or punishment for non-compliance. Instead, the focus is on encouraging nations to make key changes in legislation, institutions or policy-making. As a result, the parties use interactive dialogue and cooperation as a means to bring about desired behavior. ${ }^{262}$ Additionally, the parties also find ways to strengthen the institutions of the party under review through technical assistance.

Schafer maintains that "[p]recisely because there are no sanctions, this mode of governance builds on a cooperative effort to criticize existing policies and generate new ones." 263 Schafer further argues:

The significant result of having the members compare, analyze, and discuss their policies is a better understanding of each other's problems and a growing recognition of the interdependence of national policies. This is one rather impalpable process that nonetheless has recognizable effects. One effect, to use the analogy of a physical phenomenon, is a kind of 'osmosis'- a diffusion of ideas, a better understanding of one country's policies by responsible officials in other countries, and the anticipation of more sympathetic response by others to these policies (and vice versa). This calls for the periodic personal contacts that also engender mutual appreciation and trust. 264

The previous discussion has defined the term peer review by focusing on three of its attributes: the absence of a third-party accountability holder, non-adversariality, and a focus on mutual cooperation. Peer review entails the

\footnotetext{
${ }^{258}$ FABRIZIO PAGANI, Peer Review: A Tool for Co-operation and Change, supra note 241, at 6.

${ }^{259} I d$. at 5-6.

${ }^{260} I d$. at 5-6.

${ }^{261} \mathrm{Id}$. at 6.

262 Organization for ECONOMic CoOperation And Development, Practical Modalities of Peer Review in a Multilateral Framework on Competition, supra note 254 , at 4, 7, 26.

263 SCHAFER, A New Form of Governance? supra note 253, at 80.

${ }^{264} \mathrm{Id}$. at 81 [citation omitted].
} 
review by member states of each other's policies with the goal of adjusting policies that do not conform to industry standards and sharing best practices among member states to achieve that end.

\section{Identifying the Main Goals of Peer Review}

The peer review approach to accountability has as its main objective, to empower a member state to comply with its obligations. Compliance is brought about by targeting seven main goals during the peer review process. Those seven goals are:

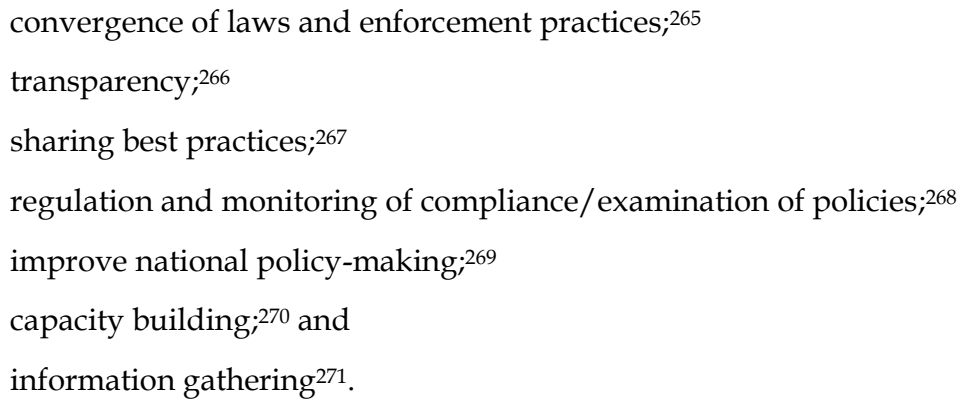

\section{A. Convergence of laws and enforcement}

Many international and supranational organizations seek to harmonize legislation within member states and the way in which laws are enforced. Convergence refers to the pursuit of uniformity in laws and practices across nations. In international organizations where peer review is employed, uniform practices are a desired outcome of the peer review process. During the peer review process members share and identify similar practices and regulatory regimes at the domestic level. The principle aim is to make national "laws and regulations...more congruent." 272 This convergence can be brought about through "extensive contacts and co-operation between national regulatory officials." 273 The main theory is that after continual cooperation and interaction "the beliefs of participants will converge over time." 274 This goal can be contrasted with the goals in adjudicatory and courtbased accountability mechanisms where dispute settlement and other adversarial resolutions are sought.

The environment of mutual trust and openness found in peer review processes foments convergence. As a member state is under review, other participants are in the process of learning. This learning comes through the disclosure of policy decisions and other information by the state under review. As the review is under way, "other parties may be wondering (and debating with their domestic authorities) 'what do country A's lessons and country B's lessons have in common?' or 'why does this policy work in country A, but not in country B?" 275 This

265 Organization of ECONOMic Cooperation And Development, Peer Review Merits and Approaches, supra note 246, at 4, 6; ORGANIZATION FOR ECONOMIC COOPERATION AND DEVELOPMENT, Practical Modalities of Peer Review in a Multilateral Framework on Competition, supra note 254 .

266 Organization of ECONOMic Cooperation And Development, Peer Review Merits and Approaches, supra note 246 , at 7.

$267 \mathrm{Id}$. at 8 .

${ }^{268}$ Id. at, 9; ORGANIZATION FOR ECONOMIC COOPERATION AND DEVELOPMENT, Practical Modalities of Peer Review in a Multilateral Framework on Competition, supra note 254 , at 7-8.

269 Organization of Economic Cooperation and Development, Peer Review Merits and Approaches, supra note 246, at 11-12; ORGANIZATION FOR ECONOMIC COOPERATION AND DEVELOPMENT, Practical Modalities of Peer Review in a Multilateral Framework on Competition, supra note 254 , at 7, 17-19.

270 Organization of Economic CoOperation And Development, Peer Review Merits and Approaches, supra note 246, at 11.

271 Organization for ECONOMic COOPERATION AND Development, Practical Modalities of Peer Review in a Multilateral Framework on Competition (2003), supra note 254, at 7, 20, 32.

272 Organization of ECONOMic Cooperation And Development, Peer Review Merits and Approaches, supra note 246 , at 6.

${ }^{273} \mathrm{Id}$.

$274 \mathrm{Id}$.

275 Blair COMLeY, Peer Review in the Context of Regional Integration Australian Government Treasury, http://www.treasury.gov.au/documents/1268/PDF/02_Peer_review.pdf. 
process of critical reflection on the specific factors that make a policy successful in a country aids in identifying and adapting practices across countries when attempting to converge policies in individual nations.

\section{B. Transparency}

Transparency is the buzzword heard in accountability and good governance discourse. Definitions of transparency vary, but in the context of peer reviews, transparency refers to the accessibility of the mechanism to outsiders. In other words, transparency involves making public the process, decisions and actions of the peer review body.

Transparency in peer reviews can be achieved in several ways because peer review mechanisms always involve reporting, interactive dialogue, and final outcomes. These phases in the process can be formulated to enhance the goal of peer review to be transparent, open and welcoming to public scrutiny.

The first way in which transparency is achieved is to make peer reviews open to the larger public either by permitting attendance at the reviews or by recording each session and making it available on the website of the organization. Transparency is also touted as a way to openly explain the decision-making process ${ }^{276}$ and to counter influence groups and lobbyists who may target member states for their own interests. ${ }^{277}$ Pagani notes that the country under review can "present and clarify national rules, practices and procedures and explain their rationale." 278 A third way to heighten transparency is to involve civil society groups in the peer review process. This can be achieved by permitting the submission of shadow reports or additional data during the review process. When non-governmental organizations and other civil society groups become part of the process, they also inform their networks of the inner working of the peer review. This publicity serves to increase awareness of the peer review process. A final way to broaden the visibility of a peer review mechanism is through the final report. The report should be available on the website of the international organization, thereby creating more information and insight into the national policy-making of the member state under review. ${ }^{279}$ In addition, a press conference or press release can be used to draw attention to the outcome of the peer review.

\section{Sharing Best Practices}

The member states who review another member state, in the context of international bodies and peer reviews, are expected to impart advice, develop source materials and exchange information regarding practices, laws and regulations. ${ }^{280}$ As member states dialogue with lead reviewers, the secretariat and other member states, those dialogues and exchanges result in sharing of best practices. The dialogue serves to educate the member under review, but the reviewers can also see from the inside how a member state approaches contact with civil society, legislators and policy-makers at the national level.

In the WTO environment, the value of peer review has been described as "an independent source of learning experiences with trade policy at all levels of development" 281 and as "exchanges of experiences on the approaches followed by competition authorities to anticompetitive practices with an impact on international trade, on the competition advocacy role of competition authorities and the review of sectoral exclusions." 282 In summary, the best practices can be aspired to by other states.

Best practices should also be viewed as a way to reward desired behavior. Again, peer review never seeks to sanction or punish. Therefore, the use of incentives is important. Member states will respond positively to praise. Peer review models that find ways to discover best practices in member states are more likely to find that member states want to engage in the process.

\footnotetext{
276 Organization of Economic Cooperation and Development, Peer Review Merits and Approaches, supra note 246 , at 7.

$277 \mathrm{Id}$. at 8.

278FABRIZIO PAGANI, Peer Review: A Tool for Co-operation and Change, supra note 241, at 21.

279 Organization of Economic CoOperation And Development, Peer Review Merits and Approaches, supra note 246, at 11-12.

${ }^{280} \mathrm{Id}$. at $6-12$.

${ }^{281} \mathrm{Id}$. at 8 .

${ }^{282} \mathrm{Id}$.
} 


\section{Regulation and Monitoring of Compliance/Examination of Policies}

All accountability mechanisms seek to check for compliance and implementation of treaties, policies or other obligations. In the context of peer reviews, we have noted in earlier discussions that sanctions and punishments are not the goals of peer review. Why, then, regulate compliance? First, peer reviews can "detect possible breaches." 283 This refers to the use of peer review to prevent a breach or violation. During the examination, reviewers can guide the country under review away from practices or policies that do not comply with expected standards.

Secondly, the peer review process can also serve as a forum to discuss and explain concerns about obligations in a non-confrontation and "non-legalistic" manner. ${ }^{284}$ In this case, countries can be advised that it in their own best interest to implement certain policies. The emphasis is on reasoning with countries to see why policies benefit their nation, rather than on punishment when the country does not implement a policy.

A third reason that compliance should be regulated is to pressure the country to seek national implementation of policies. Peer pressure, rather than sanctions, can be an effective way to ensure that the state under review to complies with its obligations. ${ }^{285}$

\section{E. Improvement of National Policy-Making}

Peer review encourages states under review to rethink national policy. In the OECD (and other) peer review models, the Secretariat plays a role in setting the agenda for the themes and issues that will be pursued during a peer review. This agenda-setting role is very important because it target policy areas for improvement.

As the state under review provides information, responds to questions and gathers information for the review, the state also takes stock of domestic policy formulation. ${ }^{286}$ Trade Policy Review Mechanism participants indicate " $[\mathrm{m}]$ embers have appreciated that such reviews help them take stock of their policies on the basis of independent objective assessment, have strengthened the hand of domestic agencies promoting liberalization and helped strengthen inter-agency discussion and co-operation in their own countries." 287

As states become immersed in a peer review, they are also learning valuable lessons about their own national agendas. They are also identifying strengths and weaknesses and looking for ways to rectify non-compliance. Interaction with the members from the Secretariat also permits them to find resolutions to identified problem areas.

\section{F. Capacity Building/Technical Assistance}

Many states lack the resources to comply with obligations. ${ }^{288}$ This is especially true in developing nations or in countries that are torn by ethnic conflict or war. During the review, these nations can be apprised of the assistance available to help them strengthen national institutions. The process can also explain policies, regulations or principles.

Technical assistance is important for even the most basic tasks. For example, it is not unusual for some nations to request assistance in the drafting of the national report. In such a case, the secretariat of an international

\footnotetext{
283 Organization for ECONOMic COOPERATION AND Development, Practical Modalities of Peer Review in a Multilateral Framework on Competition, supra note 254 , at 7.

${ }^{284}$ Organization of Economic Cooperation And Development, Peer Review Merits and Approaches, supra note 246, at 9.

${ }^{285} \mathrm{Id}$. at 10.

286 Id. at 9.

${ }^{287} \mathrm{Id}$.

${ }^{288}$ Even the process of review is time-consuming and costly for developing nations that may not have the necessary personnel and structure to respond to requests from reviewers.
} 
organization can send experts who assist in developing a plan to gather data from the governmental agencies and national institutions in order to assemble the national report.

Capacity building looks to develop the skills and expertise in local government to carry out the reporting duties. This can be done through training sessions, regular meetings and other on-the-ground education to enhance expertise.

\section{G. Information Gathering/Dissemination}

Information is often hard to come by. Having a mechanism that gathers information and publishes the information in one place is helpful for transparency and availability of data. The data is useful outside of the international organization and can be tapped into by researchers, policy-makers and civil society organizations.

The national reports that are often assembled prior to a peer review are invaluable sources of data. In many contexts, such technical information is not widely accessible. By requiring that a country respond to a questionnaire or survey or that the country prepare a report prior to a review, the international organization contributes to the available data regarding the situation on the ground in a country.

The data that is produced in the final report is also of value. This information can serve as evidence of a country's compliance with certain identifiable standards. The information is also useful for local civil society organizations to see how their country is faring in a specific policy area.

\section{Peer review in an historic context}

Peer review has been used as a tool to ensure the quality of research, writing and grant-making in academic settings. Although peer review is centuries old, it is still currently used in several fields on both the national and international level. Historically, peer review has been used by editorial boards in the scientific community (both in health care and experimental science) ${ }^{289}$ to evaluate the soundness of research and to uphold the integrity of scientific research used in journal articles and other publications. It has also been used in scientific grant-making. More recently, peer review has been adopted in regulatory and administrative contexts. Finally, the international community has also employed peer review as a means of evaluating performance and encouraging states to meet their obligations. This portion of the chapter will examine these four contexts for peer review.

\section{A. Scientific Research/Journals and Peer Review}

The use of peer review is not a new phenomenon, as noted earlier. In fact, peer review has been used in scientific and academic settings for at least three centuries. ${ }^{290}$ This is the case with scientific journals, where peer review is esteemed to be important in maintaining "integrity in scientific and scholarly communication." 291 Hence, Ruhl and Salzman have defined scientific peer review as:

a rigorous review and critique of a study's methods, results, and findings that is conducted by others in the relevant field who have the requisite training and expertise, who have no pecuniary or other disqualifying bias with respect to the topic, and who are independent of the persons who performed the study. ${ }^{292}$

Scientific journals have used a peer review process to determine whether a proposed article meets the standards of the scientific community since the early $1700 \mathrm{~s} .{ }^{293}$ The process begins when an article is submitted by the author to the editorial board of a scientific journal to be considered for publication in a future issue of the journal. The editor reads the article and makes a preliminary assessment of whether the article is worthy of

\footnotetext{
${ }^{289}$ WASHINGTON, supra note 257, at 445; LEHTONEN, Deliberative Democracy, supra note 244, at 189.

290 RUHL \& SALZMAN, supra note 70, at 10553; VIRELLI., supra note 70, at 732.

291 RUHL \& SALZMAN, supra note 70, at 10555, citing Lars Noah, Scientific "Republicanism": Expert Peer Review and the Quest for Regulatory Deliberation, 49 EMORY L.J. 1033, 1045 (2000).

292 Id. at 1055.

293 VIRELLI, supra note 70, at 732.
} 
publication. The article is then disseminated to a group of peer reviewers, who are experts in the field covered in the article. These peers are not known to the author; thus the term "blind" (anonymous) review process. During the peer review, the experts evaluate the scientific method used in the article and they consider whether the article makes a significant contribution to the field. ${ }^{294}$ The reviewers send back their assessment, with recommendations of various strengths to publish or not to publish, or to ask for revisions. ${ }^{295}$ Once the submission is screened and peer reviewers are satisfied that the article meets the high standards of the scientific community, the article is accepted for publication in the journal.

In journal editing, the nature of the peers is of great importance. Three characteristics are critical: peers must have the requisite expertise, must be independent and must not have a conflict of interest. ${ }^{296}$ Kanbur notes that scientific and academic peer review finds its longevity in the "notion of competence" of both the reviews and the editor. ${ }^{297}$ The journal editor is considered an authority in the field and the experts demonstrate their competence in the reports submitted after reviewing the submission.

While peer review in journal editing is still in use, in recent years, the use of peer review has come under siege. Lehtonen states that peer reviews in fields such as medicine and academic journal writing "have become threatened by the increasing use of performance measurement....298

\section{B. Peer Review and Grant-Making}

Peer review has also been widely used in grant-making decisions. Grants are the backbone of scientific research and the grant-making process is highly competitive. Therefore, grant-making institutions have become increasing sophisticated in their efforts to subsidize only those projects that are most likely to make an outstanding contribution to the field of science. Current practice by scientific grant institutions is to use independent experts to determine which grant proposals are worthy of financial support. ${ }^{299}$ During the process, the grant proposals are submitted to independent experts who evaluate the proposals and the research methods described therein. The proposals that have the best prospects are chosen for funding.

The main goal of peer review in grant-making is to guarantee the quality of the research, while fomenting collaboration among scientists. In both the grant-making and scientific journal contexts, peer review is a nonbinding, voluntary endeavor. Moreover, the review by independent experts looks at the article or the project's "novelty, methods, rationality, and contribution to scientific knowledge." 300 Peer review in this context does not pretend to detect fraud, nor does it seek to verify the accuracy of findings or data. ${ }^{301}$ As Washington notes, peer review operates on the "premise that, while scientific methods may vary within a particular field, there are accepted criteria to evaluate experiment design and data interpretation to sure impartiality; these criteria are best applied by other experts in the field." 302 Washington further notes that peer review can be evidenced, in the very minimum, by an "exchange of ideas and comments between researchers in the same laboratory" or in a more expansive sense by the bringing together of "experts and scientists from across the globe via conferences, scholarly colloquia, and academic journals." 303

\section{Administrative Peer Reviews}

Even as peer review was a trusted tool for legitimizing scientific research, it has also become a tool for national agencies to bolster policy decisions. These types of peer reviews are known as "administrative peer reviews." Administrative peer reviews involve governmental agencies and the use of science in policymaking. For

\footnotetext{
${ }^{294} I d$. at 734 .

295 J.B. RuHL \& SALZMAN, In Defense of Regulatory Peer Review, 84 WASH. U. L. REV. 1, 12 (2006).

${ }^{296}$ RuHL \& SAlzMAN, supra note 70 at 10555, citing Ann C. Weller, Editorial Peer Review: Its Strengths and Weaknesses 1-7 (2001).

${ }^{297}$ Kanbur, supra note 242 , at 5.

${ }^{298}$ LEHTONEN, Deliberative Democracy, supra note 244, at 189.

${ }^{299}$ VIRELLI, supra note 70 , at 733.

$300 \mathrm{Id}$. at 733,734 .

301 Id. at 734 .

302 WASHINGTON, supra note 257 , at 446.

${ }^{303} \mathrm{Id}$.
} 
example, if a national environmental protection agency chooses to ban a certain pesticide from use, it will want to have scientific evidence and reliable studies and reports to demonstrate that the banned pesticide is detrimental to the environment and/or to humans and animals. ${ }^{304}$ However, governmental agencies do not always possess the wherewithal or the know-how to properly assess the validity of studies and scientific evidence; therefore, administrative peer review serves as a check against unreliability and as a method of quality control.

Administrative peer review has many similarities to the peer review employed by grant-making institutions and scientific journals. For example, administrative peer reviews are non-binding and voluntary; the reviewers are independent experts; the review is limited to methods, not to the validity of the data. ${ }^{305}$ There are, however, several important distinctions between administrative peer review and the peer review used in journal and grantmaking.

The differences between administrative peer review and the peer review used in journals and grant-making is due, in part, to the differing goals of the two peer review processes. While traditional peer review for journals and grant-making seek to advance human knowledge, the administrative peer review process is designed to fill in the gaps in scientific knowledge relevant to a specific public policy issue. ${ }^{306}$ Administrative peer review assists policymakers in designing effective regulatory institutions rather than in determining whether a scientific study constitutes a valuable contribution to the field of science. ${ }^{307}$

\section{Peer Review in Global Governance Today}

The historical uses of peer review in the academic community and in administrative contexts bear very little resemblance to the way in which peer review is implemented in used in the international community. Indeed, the goals and purpose of peer review in international organizations is distinct from those of the scholarly journals and administrative peer review. In the global community, states have been using peer review in the OECD setting as well as in other international organizations such as the European Union and the Council of Europe. The predominant features of the international peer reviews can be described as follows: non-adversarial, highly reliant upon mutual trust among the States, a shared confidence by States in the process and the important role of the Secretariat in "supporting and stimulating the process." 308 Evaluations are reciprocal as States hold each other mutually accountable. ${ }^{309}$ Additionally, the peer reviews can cover a gamut of topics, themes and even principles:

An individual country peer review could relate to economics, governance, education, health, environment, energy or other policies and practices. Within one or more of those subject areas, a State may be examined against a wide range of standards and criteria, such as conformity with policy guidelines, or implementation of legally binding principles. Peer review can also be carried out thematically, where several countries are examined at the same time with respect to a particular theme. Peer review with regard to an individual State or thematically typically is carried out on a regular basis, with each review exercise resulting in a report that assesses accomplishments, spells out shortfalls and makes recommendations. ${ }^{310}$

International peer review often differs from other monitoring and supervisory techniques in the nature of its outcomes. Judicial proceedings are binding in their nature and are conducted by a higher organ or body. ${ }^{311}$ This is not the case with peer review. The outcomes of peer reviews may be non-binding and may lack sanctioning power, ${ }^{312}$ but they often combine other elements found in international supervisory mechanisms. For example, peer reviews may be coupled with a fact-finding mission carried out on-site by experts. ${ }^{313}$ Peer reviews may also

\footnotetext{
${ }^{304}$ VIRELLI, supra note, 70 at $725-729$.

${ }^{305} \mathrm{Id}$. at $734-735$.

${ }^{306} \mathrm{Id}$. at $736-740$.

307 Administrative peer reviews must differentiate between political considerations and scientific inputs. They are designed to assist policymakers, not academics and scientists. The final goal of an administrative peer review is to assess the scientific inputs into an administrative policy decision. VIRELLI, supra note 70, at 737-738.

${ }^{308}$ PAGANI, Peer Review: A Tool for Co-operation and Change, supra note 241, at 16.

${ }^{309} \mathrm{Id}$. at 5 .

${ }^{310} \mathrm{Id}$. at 5 .

${ }^{311} \mathrm{Id}$.

312 Id.

${ }^{313} \mathrm{Id}$.
} 
be conducted in a periodic reporting process. ${ }^{314}$ By combining peer review with on-site visits and periodic reporting, the overall surveillance mechanism is strengthened and takes on the aura of a judicial proceeding even as it remains a mechanism that operates on "soft persuasion."

In this portion of the chapter, we examine the peer review programs in the OECD, the Council of Europe, the European Union and the New Partnership for Africa's Development. The aim of this examination is to ascertain how peer review mechanisms are structured in international organizations. To do so, we will focus on three aspects: participants, process and product. ${ }^{315}$ By participants, we refer to the entities or individuals that take part in a peer review. The process refers to the phases and modalities of the peer review. Product refers to the outcome of the peer review process.

\section{A. Peer Review and the OECD}

Peer review has been the working method of choice of the Organization of Economic Co-operation and Development (OECD) since its formation in 1961. ${ }^{316}$ The OECD mandate is to promote economic growth and employment and to stimulate multilateral, non-discriminatory trade. ${ }^{317}$ The OECD does not use legal or financial pressure to bring about compliance with OECD standards; instead it uses "soft" procedures, also known as multilateral surveillance. ${ }^{318}$ Martin Marcussen emphasizes that the OECD was designed to "be a different body to its predecessor, the Organization for European Economic Cooperation (OEEC). Whereas the OEEC had supranational traits and was able to issue binding decisions with effects on its member countries, the OECD was designed to be a meeting place, primarily for national civil servants with a focus on dialogue among equals." 319

Though the OECD relies on soft law in governance, the organization has the capacity to produce "binding acts." ${ }^{20}$ Marcussen notes that, as of 2003, the OECD had a total of 188 acts in force and that 36 of those were binding. ${ }^{321}$ Those acts covered many areas, including agriculture, capital movements, employment and labor, steel and trade. ${ }^{322}$ However, the climate of tolerance for binding acts deteriorated, leading to the OECD's development of more soft governance and peer pressure mechanisms, particularly in the area of anti-bribery. ${ }^{323}$ Marcussen notes that the anti-bribery convention "stipulates that the parties shall work out a model for continuous monitoring and peer review in order to guarantee effective compliance." 324 In other words, even in the context of hard law (a treaty), the OECD "is relying primarily on 'soft' measures to enhance its efficiency. The organization has realized, as recommended by international law scholars in the 1990s, that dialogue and peer pressure and the threat of reputation loss and social exclusion are more effective and more desirable than legal enforcement." 325

The OECD promotes harmonization of economic policies by continuously reviewing member country's performance, leading to "frank and open exchanges, often resulting in recommendations for policy changes." 326 The OECD currently has four types of multilateral surveillance programs in place: Economic Surveys; Development Assistance Committee Peer Reviews; Environmental Performance Reviews and Country Review on

\footnotetext{
$314 \mathrm{Id}$.

315 These three elements are important to understand the process as a whole- the actors, the actual steps for the review and the outcome of the review.

316 SCHAFER, A New Form of Governance? supra note 253, at 73.

317 JeAn-H. GUILMETTE, MARTIN RUDNER, The OECD Approach and it Relevance to the Management of the Dnieper River Basin, The International Development Research Centre 2 (2000).

${ }^{18}$ NANNA KILDAL, Perspectives on Policy Transfer: The Case of the OECD, 8-9, http://www.ub.uib.no/elpub/rokkan/N/N13-03.pdf.

${ }^{319}$ MARCUSSEN, supra note 241, at 103.

320 Id. at $106-07$.

${ }^{321} \mathrm{Id}$. at 107.

$322 \mathrm{Id}$.

323 Id. at 111.

${ }^{324} I d$. at 112 (noting that the anti-bribery convention requires each signatory state to submit a progress report which is evaluated by the Working Group on Bribery in International Business. The working group meets every two months in Paris to review three to five countries. The meeting is closed to the public, but the final evaluation report is made public. Later, visiting teams of experts meet with "political and administrative authorities, with the police, the customs and with juridical authorities and other relevant bodies to discuss enforcement.") Id.

${ }^{325} \mathrm{Id}$. [citation omitted].

${ }^{326}$ GUILMETTE, supra note, 317 at 3.
} 
Regulatory Reform. ${ }^{327}$ For this inquiry, we will examine the process for the Economic Surveys, though the actors and the procedural steps are very similar across all monitoring and surveillance programs. ${ }^{328}$

\section{OECD Economic Surveys}

Economic Surveys are reports that describe economic developments, forecasts and trends on macroeconomic policy and structural policy in OECD member states. ${ }^{329}$ The OECD Secretariat plays an important role in the drafting of the Economic Surveys. The Secretariat is comprised of " 1,200 staff members, gathers statistical and policy information from member country government and processes it on a comparative basis, does analysis, formulates forecasts, manages policy reviews, organizes meetings, provides translation services, prepares directories and other reference materials, monitors agreement reach by member countries and publishes much of the analysis, forecasts and statistical information. Member country governments fund the work of the OECD Secretariat." 330

Marcussen describes the OECD staff as "well educated in their home countries and at various prestigious universities throughout the world." 331 He also mentions that they have written for scientific journals and participated in academic conferences both nationally and internationally. ${ }^{332}$ The Secretariat plays an important role in the review process in that it takes the lead by posing questions, making country visits, drafting the initial survey, and setting the agenda for the review. ${ }^{333}$ Finally, OECD country desk economists routinely make statements to the media and those statements garner reaction from "high-level politicians and central bankers." 334

The Economic Surveys promote a better understanding of a country's situation, enrich policy debate domestically and internationally and the issue policy recommendations to improve a country's economic performance. ${ }^{335}$ The surveys are conducted every year to year-and-a-half. ${ }^{336}$ The process has two main phases. The first phase - a bilateral phase - begins with the collection of data about the country which is based both on "office work and field missions." 337 A questionnaire is sent to the state and in which "national administrations inform the OECD staff about recent economic developments, their forecasts and the underlying assumptions." 338

Groenendijk explains that the questionnaires are sent to "officials from involved ministries, experts, key economic players... who are encouraged to provide written responses and relevant background material." 339 Marcussen states that the questionnaires are sent "with a view to steering the on-the-spot interview in the desired direction. ${ }^{340}$ Following the response to the questionnaire, the OECD Secretariat's staff visits the country to gather information and meet official from "key ministries, the central bank, social partners and scientific institutes to gain a better understanding of the host country." 341 Marcussen explains that the data collection phase typically ends in a list of "topics that should be objects of investigation in the survey." 342

\footnotetext{
recommendations during the evaluative phase." ) Id. at 113.

329 SCHAFER supra note 253 , at 73-74.

${ }^{330}$ GUILMETTE, supra note 317 , at 3.

${ }^{331}$ MARCUSSEN, supra note 241 , at 117.

$332 \mathrm{Id}$.

$333 \mathrm{Id}$.

$334 \mathrm{Id}$. at 118.

${ }^{335}$ GROENENDIJK, supra note 247, at 9 .

336 SCHAFER, supra note 253 , at 73.

${ }^{337}$ MARCUSSEN, supra note 241, at 116.

338 SCHAFER, supra note 253, at 73. MARCUSSEN, supra note 241, at 116.

${ }^{339}$ GROENENDIJK, supra note 247, at 9.

340 MARCUSSEN, supra note 241 , at 116 .

${ }^{341}$ SCHAFER, supra note 253 , at 74 .

${ }^{342}$ MARCUSSEN, supra note 241, at 116.
}

327 ORGANIZATION OF ECONOMIC CO-OPERATION AND DEVELOPMENT, Examples of Peer Review, OECD, at http://www.oecd.org/document/8/0,3746,en_21571361_37949547_37970056_1_1_1_1,00.html.

${ }^{328}$ MARCUSSEN, supra note 241 , at 113 (stating that, as of 2002, there were "69 monitoring and surveillance procedure distributed over twelve issues." Id. at 112-113. The procedural steps are basically the same: "the issuing of questionnaires and missions to the ocuntry under review during the preparatory phase; the drafting of a report during the analytical phase; and the collective assessment, discussion and adoption of 
The OECD staff prepares the initial draft of the Economic Survey which is made available on the OECDinternal OLIS database. ${ }^{343}$ The Economic Survey is based on the following general structure:

(1) assessment and recommendations: recent trends, prospects and macroeconomic policy requirements; (2) an overview of structural policy developments, key challenges and implementation of structural reforms; and (3) a country-specific special chapter (e.g. on public sector spending, aging, environmental sustainability) ${ }^{344}$

Armin Schafer's 2006 study of the OECD mentions a second country visit ${ }^{345}$ made by the OECD Secretariat's staff approximately three months after the first visit, with a view to address the "weaknesses and vulnerabilities" identified in the first draft of the Economic Survey. ${ }^{346}$ The second mission also differs from the first in that its mission is to engage the country under review in policy discussions with the OECD and national officials. ${ }^{347}$ This second country visit is not mentioned by Marcussen or Groenendijk.

The final draft of the Economic Survey is prepared and distributed to all member countries four weeks before the multilateral discussion before the Economic Development and Review Committee. ${ }^{348}$

The second phase of the process involves discussion within the Economic Development and Review Committee (EDRC). Groenendijk notes that the OECD appoints examiners using the following criteria:

Reciprocal relationship between examiners and members under review are not desirable

Two G7 countries must not examine each other;

For G7 countries and if possible also for other countries, one examining state should be from the EU and one from outside of the EU. 349

The examiners often serve several times as a review for a particular member country thereby permitting the examiner to "develop expertise in that country's economic situation and major policy issues." 350

The EDRC consists of representatives from all member states and the European Commission ${ }^{351}$ and, rather than the Secretariat of the OECD, is solely responsible for the publication of the Economic Survey. ${ }^{352}$ The EDRC scrutinizes "economic trends and policies in individual OECD countries, asses[es] the broad performance of each economy and make[s] policy recommendations." 353

Marcussen considers the EDRC to be "one of the most prestigious committees among the more than 200 committees, working parties and other subsidiary bodies that comprise the OECD structure." 354 The 30-member body consists of the economic counselors from the permanent delegations of OECD member countries. 355 The EDRC is convened "between 20 and 24 times a year to examine a draft survey produced by one of the country desks of the OECD secretariat. ...[T] permanent members of the committee, the chair, the two vice-chairs and a few OECD staff members are joined by a national delegation that travels to Paris to explain or defend the

${ }^{343} \mathrm{I} d$. (the EDRC members have access to the OLIS database.Id. at; SCHAFER, supra note 229 , at 74; ORGANIZATION FOR ECONOMIC CoOperation And Development, Practical Modalities of Peer Review in a Multilateral Framework on Competition (2003), supra note 254, at 27.

${ }^{344}$ SCHAFER, supra note 253, at 74, citing H. Nottage, Peer Review: Merits and Approaches in a Trade and Competition Context, OECD, 2002.

345 The OECD literature, dating to 2002 and 2003, does not reference a second country visit. Schafer's study is later (2006) and is based upon expert interviews. Therefore, this second visit may reflect a new phase introduced later in the process.

346 SCHAFER, A New Form of Governance? supra note 253, at 74.

${ }^{347} \mathrm{Id}$.

$348 \mathrm{Id}$.

349 GroenendiJ, supra note 247, at 9; OrGANIZATION FOR ECONOMIC COOPERATION AND DeVELOPMENT, Practical Modalities of Peer Review in a Multilateral Framework on Competition, supra note 254, at 28.

${ }^{350}$ Organization for ECONOMic CoOperation And Development, Practical Modalities of Peer Review in a Multilateral Framework on Competition, supra note 254, at 28 .

351 OECD, Peer Review in Economic Surveys: the Role of the EDRC, http://www.oecd.org/document/23/0,3746,en_21571361_37949547_37970135_1_1_1_1,00.html.

352 SCHAFER, supra note 253 , at 74 .

353 OECD, Peer Review in Economic Surveys: the Role of the EDRC, supra note 351.

${ }^{354}$ MARCUSSEN, supra note 241, at 115.

${ }^{355} \mathrm{Id}$. 
problematic issued raised by the draft country survey. The number of participants in these regular meetings can range from approximately 45 to well over $100 .{ }^{\prime \prime 356}$

The examination of a country is carried out by the EDRC and two examiners, 357 which can last for a half day or full day, commences with a statement by the government under review of its interpretation of the Economic Survey. ${ }^{358}$ This statement should:

provide a brief update on any major economic or policy developments since the draft Economic Survey was completed; and

identify any substantive points of disagreements with the draft Assessment and Recommendations and with the analysis presented in the main text. 359

The member countries' permanent delegations to the OECD participate, together with high-level government officials. ${ }^{360}$ Two reviewers question the government delegation then open the floor for general discussion by all members of the intergovernmental body. ${ }^{361}$ Groenendijk states that the "examiners prepare a 'Questions for Discussion Note' in which they identify key themes around which the discussion is organized." 362

The chair verbally draws the main conclusions for the policy issues and for changes to the draft Economic Survey. ${ }^{363}$ The process ends in a redrafting of the Economic Survey over the next days-- a process in which the country under review often fights to have the Assessment and Recommendations portion of the survey amended. ${ }^{364}$ The Secretariat and the country under review have bilateral talks in light of the chair's conclusions and must agree on changes to the text. ${ }^{365}$ The final draft must be agreed on by all EDRC members and is announced in a press conference; the countries are encouraged to resolve details within two weeks of the meeting. ${ }^{366}$

In the OECD's Economic Survey peer review, the main participants are the OECD Member States (non-OECD countries can also participate), the OECD Secretariat and the EDRC. The process involves country visits, production of a country report responding to themes raised in a questionnaire/survey, and an interactive review in which the country under review responds to questions from the lead reviewers and member states. The product of the peer review process is an Economic Survey made available to the public, which permits all to see a country's economic performance and compare that performance to other participating countries.

\section{B. GRECO: The Council of Europe's anti-corruption mechanism}

Upon the recommendation of the Committee of Ministers to "take measures against economic crime, including bribery", The Council of Europe (CoE) has led efforts to combat corruption, including, in 1999, the establishment a peer pressure mechanism to tackle the problem: GRECO, the Group of States Against Corruption. ${ }^{367}$ The Statute of GRECO states that the aim of the body is "to improve the capacity of its members to fight corruption by follow up, through a dynamic process of mutual evaluation and peer pressure, compliance

${ }^{356} \mathrm{Id}$.

357 GROENENDIJK, supra note 247, at 9.

358 SCHAFER, supra note 253 , at 74 .

359 OECD, Peer Review in Economic Surveys: the Role of the EDRC, supra note 351.

${ }^{360} \mathrm{Id}$.

361 SCHAFER, supra note 253, at 74.

362 GROENENDIJK, supra note 247, at 9; MARCUSSEN, supra note 241, at 116.

363 OECD, Peer Review in Economic Surveys: the Role of the EDRC, supra note 351.

364 SCHAFER, supra note 253, at 74-75.

365 OECD, Peer Review in Economic Surveys: the Role of the EDRC, supra note 351.

366 SCHAFER, A New Form of Governance? supra note 253, at 75-76; MARCUSSEN, supra note 241, at 116.

367 COUNCIL OF EUROPE, What is GRECO?, http://www.coe.int/t/dghl/monitoring/greco/general/3.\%20What\%20is\%20GRECO_en.asp. 
with their undertaking in this field." 368 Membership in GRECO is not limited to CoE states, but is open to states which participated in the process leading up to the Enlarged Partial Agreement ${ }^{369}$ or who have become a party to the Criminal or Civil Law Conventions on Corruption. ${ }^{370}$ Currently, there are 48 member states and United States of America who are participating in GRECO. ${ }^{371}$ The Member States appoint "two representatives who participate in GRECO plenary meetings" and give the names of experts who can participate in GRECO evaluations. ${ }^{372}$

Article 2 of the GRECO statute specifies that to achieve its aim, GRECO will monitor the "observance of the Guiding Principles for the Fight against Corruption" adopted on November 6, 1997 and the "implementation of international legal instruments to be adopted in pursuance of the Programme of Action against Corruption." 373 GRECO monitors its members in two ways: through and evaluation round in which it assesses the legislation of a member country and makes recommendations or observations for "legislative, institutional and practical reforms;" and through a compliance procedure in which it monitors the implementation of recommendations made during the evaluation round. ${ }^{374}$ We look at these two processes in turn. ${ }^{375}$

In accordance with Article 10 of the Statute of the GRECO, 376 the evaluation rounds are carried out periodically $y^{377}$ and are based on themes. ${ }^{378}$ For example, the first evaluation round (2000-2002) was centered around "independence, specialization and means of national bodies engaged in the prevention and fight against corruption" and the scope of immunities for public officials from arrest and prosecution. ${ }^{379}$ GRECO has held two other evaluation rounds since the first round and each has covered distinct topics. ${ }^{380}$ The fourth evaluation round is scheduled to begin in 2012. GRECO retains the authority to select the provisions for an evaluation round. ${ }^{381}$

The evaluation procedure is, according to the GRECO Rules of Procedure, "based on the principle of mutual evaluation and peer pressure." 382 During the evaluation round, a team of experts is appointed, pursuant to Article

\footnotetext{
368 Article 1, Statute of the GRECO, COUNCIL OF EUROPE, Statute of the GRECO, http://www.coe.int/t/dghl/monitoring/greco/documents/statute_en.asp.

369 Belarus, Canada, the Holy See, Japan, Mexico, the United States of America and Bosnia and Herzegovina participated in the elaboration of the Enlarged Partial Agreement. Article 4 (4) of the Statute of the GRECO permits the Committee of Ministers of the Council of Europe to invite non-Member states to join GRECO.

${ }^{370}$ Article 4, Statute of the GRECO, supra note 368;EUROPE, What is GRECO?, supra note 367.

${ }^{371} \mathrm{Id}$.

$372 \mathrm{Id}$.

${ }^{373}$ EUROPE, Statute of the GRECO, supra note 368.

374 COUNCIL OF EUROPE, How Does GRECO Work?,

http://www.coe.int/t/dghl/monitoring/greco/general/4.\%20How\%20does\%20GRECO\%20work_en.asp.

375 The modalities of the GRECO process are outlined in the Statute of the GRECO - Articles 10 to 16 - and elaborated in detail in the GRECO Rules of Procedure, Rules 22 through 37. EUROPE, Statute of the GRECO, supra note 368; COUNCIL OF EUROPE, GRECO Rules of Procedure, http://www.coe.int/t/dghl/monitoring/greco/documents/Greco(2010)9_RulesOfProcedure_EN.pdf.

376 Article 10 provides that "The evaluation shall be divided in rounds. An evaluation round is a period of time determined by the GRECO, during which an evaluation procedure shall be conducted to assess the compliance of members with selected provisions contained in the Guiding Principles and in other international legal instruments adopted in pursuance of the Programme of Action against Corruption." COUNCIL OF EUROPE, GRECO Rules of Procedure, supra note 375.

377 Rule 23(1) of the GRECO Rules of Procedure permit GRECO to "determine the length of each evaluation round." COUNCIL OF EUROPE, GRECO Rules of Procedure, supra note 375.

378 RICK LAWSON, How to Maintain and Improve Mutual Trust Amongst EU Member States in Police and Judicial Cooperation in Criminal Matters? Lessons from the Functioning of Monitoring Mechanisms in the Council of Europe 296 (Marlen Dane and Andre Klip, eds., 2009).

${ }^{379}$ EUROPE, How Does GRECO Work?, supra note 374.

380 As of August 2011, GRECO had conducted four evaluation rounds. The first evaluation round (2000-2002) dealt with the independence of national bodies to fight corruption. The second evaluation round (2003-2006) was based on seizure of corruption proceeds. The third evaluation round (2007-2010) focused on incriminations under the Criminal Law Convention on Corruption and transparency of party funding. EUROPE, What is GRECO?, supra note 367. In 2011, GRECO adopted the questionnaire for the fourth evaluation round, which looks at corruption prevention in respect of Members of Parliament, judges and prosecutors. The evaluation round will begin in 2012. COUNCIL OF EUROPE, GRECO Evaluations, http://www.coe.int/t/dghl/monitoring/greco/evaluations/index_en.asp.

381 Rule 23 (2) GRECO Rules of Procedure. GRECO Rules of Procedure, supra note 375.

382 Id.; Rule 22 (2), GRECO Rules of Procedure.COUNCIL OF EUROPE, GRECO Rules of Procedure, supra note 375.
} 
12 of the Statute of the GRECO,,383 to assess a member country based on written replies to questionnaires ${ }^{384}$ and information gathered during on-site visits and meetings with public officials and civil society, as envisioned in Article 13 of the Statute of the GRECO. ${ }^{385}$ The experts come from lists submitted by GRECO members. ${ }^{386} \mathrm{~A}$ total of three experts are chosen and one person from the Secretariat assists the team of experts. ${ }^{387}$ Country visits take place a minimum of three months following the receipt of a reply to the questionnaire and are generally no longer than four days in length; the visit is preceded by a "preparatory meeting" to exchange preliminary views and ends with a "final on-site meeting" to "discuss all outstanding issues." 388

A draft mutual evaluation report is written based on the questionnaire and country visit and is submitted to the country for comments. ${ }^{389}$ Rule 28 of the GRECO Rules of Procedure stipulates the content of the report and the contribution of the Secretariat and experts to the report. The mutual evaluation report consists of a "descriptive part, based on the reply to the questionnaire and other information gathered, and an analytical part, containing observations and recommendations and their motivation." 390 The Secretariat prepares the description and the experts provide the analysis for the mutual evaluation report, which is also subject to comments from the member state. ${ }^{391}$ GRECO considers and adopts the country report in a plenary debate that takes place within six months of the country visit and in which the member under review may submit observation orally or in writing. ${ }^{392}$

The plenary session begins with the evaluation team's verbal report and a general response by the country under review. ${ }^{393}$ The session can also be led by two representatives on GRECO who pose questions concerning the draft evaluation report, followed by the opportunity for all representative and experts in the evaluation team to question the member state. ${ }^{394}$ Professor Rick Lawson states that the "discussions in GRECO are said to be very lively and ... other countries may be actively involved." 395

\footnotetext{
383 Article 12 of the Statute of the GRECO provides that the team of experts "shall examine the replies given to the questionnaire and may request, where appropriate, additional information from the member undergoing the evaluation, to be submitted either orally or in writing." Article 12 (2) of the Statute of the GRECO, supra note 368; COUNCIL OF EUROPE, GRECO Rules of Procedure, supra note 375.

384 Article 11 of the Statute of the GRECO specifies that the body adopt a "questionnaire for each evaluation round, which shall be addressed to all members concerned by the evaluation." Article 11(1) of the Statute of the GRECO. The Article also directs members to address replies to the questionnaire to the Secretariat within the time frame fixed by the GRECO. Article 11(3) of the Statute of the GRECO, supra note 368; COUNCIL OF EUROPE, GRECO Rules of Procedure, supra note 375.

385 "The GRECO may instruct the team to visit a member, for the purpose of seeing additional information concerning its law or practice, which is useful for the evaluation." Article 13(1) of the Statute of the GRECO. GRECO must notify the country of a visit two months in advance. Article 13(2) of the Statute of the GRECO, supra note 368; COUNCIL OF EUROPE, GRECO Rules of Procedure, supra note 375.

${ }^{386}$ LAWSON, supra note 378, at 297 ("The experts (academics, practitioners, government officials and so on) are selected from lists submitted by each Member States. Although the experts are appointed by GRECO itself, it is the secretariat that tables a first proposal, taking into account the need to strike a geographical balance and to have a sound division of expertise; a team should not contain, for instance, two prosecutors. Experts will never be involved in the evaluation of their own country. For each evaluation round new lists of experts are complied, taking into account the substantive expertise that is required for that particular round.").

387 The selection process for the team of experts is found in Articles 10 and 12 of the Statute of the GRECO and Rules 25 and 26 of the GRECO Rules of Procedure. When a member country joins GRECO, it must submit a list of five experts (which can be modified). The team of experts for country visits is chosen by the Bureau (President, Vice President and five representatives of GRECO) from among the experts listed by the country. While three experts is the norm, additional scientists can be added to a team where justified. The member country under review has a say in which experts are chosen and if in disagreement, alternates can be proposed.

${ }^{388}$ Rule 27 (2), (4)-(6), GRECO Rules of Procedure. COUNCIL OF EUROPE, GRECO Rules of Procedure, supra note 375.

${ }^{389}$ EUROPE, How Does GRECO Work?, supra note 374; Art. 14, COUNCIL OF EUROPE, Statute of the GRECO; Rule 24, COUNCIL OF EUROPE, supra note 368, GRECO Rules of Procedure, supra note 375.

${ }^{390}$ Rule 28(1) GRECO Rules of Procedure, COUNCIL OF EUROPE, GRECO Rules of Procedure, supra note 375.

${ }^{391}$ Id.; Rule 28 (1)-(10). The rule imposes strict timetables for submission of draft mutual reports to the country under review and for the return of comments and submission of a final version prior to the plenary, COUNCIL OF EUROPE, GRECO Rules of Procedure, supra note 375.

392 EUROPE, How Does GRECO Work?, supra note 374; Article 15, Statute of the GRECO, supra note 368; Rule 29(1), GRECO Rules of Procedure, supra note 375 .

${ }^{393}$ Rule 19 (2) GRECO Rules of Procedure, supra note 375.

${ }^{394}$ Id., Rule 29(3)-(5), GRECO Rules of Procedure, supra note 375.

${ }^{395}$ LAWSON, supra note 378, at 298.
} 
The evaluation reports draw a conclusion as to whether a state's "legislation and practice comply - or do not comply- with the provisions under scrutiny. " 396 The reports also contain recommendations and observations. ${ }^{397}$ Recommendations "require action within 18 months" and observations are to be taken into account but do not require follow up in the subsequent compliance procedure. ${ }^{398}$ Article 15(5) of the Statute of the GRECO provides that the evaluation report is confidential. ${ }^{399}$ However, member states can request to make a report public and GRECO may adopt a summary of a report and make it public. ${ }^{400}$

The second phase of the GRECO monitoring procedure is the compliance procedure. 401 Eighteen months after the adoption of the country report during the evaluation process, the member under scrutiny submits a situation report, with supporting documents regarding the implementation of recommendations made during the evaluation process. ${ }^{402}$ GRECO reexamines within another 18 months in cases where states have not complied with recommendations. ${ }^{403}$ GRECO makes an overall conclusion on the implementation of recommendation.

In addition to the two phases explained above, GRECO has a special procedure to handle member states "whose response to GRECO's recommendations has been found to be globally unsatisfactory." 404 Rule 32 advises that non-compliance will be tempered by the principles of equality of treatment between GRECO members, a graduated approach and approval by the Plenary of any action taken for non-compliance. ${ }^{405}$ Non-compliance can result in any or all of the following:

- GRECO requiring the head of delegation of the non-complying member to provide a report or regular reports on its progress in implementing the relevant recommendations within a fixed time-frame;

- the President of GRECO sending a letter, with a copy to the President of the Statutory Committee, to the Head of Delegation concerned, drawing his/her attention to non-compliance with the relevant recommendations;

- GRECO inviting the President of the Statutory Committee to send a letter to the Permanent Representative to the Council of Europe of the member concerned, drawing his/her attention to noncompliance with the relevant recommendations;

- GRECO inviting the Secretary General of the Council of Europe to send a letter to the Minister of Foreign Affairs of the member State concerned, drawing his/her attention to non-compliance with the relevant recommendations;

- arranging a high-level mission (including the President and the Executive Secretary of GRECO, the Director General of Legal Affairs and selected Heads of delegation) to the non-complying member to reinforce this message;

\footnotetext{
396 Council of EUROPE, GRECO Evaluations, supra note 380.

397 Article 15(6) "The GRECO's report may contain recommendations addressed to the member undergoing the evaluation in order to improve its domestic laws and practices to combat corruption. The GRECO shall invite the member to report on the measure taken to follow these recommendations." Council of EUROPE, Statute of the GRECO, supra note 368.

398 Rule 30(2), GRECO Rules of Procedure, supra note 375. "In conformity with article15, paragraph 6, of the Statute members shall address to GRECO a situation report...indicating the measures taken to follow the recommendations in the evaluation report. GRECO will examine these reports and decide whether or not the recommendations have been complied with."

${ }^{399}$ EUROPE, Statute of the GRECO. Article 16 permits a public statement by the Statutory Committee if a member "remains passive or takes insufficient action in respect of the recommendations addressed to it." Articles 16 (1) and (2) of the Statute of the GRECO, supra note 368. See discussion of the compliance procedure for more details about the public statement.

400 Rule 34(2), GRECO Rules of Procedure, supra note 375.

${ }^{401}$ Information regarding the compliance report differs, according to the source that you use. The GRECO Rules of Procedure indicate that the report originates from two members chosen by the Bureau to determine if a member is in compliance with recommendations from the mutual evaluation report. See Rule 31(1) revised. The website of the Council of Europe describes the process differently, stating that the member state self reports regarding compliance. Rule 31 revised also speaks of adoption of the compliance report in a plenary session, while no such plenary is mentioned on the website description.

402 EUROPE, GRECO Evaluations, supra note 380.

${ }^{403} \mathrm{Id}$.

${ }^{404} \mathrm{Id}$.

405 Rule 32(1), GRECO Rules of Procedure, supra note 375.
} 
- $\quad$ in the context of the application of Article 16 of the Statute, bringing the matter before the Statutory Committee. ${ }^{406}$

The GRECO has an additional tool in its arsenal to combat non-compliance: the public statement. Article 16 permits a public statement by the Statutory Committee if a member "remains passive or takes insufficient action in respect of the recommendations addressed to it." 407

GRECO's participants are the 48 Member States plus the United States of America. The process takes places in two stages in which the member state is first evaluated and given a set of recommendations that must be implemented. After 18 months a second phase determines whether the implementation is satisfactory. There are also procedures for countering states that have not properly implemented recommendations. The product of the GRECO process is the evaluation report.

\section{Peer Review in the European Union: The Open Method of Coordination}

The European Union also employs peer review as a way of sharing best practices and harmonizing policies among the EU Member States. ${ }^{408}$ The formal launch of the peer review mechanism, referred to as the Open Method of Coordination (OMC) was at the Lisbon European Council in 2000, 409 when it was "introduced as a device to stimulate policy changes in the Member States without the EU using its powers to regulate or to control national implementation and without transferring powers from national or sub-national governments to the European level." 410 The soft governance tool - peer review - was considered the best "device for generating and spreading best practice and achieving greater convergence towards the EU's policy...." 411

The OMC, as alluded to in the Lisbon Presidency conclusion, would be used in many Council and Commission projects, including employment initiatives. ${ }^{412}$ The application of OMC differed in each context for which it was applied. ${ }^{413}$ In 2008, the European Commission - seeking to "respond effectively to today's economic and social challenges" 414 introduced another instrument in the area of social protection in which peer review would be employed to encourage mutual learning in the economic and social policies within EU Member States. The project, PROGRESS, adopts a novel form of peer review in which countries highlight their own successful programs and invite other countries to visit and observe the program, interact with host country stakeholders and experts, and discuss ways to transfer the knowledge to their own country. ${ }^{415}$

The modalities of the PROGRESS peer reviews begin with the host country choosing a topic or policy area that is worthy of sharing with other countries. (A list of potential policies for sharing is identified and disseminated by the European Commission. $)^{416}$ For example, in past years peer reviews have been organized around integration of immigrants into the labor market (Norway); social inclusion of children in rural

\footnotetext{
${ }^{406} \mathrm{Id}$. at Rule 32(2).

${ }^{407}$ Articles 16 (1) and (2) of the Statute of the GRECO, Council of EUROPE, Statute of the GRECO, supra note 368; See also Rule 33, GRECO Rules of Procedure, supra note 375.

${ }^{408}$ For scholarly discussions regarding the OMC as a policy tool, see generally, KERSTIN JACOBSSON, Between Deliberation and Discipline: Soft Governance in EU Employment Policy in ULRIKA MORTH (ed), Soft Law in Governance and Regulation: An Interdisciplinary Analysis (Edward Elgar 2004); ANDRE KLIP, ESTHER VERSLUIS \& JOSINE POLAK, Improving Mutual Trust Amongst European Union Member States in the Areas of Police and Judicial Cooperation in Criminal Matters, in An Additional Evaluation Mechanism in the Field of EU Judicial Cooperation in Criminal Matters to Strengthen Mutual Trust, MARLEn DANE \& ANDRE KLIP, eds. Celsus, 2009; Claudio M. RADAELli, The Open Method of Coordination: A New Governance Architecture for the European Union? Swedish Institute for European Policy Studies, 2003; CHARLES F. SABEL \& JONATHAN ZEITLIN, Learning from Difference: The New Architecture of Experimentalist Governance in the European Union, European Governance Papers (EUROGOV) No. 2-07-02, 2007.

${ }^{409}$ Lisbon European Council 23 and 24 March 2000 Presidency Conclusions. (2000).

${ }^{410}$ ARTHUR BENZ, Accountable Multilevel Governance by the Open Method of Coordination, 13 European Law Journal 506 (2007).

${ }^{411} \mathrm{Id}$. at 510 .

412 JACOBSSON, supra note 408 at $82-83$.

${ }^{413}$ Scholars describe the OMC process and modalities in different ways. See Benz, supra note 410, at 510 (discussing Trubek and Trubek, The Open Method of Coordination and the Debate over "Hard"and "Soft Law"); The Open Method of Coordination in Action (Zeitlin, Pochet and Magnusson, eds., 2005).

${ }^{414}$ EUROPEAN COMMISSION, Operational Guide - Peer Reviews, http://www.peer-review-social-inclusion.eu/peer-reviews.

${ }^{415} \mathrm{Id}$. at 3.

${ }^{416} \mathrm{Id}$. at 6.
} 
environments (Hungary); city strategies for combating unemployment and poverty (United Kingdom). ${ }^{417}$ Once the country identifies an area that can be shared with other nations, a discussion paper is drafted by a thematic expert (with the assistance and cooperation of the host country) from the support services team. ${ }^{418}$ The paper "presents the policy under consideration, commenting on its effects and operating conditions and focusing on evaluation results, bringing in European comparative aspects." 419 The host country should also prepare a paper to complement the discussion paper. ${ }^{420}$

Countries that are participating in the peer review must provide "comments and question" papers in response to the discussion paper and the host country's paper. ${ }^{421}$

A peer review seminar follows the exchange of papers. At the seminar, the host will present officials and policy experts and permit the thematic experts to present the discussion paper. ${ }^{422}$ The host country also permits peers to make local visits to "institutions active in the delivery of such policies, workshops, discussion with those responsible for local implementation, analysis of evaluation studies." 423 The participants discuss transferability of practices and also listed to presentations by European stakeholders. ${ }^{424}$

Following each peer review, the participants complete a questionnaire to evaluate "the results and methodological approach used." 425

In summary, the PROGRESS peer review participants are any EU member state, though some limited role is also played by the European Commission. The process involves the identification of a practice or policy worthy of sharing with other member states, the exchange of discussion papers and visits by other countries to a host country to view the policy in action. The product is the worship, discussion and visit in the host country.

\section{The African Peer Review Mechanism}

In 2001, the New Partnership for Africa's Development (NEPAD) began. ${ }^{426}$ Among NEPAD's missions is the creation of a mechanism to "ensure that the policies and practices of participating countries conform to the agreed values in the following four focus areas: democracy and political governance, economic governance, corporate governance and socio-economic development." ${ }^{427}$ Magnus Killander describes the peer review mechanism devised by NEPAD as "a process for assessing political, economic and corporate governance and socioeconomic development" with an aim to "prompt states to draft a national program of action to remedy identified governance deficiencies." ${ }^{2} 8$ Okezie Chukwumerije states that the APRM is designed to encourage members to create policies that reflect mutually agreed upon standards and to work toward greater transparency by requiring "public disclosure of government policies." 429

The African Peer Review Mechanism (APRM), under the auspices of the African Union, ${ }^{430}$ is managed and directed by the Panel of Eminent Persons, which is appointed by the committee of the Participating Heads of State

${ }^{417}$ EUROPEAN COMMISSION, Peer Review Social Inclusion, http://www.peer-review-social-inclusion.eu/peer-reviews

418 EUROPEAN COMMISSION, Operational Guide - Peer Reviews, supra note 414 at 7 . The support services team is comprised of consultants from firms in Austria, Luxembourg, the United Kingdom and Belgium selected through public tendering.

${ }^{419} \mathrm{Id}$. at 7.

${ }^{420} \mathrm{Id}$.

${ }^{421} \mathrm{Id}$.

$422 \mathrm{Id}$.

${ }^{423} \mathrm{Id}$.

${ }^{424} \mathrm{Id}$. The European stakeholders are representatives of two European NGOs or other stakeholder organisations and if appropriate one or two representatives of national stakeholder expressing the viewpoints of the beneficiaries or other important actors involved. Id at 9.

${ }^{425} \mathrm{Id}$.

${ }^{426}$ African PeEr Review Mechanism, The New Partnership for Africa's Development(2011),

http://www.nepad.org/economicandcorporategovernance/african-peer-review-mechanism/about. .

${ }^{427} \mathrm{Id}$.

428 Id.; KILLANDER, supra note 242, at 41.

${ }^{429}$ OKeZIE CHUKWUMERIJe, Peer Review and the Promotion of Good Governance in Africa, 32 North Carolina Journal of International Law and Commercial Regulation, 73 (2006).

${ }^{430}$ KILLANDER, supra note 242, at 41. 
and Government, the supreme political authority of the APRM. ${ }^{431}$ Chukwumerije notes that the members of the panel are persons with a commitment to Pan-Africanism of high moral stature and with distinguished records in macro-economic policy, financial management and governance. ${ }^{432}$ The panel members "serve for terms of up to four years and retire by rotation" and are expected to ensure that the review process is credible and professional and that the countries under review receive the necessary assistance to improve governance and socio-economic development. 433

The peer review process begins by gathering information. The Secretariat ${ }^{434}$ sends a questionnaire to the country under review which is to be utilized as a self-assessment exercise to draw of a Plan of Action. ${ }^{435}$ Killander notes that, in practice, the way in which governments have approached the drafting of the action plan has varied. In some cases the countries have left the drafting to the government; in other cases, civil society groups have been permitted to lead the effort. 436 The Secretariat draws up an "issues paper," outlining the "challenges faced by the country under review." 437

During the country review mission, an APRM Review Team visits the country under review to meet with "the government, political entities such as the parliament and political parties, and civil society broadly construed." 438 The review team must "determine compliance with core commitments and ... suggest improvements" by examining the progress made by the country in "implementing the Declaration" and by identifying weaknesses in governance. ${ }^{439}$ The meetings with civil society and stakeholders should enable the team to outline the steps that need to be taken to tackle the issues and challenges facing the country under review. ${ }^{440}$

Following the country visit, a report is prepared and discussed with the government and any responses from the government are attached to the report. ${ }^{441}$ Killander described the content of the country review report as follows:

The reports set out a summary of the self-assessment followed by the findings of the country review mission and the Panel's recommendations. However, sometimes the distinction between what has been included in the self-assessment and what the mission has found is not clear. ${ }^{442}$

The report is reviewed by the Participating Heads of State and Government. ${ }^{443}$ The information in the report cannot be amended, unless it is a clear factual error. ${ }^{44}$ "The final report is, in fact, the program of action to be implemented by the government. ${ }^{445}$ The report must "state what resources are needed for the effective implementation of the corrective measures... and contain specific measures to address the shortcomings" which are included in the country's programme of action. ${ }^{446}$ The assumption is, however, that participating countries will assist the country under review in implementing corrective measures. ${ }^{447}$

If the country under review is willing to "rectify the shortcomings" then participating governments must come to its aid, but if there is no political will on the part of the country under review to engage in constructive

\footnotetext{
${ }^{431}$ AFRICAN PEER REVIEW MECHANISM, supra note 426.

${ }^{432}$ CHUKWUMERIJE, supra note 429 , at 80 .

${ }^{433} \mathrm{Id}$. at 81.

${ }^{434}$ For a description of the Secretariat's role, see Chukwumerije, supra note 429 , at 83-4.

435 KILLANDER, supra note 242 , at 48.

${ }^{436}$ KILLANDER, supra note 242, at 48,49,50. (self-assessment by Ghana, Rwanda, South Africa, Algeria and Benin).

${ }^{437}$ CHUKWUMERIJE, supra note 429 , at 84 .

${ }^{438}$ KILLANDER, supra note 242, at 50 (delegations have included APRM and NEPAD Secretariat members as well as partner institutions such as the African Development Bank, the UN Development Program and the UN Economic Commission for Africa).

${ }^{439}$ CHUKWUMERIJE, supra note 429 , at 81.

${ }^{440} \mathrm{Id}$. at 85 .

${ }^{441}$ KILLANDER, supra note 242 , at 51 .

${ }^{442} \mathrm{Id}$.

${ }^{443}$ KILLANDER, supra note 242 , at 52-53.

${ }^{444}$ KILLANDER, supra note 242 , at 51 .

${ }_{445} \mathrm{Id}$. at 52.

${ }^{446}$ CHUKWUMERIJE, supra note 429 , at 86 . The report must also have specific time frames for implementation.

${ }^{447} \mathrm{Id}$.
} 
dialogue, then the Participating Heads of State and Government may put the country on notice of their "intention to proceed with appropriate measures." 448 The final report (program of action) is published in regional and subregional institutions ${ }^{449}$ and is also available on the NEPAD website..$^{450}$

In summary, in the APRM, the participants are the member countries, the Panel of Eminent Persons, and the Secretariat. The process involves state reporting, a review and recommendations to be implemented by the state under review. The product is the final report with the program of action for the nation under review.

This inquiry has examined the OECD, GRECO, OMC and APRM. These peer review mechanisms have similar structures, participants, processes and products. Therefore, the following section will explore how a typical peer review mechanism is structured.

\section{Structure of Peer Review Mechanisms}

In this last portion of this chapter, we examine the way in which peer reviews are structured. The processes examined earlier, show a pattern of how peer reviews are generally carried out in international organizations. We see that the process usually involves a secretariat, member states and reviewers. The process is divided into three main phases: information gathering, review and final outcome with recommendations to be implemented by the state under review. Each feature is examined below.

\section{A. Participation}

The first consideration in structuring a peer review mechanism is who the participants will be. In international organizations, this choice is not as simple as it first appears. While it is evident that the member states will participate in the process, it is not always as clear that the other participants will be. In most cases, the secretariat of the international organization will provide administrative assistance. Generally, the states themselves examine each other regardless of the level of expertise of the individuals taking part.

\section{Member States}

The Member States are those countries whose policies, legislation, actions and behavior are under scrutiny. Member States are usually countries who have acceded to a treaty or who have joined the international organization and undertaken to uphold specified standards, benchmarks, indicators or norms. ${ }^{451}$

One of the basic questions regarding participation is whether the participation in the review mechanism is voluntary or compulsory for the Member States of the international organization. This differs from organization to organization. For example, the IMF Country Surveillance program, discussed in the previous chapter is a compulsory process. All 184 Member States must be reviewed annually. ${ }^{452}$ In contrast, the OECD Competition Policy Reviews are voluntary. Those reviews are carried out each year regarding the "adequacy of basic legislation, enforcement structures and practices human and financial resources, legislative and regulatory exclusions and advocacy function." 453

\section{Secretariat}

Most, if not all, international peer review mechanisms use the services of the secretariat of the international organization. The secretariat is "an office or group of people responsible for the management of the international

\footnotetext{
${ }^{448}$ AfriCAN PEER REvIEW MECHANISM, APRM Stages, http://www.uneca.org/aprm/APRMStages.asp

${ }^{449}$ Chukwumerije identifies the summit of the African Union, the Pan African Parliament, the African Commission on Human and Peoples' Rights, the Peace and Security Council and the Economic, Social and Cultural Council of the African Union as the key regional and subregional groups. CHUKWUMERIJE, supra note, 429 at 87.

450 KILLANDER, supra note 242, at 53.

${ }^{451}$ Organization for ECONOMic Cooperation And Development, Practical Modalities of Peer Review in a Multilateral Framework on Competition, supra note 254 , at 8 .

${ }^{452} I d$. at 19.

${ }^{453} \mathrm{Id}$.
} 
organization under whose auspices the peer review takes place." 454 The role of the secretariat runs the gamut from organizing meetings to producing reports or materials for the substantive review of a Member State. ${ }^{455}$ The secretariat may "produce documentation and analysis" or arrange missions to the country under review. 456 Because of the way in which Secretariats are structured, the officials tend to have gained a certain amount of expertise in the subject and they have access to practices and policies from all member states. This gives the added advantage of being able to transfer knowledge and recognize weaknesses and signs of potential violations.

\section{Examiners}

The parties that carry out a review, the examiners or reviewers, differ from one peer review mechanism to the next. It is in this context that one of the most important questions can be raised. Who is in your peer group? In other words, if an international organization is examining a member state, then who is the peer of the member state? Is it another member state? Is it a group of diplomatic delegates? Are experts in the subject matter under review also peers? Can civil society members be peers?

Regarding examiners, the OECD peer review mechanisms provide interesting paradigms for peer review. First, in many of the OECD peer mechanism, the peer group is not a homogeneous group. Instead the mechanisms have a mix of diplomatic representatives, experts and others. The OECD's Economic and Development Review Committee (EDRC) "conducts an Economic Survey...of each of the 30 OECD member countries every 12 to 18 months." 457 The Economic Survey is carried out by examiners who are appointed by the EDRC. Members are appointed with specific criteria:

[T]here should be no reciprocal relationship between examiners and members under review;

two G7 countries should not examine the same member...; and

for G7 member examinations, and as far as possible in other cases, one examiner should be from and EU country and one from a non-EU country. 458

At first glance, these surveys do not seem to require the members of the reviewing member state to have an expertise in the subject matter. However, examiners will review one member country several times, thereby becoming an "expert in that country's economic situation and major policy issues. " ${ }^{59}$

One additional example is the IMF Country Surveillance Mechanism. In this mechanism, the examining peer group is the Executive Board. ${ }^{460}$ The Executive Board is the permanent decision-making organ of the IMF. ${ }^{461}$ The Executive Board consists of 24 members. ${ }^{462}$ Many of these members ${ }^{463}$ have experience and expertise in the banking and financial sector, both at the international and national level. 464

Many OECD peer review mechanism use a lead examiner. The lead examiner encourages dialogue during the examination stage and "helps to ensure a thorough examination" by making certain that "major topics will be

${ }^{454} \mathrm{Id}$

$455 \mathrm{Id}$. at 8 .

${ }^{456} \mathrm{Id}$.

${ }^{457} I d$. at 27.

${ }^{458} \mathrm{Id}$. at 28 .

${ }^{459} \mathrm{Id}$.

${ }^{460} \mathrm{Id}$. at 30 .

${ }^{461} \mathrm{Id}$.

$462 I d$.

463INTERNATIONAL MONETARY FUND, http://www.imf.org/external/np/sec/memdir/eds.aspx

${ }^{464}$ For example, board member Meg Lundsager, of the U.S. had formerly worked with the Treasury Department. http:/ / www.bicusa.org/en/Article.3232.aspx;

Former Board Member Age Bakker, of the Netherlands, was formerly financial markets director at De Nederlandse Bank (DNB) and teaching finance and banking at Free University of Amsterdam. http://www.nisnews.nl/public/240107_3.htm. 
taken up." 465 Two matters for consideration when using a lead examiner: should the lead examiner be appointed or selected? What should be the criteria for expertise?

\section{B. Process}

The peer review process consists of three stages. These stages are identified as: ${ }^{466}$

(1) Investigation

(2) Examination

(3) Dissemination

The following chart depicts and describes the three phases of a peer review:

\begin{tabular}{|c|c|c|}
\hline Phase and description & Actor & Role \\
\hline \multirow{3}{*}{$\begin{array}{l}\text { Goal: get an overall picture of the situation in the } \\
\text { state under review through information } \\
\text { gathering. Cooperation between the State under } \\
\text { review and the examiner and Secretariat. On-site } \\
\text { inspections, questionnaires or reports form the } \\
\text { basis for gathering the data. }\end{array}$} & $\begin{array}{l}\text { State under } \\
\text { review }\end{array}$ & $\begin{array}{l}\text { Produce a national report; respond to } \\
\text { questionnaires; answer questions; } \\
\text { collaborate with Secretariat; make } \\
\text { officials and agencies available for } \\
\text { inspection }\end{array}$ \\
\hline & Examiner & $\begin{array}{l}\text { Pose questions to State under review; } \\
\text { gather information from all sources } \\
\text { inside the state; begin report of the } \\
\text { situation }\end{array}$ \\
\hline & Secretariat & $\begin{array}{l}\text { Write report regarding situation in state } \\
\text { under review; assemble other reports, } \\
\text { data, etc. regarding the state under } \\
\text { review; conduct on-site inspections }\end{array}$ \\
\hline \multirow{2}{*}{$\begin{array}{l}\text { Interactive dialogue putting the member state } \\
\text { under review before the international body and } \\
\text { discussing the situation in the country and the } \\
\text { compliance with relevant regulations and } \\
\text { principles. Sometimes led by the examiner. }\end{array}$} & Examiner & $\begin{array}{l}\text { Leads the discussion and the reporting } \\
\text { about the situation in the state under } \\
\text { review }\end{array}$ \\
\hline & $\begin{array}{l}\text { State under } \\
\text { review }\end{array}$ & $\begin{array}{l}\text { Sometimes presents their own report; } \\
\text { responds to questions from members of } \\
\text { the body }\end{array}$ \\
\hline
\end{tabular}

${ }^{465}$ Organization For ECONOMIC COOPERATION AND Development, Practical Modalities of Peer Review in a Multilateral Framework on Competition (2003), supra note 254, at 13.

$466 \mathrm{Id}$. at 8 . 


\begin{tabular}{|c|c|c|}
\hline $\begin{array}{l}\text { DISSEMINATION } \\
\text { Distribution or publication of the final outc }\end{array}$ & Secretariat & $\begin{array}{l}\text { Prepares final report with outcomes } \\
\text { and recommendations; media contact; } \\
\text { posting on website }\end{array}$ \\
\hline contacts may also be made. & Examiner & Assists in preparation of final report \\
\hline
\end{tabular}

\section{Product}

Once the review is over, the final product of the review must be made available to the larger group and to the public. Often, the final product is the report adopted at the end of the review. But, the final product can also be a rating, score or ranking designed to show how the member state measures up to other member states. In addition, attention to the process can be brought through a press release or a press conference outlining the findings of the review.

In both OECD, GRECO and the APRM, the final report has a list of recommendations that must be implemented by the member state under review. These recommendations are often translated into national action plans by the state. The recommendation also leads to important new legislation, amendments to existing legislation or to the introduction of new initiatives in training, education or the like.

\section{Post-review}

This period is not always recognized as a formal part of the review process. However, following the dissemination of the final report several issues arise. Questions arise as to how the international organization will ensure that a member state is following the recommendations and/or responsibilities communicated in the final report. The follow-up can be in the form of written, voluntary government responses giving information about their own progress. The governments can also make verbal statements at subsequent meetings.

The peer review mechanisms in international organizations and supranational organizations show that peer reviews are often structured in a similar way. Peer review mechanisms begin with a preparatory phase where information is gathered and where the member state discloses the national situation with the reviewing states. The review often takes place during a time of interactive dialogue and exchange. A final report is written with outcomes and recommendations for the member states. The results of the review are disseminated to the member state and to the public at large.

\section{Conclusions}

This chapter has explored the peer review process as an accountability mechanism. We have seen that peer review differs from other types of accountability mechanisms in that it does not sanction or punish. To the contrary, peer review is non-confrontational and seeks to bring the member state into compliance by strengthening national policy-making, fine tuning regulations and giving technical assistance where necessary. During the peer review, the member state under review can openly admit weaknesses, disclose areas where national policy does not meet organizational objectives and share best practices where national practice is successfully meeting expectations.

The peer review mechanisms found in the OECD, Council of Europe, EU and NEPAD offer models of how peer review can change policy and harmonize practices across member states. What is common to each of these 
processes is that the review is carried out on the basis of a report issued by the state under review, that the report is often drafted by a Secretariat and serves as the basis for the review itself. The review is led by reviewers who pose questions about issues raised during the drafting of the report. During the review other member states are also invited to question the country under review. A final report is issued and made available to the public some weeks after the review. This report contains recommendations that must be implemented by the country. Many peer reviews also follow up to ensure that recommendations have been duly implemented by a country. 


\section{Chapter Five}

\section{Peer Review and Universal Periodic Review}

In the previous chapters of Part Two, we examined the concept and definition of accountability and we have identified accountability mechanisms. In addition, we have discovered that the Universal Periodic Review (UPR) mechanism is a peer review mechanism. We also know that the UPR is a non-judicial accountability mechanism.

This chapter will look at how the UPR is designed, its actors and its main phases. ${ }^{467}$ We will also answer, in the second part of this chapter, the research sub-question: Does a peer review mechanism change the human rights discourse at the international level?

\section{Original conception: from peer review to periodic review}

The original concept of the universal periodic review was shaped by then Secretary-General Kofi Annan. Annan had expressed his vision in a speech which was later incorporated into an explanatory note. Annan believed that the new Human Rights Council should include a chamber of peer review that would "give expression to the principle that human rights are universal and indivisible." 468 Annan further explained his vision for the new procedure, stating:

Peer review would be a process whereby States voluntarily enter into discussion regarding human rights issues in their respective countries, and would be based on the obligations and responsibilities to promote and protect those rights arising under the Char[t]er and as given expression in the Universal Declaration of Human Rights.

Implementation of findings should be developed as a cooperative venture, with assistance given to States in developing their capacities. ${ }^{469}$

The explanatory note emphasized the need for a universally applicable review:

Crucial to peer review is the notion of universal scrutiny, that is, that the performance of all Member States in regard to all human rights commitments should be subject to assessment by other States. The peer review would help avoid, to the extent possible, the politicization and selectivity that are hallmarks of the Commission's existing system. It should touch upon the entire spectrum of human rights, namely, civil, political, economic, social and cultural rights. The Human Rights Council will need to ensure that it develops a system of peer review that is fair, transparent and workable, whereby States are reviewed against the same criteria. A fair system will require agreement on the quality and quantity of information used as the reference point for the review. In that regard, the Office of the High Commissioner could play a central role in compiling such information and ensuring a comprehensive and balanced approach to all human rights. The findings of the peer reviews of the Human Rights Council would help the international community better provide technical assistance and policy advice. Furthermore, it would help keep elected members accountable for their human rights commitments. ${ }^{470}$

What is evident from the explanatory note was that the notion of peer review was present from the early deliberations regarding the nature of the review mechanism. However, the use of the phrase "peer review" was not carried through to the final documents establishing the review mechanism. Instead, the phrase "periodic review" was preferred. Felice Gaer notes that in the drafting process for the reform proposals, there was an initial

\footnotetext{
${ }^{467}$ The ideas of peer review and periodic review were first posited by former UN Secretary-General Kofi Annan in April 2005 at the final Session of the Commission. In the end, the process was called periodic review and peer review was dropped. This inquiry will not trace the steps from ideation to realization; however it is important to note that the process was dominated by the desire to avoid the politicization that had occurred with the Commission and to ensure universality of application. In addition, Canada played a prominent role in establishing the structure and modalities of the mechanism. See Gaer, supra note 71, at 109-139; Addendum to 'In Larger Freedom,' Human Rights Council: Explanatory note bythe Secretary-General, 23 May 2005, Add.19 6 UN Doc A/59/2005/; ALSTON, supra note 21, at. 185-224.

${ }^{468}$ U.N. SECRETARY GeNERAL, In Larger Freedom: Towards Development, Security and Human Rights for All, Addendum, para. 6, U.N. Doc. A/59/2005/Add.1 (May 23, 2005).

${ }^{469} \mathrm{Id}$. at para. 7.

${ }^{470} \mathrm{Id}$. at para. 8.
} 
interchangeable use of "peer review" and "periodic review," but that by the end of the process "peer review" had fallen away. ${ }^{471}$

The notion of a peer review also enjoyed the support of the then High Commissioner for Human Rights, Louise Arbour, who stated in a letter:

It is essential that a new body find effective means to carry out its supervisory responsibilities, which will necessarily entail some system for measuring States' human rights obligations against their actual practice. The present system for country scrutiny in the Commission is, all agree, unsatisfactory. At the same time, there must be some system in place for considering the actual human rights situation in countries.

For this reason, I strongly support the proposal that country scrutiny be exercised through a system of peer review, whether in a new Human Rights Council or a reformed Commission on Human Rights. This system should be built on the principle of universal scrutiny, whereby all States submit to a review of law and practice concerning their human rights obligations. For such a system to be credible and gain the confidence of all, it will be essential that a fair and transparent method be developed to compile information upon which to base the peer review. As the Secretary-General has emphasized, a new Human Rights Council should also continue the practice of the Commission regarding access for non-governmental organizations and preserve the independent role of the special procedures. ${ }^{472}$

Canada circulated two non-papers describing peer review processes that could be used to examine the human rights records of UN member states. ${ }^{473}$ The April 2005 draft of the non-paper outlined two alternatives - one for a process that could be very rigorous with an expert assessment ${ }^{474}$ of the human rights situations in every country, responses to questionnaires or statements from states under review and another less rigorous process ${ }^{475}$ with an interactive dialogue in which challenges would be evoked and countries would respond to questions about those challenges. The papers also examined the advantages and disadvantages of each system. ${ }^{476}$ Both papers viewed the process as a peer review, but the second paper also recommended that the review take place on a periodic basis. ${ }^{477}$ The second paper revised the first non-paper to combine both ideas into one and emphasized that the process should not replace other UN human rights mechanisms, but should highlight implementation. ${ }^{478}$

Two other key initiatives influenced the development of the UPR and deserve a brief mention here. First, the Swiss government organized several consultations ${ }^{479}$ regarding the reforms, including a meeting in Lausanne in May 2005 at which the non-paper from Canada was on the agenda, as were topics regarding the new UN Human Rights Council and its modalities. ${ }^{480}$ Second, in December 2005, 27 ambassadors and diplomats assembled to study what peer review mechanism would look like. ${ }^{481}$ Three experts from other International Organizations the OECD, the ILO and the African Peer Review Mechanism addressed the participants and explained how peer review functioned in their respective organizations. ${ }^{482}$

\footnotetext{
${ }^{471}$ FELICE D. GAER, supra note 71, at 110-112.

472 U.N. SECRETARY GENERAL, In Larger Freedom: Towards Development, Security and Human Rights for All, Addendum, Letter dated 26 May 2005 from the Secretary-General to the President of the General Assembly, paras. 91, 92, U.N. Doc. A/59/2005/Add.1 (May 23, 2005).

${ }^{473}$ Human Rights Peer Review, Draft Concept and Options Paper, Prepared by Canada, April 29, 2005 at http://www.eyeontheun.org/assets/attachments/documents/human_rights_peer_review_canada.pdf; Human Rights Peer Review, Nonpaper Version \#2, Prepared by Canada July 6, 2005 at

http://www.eyeontheun.org/assets/attachments/documents/hr_peer_review_mechanism_canada.pdf

${ }_{474}$ Model A: The Comprehensive Approach, suggested a full review by experts who later questioned the country under review regarding the information gathered. April Non-Paper, supra note _, at 2-3.

475 Model B: The Interactive Dialogue. Id. at 3-4.

${ }^{476} \mathrm{Id}$. at 4 . July Non-Paper, supra note 449 at 3.

477 July Non-Paper, supra note 476 at 4.

$478 \mathrm{Id}$. at 2-4.

479 Informal Consultations on the Human Rights Council, Oct. 11, 2005, at

http://www.eda.admin.ch/etc/medialib/downloads/edazen/topics/intorg/un/missny/60/ga.Par.0021.File.tmp/CH\%20Intervention\%20H RC\%201110\%20final.pdf

${ }^{480}$ Report of the Workshop on the Reforms of the UN Human Rights Mechanisms, May 2, 2005 at

http://www.eda.admin.ch/etc/medialib/downloads/edazen/topics/intorg/un/missny/59/misc.Par.0002.File.tmp/050502-EN.pdf

481 Peer Review and State Performance in the new Human Rights Council: Building New Compliance Mechanisms, Dec. 7, 2005 at

http://www.eyeontheun.org/assets/attachments/documents/peer_review_and_state_performance_in_the_new_hr_council.pdf

$482 \mathrm{Id}$.
} 
In the final analysis, the words peer review would not be included in the documentation describing the modalities and purpose of the mechanism, the phrase "periodic review" was adopted and the process would combine the elements proposed in the Canadian non-paper. The process that brought about the final mechanism was collaborative and involved intense negotiation regarding the language of the founding documents and the main phases of the review process. The process would include both a preparatory phase with extensive consultations with civil society, an interactive dialogue in Geneva and a time to identify recommendations to improve human rights and to implement the same.

\section{The mission of the UPR}

The founding resolution of the Council and subsequent Council resolutions give a clear purpose for the UPR. Its mission is to periodically review the full human rights situation of all UN Member States. In addition, reviews are to be conducted in an environment of objectivity and non-selectivity, where double standards and politicization are unwelcome. This portion of the chapter examines the legal basis for UPR reviews, the three phases of the UPR process and the post-review arrangements.

\section{A. Founding Resolutions}

Resolution 60/251 mandated the Council to:

Undertake a universal periodic review, based on objective and reliable information, of the fulfillment by each States of its human rights obligations and commitments in a manner which ensure universality of coverage and equal treatment with respect to all States; the review shall be a cooperative mechanism, based on an interactive dialogue, with the full involvement of the country concerned and with consideration given to its capacity-building needs; such a mechanism shall complement and not duplicate the work of treaty bodies. ${ }^{483}$

Thus, according to the resolution, the UPR was to be set apart from the treaty body and special procedures mechanisms in two very important aspects. First, it would consider the totality of human rights situations. In that sense, its mandate would cover all human rights obligations undertaken by a State thereby exceeding the treaty body mandates which cover only the subject matter of the treaty in question. ${ }^{484}$ Secondly, the review was to be cooperative in nature and take the form of an interactive dialogue. This second requirement appears to have been a response to the politicized atmosphere that had grown up around the debates in the old Commission; the UPR was designed to transcend such politicization by being cooperative in nature and requiring an interactive dialogue rather than a closed process where the state would have no say in the outcome. In summary, the mandate would forge new ground for the participants in that it permitted a broad discussion on the ensemble of human rights obligations, whether voluntary or binding in nature.

\section{Resolution 5/1 further required the UPR to}

(a) Promote the universality, interdependence, indivisibility and interrelatedness of all human rights;

(b) Be a cooperative mechanism based on objective and reliable information and on interactive dialogue;

(c) Ensure universal coverage and equal treatment of all States;

(d) Be an intergovernmental process, United Nations Member-driven and action-oriented;

(e)Fully involve the country under review;

(f) Complement and not duplicate other human rights mechanisms, thus representing an added value; manner;

(g) Be conducted in an objective, transparent, non-selective, constructive, non-confrontational and non-politicized

(h) Not be overly burdensome to the concerned State or to the agenda of the Council;

483 UNGA Res 60/251, 15 March 2006 9 5(e).

${ }^{484}$ GARETH SWEENEY \& YURI SAITO, An NGO Assessment of the New Mechanisms of the UN Human Rights Council, 9 Human Rights Law Review, 206 (2009). 
(i) Not be overly long; it should be realistic and not absorb a disproportionate amount of time, human and financial resources;

(j) Not diminish the Council's capacity to respond to urgent human rights situations;

(k) Fully integrate a gender perspective;

(l) Without prejudice to the obligations contained in the elements provided for in the basis of review, take into account the level of development and specificities of countries;

(m) Ensure the participation of all relevant stakeholders, including non-governmental organizations and national human rights institutions, in accordance with General Assembly resolution 60/251 of 15 March 2006 and Economic and Social Council resolution 1996/31 of 25 July 1996, as well as any decisions that the Council may take in this regard. 485

\section{B. Objectives of the review}

The Council later adopted Resolution 5/1486 containing the detailed objectives, standards and modalities for the universal periodic review process. According to Resolution 5/1, the UPR had the following objectives:

(1) The improvement of the human rights situation on the ground;

(2) the fulfillment of the State's human rights obligations and commitments and assessment of positive developments and challenges faced by the state;

(3) the enhancement of the State's capacity and of technical assistance, in consultation with, and with the consent of, the State concerned;

(4) the sharing of best practice among States and other stakeholders;

(5) support for cooperation in the promotion and protection of human rights;

(6) the encouragement of full cooperation and engagement with the Council, other human rights bodies and the Office of the United Nations High Commissioner for Human Rights.487

\section{Standards for the review}

As noted above, the UPR distinguishes itself from the tasks of treaty bodies and special procedures in that it is mandated to consider the ensemble of human rights obligations of a member state. ${ }^{488}$ The basis for review of States, set forth in Resolution 5/1, includes the United Nations Charter, the UDHR, and the human rights instruments to which the State is party and "voluntary pledges and commitments made by States, including those undertaken when presenting their candidatures for election to the Human Rights Council." 489 The review also takes into account "applicable international humanitarian law." 490 The standards for review comprise, therefore, both hard and soft law, as well as binding and non-binding agreements and undertakings. ${ }^{491}$

\footnotetext{
${ }^{485}$ Human Rights Council Res. 5/1, Rep. of the Human Rights Council, 5th Sess., 11-18 June 2007, UN GAOR, 62nd Sess., Supp No. 53, A/62/53/, at 48 II I.B.1 (18 June 2007).

${ }^{486} I d$.

${ }^{487} I$ Id. at 9 I.B.2.4.

488 There has been considerable debate as to whether the UPR should replace the treaty bodies. See BERNAZ, Reforming the UN Human Rights Protection Procedures:,supra note 16 at 87 et seq.

${ }^{489}$ Human Rights Council Res. 5/1, Rep. of the Human Rights Council, 5th Sess., 11-18 June 2007, UN GAOR, 62nd Sess., Supp No. 53, A/62/53/, at 48 I.A (18 June 2007).

${ }^{490} I d$.

491 That the basis of review comprises both binding and non-binding obligations is also significant. Commentators have noted that this approach will strengthen the perception of human rights standards and norms as indivisible. See DOMINGUEZ REDONDO, supra note 71 at 726. Others have taken a dimmer view of the use of soft law standards. BERNAZ, Reforming the UN Human Rights Protection Procedures,supra note 16, at 79-84. Still others believe it will ensure a "universality of coverage" that is not envisioned under the treaty bodies. GAER, supra note 71, at 125 ; DOMINGUEZ REDONDO, supra note 71, at 725.
} 


\section{Periodicity and phases of the review}

At the inception of the UPR, the intention was to place each UN Member State under review once every four years. ${ }^{492}$ The review process can be divided into three main phases: (1) pre-review preparation of reports and national consultation; (2) report by and review of the country through an interactive dialogue (3) adoption of final report in a plenary session before the Council. ${ }^{493}$

This chart gives a visual picture of the UPR reporting cycle:

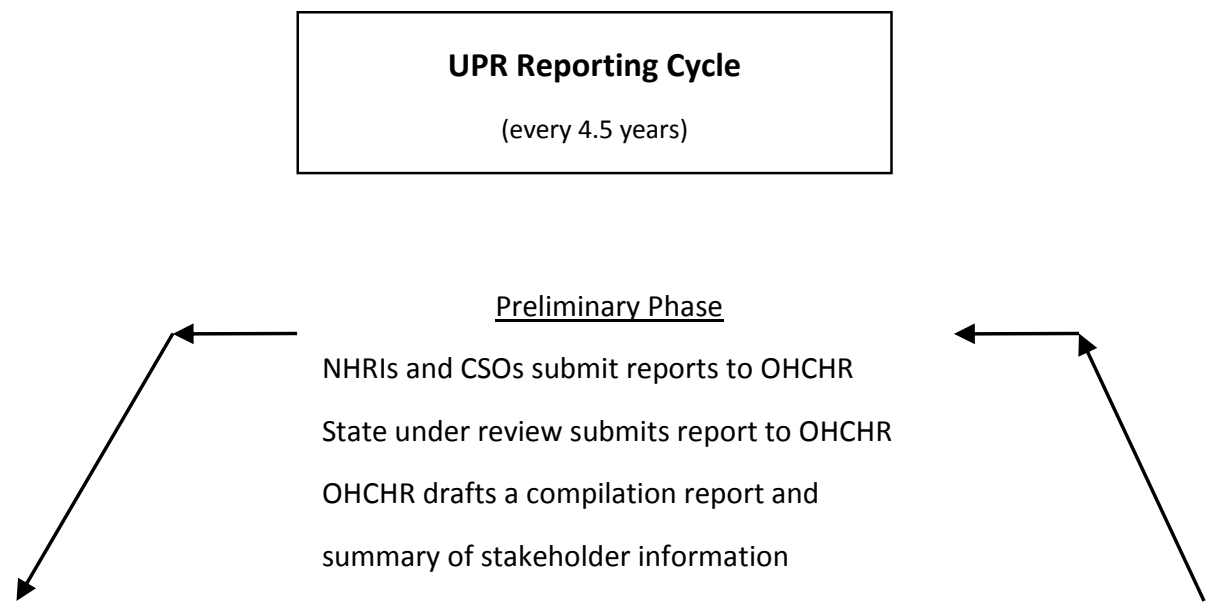

Interactive Dialogue (3 hours in Geneva)

State under review gives verbal report to Human Rights Council

Other states make comments, recommendations
Implementation (Interim between cycles)

States responsible for implementing accepted recommendations NHRIs pressure ministries to implement recommendations
Report of Working Group (48 hours after Interactive Dialogue)

All recommendations presented in written report by troika

Report adopted by Working Group of Human Rights Council
Final Outcome (Plenary Session of Human Rights Council)

State explains which recommendations it accepts or rejects

NHRIs and CSOs take the floor to make comments

FIGURE 4

\footnotetext{
${ }_{492}$ Resolution 5/1 provided for a four-year review cycle. Human In the most recent reforms, the cycle became four-and-a-half years. Human Rights Council, Decision 6/102 Follow-up to Human Rights Council resolution 5/1, ( 27 September 2007).

${ }^{493}$ Increasingly through the first four-year cycle, member states began to report on the measures taken to comply with UPR recommendations and outcomes. Although this was not envisioned in Resolution 5/1, it is evidence of a fourth phase in the review process: follow-up to the implementation of recommendations of the final report.
} 
There are three main reports produced during the pre-review period (preliminary phase):494 (1) a national report prepared by the State under review; 495 (2) a compilation submitted by the Office of the High Commissioner for Human Rights (OHCHR), not to exceed 10 pages; 496 and (3) a summary of other information provided by stakeholders and prepared by the OHCHR, not to exceed 10 pages. ${ }^{497}$ The reports form the basis for the review of the country during the interactive dialogue.

With respect to the national report, Resolution 5/1 specifies that the report must adhere to guidelines adopted by the Council and "any other information considered relevant by the State concerned." 498 The substance may be reported either orally or in writing. If provided in writing, the report must not exceed 20 pages. ${ }^{499}$ Finally, States are "encouraged to prepare the information through a broad consultation process at the national level with all relevant stakeholders." 500

The Council adopted some additional guidelines for the national report in Decision 6/102. 501 The six guidelines directed states under review to include the following information in their reports:

(1) A description of the methodology and "broad consultation process" followed to prepare the materials submitted;

(2) The "normative and institutional framework" for protecting human rights in the country, including the constitution, legislative and jurisprudential systems and human rights institutions;

(3) The situation of the "promotion and protection of human rights on the ground;"

(4) Identification of "achievements" and "constraints;"

(5) Initiatives and commitments to be undertaken by the country to overcome constraints and improve human rights;

(6) Requests for capacity-building and technical assistance; and

(7) Presentation of follow-up by the State. ${ }^{502}$

In practice, the pre-review period generally involves civil society mobilizing to draft reports to send to the $\mathrm{OHCHR}$ to be included in the OHCHR stakeholder summary. If the country has a national human rights institution (NHRI), the NHRI also mobilizes civil society and preparing its own report. Both civil society and the NHRIs generally interface with the government to see what the government expects to include in the national report. The interaction with the government is part of the national consultation which has taken on many forms in the domestic jurisdictions during the first cycle. The information gathered by the government in the national consultation(s) is used to draft the government's report.

\footnotetext{
${ }^{494}$ The content and format of the three reports is also specified in some detail by HRC Resolution 5/1. Resolution 5/1 also limits the OHCHR submissions to the "structure of the general guidelines" adopted by the Council and applicable to information submitted by the state under review. (These guidelines are set forth in HRC Decision 6/102.) All three reports are to be submitted six weeks prior to the review by the working group so that the documents can be made available in the six official languages of the UN.

${ }^{495}$ Human Rights Council Res. 5/1, Rep. of the Human Rights Council, 5th Sess., 11-18 June 2007, UN GAOR, 62nd Sess., Supp No. 53, A/62/53/, at 48 ๆ 15 (a) (18 June 2007).

${ }^{496}$ The OHCHR report compiles the information contained in the reports (including observations and comments by the state under review) of treaty bodies, special procedures and other UN documents. Like the national report, the OHCHR report is also subject to page restrictions (in this case, 10 pages).Id. at $\uparrow 15$ (b).

${ }^{497}$ This final document upon which a country is reviewed is the summary of "credible and reliable information provided by other relevant stakeholders to the universal periodic review." The same page strictures exist as are in place for the OHCHR report.. Id., para 15 (c).

${ }^{498}$ Human Rights Council Res. 5/1, Rep. of the Human Rights Council, 5th Sess., 11-18 June 2007, UN GAOR, 62nd Sess., Supp No. 53, A/62/53/, at 48 (18 June 2007).

${ }^{499} \mathrm{Id}$.

$500 \mathrm{Id}$.

${ }^{501}$ Human Rights Council, Decision 6/102 Follow-up to Human Rights Council resolution 5/1, ( 27 September 2007).

502 Id. at 9 ฯ I.A. - I.G.
} 
The OHCHR's process is also complex. The office has approximately 22 dedicated staff to the UPR process. 503 Other persons also assist to prepare reports in the field offices. The regular budget for direct staff is nearly five million dollars (out of a total budget of 75 million dollars.) ${ }^{504}$

\section{Review and interactive dialogue}

The preparations leading to the periodic review itself are facilitated by a group of three rapporteurs selected by lot from among the regional groups, known as the troika. ${ }^{505}$ The troika facilitates the interactive dialogue by collating issues and transmitting questions to the state under review. 506 (This group is equally responsible for the preparation of the report of the working group which eventually becomes the final report of the recommendations emanating from the review. ${ }^{507}$ ) The troika generally sits during the adoption of the working group report and presides over that 30-minute session.

The key event in the periodic review is the interactive dialogue, conducted in a working group chaired by the President of the Council and composed of the 47 member States of the Council over a period of three hours. The way in which the reviews have taken place has evolved over the first cycle and the Council has issued several additional directives to develop this very fluid process, including a statement by the President of the Council on April 9, 2008 indicating that member states wishing to address questions to the state under review must submit those questions to a troika state. In turn, the question would need to be transmitted to the OHCHR who would contact the state under review no more than ten (10) working days before the official review of the state before the Council. The president also indicated that for transparency reasons, any questions submitted to the state would also be made available to all members of the Council. Finally, the president acknowledged the sovereignty of states and their discretion in responding to questions submitted from peers. 508 The President of the Council made further remarks on April 9, 2008 to establish a structure for the three-hour interactive dialogue. The president stated that within the 60 minutes allotted to the state under review to present the human rights situation in its country, the state could opt to do any or all of the following: a) an initial presentation of the national report / responses to written questions; (b) reply to the questions raised from the floor during the interactive dialogue, if desired; or (c) make concluding comments at the end of the review, in an interactive dialogue under the guidance of the President. 509

Webcasts of the reviews of each member state are archived on the website of the OHCHR. The recommendations made by nations who speak during the interactive dialogue become part of the final report. The final report of the Working Group is adopted by the working group of the Council approximately two working days after the state's review. That session lasts approximately 30 minutes and his presided over by the troika.

\section{Adoption of the final outcome}

The Council adopts the final outcome approximately six months following the review of the country in a plenary session of the Council. The final outcome consists of a written report containing a "summary of the proceedings of the review process" as well as any "conclusions and/or recommendations, and the voluntary commitments of the States concerned." 510 The content of the outcome may include:

- an "objective and transparent" assessment of the human rights situation in the country under review including "positive developments" and "challenges;"

\footnotetext{
${ }^{503}$ Interview with Bacre Ndiaye, UPR Division, Office of the High Commissioner for Human Rights, March 17, 2012.

${ }^{504} \mathrm{Id}$.

505 Human Rights Council Res. 5/1, Rep. of the Human Rights Council, 5th Sess., 11-18 June 2007, UN GAOR, 62nd Sess., Supp No. 53, A/62/53/, at 48 I I.D.2.18 (d) (18 June 2007).

${ }^{506}$ Id. at 9 I.D.2.21

${ }^{507} \mathrm{Id}$.

${ }^{508}$ Human Rights Council, 8/PRST/1, Modalities and Practices for the Universal Periodic Review Process $₫$ ๆ 1-5, 7

<http://ap.ohchr.org/documents/E/HRC/p_s/A_HRC_PRST_8_1.pdf>

${ }^{509} \mathrm{Id}$. para. 7.

${ }^{510}$ Human Rights Council Res. 5/1, Rep. of the Human Rights Council, 5th Sess., 11-18 June 2007, UN GAOR, 62nd Sess., Supp No. 53, A/62/53/, at 48 I.E.1 (18 June 2007).
} 
- $\quad$ best practices;

- $\quad$ enhanced "cooperation for the promotion and protection of human rights;"

- provision of "technical assistance and capacity-building;"

- " $\quad$ voluntary commitments and pledges made by the country under review." 511

The country under review is entitled to full participation in the outcome and may present "replies to questions" and issues "not sufficiently addressed during the interactive dialogue." 512 Prior to the report's adoption, Member States of the Council, states with observer status are also eligible to participate, while "[o]ther relevant stakeholders" can make general comments before the report is adopted. ${ }^{513}$

One significant proviso for adoption of the report involves the ability of the country under review to indicate whether it is in agreement with the recommendations. ${ }^{514}$ Resolution $5 / 1$ envisions that the state under review will be able to have its comments recorded in the final report. In practice, the country under review often explains which recommendations it will accept, reject or take under advisement. 515

During the adoption of the final outcome, accredited members of non-governmental organizations and others who are given the right to observe the Council may address the Council regarding the report. The total time allotted to the adoption of the outcome is one hour.

\section{Implementation}

Resolution 5/1 identifies the state under review as the party primarily responsible for implementation of the outcomes of the review, states that subsequent reviews should build upon each other, and specifies that the Council must maintain a "standing item on its agenda" devoted to the UPR. ${ }^{516}$ The resolution also indicates that the international community will assist in capacity-building measures and technical assistance. ${ }^{517}$ While the follow-up measures are somewhat undefined, the resolution exhorts the Council to determine what measures should be taken for follow-up and to address "cases of persistent non-cooperation with the mechanism." 518

This portion of the chapter has described the mission and phases of the UPR. The mission of the UPR is best described as a forum where UN Member States consider the human rights records of peers and share best practices for human rights policies. Member States are responsible for identifying positive advances in human right and for revealing areas where human rights obligations are not met. In this latter goal, peers assist other Member States to address the deficiencies through policy diffusion and knowledge transfer, technical assistance and capacity building. The recommendations for addressing deficiencies are found in the final report of the country's periodic review. Implementation of the recommendations lies with the individual member state.

\section{E. Reforms and Modifications for the Second Cycle}

As the first cycle of reviews neared its end, the Council began to consider ways to reform the UPR mechanism. The following reforms were made, pursuant to Council Resolution 16/21:

(1) The periodicity for the reviews changed from four years to four and-a-half years;

(2) The order of review will be the same as in the first cycle;

${ }^{511} \mathrm{Id}$. at ๆ I.E.2 (1)-(e).

512 Id. at II I.E.3.28-29.

${ }^{513} \mathrm{Id}$. at II I.E.3.30-31.

${ }^{514} \mathrm{Id}$. at 9 I.E.3.3.2

${ }^{515}$ Each final report has a section for recommendations. That section is often further subdivided into categories that can include any and all of the following: recommendations which enjoy the support of the state under review, those which will be taken into consideration, those which the state believes it has already implemented, those which the state rejects. In addition, some states add voluntary commitments in this section. ${ }^{516}$ Human Rights Council Res. 5/1, Rep. of the Human Rights Council, 5th Sess., 11-18 June 2007, UN GAOR, 62nd Sess., Supp No. 53, A/62/53/ , at 48 ๆ I.F (18 June 2007).

517 Id. at 9 I.F.36.

${ }^{518} \mathrm{Id}$. at II.F. 37-38. 
(3) The second and subsequent cycles will focus on the implementation of the accepted recommendations and the developments of the human rights situation in the State under review;

(4) The OHCHR summary of stakeholder information will include a separate section for fully-accredited NHRI's contributions;

(5) NHRIs will have the right to intervene in the adoption of the final outcome in the plenary session before the Council, immediately following the state under review's intervention;

(6) The voluntary fund should be strengthened and become fully operational. 519

Resolution 17/119, designed to give further clarity to Resolution 16/21, provided that:

(1) The duration of the review be extended to three hours and thirty minutes, with up to 70 minutes for the State under review to present and respond to questions;

(2) The speaker list will be opened at 10 am at a registration desk within the Palais des Nations on Monday of the week preceding the beginning session of the Working Group and remain open for four days, closing on Thursday at 6 $\mathrm{pm}$;

(3) Speakers will speak in alphabetical order (by English name of the country);

(4) Three minutes will be allotted to Member States; two minutes to observer states, if time permits; if time does not permit, the speaking time is divided among all delegations on the list. ${ }^{520}$

\title{
II. Contributions to the UN Human Rights Machinery
}

The introduction of a peer review mechanism to the UN Human Rights machinery has also made positive contributions to the UN Human Rights machinery. Those contributions are found in the following areas: data gathering, national consultations, recommendations, and transparency.

\section{A. Data gathering}

When the UPR was introduced, it required states to submit a national report about human rights on the ground. In addition, other data regarding the state is compiled by the OHCHR for its summary of the states' performance in treaty bodies and special procedures, as well as in the field offices. The stakeholder summary also adds additional information regarding human rights in the domestic jurisdiction.

The importance of data gathering cannot be overstated. Scholar Martens and Jakobi note that "generating data regarding a country makes it possible to compare states and measure the success of national policy making." ${ }^{521}$ In addition, this author has written elsewhere that:

\begin{abstract}
Some examples of the progress that the UPR has brought in seeing the full picture of human rights are the cases of North Korea and Burma/Myanmar. These countries are known for their isolationist policies. Yet, to date, all nations have participated in the process, including those nations with reputations as outliers or pariahs. Both Burma/Myanmar and North Korea sent delegations to the UPR. While some rights groups may have expressed disappointment with the outcomes of their reviews, these two nations' delegations did respond to challenges and criticisms leveled at them during their respective reviews. In addition, following their reviews, we now have a picture of their overall situation regarding the respect for human rights in these otherwise closed societies.522
\end{abstract}

Prior to the UPR, there was no comprehensive reporting regarding the whole human rights picture in a country. The United States Department of State issues annual reports concerning human rights conditions in every nation, but those reports generally focus on religious freedoms, voting rights and other political and civil

\footnotetext{
${ }^{519} \mathrm{HRC}$ Res 16/21, ๆ ๆ 2-4, 6,9,11, 13-14 UN Doc A/HRC/RES/16/21, 21 March 2011.

${ }^{520}$ HRC Res 17/119, ๆ ๆ 3, 5-8 UN Doc /HRC/DEC/17/119, 17 June 2011.

${ }^{521}$ DE LA VEGA \& LEWIS, supra note 12 (citing Kerstin Martens et al., supra note 251 at 11-12 (explaining that the OECD generated quantitative datases to rank its members' performance in certain policy fields.)

${ }^{522} \mathrm{Id}$. at at 369 [citations omitted]
} 
rights. Amnesty International also issues reports that cover a broader range of rights than do the US Department of State reports; however, these reports are not designed to assess the broad range of human rights engagements of each country. Likewise, treaty body periodic reports are limited to a specific set of obligations. In contrast, the UPR reports are designed to cover the broad range of rights. In the national reports, countries discuss organization of powers in the nation, the constitutional guarantees for human rights and fundamental freedoms and the legal system. This information is important in understand the domestic structures in place to protect and defend fundamental rights. The reports are archived on the website of the OHCHR and are therefore available for consultation by citizens, media, civil society, governments and other interested parties.

\section{B. National consultations 523}

Perhaps one of the most innovative aspects of the UPR is its requirement that national governments consult with civil society about the state of human rights on the ground. This consultation has been taken to extraordinary levels in some nations. Denmark held two consultations on the mainland in which the Danish Institution for Human Rights recorded the civil society concerns on chart paper, explained the complaints orally and presented the information to government officials. In the United States of America, government officials were taken on site visits to witness mold and decay in housing projects in New York City. The national consultations have become a way of encouraging contact and dialogue between the government and its citizens and advocacy groups. It has also become a rallying point for national human rights institutions (NHRIs) which have found new ways to interface with civil society and government agencies. The national consultations have also raised awareness at the local level about the Geneva-based human rights machinery. More civil society groups are involved and expectations about changes on the ground are heightened.

Not all consultations were broad and participatory. For example, the Netherlands held consultations with some 30 civil society organizations, 524 but it was not perceived by all to be broad or consultative. 525 Haiti experienced an earthquake and later political turmoil dampened the spirit of the process, which did not benefit from the leadership or collaboration of an accredited NHRI. ${ }^{526}$ In Uganda, the civil society organizations felt unable to directly contact the national government regarding the progress of the national report, demonstrating the difficulties certain societies face in getting their voices heard in the national report. ${ }^{527}$

\section{Recommendations}

The final outcome documents for the UPR process include recommendations that may be accepted, taken under advisement or rejected by the state under review. While it is true that in some cases hundreds of recommendations have been made to specific countries, it is also true that the recommendations that have been made during the first cycle have called for improvements and action in specific areas of human rights within a country. This is a positive step, as it shows that states are willing to require other states to take measures to improve the human rights within their borders.

The final recommendations that have come out of the UPR process have often asked nations to explain what they are doing to implement treaty body of special procedures concerns. This is encouraging because it demonstrates a willingness to complement the other human rights machinery. In a similar vein, the recommendations always urge a country to ratify the core human rights instruments and their optional protocols. This again seems to be a positive step that will strengthen the existing human rights machinery.

\footnotetext{
${ }^{523}$ Part Three will fully elaborate on how national consultations have been carried out in Denmark and Kenya. In addition, the listening sessions of the United States of America will be discussed together with Amnesty International's participating in national consultations in the Netherlands and Hungary.

${ }^{524}$ Interview with Walter Oostelbos, Strategic Adviser Migration Policy Department, the Netherlands, April 6, 2012.

${ }^{525}$ Interview with Gerbrig Klos, AI Netherlands, April 24, 2012.

526 Interview with Florence Elie, Protectrice du Citoyen, Haiti, March 17, 2012.

527Interview with Official from Ugandan NGO, March 20, 2012.
} 
To illustrate the constructive nature of the recommendations coming out of the UPR, we can examine the following recommendations made to (and undertaken by) Timor Leste: 528

Ratify the Convention on the rights of Persons with Disabilities (Austria); 529

Implemented without delay and with the assistance of international cooperation, a broad strategy which complies with the Convention on the Elimination of All Forms of Discrimination against Women, aimed at modifying or eliminating practices and cultural stereotypes that are harmful and discriminate against women (Uruguay). ${ }^{530}$

During the seventh session of the UPR, held in February 2010, the number of recommendations that referred to one of the core treaties was made to each country under review, as evidenced by the following chart:531

\begin{tabular}{|l|c|c|}
\hline Country Name & $\begin{array}{c}\text { Number of Final Outcomes } \\
\text { Referring to Implementation of } \\
\text { a Treaty Body } \\
\text { Recommendation }\end{array}$ & Specific Treaty References532 \\
\hline Nicaragua & 16 & $\begin{array}{c}\text { ICESCR, CEDAW, CAT, } \\
\text { CRC, CRPD }\end{array}$ \\
\hline Italy & 8 & ICCPR, ICESCR, CAT, CRC \\
\hline Bosnia \& Herzegovina & 8 & CEDAW, OP-CAT, CRC \\
\hline Egypt & 12 & ICCPR, CEDAW, CAT \\
\hline Qatar & 11 & CEDAW, CAT, CRC \\
\hline Gambia & 20 & ICCPR, CEDAW, CRC \\
\hline Fiji & 1 & CRC \\
\hline Bolivia & 2 & ICERD, CEDAW \\
\hline Angola & 5 & CEDAW, CRC \\
\hline
\end{tabular}

${ }^{528}$ Report of the Working Group on the Universal Periodic Review Hungary, UN Doc A/HRC/18/17, 11 July 2011

${ }_{529}$ Report of the Working Group on the Universal Periodic Review Timor-Leste, 1 77.1 UN Doc A/HRC/19/17, 3 January 2012.

$530 \mathrm{Id}$. at $\mathbb{9} 77.18$.

${ }^{531}$ The information in this chart is based on the research of Nordwing Veszter (B.S./M.A. Criminal Justice, City University of New York, John Jay College of Criminal Justice), research assistant at the Maastricht University Faculty of Law, summer 2011. The chart is based solely on the sixteen states reviewed in the seventh session of the UPR in February 2010.

${ }^{532}$ Key to abbreviations in the chart: ICESCR - International Covenant on Economic, Social and Cultural Rights; ICCPR - the International Covenant on Civil and Political Rights; ICCPR-OP2 - ICCPR Optional Protocol 2; ICERD - the International Convention on the Elimination of All Forms of Racial Discrimination; CEDAW - the Convention on the Elimination of All Forms of Discrimination Against Women; CAT - the Convention Against Torture and Other Cruel, Inhuman and Degrading Treatment or Punishment; OP-CAT Optional Protocol to the CAT; CRC -the Convention on the Rights of the Child; CRC-OP - Optional Protocol to CRC; ICRMW - the International Convention on the Protection of the Rights of All Migrant Workers and Members of their Families; CRPD- the International Convention on the Protection and Promotion of the Rights and Dignity of Persons with Disabilities; CPED -the International Convention for the Protection of All Persons from Enforced Disappearance. 


\begin{tabular}{|c|c|c|}
\hline Madagascar & 9 & $\begin{array}{l}\text { ICERD, ICCPR, CEDAW, } \\
\text { CAT, CRC }\end{array}$ \\
\hline Kazakhstan & 12 & ICCPR, CAT, OP-CAT, CRC \\
\hline Iran & 24 & ICCPR, ICCPR-OP2, CRC \\
\hline Iraq & 6 & ICCPR, CEDAW, CRC \\
\hline El Salvador & 8 & $\begin{array}{l}\text { ICESCR, CEDAW, CAT, } \\
\text { CRC }\end{array}$ \\
\hline Slovenia & 9 & $\begin{array}{l}\text { ICERD, ICCPR, CEDAW, } \\
\text { CRC, OP-CRC }\end{array}$ \\
\hline San Marino & 4 & ICESCR \\
\hline
\end{tabular}

The recommendations also cover the breadth of human rights topics, from the most sensitive topics, such as torture, enforced disappearances, and sexual violence, to more modern-day concerns such as children's rights, sexual orientation, and human trafficking. Based on this fact, it appears that the first cycle has succeeded in being universal in nature, in that it covers the gamut of rights. In addition, these rights are raised in most of the reviews of the member states. 533

\section{Transparency}

The UPR is a very accessible mechanism. The OHCHR posts a calendar indicating when each country will be reviewed. The reviews can be seen live on the day of the review and are archived to be consulted at a later date by accessing the webcasts on the OHCHR webpages. All documents regarding the reviews are readily available to the public on the website of the OHCHR. Public press releases from the OHCHR tell the highlights of each review shortly after they are concluded.

Non-governmental organization and civil society groups have used the mechanism and the participation among these groups has been broadened as a result of the national consultations. ${ }^{534}$ In addition, in countries where civil society is active or where National Human Rights Institutions exist, awareness raising campaigns are carried out regarding the UPR process, the Geneva events and progress in the implementation of recommendations.

\section{Conclusion}

Part Two has examined the notion of accountability at the national and international levels. In addition, we have seen examples of accountability mechanisms at the domestic and global levels. The human rights machinery of the United Nations has many types of instruments available to monitor, supervise or otherwise hold states accountable for their human rights obligations. The UPR, however, is a unique mechanism that is based upon the principles of peer review and non-judicial accountability. The UPR is uniquely placed to assist nations to discover ways to approach the issues faced in the area of human rights. It is a non-confrontational discourse between nations, but at the national level, accountability holders shift to non-governmental organizations, civil society organizations and national human rights institutions. The UPR has made a contribution to the human rights machinery by introducing a mechanism that is transparent, gives constructive recommendations for improving

${ }_{533}$ See chart depicting the broad nature of subject matter covered in the recommendations, found in Part Four of this inquiry. ${ }^{534}$ DE LA VEGA \& LEWIS, supra note 12 at 276, note 91. 
human rights on the ground, while encouraging more interaction between governments and civil society in preparation for the review. 


\section{CASE STUDIES OF GOVERNMENTS, NATIONAL HUMAN RIGHTS INSTITUTIONS AND CIVIL SOCIETY ORGANIZATIONS IN THE UNIVERSAL PERIODIC REVIEW}

Parts One and Two have set forth the historical context of human rights monitoring and comparative aspects of international supervisory mechanisms as well as the elements of the UPR mechanism as they exist in theory. This Part Three will demonstrate the UPR in practice. At the writing of this dissertation, the UPR has completed the first four-year cycle and has begun the reviews in the second cycle, after making adjustments to the periodicity and functioning of the mechanism. Part Three will consider how the UPR has been carried out in national jurisdictions, by examining how governments and civil society participate in the submission of national reports and stakeholder reports and how governments include civil society in national consultations. This third part also casts a glance at implementation processes in national jurisdictions. Part Three also considers the national human rights institutions and how they interface with civil society and government in the submission of stakeholder reports and in the preparation of the national report. Of equal interest is the role that civil society and national human rights institutions have played in the international arena both during the interactive dialogue and in the plenary session of the adoption of the final outcome. In summary, this gives a behind-the-scenes view of the UPR in national jurisdictions and in Geneva.

\section{Research Sub-Question}

Part Three of this inquiry is concerned with the ways in which the human rights discourse has changed nationally (in the individual country under review) and internationally (within the human rights mechanisms in Geneva, particularly the UN Human Rights Council) as a result of the Universal Periodic Review (UPR). The formal research sub-questions are:

- Does government participation in the UPR transform human rights discourse nationally and internationally?

- Does the participation of National Human Rights Institutions participation in the UPR transform human rights discourse nationally and/or internationally?

- Does the participation of civil society in the UPR transform the human rights discourse nationally and/or internationally?

\section{A. Human rights discourse defined}

Human rights discourse comprises both verbal and written content. Human rights discourse refers to the way in which the subject of human rights is debated, discussed and understood by the participants (in the larger context of creating a legal and moral framework for rights -based claims). The study of the human rights discourse also includes how the subject is described, portrayed and explained in written texts. Among the elements to be considered are the topics and themes that arise during discussions and debates. From the national perspective, human rights discourse can include how rights are discussed in the media or by activists, citizens and politicians or how they are evoked and made to be respected in fora such as courts, administrative bodies and legislative processes. Other factors that play into the human rights discourse are setting and atmosphere and forum of the discourse. In this case, the fora are not just the interactive dialogue of the UPR itself before the Working Group of the Council and the plenary sessions of the Council, but also national jurisdictions. Scholars of 
human rights discourse refer to its power to frame issues as violations and mobilize societies to demand rectification of recognized violations. ${ }^{535}$

While conducting research and interviewing key informants, the working hypothesis was that the UPR has permitted actors such as national governments, National Human Rights Institutions (NHRIs) and Civil Society organizations (CSOs), including non-governmental organizations (NGOs) and advocacy groups to engage in new ways with states and each other. This hypothesis was confirmed by the data gathered from interviews with key informants from NHRIs and CSOs and from accounts of particular UPRs in newspapers and on websites. Human rights are now openly broached in public exchanges between diplomats, government officials and members of civil society during national consultations.

\section{Structure and Methodology}

\section{B. Case Study: Governments}

Part Three begins with the study of the UPR process in the Netherlands. The Netherlands has undergone two UPR reviews - one in 2008 and a second in 2012. The study looks at the national consultation and the drafting of the national report, as well as the presentation of the Dutch report in the interactive dialogue, the decisions about which recommendations to accept and reject and the implementation of recommendations between the first and second reviews.

This case study relies on the documents submitted by civil society and by the national government as well as on interviews of three key officials who were involved in the first and second cycle, respectively, and interviews with an Amnesty International staff member from the Dutch chapter of the organization and with a Program Officer from Jusitia et Pax, a catholic NGO operating in the Netherlands.

\section{Case Study: National Human Rights Institutions}

Part Three's second examination involves the interaction of two NHRIs - the Danish Institute for Human Rights and the Kenyan National Commission for Human Rights - in the UPRs of their respective nations. Both are A-accredited NHRIs that played a significant role in the UPRs of their respective nations, but also reached out to civil society and other NHRIs (both in their own nations and abroad) to train and build capacity.

The case studies of the Danish and Kenyan NHRIs look at the entire UPR process from start to finish in these nations. The studies were done by examining the three reports for both countries, using text analysis; by observing the webcasts of the interactive dialogue, adoption of the report of the working group and adoption of the final outcome in the plenary session before the Council; and by interviewing two key informants from Denmark's NHRI and one informant from Kenya's NHRI about the UPR process within their respective nations.

\footnotetext{
535 For a summary of literature considering the concept of human rights discourse See NEVE GoRDON \& NITZA BERKOVITCH, Human Rights Discourse in Domestic Settings: How Does it Emerge?, 55 Pol. Sci. Studies 243, 243-246 (2007).
} 


\section{Case Study: Civil Society Organizations}

Following the cases of NHRIs, Part Three turns to civil society and the changes it brings to the human rights discourse during the UPR. First, the listening sessions conducted during the UPR of the United States of America are discussed. The discussion is limited to the listening session, conducted as a part of the national consultation, and does not examine the entire UPR. Resources for the discussion of the listening session included the US Department of State's website and summaries of national consultations, interviews with two key informants involved in the organization of listening sessions in San Francisco and New York City, an audio CD of the New York listening session, as well as online materials (blogs, webpages, newspaper articles) advertising the listening sessions. Second, the strategy of Amnesty International's secretariat and national chapters are explained based upon interviews with three key informants familiar with the UPRs in Hungary, and the Netherlands, and based on additional written materials from AIs website. In addition, AIs stakeholder submissions together with its interventions in the plenary sessions to adopt final outcomes are assessed to better understand its strategies and the ways in which it has changed the human rights discourse. OHCHR documents, including the three reports for each of the countries were assessed. In the case of the Netherlands, which was reviewed a second time in May 2012, the available documents for the second review were also considered. 


\section{Chapter Six}

\section{Case Study of the Role of Governments in the Universal Periodic Review: The Netherlands}

\section{Introduction}

Governments play a central role in the Universal Periodic Review (UPR). As noted in earlier discussions, national governments are the leading actors in the UPR process because they are responsible both for initiating a national consultation in their own countries to assess the realization of human rights by their own citizens, and for reviewing the human rights records of peer states in the interactive dialogue in Geneva. The government must carry out a national consultation prior to its own review in Geneva, but the method used for these consultations is not spelled out in the modalities for the UPR. Therefore, the national consultations have varied in style and substance. In the United States of America, Ireland and Denmark, listening sessions or town hall meetings were held in which civil society organizations were invited to participate. The Netherlands opted to have a more modest consultation, inviting civil society organizations for a one-day discussion of issues and following up with a second session to present what the government intended to write in the national report. This chapter undertakes to study the UPR process for the Netherlands from start to finish for both the first and the second UPR cycles.

The national consultation guides the drafting of a national report of no more than 20 pages, presenting the human rights situation in the country. Ideally, the information gathered and issues and criticisms raised in the consultations are to be included in the national report. In practice, governments follow an OHCHR format in which they must discuss five points in the first national report:

- The methodology of the consultation process;

- Normative and institutional framework;

- Promotion and protection of human rights on the ground;

- Identification of achievements, best practices, challenges and constraints; and

- Priorities for human rights policy.

(The national reports for the second and subsequent cycles should report on the progress in implementation of the recommendations from the previous cycle.) The Netherlands adhered to this process its participation for both cycles.

In the interactive dialogue, the government responds to questions from its peers during a three-hour interactive dialogue before the Working Group of the United National Human Rights Council (Council). The comments from peers are formulated as recommendations upon which the government is advised to act before the next review. These comments are compiled into a Working Group report which is adopted 48 hours after the interactive dialogue in consultation with the government under review. During the period between the adoption of the report in the Working Group and the plenary session, governments must make decisions about which recommendations to adopt and which to ignore, which to implement and which have already been achieved. They do this by consulting the main agencies in their capitals and discussing which recommendations made during the interactive dialogue are feasible to achieve. Often, governments also reject recommendations. These decisions to reject can be political because certain recommendations may be rejected simply because of who offered them or because they involve sensitive issues that the government refuses to concede. Sometimes, governments will take no clear position on a recommendation, leaving ambiguity regarding their intention to implement or ignore the suggested measure. Again, in both cycles, the Dutch government interacted with its 
peers by responding to questions. It also met with civil society groups in side events designed to highlight human rights challenges in the Netherlands.

The final public appearance of the government is in a plenary session of the Council during which the government publicly expresses its decision regarding which recommendations to accept, reject or take under consideration. During the plenary session before the Council, some governments have also given explanations for their refusal to agree to certain recommendations. Governments have also taken recommendations under consideration and later decided to accept or reject them. The plenary session is also open to NGOs which often take the opportunity to harshly criticize governments who reject large numbers of recommendations. The government's appearance in the second cycle drew sharp criticism from NGOs who felt the government surprised them by announcing it was implementing a national plan for human rights. ${ }^{536}$

In the time between the plenary session and its next review, the government is presumed charged with the implementation of accepted recommendations at home. The implementation of recommendations is a key role for governments; however, this is the phase where there is little public scrutiny. Governments engage to carry out the recommendations they've agreed to implement, but who monitors the implementation? The process in each country differs. Where a national human rights institution exists, governments may be held to a timetable by such NHRIs. However, where no such institutions are in place, civil society is the only accountability holder. The resources available to and organization of civil society often influences whether follow-up can and is done with the government to ensure implementation of recommendations from the UPR process. The Dutch government introduced an innovative practice following the first cycle. It submitted a progress report to the OHCHR explaining the steps taken to implement each recommendation accepted in the first cycle.

\section{Criteria for the case study}

In this section, the role of governments is examined from the perspective of the Netherlands. The Netherlands was chosen as a case study for several reasons. ${ }^{537}$ First, it offers a look at both the first and second cycles, having undergone its first UPR in 2008, and a second UPR in May 2012. Because the country has done undergone two UPRs, some observations can be made regarding follow-up and implementation of UPR recommendations. Of equal value is a comparison of the national consultations and reports from both cycles. In addition to the advantages of studying a country that has been reviewed twice, this study of the Netherlands is useful because the country has both an active civil society and an emerging National Human Rights Institution and ombudsman process. Therefore, it is possible to observe how the government interacts with these important UPR actors. Finally, the Netherlands was chosen because the officials with whom the author spoke were interested and even eager to describe the process, their thoughts about the viability of the mechanism and to be candid about the two Dutch national consultations and interactive dialogues.

Three factors aid in assessing a government's participation in the UPR process. ${ }^{538}$ These factors will be assessed regarding the Dutch reviews in both 2008 and 2012:

(1) the quality of the national consultation - including how inclusive the dialogue is with civil society; whether the issues raised by civil society in the national consultations or in their submissions to the Office of the High Commissioner for Human Rights are disclosed and discussed in the national report, and whether those same issues are again explained in the interactive dialogue;

\footnotetext{
${ }^{536}$ NGO representatives said this was new. Interview with G. Klos, dated April 8, 2013. The official from the Ministry for the Interior indicated that the plan is still being developed and could give no details at the time of the interview.

537 This case study looks at one government only. The author contacted governments in South America and Africa, but none were willing to discuss their UPR preparations and experiences.

538 The author derived these three criteria by reasoning that peer reviews function best with broad civil society involvement, honest assessment of strengths and weaknesses and good faith efforts to devise legislation, create policy and implement changes to human rights practices.
} 
(2) the posture of the government during the interactive dialogue - whether the government openly refers to challenges and whether the government is forthcoming with details and information in response to the questions posed by peer nations; and

(3) whether the government undertakes and reports on its efforts to implement recommendations accepted during the process.

In the first part of this case study, the analysis starts with a description of the consultation process based on interviews with the only Dutch official responsible for the coordination and drafting of the national report in the first cycle ${ }^{539}$ and three Dutch officials - one from the Ministry of the Interior and two from the Ministry of Foreign Affairs - responsible for the second cycle national report. Two non-governmental organization staff members who took part in the first or second cycle consultations in their respective organizations were also interviewed. Then, the content and written discourse of the national report is considered. The interactive dialogue, adoption of the working group report and presentation at the plenary session are reviewed both from the standpoint of the webcasts and the written final outcome report. Finally, this analysis also looks at the interim report and subsequent efforts to implement the recommendations from the first cycle.

The second perspective taken in this chapter is to trace how certain human rights issues were dealt with from the start of the process during the national consultation straight through to implementation, by assessing the quality of the consultation surrounding the issue, the posture taken in the national report and interactive dialogue, the willingness to accept recommendations regarding the subject and the way in which the government implemented policies to address the recommendations it accepted.

Accordingly, the second part of this case study traces the Dutch government responses to two human rights issues - (1) treatment of asylum seekers and (2) counterterrorism measures. Using these two issues, I assess whether the government was responsive to criticism regarding the policies surrounding the two issues, whether there was open and candid acknowledgement of the weaknesses in these areas, and what recommendations were adopted and implemented to effect improvements in those areas between the first and second cycles. These two issues were chosen because they are topical - countries around the world face the same human rights dilemmas related to asylum seekers and counterterrorism. In addition, the issues have been raised by several stakeholder groups and are also widely spoken about in the media. Therefore, tracing the two issues is a way to see whether the government addresses problems and challenges during the interactive dialogue and whether measures are taken to implement any recommendations from peer states to remedy the problem.

The final part of the case study of the Netherlands identifies two best practices from the way in which the Netherlands has participated in the UPR process. While these best practices are useful, they are limited in their application, because they are drawn from the experience of a democratic society with a reasonably independent and broad civil society. Autocratic countries and nations without a thriving civil society cannot be expected to implement such practices in their contexts. Attention is given to the dialogue with civil society and to the accountability for implementation of recommendations.

\section{The Dutch Universal Periodic Reviews of 2008 and 2012}

\section{A. The national consultation and preparation of the national report}

The Dutch national consultation was conducted in both cycles with approximately 20 civil society organizations. These organizations have regular contact with the ministries and they were notified of the national consultation because of the ongoing relationship. ${ }^{540}$ The consultations were not publicized, nor were they open to

\footnotetext{
${ }^{539}$ In the first cycle, the report was written with the aid of the various ministries, but one official was solely responsible for the coordination and drafting of the national report.

${ }^{540}$ Both key informants from AI and Justitia et Pax expressed that the Ministry of Foreign Affairs had a history of regular and constructive contact with NGOs, but this was less the case with the Ministry of the Interior which had not had sustained contact with civil society groups.
} 
the general public. The content of the consultation was determined by the government though input from civil society organizations was encouraged.

During the first cycle, the national consultation was conducted by the Ministry of Foreign Affairs. ${ }^{541}$ In the second cycle, that task was handed over to the Ministry of the Interior. ${ }^{542}$ Amnesty International's Netherlands chapter as well as Justitia et Pax, a Dutch NGO, welcomed the change of ministries. ${ }^{543}$ During both cycles, the government estimated that it consulted with approximately 20 civil society groups on two separate occasions. 544

In the first cycle consultations, the key official already had a rough draft of the national report when he met with the civil society groups. ${ }^{545}$ The groups were convened mainly to explain what the government was going to do. ${ }^{546}$ At the meeting an outline of the topics to be addressed in the national report was given to the groups. ${ }^{547}$ At the second meeting, more information about the national report was discussed. ${ }^{548}$ The government believed the discussions were open and that there was a lot of contact afterwards with the groups. ${ }^{549}$

The second cycle national consultations were conducted similarly, albeit by a different lead ministry - the Dutch Ministry of the Interior. At the first consultation, officials from the Ministry of the Interior told the civil society which topics it wanted to include in its national report and asked them to tell them what should be mentioned under each topic. ${ }^{550}$ In some cases, the ministry had to prioritize and left out items brought up by the civil society organization in the report. ${ }^{551}$ In the second meeting with civil society, an outline of the national report was explained. .52

The view from civil society regarding the consultations in the second cycle was mixed. Amnesty International's Netherlands chapter recalls the senior policy officer from the Ministry of the Interior as being interested in seeing the AI report and viewed the consultation as a friendly atmosphere in which some conversation occurred. ${ }^{553}$ However, Amnesty also recalled the venue for the second meeting as an auditorium which wasn't conducive to conversation and further recollected that nothing new was put on the agenda and no draft of the national report was made available. ${ }^{554}$ The second consultation was not a proper consultation, in the view of AI. ${ }^{555}$ The Ministry of the Interior believed that the consultation was properly conducted and noted that, following the first session where CSOs placed heavy emphasis on the issues of data privacy asylum and humane treatment of asylum seekers, the government gave more space to those issues in the report.556 The Program Officer from Justitia et Pax, another Dutch NGO, viewed the consultations as "interesting" because it created a group where everyone was at the table with the Ministry of the Interior, yet it was still very "formal." ${ }^{57}$ The Justitia et Pax staff member stated that two views could be taken - one was that the Ministry was only conducting the consultation so that it would be surprised by the critiques to human rights policy; the other was that it simply wished to be well-prepared. ${ }^{558}$ The Ministry of the Interior was also called upon to answer questions about the

\footnotetext{
${ }^{541}$ Interview with Walter Oostelbos, Strategic Adviser Migration Policy Department, the Netherlands, April 6, 2012.

542 Interview with Official from the Dutch Ministry of Foreign Affairs, September 6, 2012.

${ }^{543}$ Interview with Gerbrig Klos, Amnesty International, the Netherlands, April 24, 2012; Interview with Official from Dutch Ministry of Foreign Affairs.

${ }^{544}$ National Report Submitted in Accordance with Paragraph 15 (a) of the Annex to Human Rights Council Resolution 5/1 - The Netherlands, UN Doc A/HRC/WG.6/1/NDL/1, Para. 4; National Report Submitted in Accordance with Paragraph 5 of the Annex to Human Rights Council Resolution 16/1 - The Netherlands, UN Doc A/HRC/WG.6/13/NDL/1, Para. 4.

${ }^{545}$ Interview with Walter Oostelbos.

$546 \mathrm{Id}$.

$547 \mathrm{Id}$.

$548 \mathrm{Id}$.

${ }^{549} \mathrm{Id}$.

${ }^{550}$ Interview with Official from the Dutch Ministry of Foreign Affairs.

${ }^{551}$ Interview with Official from the Dutch Ministry of the Interior, April 10, 2013.

$552 \mathrm{Id}$

${ }^{553}$ Interview with Gerbrig Klos.

$554 \mathrm{Id}$.

$555 \mathrm{Id}$.

556 Interview with Official from the Dutch Ministry of the Interior.

$557 \mathrm{Id}$.

$558 \mathrm{Id}$.
} 
adequacy of the national consultation during the second cycle review by a member of the Tweede Kamer (the Dutch lower house of parliament). The response of the Minister of the Interior is described later in this chapter.

The national report in the first cycle was remarkable for its candor and openness in acknowledging challenges to meeting human rights obligations. In its national report for the first cycle of the UPR, the government described the consultation process as "open and constructive." 559It further summarized its normative and institutional framework by emphasizing its ranking as the $10^{\text {th }}$ highest country on the UNDP Human Development index. ${ }^{560}$ It acknowledged a new dimension on values and standards due to the increasing diversity of the Dutch society and it stated that the government had launched new initiatives in integration, youth policy, education public safety and security to raise awareness about shared values. ${ }^{561}$ The report pointed to the Constitution and the fundamental rights set forth therein; it also referred to international law and treaties which it reaffirmed had binding effect, but also pointed out that the Netherlands is a qualified monastic system and that treaties and resolutions of international institutions are applied when they are binding on all persons and have been published. ${ }^{562}$ Regarding human rights treaties, the report listed the treaties and protocols which it had yet to sign and explained whether they were under consideration for ratification. ${ }^{563 S e c t i o n}$ Three, dedicated to the protection and promotion of human rights on the ground, referenced: (1) equal treatment and included summaries of the legislation passed in 1994, 2003 and 2007,,564 as well as a commission enforcing equal treatment; ${ }^{565}$ (2) gender mainstreaming, including a policy to improve women's prospects; 566 (3) domestic violence, including a 10-day domestic exclusion order available to the police if they suspect domestic violence; 567 (4) human trafficking and efforts to tighten the oversight of the Dutch sex industry; 568 and (5) refugees and asylum issues such as the policy to detain "aliens" who resist expulsion. ${ }^{569}$ The government highlighted its National Ombudsman as an achievement because it permitted scrutiny of public authorities and their actions; similarly, it held out its openness to input from civil society as a best practice. ${ }^{570}$ At the same time, the government also admitted weaknesses, particularly regarding the balance between privacy and other fundamental rights and the need to protect society from terroristic threats; ${ }^{571}$ human rights education; $; 72$ treaty body reporting obligations,; ${ }^{573}$ and encouraging proper use of the Internet while combating cyber infringements such as child pornography. ${ }^{574}$ The government listed its priorities to be integration of children and families from other cultures and religious backgrounds into Dutch society; 575 a focus on combating conditions that hinder youth from enjoying a healthy and safe childhood; 576 promotion of multi-ethnic schools and increasing the ethnic minorities in higher education; 577 and the creation of the national human rights institution for the Netherlands. ${ }^{578}$

The national report for the second cycle followed a modified the format. In its second national report, the government addressed these topics: Methodology, Constitutional relations, achievements and best practices,

\footnotetext{
${ }_{559}$ National Report Submitted in Accordance with Paragraph 15 (a) of the Annex to Human Rights Council Resolution 5/1 - The Netherlands, UN Doc A/HRC/WG.6/1/NDL/1, Para. 4.

560 National Report, supra note 533, at 9.

${ }_{561}$ National Report, supra note 533, at 910.

562 National Report, supra note 533, at 917.

${ }_{563}$ National Report , supra note 533, at $921-22$. The Netherlands stated that it would not sign the Convention on the Protection of the Rights of All Migrant Workers and Members of Their Families because it is opposed to the concept that rights can be granted to persons without legal residence rights.

${ }^{564}$ National Report, supra note 533, at 9 .

565 National Report, supra note 533, at 9 Para. 31.

566 National Report, supra note 533, at 9 Para. 41.

567 National Report, supra note 533, at 9 Para. 53.

568 National Report, supra note 533, at 9 Para. 63.

569 National Report, supra note 533, at 9 Para. 68.

${ }^{570}$ National Report, supra note 533, at 9 Paras. 69, 73.

${ }^{571}$ National Report, supra note 533, at $9.77-79$.

572 National Report, supra note 533, at $90-82$.

${ }^{573}$ National Report , supra note 533, at Paras. 83-85.

${ }^{574}$ National Report, supra note 533, at Paras. 86-87.

575 National Report, supra note 533, at Paras. 88-93.

${ }^{576}$ National Report, supra note 533, at 9 Paras. 94-100.

577 National Report, supra note 533, at 9 Paras. 101-102.

578 National Report, supra note 533, at I| Para. 103.
} 
challenges, international conventions, non-discrimination, integration and society, domestic violence, trafficking, refugees and asylum, education and other recommendations.

Regarding the two consultations with civil society, the government described them as "a constructive exchange of "views" and "a constructive dialog," respectively. ${ }^{579}$ The government also reported that the Curaçao and St. Maarten were now countries within the Kingdom of the Netherlands. ${ }^{580}$ It highlighted achievements, including the establishment of a national human rights institution and a children's ombudsman. ${ }^{581}$ The government equally acknowledged challenges, including the right to the protection of personal data, including the privacy of electronic patient records. ${ }^{582}$ The national report also listed new treaties ratified since the first UPR, among them the Convention on the Protection of All persons from Enforced Disappearance and the Optional Protocol for the Convention Against Torture. ${ }^{583}$ In substantive rights, the government emphasized that it regularly updates the House of Representatives regarding efforts to combat discrimination and that in 2011 they sent an anti-discrimination action program to the House of Representatives. ${ }^{584}$ The government noted that it had made strides to address low literacy rates among women, ${ }^{585}$ conducted a study into the problems in employment and health care experienced by transgender people, ${ }^{586}$ and would encourage women's economic independence by withdrawing financial support to women who are "dependent upon a breadwinner." 587 The government stated that integration of immigrants into society is a priority ${ }^{588}$ and also noted that it was important for young people to "take responsibility for finding jobs or training opportunities." 589 Regarding domestic violence, the report reiterated the policy to favor a "gender-specific approach," 590 noted the action plan against child abuse, ${ }^{591}$ and referenced the Temporary Domestic Exclusion Order Act.592 The report further noted a task force for human trafficking whose mandate was extended, the National Rapporteur on trafficking whose authority now includes child pornography investigations, ${ }^{593}$ a revised asylum procedure permitting a process of up to 14 days, instead of the 48-hour accelerated procedure, ${ }^{594}$ and the criminalization of illegal residency. ${ }^{595}$ Finally, the national report stated that human rights were included in secondary and primary education curricula designed to promote good citizenship and social integration. ${ }^{596}$ The report stated that draft legislation on counterterrorism should be reviewed to ensure that it is compatible with human rights principles 597 and also stated that the freedom of expression does not "protect utterances that are insulting, incite hatred or discrimination, or propagate violence." 598

\section{B. Interactive Dialogue}

The first cycle also saw frankness applied in the Geneva-based interactive dialogue. The first cycle brought declarations of support for the UPR process and for human rights in general. The Dutch delegation was led by Nebahat Albayrak, then Dutch Secretary of State for Justice. ${ }^{599}$ Regarding its respect for human rights and its

\footnotetext{
${ }^{579}$ National Report Submitted in Accordance with Paragraph 5 of the Annex to Human Rights Council Resolution 16/1 - The Netherlands, UN Doc A/HRC/WG.6/13/NDL/1, Para. 4.

${ }_{580}$ National Report, supra note 553 , at 96.

${ }_{581}$ National Report, supra note 553, at 9 7-12.

582 National Report, supra note 553, at $₫ 28-31$.

583 National Report, supra note 553, at 9 Para. 35.

${ }_{584}$ National Report, supra note 553, at 942.

585 National Report, supra note 553, at 9.55.

${ }^{586}$ National Report, supra note 553, at 956.

${ }^{587}$ National Report, supra note 553, at 94.

588 National Report, supra note 553, at 9 72-76.

589 National Report, supra note 553, at 66.

${ }^{590}$ National Report, supra note 553, at 9 84-85.

${ }^{591}$ National Report, supra note 553, at 86.

592 National Report, supra note 553, at 87.

${ }^{593}$ National Report, supra note 553, at 9101.

594 National Report, supra note 553, at $₫$ 104-107.

${ }^{595}$ National Report, supra note 553, at 9 108-110.

${ }^{596}$ National Report, supra note 553, at 9 111-112.

${ }^{597}$ National Report , supra note 553, at 9119.

598 National Report, supra note 553, at 9120.

599 All information regarding the Interactive Dialogue is based on the Review in the Working Group Webcast which is available on www.UPRInfo.org under the 2008 review for the Netherlands.
} 
commitment to the promotion of human rights at home and abroad, Secretary Albarak stated, "the Kingdom of the Netherlands traditionally attaches great importance to promoting and protecting human rights both at home and abroad." 600

The Dutch delegation chose to highlight human rights challenges and achievement during the first 20 minutes of the review. Secretary Albayrak stated that in its anti-terrorism activities, the Kingdom of the Netherlands believes that human rights comes first, but must prevent radicalization. She noted that the government will counter the instigation of violence through the Internet and other means. Acknowledging that certain persons and organizations would be observed more closely, she reiterated that the Dutch government has no desire to violate the prohibition of torture, even when dealing with terrorist suspects who are in detention.

Albayrak further explained that the Netherlands combats trafficking and prostitution and was the first nation to establish an independent rapporteur for human trafficking. The policy permits victims of trafficking to have three months to determine whether they want to cooperate with the police; those who do will receive a temporary residence permit. Those who do not cooperate can apply for a residence permit through the regular process.

Minister Albayrak emphasized that a policy plan is being developed to combat racial discrimination in the labor market, law enforcement and on the Internet. In addition, the government is aware that it must protect the freedom to practice Islam and improve women's positions through safety and emancipation policies. The Dutch government has a Minister for Youth and Family who focuses on children's rights and an action plan on child abuse called Children Safe at Home. The minister also stated that the government expected to also receive criticism and suggestions during the interactive dialogue, not just compliments. She answered questions submitted in writing regarding a national human rights institution, ratification of the Convention Against Forced Disappearances and other relevant topics.

Several topics arose during the first round of questions and comments from peer states. Two issues of interest for this inquiry were: asylum and migration policy as well as counterterrorism policy. The first issue included the 48-hour window for decisions regarding the return of "illegal" migrants to their home country together with a loss of life of 11 detainees at a fire at Schiphol airport in 2008. Both issues were raised by NGOs in their submissions, including Amnesty International's submission and by peer states during the interactive dialogue. While the Secretary of State for Justice did say measures were taken to ensure that fire safety standards were observed in detention facilities, the issue of the 48-hour decision process was not directly answered.

The plenary session was attended by Arjan Hamburger. ${ }^{601}$ In his opening remarks, he referenced the UPR's "potential to become a platform to discuss all Member States' challenges and constraints, achievement and best practices in the area of human rights." 602 He further urged all UN Member States to opt for more civil society involvement and to participate in country-specific side events in Geneva, as the Netherlands did directly following their review in April 2008. No states took the floor. The NGOs who spoke did reference asylum issues and counter-terrorism measures. Hamburger did not directly respond to any NGO remarks, but concluded by promising that the Netherlands would submit an interim report explaining how it was implementing recommendations and undertakings made as a member of the UN Human Rights Council. He also promised to continue the dialogue with civil society.

In its second cycle interactive dialogue, the Netherlands was represented by the Minister of the Interior, Liesbeth Spies. ${ }^{603}$ The interactive dialogue presentation was very formal and the minister emphasized the country's support for human rights, its existing institutions and Constitutional framework. The Netherlands also noted the establishment of the national human rights institution, which was expected to begin work in the few months and stated that the representatives of the institute were present at the dialogue. Finally, it named the

\footnotetext{
${ }^{600}$ Review in the Working Group of The Netherlands, 15 April 2008, at 1:40.

${ }^{601}$ Mr. Hamburger was the Human Rights Ambassador at the time.

${ }^{602}$ Review in the Working Group Webcast at 1:30.

${ }^{603}$ All information regarding the Interactive Dialogue is based on the Review in the Working Group Webcast which is available on www.UPRInfo.org under the 2012 review for the Netherlands.
} 
children's ombudsman. The Minister also outlined the priorities of the government (which she acknowledged was to be replaced in September 2012) as equality of all persons, integration of all groups in society, combating domestic violence, eliminating human trafficking, ensuring asylum-seeker protections, encouraging equality for Lesbians, Gays, Bi-sexual and Transgender persons, and education regarding human rights. The Minister answered written questions coming from countries, including Slovenia, the United Kingdom and Norway. Among the questions raised was one concerning the banning of facial covering and whether it infringed the right to freely exercise religion. The Minister responded that the government believed that the right to exercise one's religion was qualified and that the Dutch government had good reason to limit the use of facial coverings. The comments from peer states were often congratulatory because the Netherlands was viewed as having largely implemented its recommendations from the first cycle. In addition, countries (Mozambique, Slovakia, Morocco) wanted to laud the establishment of the national human rights institution.

Following the first and second rounds of comments and recommendations by peer countries, the minister also made remarks and responded to concerns raised stating that the country must be aware at all times about human rights, but expressing that she was glad that people view the Netherlands as "making steps." 604 The Netherlands stated it did not intend to ratify the Convention for Migrant Workers because it requires equal treatment for social provisions for illegal migrants and the government did not agree that illegal migrants should have the same economic and social rights as people who work in the country legally.

While the Dutch presentation at the interactive dialogue appearance in both cycles gave the impression of a Dutch government that was working to maintain an image of compliance with international human rights standards, the view from civil society was different. The Dutch AI chapter was unhappy with the lack of contact during the months between the interactive dialogue and the appearance before the Council plenary to announce which recommendations it was accepting and rejecting. The Dutch AI was concerned by the number of recommendations with "unclear" status following the second cycle. ${ }^{605}$ In addition, it did not like the way in which the government surprised civil society by announcing that a human rights action plan was "in the pipeline;" something that was unknown to the CSOs and the newly formed national human rights institution. 606 The key informant from the Ministry of the Interior explained that in some cases, it is not possible to give a clear answer as to whether the government will implement a recommendation. ${ }^{607}$ For example, if the government receives a recommendation to ratify a certain human rights treaty and its optional protocol, the government may respond that it accepts the recommendation to ratify a treaty, but it may not give a clear answer regarding the ratification of the option protocol because the issue is premature. The government is not in a position to decide about the optional protocol until after the treaty itself is ratified, according to the Ministry of Interior informant.

\section{Tracing implementation of recommendations regarding two human rights concerns}

While the above analysis of the written and verbal discourse that occurred in the national consultations and in the report of the Netherlands is useful for assessing best practices, it is also important to ascertain the degree to which the Netherlands implemented its recommendations. The author has chosen human rights concerns that came out in the first cycle from civil society and the national report.

Two human rights issues raised by civil society groups and discussed in the first cycle national report involve the treatment of migrants, including asylum conditions and measures for counter terrorism. This part of the analysis will look at these two issues and what steps the government took to acknowledgement them in the UPR process and to improve the situation in the lead up to the second cycle.

At the end of the first cycle, the government accepted the following recommendations regarding asylum policy:

\footnotetext{
${ }^{604}$ Review in the Working Group of The Netherlands, 31 May 2012, at 1:00:00.

${ }^{605}$ Interview with Gerbrig Klos.

${ }^{606} \mathrm{Id}$.

${ }^{607}$ Interview with Official from the Ministry of the Interior.
} 
Take appropriate measures to prevent the use of excessive force by security forces when forcibly repatriating migrants, refugees and asylum-seekers (Nigeria);608

Establish or strengthen the machinery for reviewing the accelerated procedure of 48 hours in order to guarantee the rights of the asylum-seekers (Mexico);609

to increase its efforts to prevent acts of discrimination against migrants (Algeria);610

Take a leading role in setting the tone of the current national debate on integration issues and have the voices of migrants and other groups also be heard (Turkey);611

The following recommendations relating to migrants was rejected by the Dutch government:

Review its legislation in order to protect fundamental rights of all persons, independently of their migrant status, and take necessary measures regarding discrimination against women refugees, migrants and women from ethnic groups, and to guarantee the integration of all women victims of trafficking (Mexico);

Accede to the International Convention on the Protection of the Rights of All Migrant Workers and Members of Their Families (Egypt, Peru, Algeria). ${ }^{612}$

The government accepted these recommendations regarding its counterterrorism measures:

While implementing anti-terrorism measures, respect international human rights obligations, including the right to a fair trial and the right to freedom and security of the person (Switzerland); and consider revising all antiterrorism legislation to bring it in line with the highest human rights standards (Cuba). 613

No recommendations regarding counterterrorism were rejected by the Dutch government.

In its interim report, ${ }^{614}$ the Dutch government reported on its progress for all of the recommendations it accepted during the first cycle. Regarding the treatment of migrants, the government did not discuss the Schiphol fire incident. However, it indicated that efforts were underway to introduce new legislation to modify the 48-hour process to make it into an 8-day decision.

With regard to the recommendation of Nigeria to take appropriate measures to prevent the use of excessive force by security forces when forcibly repatriating migrants, refugees and asylum-seekers, the Netherlands stated that:

many safeguards apply to exceptional situations in which the use of limited and proportional force by expulsion of persons is allowed. An independent committee supervises the process regarding return, including forced expulsions and the use of force. Every year it concludes that no structural excessive force is used in the process of expulsion. In addition, the committee makes recommendations to further limit the necessity of the use of force in individual cases. These recommendations are always used to continue improving the process of return and forced expulsions. ${ }^{615}$

Responding to Algeria's recommendation to increase efforts to prevent acts of discrimination against migrants, and in response to Mexico's challenge that the Netherlands review its legislation in order to protect fundamental rights of all persons, independently of their migrant status, and take necessary measures regarding discrimination against women refugees, migrants and women from ethnic groups, and to guarantee the integration of all female children, the Netherlands government gave the following statement:

\footnotetext{
${ }^{608}$ Report of the Working Group on the Universal Periodic Review - The Netherlands, U.S. Doc. A/HRC/8/31 (May 13, 2008$)$, II 6.

${ }^{609}$ Report of the Working Group, supra note 580, at $\mathbb{I} 24$.

${ }^{610}$ Report of the Working Group, supra note 580, at II 7.

${ }^{611}$ Report of the Working Group, supra note 580, at II 13.

612 Report of the Working Group, supra note 580, at III $7,23$.

${ }^{613}$ Report of the Working Group, supra note 580, at II 29.

${ }^{614} \mathrm{OHCHR}$, Universal Periodic Review, The Netherlands, National Interim Report (April 2010),

http://lib.ohchr.org/HRBodies/UPR/Documents/Session1/NL/Netherlands_Interim_report.pdf.

${ }^{615} \mathrm{Id}$. at 96
} 
All persons are equal and protected against discrimination by law, regardless of sex, sexual orientation, ethnic origin, age, disability, religion or belief. Article 1 of the constitution does not permit discrimination on the grounds of religion, belief, political opinion, race or sex or on any other grounds whatsoever. Antidiscrimination policy is generic and applies to all individuals. It does not address specific target groups.

The Netherlands has an extensive network of agencies which combat discrimination. There is a national network of antidiscrimination bureaus (also see the answers to recommendations 11 and 28), an Equal Treatment Commission and a National Ombudsman. Anyone can report discrimination to these organisations or even to the police. Some time ago, the Ministry of Social Affairs and Employment presented an action plan to parliament on combating discrimination against non-Western migrants in the labour market. In recent years, the police and the Public Prosecution Service have become much more alert to discrimination. In November 2009, the government sent parliament a letter on integration, announcing measures to combat racial discrimination in the hospitality industry and on the internet, increase the resilience of victims of discrimination and increase the professionalism of antidiscrimination organisations. The government monitors discrimination continuously and may introduce supplementary measures if necessary. The Second Racial Discrimination Monitor and the Second Monitor on Discrimination against Non-Western Migrants in the Labour Market are both due to be published before the summer of 2010.616

Regarding a second recommendation from Mexico to establish or strengthen the machinery for reviewing the accelerated procedure of 48 hours in order to guarantee the rights of the asylum-seekers, the government highlighted the following new procedure:

A legislative proposal with a coherent package of measures has been submitted to parliament that aims to improve the quality of the current asylum application procedure.

The 48-hour accelerated procedure will be replaced by a general procedure lasting 8 days. A quick and thorough decision on an asylum request is in the best interest of the asylum seeker, also for vulnerable groups. Asylum requests will be handled within eight days only if a thorough decision can be taken within that timeframe. If this is not the case, the asylum request will be dealt with in the extended procedure. A medical advice before the general asylum procedure starts, will make sure that the Immigration and Naturalisation Service (IND) will take into account medical problems (including psychological problems). If the medical advice is such that the asylum request should be dealt with in the extended procedure, the IND will follow this advice. Both asylum seekers whose initial application for asylum has been refused at the application centre and asylum seekers whose application for asylum has been refused in the extended procedure will be accommodated during four weeks. After the procedure in the application centre judges will usually make a decision on appeal within these four weeks. Appeal has suspensive effect after the extended procedure.

The new asylum procedure is expected to enter into force in the second half of 2010.617

On the second human rights issue regarding counter terrorism recommendations, the Netherlands reported, in response to Swiss and Cuban recommendations to respect certain procedural rights when implementing antiterrorism measures, the Netherlands asserted that:

Further to its responsibility to exercise due care in drawing up legislative measures to combat terrorism, various mechanisms to monitor the effects of the new legislation are introduced. In addition, in response to a request by parliament, provision was made for a review of the body of legislation aimed at preventing and combating terrorism and of practices in counterterrorism in order to assess their effectiveness. This will include a review of issues like coordination and alignment between government services, purpose limitation, intentional and unintentional side effects, and the proportionality and subsidiarity of the measures applied.618

${ }^{616} \mathrm{Id}$. at $4 \mathrm{f}, 23$.

${ }^{617} I d$. at II 24.

${ }^{618} \mathrm{Id}$. at $\mathbb{\text { II }} 29$. 
While the second cycle brought new inquiries regarding migration, they did not specifically challenge the new policy nor make reference to the new measures reported in the Interim Report. ${ }^{619}$ Counterterrorism was not discussed in the second cycle during the interactive dialogue.

The key informant from Justitia et Pax stated that the organization was not satisfied with the progress on the treatment of migrants because it viewed the change from the 48 hour policy to the 8 day policy and the pilot programs to be too small-scale because larger, more broad movement was needed regarding the detention of migrant issues as a whole. 620 The view was that the measures touted by the government to show that it had implemented its recommendations were window dressing because the government was too cautious. Justitia et Pax had pushed hard on the issue following the first cycle, asking for meetings with the Minister of Migration and with the Minister of Justice. In some cases they directly confronted the ministers with specific anecdotes from detention center chaplains. In one case, a minister's initial reaction was one of hostility to the organization's assertions and indignation at being confronted by a report critical of Dutch migration policy.

\section{Best Practices}

The Netherlands preparation for the consultations and drafting of the national report offers some ideas for how to effectively interact with civil society and National Human Rights Institutions. In addition, its interim report is another way to be accountable for implementation of recommendations coming from the UPR. These two best practices merit additional analysis.

\section{A. Readiness to dialogue and form partnerships with civil society and NHRIs}

One lesson from the Dutch case study is that governments should be eager to form partnerships and dialogue with civil society. This is done by having a transparent process in which civil society is invited to participate. Keeping everyone informed about the national report and asking for input are key ways to ensure that partnerships continue and constructive dialogue ensues.

The Dutch example of sharing what is to be included in the report in advance of the submission to the OHCHR lets civil society have input in what is covered in the report. In addition, by openly collaborating with civil society, the government gave the message that it took the UPR process seriously as well as its responsibility to have a national consultation. This approach also lends more credibility to the mechanism as a whole both in the international and domestic context.

\section{B. Reporting about progress}

The Dutch government led the way to voluntary interim reports. Government should be willing to show progress and the report about what is working and not working in the implementation process. A good interim report will outline all steps taken with regard to each accepted recommendation. In addition, the governments should be in constant dialogue with NHRIs and civil society in the period after the UPR to partner together to implement all recommendations.

The form of the interim reports need not be specified, what is important is that the government report on each of the undertaken responsibilities with substantive information about what steps are being taken to implement the recommendations. The Dutch government's report was very specific regarding the two issues outlined here counterterrorism and asylum policies. This sets a good example for peer governments searching for ways to report on their own progress.

\footnotetext{
${ }^{619}$ General statements were made by Ecuador, Mexico the United Kingdom regarding migration or immigration policy, detention and asylum seeking. See Report of the Working Group on the Universal Periodic Review - The Netherlands, U.N. Doc. A/HRC/21/15 (9 July 2012), IIII 98.104, 98.105, 98.113, 98.114, 98.117.

${ }^{620}$ Interview with Official from the Ministry of the Interior. The official did acknowledge that the new policy was a step in the right direction.
} 
While the Dutch government did report to the OHCHR regarding its progress, it was also called upon to respond to certain criticisms of the UPR process by a (then) member of the Tweede Kamer (the Dutch lower house of parliament.) In October 2012, then Tweede Kamer member, Frans Timmermans, asked the Ministry of the Interior to provide answers to nine questions about the second cycle UPR review for the Dutch government. The process placed the government in the position of explaining its conduct to an independent branch of government - the parliament. The questions included the following: ${ }^{21}$

- Why didn't the government timely involve NGOs in the national consultation process?

- Can you inform parliament where you are in the process of creating a National Human Rights plan, which you stated during the UPR was 'in the pipeline'?

- Why it could not accept the recommendation to ratify the option protocol of ICESCR?

The Ministry returned its answers in November 2012 and stated that it believed that the NGOs were properly informed about the national consultation and that they had ample opportunities to participate by submitting shadow reports. The government further indicated that NGOs do not need to be consulted about whether to accept or reject recommendations because that is the function of the individual Dutch ministries.

The Ministry also stated that the National Human Rights plan would be developed in association with the Dutch National Human Rights Institution and that the Tweede Kamer would be apprised of its progress.

With regard to the optional protocol of the ICESCR, the government noted that bringing individual complaints under the covenant was a 'novel' idea under international law. It further noted that such complaints could also overburden the national legal system. The Ministry pointed out that other EU countries have similar concerns over ratification of the Optional Protocol to the ICESCR.

\section{Conclusion}

This study of the Netherlands provides some insights into what democratic governments confront when undergoing a review. The Dutch government faced several challenges when carrying out the national consultation, appearing at the interactive dialogue in Geneva, accepting and rejecting recommendations and implementing accepted recommendations. First, while this study has looked at the Dutch reviews, the findings from the United States' listening sessions and the review of Hungary also bear out the idea that, at least in democratic nations, governments feel obligated to appear open and honest in their assessments of human rights situations, but they also feel constrained to highlight their achievements and to place weaknesses in the best light possible. While the Dutch national reports in the first and second cycle of review did admit to struggles and challenges, it also took pains to describe legislation and policies in place to combat discrimination or racism or whatever the offending condition was.

When describing weaknesses in the best possible light, governments run the risk of seeming dishonest because reports by CSOs tend to be hypercritical, highlighting human rights abuses and violations and glossing over achievements. For example, the informant at Justitia et Pax acknowledged that the organization considered the reform to the detention policy to be a very small step and not the overarching reform to detention of migrants that the organization felt should occur in the Netherlands. Similarly, the informant from AI- Netherlands expressed general dissatisfaction with the second cycle consultation, not willing to even consider it to have been a true consultation. During the national consultations, the governments sought to listen to concerns from civil society, but also knew that it must summarize the situation in 20 pages; therefore, the Dutch government made

${ }^{621}$ The information regarding the questions and the answers discussed are based upon the following: Beantwoording vragen van het lid Timmermans over het VNmensenrechtenexamen (Universal Periodic Review), Nov. 1, 2012 (on file with the author). 
decisions about which topics to include and which to exclude from the final report. The CSOs do not take kindly to their topics being omitted from the report.

At the interactive dialogue, The Netherlands, like all other states under review, was before its peer states. This interaction tends to be very formal. This informant observations of several UPRs during the first cycle showed that peer states couch their criticisms in diplomatic language, preferring to "welcome" and "congratulate" before "urging" and "recommending." It is probably fair to say that governments are reluctant to embarrass fellow states; however, that does not mean that governments will not be asked the tough questions during a review. Statements may be couched in diplomatic friendliness, but still request more information about a distressful situation or directly ask for new legislation or new policies to address a violation. The United States offered the following criticism regarding Dutch asylum procedures during its intervention in the interactive dialogue of the second cycle review

In the area of asylum, we note with concern that the National Ombudsman for Children has reported that over 3,000 undocumented children of families who seek asylum have been waiting for 4 years or more for a decision, and 80 percent of asylum requests made by children outside the country who want to join their parents in the Netherlands are turned down. ${ }^{622}$

When determining which recommendations to accept or reject, the Dutch government did not only take into consideration its human rights obligations under treaties and international law, but it also looked at the political climate within its territory. This was evident with the detention and migration policy issue. While the Netherlands was willing to make very small concessions like introducing the 8-day decision-making policy, it was not politically able to significant redo migration policy or rid itself of migrant detention centers. The political climate in the Netherlands would tolerate no such policies; moreover, no government wants to be seen as the "soft"immigration state in the region. ${ }^{623}$ As a result, no matter what progress is made by governments on a particular policy, it is likely not to satisfy civil society groups who are advocating for sweeping changes to human rights policy.

Even with these challenges, the Dutch UPR did shed light on questionable human rights practices and the government was pressured to make small steps to change the situation for the better. In addition, the interaction of the government was useful for pointing to best practices for interaction with civil society and for ways to report progress and demonstrate accountability in the interim period between review cycles.

${ }_{622}$ U.S. Statement at the UPR for the Netherlands, May 31,2012, available at http:/ / geneva.usmission.gov/2012/05/31/u-s-statement-at-theupr-for-the-netherlands/.

${ }^{623}$ Interview with Program Officer, Justitia et Pax. 


\section{Chapter Seven}

\section{Case studies of the Role of the National Human Rights Institutions in the Universal Periodic Review: Denmark and Kenya}

\section{Introduction}

The rise of National Human Rights Institutions (NHRIs) has been of great importance in the past two decades. National Human Rights Institutions are domestic bodies "vested with competence to protect and promote human rights." 624 In 1991, NHRIs held an international workshop in Paris where they adopted a document outlining their working methods. In 1993 the United Nations Commission on Human Rights endorsed the Principles Relating to the Status of National Institutions, more commonly referred to as the Paris Principles, which were adopted in the UN General Assembly. In general, the Paris Principles provide that NHRIs should enjoy a broad mandate ${ }^{625}$ set forth in "constitutional or legislative text." 626 They should be independent bodies which are composed of a "pluralist representation of the social forces (of civilian society) involved in the promotion and protection of human rights." ${ }^{627}$ The funding for the NHRI should be independent of the government and not subject to financial control. ${ }^{628}$ The NHRI should have the latitude to freely consider questions regarding human rights. ${ }^{629}$ Finally, the Paris Principles make it optional as to whether NHRIs should be given the right to hear complaints. 630

Since the adoption of the Paris Principles, many NHRIs have arisen in countries around the globe. Those NHRIs can now undergo a process of accreditation through the Sub-committee on Accreditation of the International Coordinating Committee of National institution for the Promotion and Protection of Human Rights (ICC). The Sub-committee grants A, B, or C status to NHRIs based on whether their peers deem them in compliance with the Paris Principles. 631 "A" status NHRIs may participate in UN Human Rights Council sessions, including the Universal Periodic Review. As of December 2011, there were a total of 99 NHRIs accredited by the ICC, 69 of those were "A" status NHRIs. ${ }^{632}$

With regard to the Universal Periodic Review (UPR), Resolution 5/1guaranteed a role for the NHRIs in the review, specifying that the review should "ensure the participation of all relevant stakeholders, including nongovernmental organizations and national human rights institutions, in accordance with General Assembly resolution 60/251 of 15 March 2006 and Economic and Social Council resolution 1996/31 of 25 July 1996, as well as any decisions that the Council may take in this regard". ${ }^{633}$ In the first cycle of the UPR, NHRIs have actively participated by submitting reports regarding the human rights situations in their countries and by delivering statements during the adoption of the final outcome. In the second cycle, the role of the NHRIs will likely increase because many nations such as the Netherlands have recently established NHRIs. In addition, Human

\footnotetext{
624 Paris Principles Relating to the Status and Functioning of National Institutions for the Protection and Promotion of Human Rights, annex to UNGA Res. 48/134 UN Doc A/RES/48/134 (20 December 1993) , $₫ 1$.

${ }^{625} \mathrm{Id}$.

${ }^{626} \mathrm{Id}$. at 92.

$627 \mathrm{Id}$. at 93.

${ }^{628} \mathrm{Id}$. at $93 .(\mathrm{g})(2)$.

${ }^{629} \mathrm{Id}$. at 93 . (g) 3. (a)-(g)

${ }^{630} \mathrm{Id}$. at Additional principles concerning the status of commissions.

${ }^{631}$ OFFICE OF THE HigH COMMISSIONER FOR HUMAN RigHTS, OHCHR and NHRIs, http://www.ohchr.org/en/countries/nhri/pages/nhrimain.aspx.

632 INTERNATIONAL COORDINATING COMMITTEE OF NATIONAL INSTITUTIONS FOR THE PROMOTION AND PROTECTION OF HUMAN RIGHTS, http://nhri.ohchr.org/EN/Documents/Chart\%20of\%20the\%20Status\%20of\%20NHRIs\%20(DIC\%202011).pdf.

${ }^{633}$ Human Rights Council Res. 5/1, Rep. of the Human Rights Council, 5th Sess., 11-18 June 2007, UN GAOR, 62nd Sess., Supp No. 53, A/62/53/, at 48 (18 June 2007) 93 (m) [emphasis added].
} 
Rights Council Resolution 16/21634 stipulates that the stakeholder summary must include, where appropriate, a separate section for contributions from the NHRIs and that:

The national human rights institution of the State under review consistent with the principles relating to the status of national institutions for the promotion and protection of human rights annexed to General Assembly resolution 48/134 (the Paris Principles) shall be entitled to intervene immediately after the State under review during the adoption of the outcome of the review by the Council plenary. ${ }^{635}$

\section{Criteria for the Case Study}

When choosing which NHRIs would provide a good study of the role NHRIs played in the UPR, the author considered the following factors:

(1) Whether the NHRI had been mentioned in any conferences or articles regarding good practices or exemplary ways to achieve best results in the UPR;

(2) Where the country fit in the regional bloc scheme, together with the size and economic resources of the country; and

(3) Accessibility and willingness of the NHRI officials to be interviewed and candidness about the process.

Denmark and Kenya were two countries that were favorably mentioned in conferences and articles regarding NHRI participation in the UPR. In May 2011, the author attended a Cost Action seminar hosted by the Danish Institute for Human Rights in which the Director of the Institute spoke about the way in which the Institute was involved in Denmark's UPR. ${ }^{636}$ Later, in articles summarizing the UPR or in stakeholder conferences, these NHRIs were identified as key participants and contributors. ${ }^{637}$ In addition, the Danish Institute for Human Rights prepared a document for use by civil society to aid in preparation for the UPR. In the document, the Kenyan Commission for Human Rights described its UPR preparation process. ${ }^{638}$ Peer countries have also asked the Kenyan Commission for Human Rights to provide assistance or training in the UPR process. ${ }^{639}$ The recognition by other groups that monitor the UPR and by peers suggests that Kenya and Denmark have forged new ground in the interaction between NHRIs and civil society and governments. Based on these criteria, a case study would be useful for extracting best practices. Indeed, both nations have several practices that are worthy of disseminating to other NHRIs. These practices are highlighted in this chapter.

Denmark operates within the Western European and others group, while Kenya is a member of the African group. Though neither country is among the largest of nations, there is a distinct difference in economic power. The diversity in blocs and economic power should give the findings validity as some best practices are shared despite differences in regional and economic backgrounds.

The key informants from Kenya and Denmark were willing to discuss the process on the record and to give their opinions about the relevancy of the UPR and its contribution to UN Human Rights machinery. This openness was crucial in providing additional narratives about how the UPR is carried out in practice.

\footnotetext{
${ }^{634}$ HRC Res 16/21, UN Doc A/HRC/RES/16/21, 21 March 2011.

${ }^{635} \mathrm{Id}$. at $\mathbb{1} 13$.

${ }^{636}$ COST Action IS0702 The Role of the EU in UN Human Rights Reform hosted by the Danish Institute for Human Rights in Copenhagen, Denmark on May 23 and May 24, 2011.

${ }^{637}$ See e.g., the International Service for Human Rights' reference to a side event held by the Kenyan national Commission on Human Rights, http://www.ishr.ch/upr/765-kenya-reviewed-by-the-upr-impressive-efforts-of-civil-society; See also UPR-Info.'s discussion of the International Coordinating Committee on NHRIs conference about UPR follow-up, http://www.ishr.ch/upr/765-kenya-reviewed-by-theupr-impressive-efforts-of-civil-society.

638DANISH INSTITUTE FOR HUMAN RIGHTS, Universal Periodic Review First Cycle, available at http://idsn.org/fileadmin/user_folder/pdf/New_files/UN/UPR_First_Cycle_DIHR_.pdf.

${ }^{639}$ KENYAN NATIONAL COMMISSION FOR HUMAN RIGHTS, Accounting for Human Rights Protection Under the UPR: The Difference Kenya's

Stakeholders Made, (September 2011) (on file with the author).
} 
In keeping with the best practices for social science research, the author triangulated the information that was given in the interviews with the written information available in the stakeholder submissions, the OHCHR summary and the national report. Using those reports, together with selected publications from the NIHRs in each country, I confirmed and verified the data gathered from the interview. For this chapter, two informants from the Danish Institute for Human Rights, one informant from the Kenyan National Commission for Human Rights. 


\section{Best Practices for National Human Rights Institutions: The Case of Denmark}

Denmark's universal periodic review provides examples of best practices for National Human Rights Institutions in interaction with civil society and government in the preparation for and implementation of recommendations coming out of the universal periodic review. Denmark is one of only a few countries with a fully-accredited National Human Rights Institution - the Danish Institute for Human Rights (DIHR). As will be demonstrated, DIHR played a pivotal role in galvanizing civil society organizations before and during the national consultation. The DIHR remained active after the UPR and continues to lead efforts to ensure that the government implements the recommendations that it accepted in the final outcome of the UPR.

\section{A. Background}

Denmark is a nation located in the North Sea, above Germany and west of Sweden. Part of the nation is connected to the European continent, while other parts of the nation are best described as islands. The Danish kingdom is also comprised of Greenland and the Faroe Islands, both of which are self-ruling jurisdictions. Denmark is a parliamentary democracy led by a monarch. The Danish Constitution, last amended in 1953, sets forth the civil and human rights for citizens of Denmark. At the time of the Danish universal periodic review, the country was led by Liberal Prime Minister Lars Lokke Rasmussen. On September 15, 2011, the Social Democrats won parliamentary elections and formed a center-left coalition led by a new, female Prime Minister, Helle Thorning-Schmidt. In recent years, Denmark has been challenged by the influx of immigrants from different religious and ethnic backgrounds. It also has challenges related to the indigenous populations in its self-ruling islands.

In the United Nations, Denmark is part of the Western European and Others Group of the United Nations and is a member of the European Union. The country of Denmark has ratified seven of the core human rights treaties, except the International Convention of the Protection of All Persons from Enforced Disappearance, the International Convention on the Protection of the Rights of All Migrant Workers and Members of the Families. In addition, it has not accepted the right of individual communications concerning the Convention of the Rights of Persons with Disabilities and the International Covenant of Economic, Social and Cultural Rights. Finally, the Danish parliament has not incorporated any of the ratified United Nations instruments into its domestic law.

Denmark's universal periodic review took place in May 2011 in Geneva. The preparations for the universal periodic review were carried out by the Ministry of Foreign Affairs in consultation with other relevant ministries. The Danish Institute for Human Rights (DIHR) aided the Ministry of Foreign Affairs in arranging for consultations in Copenhagen and Aarhus.

\section{B. NHRIs Stimulate Stakeholder Participation}

\section{The Danish Institute for Human Rights}

Denmark's UPR is a salient case study in the way in which a national human rights institution (NHRI) can positively aid and impact the national consultation, the interactive dialogue, the recommendations and the followup to recommendations. The DIHR is Denmark's NHRI, having come into being in 1987.640 At that time, it was known as the Danish Centre for Human Rights. ${ }^{641}$ The centre's authority as a national human rights institution was acknowledged in the parliamentary Act Governing the Establishment of the Danish Centre for international Studies and Human Rights on June 6, 2002. ${ }^{642}$ Currently, the DIHR enjoys A status in accordance with the Paris

\footnotetext{
${ }^{640}$ DANISH INSTITUTE FOR HuMAN RIgHTS, Who We Are: The Mandate of Danish Institute for Human Rights, http://www.humanrights.dk/who+we+are.

${ }^{641} \mathrm{Id}$.

${ }^{642}$ DANISH INSTITUTE FOR HUMAN RIGHTS, DIHR's Mandate , http://www.humanrights.dk/who+we+are/dihr's+mandate
} 
Principles. The DIHR also acts as the designated body for the promotion, protection and monitoring of the implementation of the UN convention on the Rights of Persons with Disabilities. ${ }^{643}$

DIHR developed a publication regarding the UPR in which it diagrammed the UPR from the point of view of the state, civil society and NHRIs. In its description of the role of NHRIs, DIHR stated, "The NHRI potentially has a unique role to play in advising the state on the UPR, co-organizing and co-hosting public consultations, consulting civil society on the process and preparing its own UPR submission. Finally, the NHRI has a task in the follow up procedure ensuring effective implementation of accepted recommendations." 644 The Institute advocated fourteen ways to intervene in the UPR process as a NHRI:

1. Dissemination of knowledge on the UPR;

2. Engage state and civil society in the process and inform of obligations and opportunities;

3. Submission of a NHRI stakeholder report;

4. Facilitate and assist other stakeholder reports with technical assistance

5. Assist state in the consultative process of the National Report;

6. Prepare suggestions for advanced questions and publish it on website

7. Public information campaign before the review;

8. Consult with civil society organisations and state before the review;

9. Consider side events and interaction with diplomatic missions;

10. Attend the review in Geneva;

11. Follow up on commitments made by the state in relation to recommendations;

12. Scrutinize rejected recommendations;

13. Approach state in follow-up process to ensure implementation of pledges without delay; and

14. Ensure domestic media coverage, dissemination and translation of recommendation and National Report and stakeholder reports. 645

DIHR was innovative in its view that the NHRI was uniquely placed, being independently funded and neither governmental nor non-governmental. Thus, the NHRI could coordinate nationally by linking the state and civil society while also "being the natural point of entry for the international system for an independent knowledge base on the present domestic human rights situation." 646

DIHR led out in the preparations for the UPR by beginning a three-front approach to the review. The DIHR created three internal teams that were dedicated to the UPR. ${ }^{647}$ One team was responsible for contacts with the Danish government and its ministries. ${ }^{648}$ A second team developed, drafted and submitted the DIHR's report to the Office of the High Commissioner for Human Rights (OHCHR). ${ }^{649}$ A third team was pivotal in collaboration with civil society groups, including non-government organizations in drafting a joint stakeholder report for submission to the OHCHR. ${ }^{650}$ These reports were due months before the government's national report. Therefore, DIHR was well-placed to both elicit participation from civil society and influence the government's approach to drafting the national report.

${ }^{643} \mathrm{Id}$.

${ }_{644}$ DANISH InSTITUTE FOR HUMAn Rights, Universal Periodic Review First Cycle, supra note 609, at 39.

${ }^{645} \mathrm{Id}$. at $39-40$

${ }^{646} \mathrm{Id}$. at 40.

${ }^{647}$ Interview with Martin Futtrup, Legal Adviser, Danish Institute for Human Rights, February 7, 2012.

${ }^{648} \mathrm{Id}$.

${ }^{649} \mathrm{Id}$.

${ }_{650} \mathrm{Id}$. 


\section{Joint Stakeholder Submissions}

DIHR took the initiative in the Denmark's UPR process by mobilizing civil society. One Project Manager for DIHR, recalls that DIHR first raised the idea of collaborating with other stakeholders in a meeting with DIHR's Council, a body consisting of 50 human rights organization and representatives from political parties and Danish universities. 651 The Council welcomed the idea and that 10 to 12 organizations began to schedule regular meetings. ${ }^{652}$ Out of the meetings came the decision to file a joint stakeholder report. The joint stakeholder report was endorsed by a wide-ranging number of civil society groups, including Amnesty International in the Faroe Islands, three Greenland organizations (among them, the Inuit Circumpolar conference), the Danish Association of Legal Affairs, the Danish Helsinki Committee for Human Rights, Save the Children Denmark, and the European Network Against Racism and Documentary and Advisory Centre on Racial Discrimination. ${ }^{653}$ The submissions by civil society groups were equally broad in its coverage of human rights issues. Among the human rights issues highlighted in the stakeholder reports:

Lack of attention to violence against women in the Faroe Islands;

Ratification by Faroe Islands of Convention on Action Against Trafficking in Human Beings;

Creation of a National Human Rights Institution for Greenland;

Tensions regarding the Thule Air Base, a US base located in the hunting territory of the Inughuit peoples;

Lack of application of a variety of rights of the indigenous communities in Greenland;

Lack of compliance by Denmark with the concluding observations of several treaty bodies;

Requirement that family reunification be granted when both spouses have reached the age of 24 years;

Deportation of asylum seekers to Greece;

Solitary confinement of suspects;

Health care for non-documented immigrants;

Reduction of the age of criminal responsibility; and

Hate crimes and speech.

\section{DIHR's Submission}

While the stakeholder meetings were drafting a comprehensive document to address the human rights picture on the ground in Denmark, a second group of DIHR team members were conducting a desk study to write DIHR's own submission as a national human rights institution. One DIHR Legal Adviser indicates that the report was due in November 2010 and was drafted on the basis of Danish legislation, case law from courts and administrative bodies and to a lesser extent reports from non-governmental organizations and academic institutions. ${ }^{54}$ The five-page report focused on the institutional framework rather than the individual human rights issues. This was a strategic decision made by the DIHR because the civil society organizations were better

${ }^{651}$ Interview with Lis Dhundale, Program Manager, Danish Institute for Human Rights, February 7, 2012.

$652 \mathrm{Id}$.

${ }^{653}$ The Joint Stakeholder report can be found on UPR-info.org. Look up the session for Denmark. See also http://lib.ohchr.org/HRBodies/UPR/Documents/Session11/DK/JS3_JointSubmission\%203-eng.pdf; http://lib.ohchr.org/HRBodies/UPR/Documents/Session11/DK/JS4_JointSubmission4-eng.pdf; http://lib.ohchr.org/HRBodies/UPR/Documents/Session11/DK/JS2_JointSubmission\%202-eng.pdf; and http:/ /lib.ohchr.org/HRBodies/UPR/Documents/Session11/DK/JS2_JointSubmission\%202-eng.pdf. ${ }^{654}$ Interview with Martin Futtrup, Legal Adviser, Danish Institute for Human Rights, February 7, 2012. 
placed to discuss individual human rights violations, which the DIHR could use its resources to highlight weaknesses in the institutional structure that impede full recognition of human rights. 655

The DIHR submission made the following recommendations:

Development of a national action plan for human rights;

Ratification and incorporation of all core regional and international human rights treaties and protocols, as well as the recognition of the competence of committees to receive individual communications;

Modification to Danish Constitution to update the catalogue of human rights to include nonincorporated rights;

Revision to Danish legislation such that equal treatment applies to all areas of society;

Training of judiciary and its staff so that human rights instruments are used in court decisions;

Make Danish case law publicly available on the internet or through free databases;

Systematic monitoring of human rights by Danish authorities;

Adequate funding of Danish NHRI; and

Development of domestic human rights indicators to improve compliance with international recommendations 656

Creating a review of the structural processes in place in Denmark for addressing human rights complaints was an essential exercise because it provided a baseline against which to measure future progress. The length of the report is merely five pages; therefore, the coordination of joint stakeholder reports permitted the DIHR to get other important individual violations and human rights issues into the forefront of the review.

\section{Other NGO Submissions ${ }^{657}$}

The response by civil society to the Danish UPR was impressive. Several NGOs, including both international and national groups, provided submissions to the OHCHR regarding human rights on the ground in Denmark. Among the fifteen submissions were reports from Amnesty International, Amnesti Nu, Association for Women's Organisation in the Faroe Islands, the Committee for Underground Refugees, ECPAT International, European Roma Rights Centre, Grandparents for Asylum and the Women's Council in Denmark. The Council of Europe (CoE) also submitted a report. In its submission, the $\mathrm{CoE}$ attached prior reports submitted regarding Denmark's performance and recommendations made to Denmark in the areas of prevention of torture and inhuman or degrading treatment, racism and intolerance and in themes covered in the European Social Charter, as well as its progress in implementing the CoE Commissioner for Human Rights' recommendations from 2004.

\section{NHRIs Constructively Engage With the Government}

\section{National Consultations 658}

Chronologically, the government's consultations occurred subsequent to the submission of the stakeholder reports. Again, the DIHR played an important role in the way in which consultations were carried out by the Danish government. DIHR had approached the Ministry of Foreign Affairs and asked what their plans were for the UPR national consultation. The DIHR team assigned to liaise with government organs played a key role in the

$655 \mathrm{Id}$.

${ }^{656}$ Submission by the Danish Institute for Human Rights to the Universal Periodic Review of Denmark 2nd May 2011, 11th Session of the Working Group Under the UN Human Rights Council , available at

http://www.humanrights.dk/files/pdf/UPR/DIHR_DanishInstituteforHumanRights-eng.pdf.

657 To access individual stakeholder submissions, visit UPR-info.org and search for Denmark's first UPR cycle.

${ }^{658}$ The information in this subsection "National Consultations" is taken from two sources: Interview with Liz Dhundal, Program Manager, Danish Institute for Human Rights, February 7, 2012 and Interview with Martin Futtrup, Legal Adviser, Danish Institute for Human Rights, February 7, 2012. 
Danish government's national consultation. The Danish government paid for and arranged hearings in the cities of Copenhagen and Aarhus, as well as on the Faroe Islands and in Greenland. The government sent invitations to its contacts, while DIHR also contacted civil society organizations and posted an announcement on its webpage. The Copenhagen hearing was held at the University of Copenhagen and was attended by two members of the Ministry of Foreign Affairs and a student assistant. DIHR also sent its director and other staff members to the event. The hearing was chaired by DIHR director, Jonas Christoffersen. The event lasted two to three hours. Some 40 to 50 persons were present representing organized civil society, academia and some citizens.

The Aarhus and Copenhagen town meetings followed a similar format. The Ministry of Foreign Affairs introduced the hearing for approximately 15 minutes. Charts had been placed around the meeting area for participants to write on. The charts were divided into the human rights enumerated in the Universal Declaration of Human Rights, with a blank chart to be used as a catch-all for categories or issues not mentioned on other charts. Participants were encouraged to write their concerns on a post-it note and place on the appropriate chart. DIHR Director Christoffersen walked around to read the charts, one-by-one and asked participants to elaborate on their own contributions. One example of a topic that was posted on the charts included the Danish law stipulating that family reunification with a foreign spouse normally requires that both persons are older than 24 years. The law forces people to move outside of the Danish border so they can get married, impacting the right to family life. Another topic included ill treatment of the mentally ill, including proceedings to take away their right to act on their own behalf. Finally, the NGO sector was very articulate in raising the issue of isolation of inmates in Danish prisons.

During the time that the charts were read and commented upon, the government's student assistant took notes. Those notes were not made available to the general public. The government also took the charts and post-it notes. No audio or video recording of the event is known to have been made.

\section{National Report659}

Following the Copenhagen and Aarhus consultations (the consultations in the Faroe Islands and Greenland were not sponsored or arranged by the DIHR), the Ministry of Foreign Affairs prepared the national report, with the "involvement of relevant ministries." 660 In its report, the government referenced the national consultations and acknowledged that the Copenhagen and Aarhus consultations were carried out jointly with DIHR. ${ }^{661}$ The government also briefly described a parallel process in which it launched a website "where all interested parties could submit suggestions on areas to be covered by the report." 662 In the report, the government also stated that a draft of the national report was released for public comment in the website. ${ }^{663}$

Denmark's national report discussed many human rights issues by highlighting the legislation that has been enacted to protect certain groups of people or specific human rights. ${ }^{664}$ The national report covered these topics: institutional protections, equal treatment, refugees and asylum seekers, integration, children, human trafficking, domestic violence, national minorities, freedom of opinion and expression, freedom of religion, the rule of law, poverty, mental illness, employment and education. ${ }^{665}$ The report also discussed situations specific to the Faroe Islands and Greenland, among them language and cultural identity, rights of indigenous peoples, health care and judicial reform. 666

\footnotetext{
${ }^{659}$ Unless otherwise noted, the description in this subsection "National Report" is based on National Report Submitted in Accordance with Paragraph 15(a) of the annex to Human Rights Council Resolution 5/1 - Denmark, UN Doc. A/HRC/WG.6/11/DNK/1 (17 February 2011). ${ }^{660}$ National Report Submitted in Accordance With Paragraph 15(a) of the Annex to Human Rights Council Resolution 5/1 Denmark, UN Doc. A/HRC/WG.6/11/DNK/1 ๆ 1.

${ }^{661} \mathrm{Id}$. at 92.

662 Id. at 93.

${ }^{663} \mathrm{Id}$.

${ }^{664} \mathrm{Id}$. at 9 - 21-23, 33-34, 37, 45, 48, 84-85.

$665 \mathrm{Id}$. at 9 १ $20-92$.

${ }^{666} \mathrm{Id}$. at 9 ฯ 95-144. 
An analysis of the text demonstrates that the national government equates passing of legislation or taking measures at the ministry level with realization of rights. There was little information revealing how Denmark planned to remedy specific human rights violations or whether the regulations and laws translated into real improvement in everyday life. In a few rare instances, the national report acknowledged criticism on certain human rights violations.

As noted earlier, most of the national report discussions involved a list of laws enacted by the Danish legislature or a brief mention of regulations. One example relates to persons with disabilities. In its report, the government acknowledged that "Denmark faces a line of challenges when it comes to ensuring that persons with disabilities have access to their physical surroundings on an equal footing with others." 667 The report then states that a number of initiatives have been launched to improve accessibility. However, when the government gives an example of the concrete steps it has taken, it turns out to be yet another regulations. The government avers, "a new set of building regulations came into force on 30 June 2010. The regulations contain provisions on accessibility...." 668 What is more telling is that the discussion regarding the new initiatives on disability is an attempt by the government to prove that it is implementing the UN Convention on the Rights of Persons with Disabilities. ${ }^{669}$ While new initiatives are laudable, they cannot be confused with realization of rights by the right holders themselves.

Two other examples of discussions about specific rights violations are the explanation regarding poor families and the police detentions in the wake of the Climate Change Summit in Copenhagen. Regarding poverty, the national report states, "there are people and families who live in poverty." ${ }^{670}$ Here again, the government report acknowledges a problem, but its only suggested solution is the "development of poverty indicators, which are designed to reflect the fact that poverty is a multi-faceted and complex problem requiring individual solutions..." 671 The government maintains that such indicators "make it possible to identify poor families and individuals, as well as implement specific initiatives to lift them out of poverty." 672

The national report was more forthcoming about use of force by the police, but it still lacked an indication of how it would prevent such violations in the futures. The report states that "use of force by police during the climate summit in Copenhagen in December 2009 has been the subject of public criticism." 673 It then refers to the number of detentions and to a judgment by the Copenhagen City Court. ${ }^{674}$ However, the report does not indicate whether measures will be taken to review the legislation regarding detention or present other alternatives to address the violations.

While the above-written analysis was formed on the basis of the written text of the national report, interviews with the key informants also expressed views that the report was lacking. The key informants indicated their disappointment with the content of the national report. One informant stated that the national report was "superficial" and lacked any self-critical views. ${ }^{675}$ The national report was perceived to be much less selfreflective than that of other countries, like Germany. ${ }^{676}$ Informants through the government did not focus enough on areas where there is a lot of work left to do. 677

\footnotetext{
${ }^{667} \mathrm{Id}$. at 928.

$668 \mathrm{Id}$.

${ }^{669} \mathrm{Id}$. at 926.

${ }^{670} \mathrm{Id}$. at 93

${ }^{671} \mathrm{Id}$.

${ }^{672} \mathrm{Id}$.

${ }^{673}$ Id. at 74

674 Id.

675 Interview with Martin Futtrup, Legal Adviser, Danish Institute for Human Rights, February 7, 2012.

676 Interview with Lis Dhundale, Program Manager, Danish Institute for Human Rights, February 7, 2012.

$677 \mathrm{Id}$.
} 


\section{Compilation and Summary from the OHCHR Offers Alternative Viewpoint}

When one analyzes the texts coming from the OHCHR and compares them to the national report, there is a distinct difference in viewpoints. The national report presents Denmark as a nation that largely complies with its human rights obligations, but has a few areas where challenges remain, but are being promptly dealt with through regulations and legislation. The OHCHR compilations present another story. As discussed earlier in this chapter, DIHR had made gargantuan efforts to involve civil society. These efforts paid off in that the views expressed in the compilations countered the picture painted in the government's submission. While Denmark appears solid in terms of its ratifications of the core UN human rights treaties, the Treaty Bodies have identified many areas in which Denmark needs to take concrete measures to address violations. Similarly, the stakeholders mobilized by DIHR submitted additional credible information regarding human rights violations within Denmark. This data contradicted the information in the national report.

The OHCHR prepared the requisite two documents. While Denmark's record is generally good and country is up to date with all of its treaty body (committee) reporting requirements, in the compilation regarding data from the treaty bodies and special procedures, it was noted that Denmark had been urged to ratify the migrant workers' convention by both the CEDAW and CERD. ${ }^{678}$ In addition, concerns were raised in many areas. For example, CERD expressed concern about negative attitudes toward newly-arrived immigrants; 679 CAT recommended that Denmark ensure that solitary confinement be used in exceptional circumstances for a limited period of time and that the principle of proportionality be observed in such cases; $680 \mathrm{CRC}$ expressed concern that the age limit for family reunification in Denmark was lowered from 18 years to 15 years ; ${ }^{681}$ HRC questions Denmark's reliance upon diplomatic assurances when returning foreign nationals to countries where "treatment contrary to the Covenant is believed to occur." 682

As discussed above, the participation by stakeholders was broad. The OHCHR compilation contained a summary of 15 stakeholders. ${ }^{683}$ The report summarized the points brought out in the DIHR's submission, as well as the joint stakeholder submissions. Regarding other concerns raised by groups that did not comprise the joint stakeholders (the joint stakeholder submission is discussed earlier in this chapter in the subsection "Joint Stakeholder Submissions"), the Committee for Underground Refugees expressed concern for increasingly racist statements made by members of parliament and the practice by government officials of using inflammatory statements against the Roma. ${ }^{684}$ This information suggests that the initiatives to combat racism described in the national report are misplaced because they focus on private citizens (doormen) and night life rather than on discrimination by elected officials in the course of their professional duties. ${ }^{685}$ A second example of how the picture in the stakeholders' report directly contradicted the government version was The Women's Council in Denmark assertion that only 8 of 40 shelters are accessible to women with disabilities. ${ }^{686}$ That data specifically challenged the government's general statement that it was focused on implementing a "large number of initiatives

\footnotetext{
${ }^{678}$ Compilation Prepared by the Office of the High Commissioner for Human Rights in Accordance with Paragraph 15 (b) of the Annex to Human Rights Council Resolution 5/1 - Denmark, UN Doc A/HRC/WG.6/11/DNK/2 ฯ 1.

${ }^{679}$ Id. at 926.

${ }^{680} \mathrm{Id}$. at 935.

${ }^{681} \mathrm{Id}$. at 946.

${ }^{682} \mathrm{Id}$. at 975.

${ }^{683}$ Summary Prepared by the Office of the High Commissioner for Human Rights in Accordance with Paragraph 15 (c) of the Annext to Human Rights Council Resolution 5/1 - Denmark, UN Doc A/HRC/WG.6/11/DNK/3, cover page.

${ }^{684} \mathrm{Id}$. at ๆ $920-21$.

${ }^{685}$ National Report Submitted in Accordance With Paragraph 15(a) of the Annex to Human Rights Council Resolution 5/1 Denmark, UN Doc. A/HRC/WG.6/11/DNK/1 I 36("Unfortunately, Denmark still faces challenges which may obstruct citizens from taking part in society on an equal footing. Therefore, legislation is being supplemented by initiatives that promote equal treatment. In 2010, the Government launched its "Action plan for ethnic equal treatment and respect for the individual", which contains 21 initiatives. This includes a research project that will contribute to the development of more accurate methods for measuring discrimination. Another initiative, in the form of an awareness campaign and special training for doormen, concerns an intensified effort to combat discrimination in the nightlife to ensure that the ban on discrimination in the racial Dsicrimination Act is upheld in practice.").

${ }^{686}$ Summary Prepared by the Office of the High Commissioner for Human Rights in Accordance with Paragraph 15 (c) of the Annext to Human Rights Council Resolution 5/1 - Denmark, UN Doc A/HRC/WG.6/11/DNK/3 q 28.
} 
aimed at a progressive realization of the rights laid down in the CRPD." 687 ECPAT International suggested that Denmark provide foreign children who were victims of trafficking the possibility of "long-term medical,

psychological, financial and legal assistance before repatriation." 688 This proposal seems to again display how the Danish government's initiatives miss the mark. The government states in the national report that it is focused on the perpetrators and therefore will aim to "criminaliz[e] human trafficking" ${ }^{689}$ while the ECPAT finding suggests that the victims of trafficking are in need of direct protective action.

\section{E. Preparations for the Interactive Dialogue ${ }^{690}$}

DIHR recognized that it must get its recommendations and ideas into the interactive dialogue and, therefore, before the Danish national government. So, in the lead-up to the review of Denmark before the Working Group of the UN Human Rights Council, the DIHR launched an intensive campaign to lobby its diplomatic contacts. The campaign was designed to get the issues that DIHR deemed important into the interactive dialogue so they would become a part of the final outcome for the Danish UPR. ${ }^{691}$

There were two initiatives. The DIHR called for a meeting of all embassies in Copenhagen. In a joint meeting the ambassadors were briefed about the DIHR, the UPR for Denmark, DIHR's selected recommendations regarding human rights in Denmark, and the DIHR's stakeholder submission. Approximately 80 to 90 embassies took part in the meeting. A second similar initiative was undertaken by DIHR in Geneva with the permanent missions willing to participate.

The campaign effectively led to DIHR getting the key issues into the interactive dialogue. One example of success is the interaction with the Norwegian delegation. One key informant described a visit with Norway's ambassador in Copenhagen ${ }^{692}$ The ambassador already had a general idea of what topics Norway wanted to raise in the interactive dialogue. In their face-to-face meeting, the informant gave the DIHR's views on those recommendations and noted that many of the things that Norway wanted to say coincided with the DIHR's own recommendations, including the issue of a child ombudsman, the lowering of the age for criminal responsibility. ${ }^{693}$ After the end of the meeting, the Norwegian ambassador was given a copy of DIHR's submission to the OHCHR and the selected recommendations. ${ }^{694}$

During Norway's intervention in the interactive dialogue, Mr. Christian Halaas Lyster, of the Norwegian delegation, took the floor to address Denmark. His intervention commended Denmark for its contribution to the development of international instruments, for its compliance with and promotion of human rights and for its efforts against torture. ${ }^{695}$ The delegate also urged Denmark to continue its efforts to achieve gender equality for women in management and for salaries. ${ }^{696} \mathrm{He}$ also specified that Denmark should ensure the rights of children and emphasized that Danish children should have access to an independent body to monitor and advocate on

\footnotetext{
${ }^{687}$ National Report Submitted in Accordance With Paragraph 15(a) of the Annex to Human Rights Council Resolution 5/1 Denmark, UN Doc. A/HRC/WG.6/11/DNK/1 ๆ 26.

${ }^{688}$ Summary Prepared by the Office of the High Commissioner for Human Rights in Accordance with Paragraph 15 (c) of the Annext to Human Rights Council Resolution 5/1 - Denmark, UN Doc A/HRC/WG.6/11/DNK/3 ๆ 37-38, 40-41.

${ }^{689}$ National Report Submitted in Accordance With Paragraph 15(a) of the Annex to Human Rights Council Resolution 5/1 Denmark, UN Doc. A/HRC/WG.6/11/DNK/1 ๆ 51.

${ }^{690}$ Unless otherwise indicated, the information in this subsection "Preparations for the Interactive Dialogue" is taken from two sources: Interview with Liz Dhundal, Program Manager, Danish Institute for Human Rights, February 7, 2012 and Interview with Martin Futtrup, Legal Adviser, Danish Institute for Human Rights, February 7, 2012.

${ }^{691}$ NIHRs have no right to directly participate in the interactive dialogue. They are not permitted to take the floor-- a fact that the Minister of Foreign Affairs rued in his opening remarks during Denmark's interactive dialogue in the first cycle of the UPR. As a result, DIHR would need to have a state give a verbal or written recommendation during Denmark's review in order for the recommendation to become part of the final outcome document for Denmark.

${ }^{692}$ Interview with Martin Futtrup, Legal Adviser, Danish Institute for Human Rights, February 7, 2012.

${ }^{693} \mathrm{Id}$.

${ }^{694} \mathrm{Id}$.

${ }^{695}$ Report of the Working Group on the Universal Periodic Review - Denmark, UN Doc A/HRC/18/4 981.

696 UN Webcast: Human Rights Council Review of Denmark, remarks by Norway: Mr. Christian Halaas Lyster.
} 
their behalf. ${ }^{697}$ He suggested that Denmark establish a children's ombudsman. ${ }^{698}$ Next, he asked whether the lowering of the age of criminal responsibility to 14 years has produced a change in juvenile crime rates. ${ }^{699}$ Finally, he inquired as to whether the reference in the penal code to the marital relationship between rape victims and the perpetrator has influenced sentencing. ${ }^{700}$ This intervention is a concrete example of how the campaign to embassies paid off handsomely for DIHR.

\section{F. The Interactive Dialogue 701}

Denmark's review before the Working Group of the UN Human Rights Council took place on May 2, 2011. The Troika for Denmark included the countries of Chile, Ghana and the Republic of Korea. There were advance questions submitted to Denmark by the delegations from Sweden, Switzerland, the United Kingdom, the Czech Republic, Estonia, France, the Netherlands, Norway and Slovenia. The topics raised in the advance questions included CIA rendition flights (Switzerland), incrimination of rape (Norway), the progress made toward ratification of the International Convention Against Enforced Disappearances (France), a request to explain the initiatives taken to target violence in intimate relations (the Netherlands), and National Action Plan for Human Rights (Slovenia).

On the day of the review, three high-level ministers appeared and spoke before the Working Group of the Council: Claus Grube, Permanent Secretary of State for Foreign Affairs, and one government representative from the Faroe Islands, Durita Lamhauge Jóansdóttir of the Fisheries, Trade and Regional Policy Department and one representative from Greenland, Marianne Lykke Thomsen, Senior Policy Advisor, Department of Foreign Affairs. The entire delegation also included individuals representing the Ministry of Justice, the Permanent Mission for Denmark in Geneva, the Head of the Human Rights Unite from the Ministry of Foreign Affairs, the Ministry of Refugee, Immigration and Integration Affairs, the Ministry of Social Affairs and the Ministry of Education.

The head of delegation made his opening remarks, highlighting the importance of the UPR as "unique in its egalitarian nature and allows for a candid debate on human rights among peer states." 702 Additionally, Mr. Grube described the UPR as a "positive innovation with a true potential to improve human rights on the ground for the benefit of citizens everywhere." Denmark contributed \$375,000 (US) to the Voluntary Fund. Regarding the human rights situation in Denmark, Mr. Grube admitted that there were challenges and explained that Denmark has undergone significant demographic changes which challenge the cohesive nature of its society. Currently, $10.1 \%$ of Danes are immigrants. This factor demonstrates the ethnic diversity which now exists in Denmark.

During the interventions by 47 peer states, many issues and questions were directed at the delegation head. Among the human rights challenges brought to the forefront were: efforts to achieve racial balance in the police force, incorporation of core human rights instruments into domestic legislation, the limited mandate of DIHR (not covering Faroe Islands), ratification of the enforced disappearance convention, non-refoulement and CIA rendition flights, availability of case law to general public, accession to the convention for rights of migrant workers, national action plan on human rights, health care for asylum seekers, overdue special procedures reports. There were also favorable interventions highlighting Denmark's human rights situation and its commitment to combat sexual violence, poverty and offering a standing invitation to special procedures.

Mr. Grube was direct when responding to delegation questions and comments. He made it clear that Denmark did not find it necessary to introduce a National Action Plan for human rights, stating that new legislation is introduced within the framework of human rights obligations and those individual human rights issues are addressed by experts responsible for the area of society in question. Regarding implementation of

\footnotetext{
${ }^{697}$ Report of the Working Group on the Universal Periodic Review - Denmark, UN Doc A/HRC/18/4.

${ }^{698}$ UN Webcast: Human Rights Council Review of Denmark, remarks by Norway: Mr. Christian Halaas Lyster.

${ }^{699} \mathrm{Id}$.

700 Report of the Working Group on the Universal Periodic Review - Denmark, UN Doc A/HRC/18/4.

${ }^{701}$ UN Webcast: Human Rights Council Review of Denmark. Unless otherwise noted, the information in this section is taken from the webcast of the Interactive Dialogue for the UPR of Denmark, held on May 2, 2011. The webcast is available on the OHCHR website at http:/ / www.un.org/webcast/unhrc/archive.asp?go=110502\#pm.

702 Id. at (:45).
} 
international obligations into national legislation, Mr. Grube indicated that the Danish government would not do so because its already has a process to assess whether national law conforms with international conventions. In addition, international conventions may always be utilized in national courts and other public authorities. Similarly, the government saw no need to address the availability of case law because case law is available from private websites (subscription necessary) or from the website of the issuing authority. The Danish court administration has also begun to prepare a database of case law, according to the Danish head of delegation. Mr.Grube responded to questions concerning persons born stateless in Denmark, family reunification laws, expulsion of Roma, hate crimes, the cartoons of the Prophet Muhammad, and women's participation in political life, the standard of living for migrants, combating xenophobia and human trafficking.

There was one moment in Mr. Grube's intervention when he appeared to take a radically different view than was expected. Regarding the issue of the convention for migrant workers, Mr. Grube stated, "Finally, let me just add, due to all the calls that the many calls on the ratification of the convention of Migrant Workers have duly impressed me and I will take this recommendation with me back to Copenhagen and the Danish government." One key informant said he was very surprised when he witnessed this statement from the Minister of Foreign Affairs. ${ }^{703}$ Alas, it would not come to fruition. When the government presented its response to the recommendations, it rejected calls for ratification of the migrant workers' convention. The key informant believes Grube made an error because, historically, it has not been the policy of the Danish government to accept such recommendations. ${ }^{704}$

Applying discourse analysis to the interactive dialogue is a challenge for the author. The environment was very formal (which is, of course, typical for the United Nations) and both the delegation under review and the states in the working group read from prepared statements. The language used during the dialogue was replete with diplomatic words that indicated that no state felt it necessary to impose an obligation, rather each state deferred to the right of the state under review to determine whether it would accept a recommendation or undertake an obligation. Therefore, phrases such as "Country X urges Denmark to...", "Denmark should consider..." or "Country Y welcomes...." These phrases underline the permissive and optional nature of the recommendations and the right of the state to accept or reject the same.

Regarding the national delegation, there was also a very diplomatic tone. The delegation thanked by country those nations that were on the speakers' list. The minister also referred to the delegations as "distinguished." The deference to fellow members is indicative of the sphere in which the UPR is held -it is an intergovernmental phenomenon. States are constantly aware that their behavior has consequences in other diplomatic environments; therefore, even where states may not always be in agreement, they uphold a level of dignity and respect when addressing one another.

Due to the level of diplomacy, it is difficult to assign meaning to the words and discourse that occur in the interactive dialogue. Is the dialogue just a fancy exercise in pointing out some human rights issues and violations without the intention of helping the state begin to address the violations or improve the situation on the ground? The interactive dialogue has a lot of potential for sharing of best practices and diffusion of policy, but those goals cannot be met when the discourse it so formal and void of meaning. Nonetheless, some recommendations were hard-hitting. For example, Finland criticized the Danish Ministry for Integration which, in its estimation, did not act in compliance with the Convention on the Reduction of Statelessness because over a period of time it had denied citizenship to 22 Palestinians. ${ }^{705}$ Finland also noted that the "application instructions of the Ministry of Refugee, Immigration and Integration Affairs do not mention that stateless persons are exempted from the regular citizenship tests and requirements." ${ }^{706}$ Honduras expressed concern that foreign women lose residency permits

\footnotetext{
${ }^{703}$ Interview with Martin Futtrup, Legal Adviser, Danish Institute for Human Rights, February 7, 2012.

$704 \mathrm{Id}$.

${ }_{705}$ Report of the Working Group on the Universal Periodic Review - Denmark, UN Doc A/HRC/18/4 943.

$706 \mathrm{Id}$.
} 
when the leave a violent spouse. ${ }^{707}$ It further noted that "child asylum-seekers receive lower education than nationals." 708

\section{G. Adoption of the Report in the Working Group 709}

The working group report contained a total of 133 recommendations. Those recommendations were made in the areas of international obligations, equality and non-discrimination, the rights of migrants, detention and prison conditions, freedom of expression, women's rights, children's rights, and issues related to Greenland and the Faroe Islands. The Working Group report was adopted on May 4, 2011. In the 48 hours that transpire between the end of the interactive dialogue and the adoption of the report in the working group, one key informant noted that quite a lot happens. The informant states that all the ministries were present at the interactive dialogue, but that they all traveled back to Copenhagen, leaving only two people in Geneva for the adoption of the report. ${ }^{710}$ The informant further opines that once there is some distance between the delegation and the UPR, you can decide not to be as open to recommendations. ${ }^{711}$ The informant believed that many of the recommendations that were rejected were actually easy to implement and would only have cost a bit of money. ${ }^{712}$

\section{H.Final Outcome Before the Council's Plenary Session ${ }^{713}$}

Four months later, on September 21, 2011, in its appearance before the Plenary of the Human Rights Council, things had changed in Denmark's political landscape. A September general election saw the social democrats rise to power. On the day of the plenary, the nation was still negotiating its new government. The government assured the plenary that the new government would continue the process of implementation of the recommendations that were accepted. The (former) government accepted 84 of the recommendations and rejected 51; the new government indicated that those recommendations would be implemented.714

The government committed to: ratify the convention against enforced disappearance, ${ }^{715}$ review existing mechanism for addressing complaints of excessive use of force by law enforcement officers, ${ }^{716}$ take measures to prevent sexual exploitation of children, ${ }^{717}$ take steps to combat prison overcrowding, ${ }^{718}$ and to allow for family reunification for children. ${ }^{719}$

Among the rejected measures were those relating to adoption of Optional Protocols permitting individual complaints under international covenants, ${ }^{720}$ the national action plan for human rights, ${ }^{721}$ ratification of the migrant workers convention, ${ }^{722}$ incorporation of ratified human rights treaties into domestic law. ${ }^{723}$

\footnotetext{
$707 \mathrm{Id}$. at 99.

${ }^{708} \mathrm{Id}$.

${ }^{709} \mathrm{Id}$. The Adoption of the Report in the Working Group can be viewed on the website of the OHCHR at

rtsp://webcast.un.org/ondemand/conferences/unhrc/upr/11th/hrc110504pm2-eng.rm?start=::\&end=::

${ }^{710}$ Interview with Martin Futtrup, Legal Adviser, Danish Institute for Human Rights, February 7, 2012.

${ }^{711} \mathrm{Id}$.

$712 \mathrm{Id}$.

${ }^{713}$ UPR-info.org provides a summary of all recommendations and whether they were accepted or rejected on its website at http://www.uprinfo.org/IMG/pdf/recommendations_to_denmark_2011.pdf.

${ }^{714}$ Report of the Working Group on the Universal Periodic Review -- Denmark, Addendum, Views on Conclusions and/or Recommendations, Voluntary Commitments and Replies Presented by the State Under Review, UN Doc A/HRC/18/4/Add.1.

${ }^{715}$ Report of the Working Group on the Universal Periodic Review - Denmark, UN Doc A/HRC/18/4 \ \ 106.4, 106.11, 106.21 and others.

${ }^{716} \mathrm{Id}$. at $\mathbb{9} 106.75,106.77$.

${ }^{717} \mathrm{Id}$. at $\mathbb{9} 106.91$.

${ }^{718} \mathrm{Id}$. at $\mathrm{I} 106.101$

${ }^{719} \mathrm{Id}$. at $\mathbf{9} 106.116$.

${ }^{720} \mathrm{Id}$. at $\boldsymbol{\|} \mathbb{1} 106.3,106.5-106.9$.

${ }^{721} \mathrm{Id}$. at $\mathbf{9} 106.42$.

722 Id. at 9 I 106.12, 106.13, 106.25, and others.

${ }^{723} \mathrm{Id}$. at $\mathbb{1} 106.26$.
} 
The plenary session of the Council724 is the only forum where NGOs are given a voice and permitted to take the floor. In Denmark's plenary, five stakeholders spoke: Amnesty International; DIHR; LBL, ILGA Europe, COC Netherlands; the Islamic Human Rights Commission; and Save the Children Denmark. Dr. Jonas Christoffersen, the DIHR director took the floor and delivered a short speech in which he emphasized that the 84 recommendations accepted by Denmark were on matters that the government "already considers addressed."725 DIHR encouraged the government to reconsider is response to other recommendations. ${ }^{726}$ Christoffersen mentioned the national human rights action plan, ratification and incorporation of all core conventions and acceptance of individual complaint mechanisms, adequate funding for the DIHR and for the child ombudsperson, as well as more specifics on the implementation of the accepted recommendations. ${ }^{727}$ Denmark did not give justifications or respond to the interventions from the stakeholders.

Following the plenary session, DIHR has been urging the new government to reconsider the rejected recommendations. One informant states that in a one-day meeting in December 2011 with the Ministry of Foreign Affairs, the government informed DIHR that they were reconsidering some of the rejected recommendations. ${ }^{728}$ They have mentioned establishing a cross-ministry working group to consider the recommendations. ${ }^{729}$ DIHR is creating a baseline document to be offered to the government which provides a quick glance at all recommendations and the ministries responsible for their implementation. ${ }^{730}$

\section{Best Practices for National Human Rights Institutions: The Case of Kenya}

Kenya's universal periodic review provides another example of best practices for National Human Rights Institutions (NHRIs) in interaction with civil society, government and with peer nations in the preparation for the UPR and implementation of recommendations flowing from the UPR process. Like Denmark, Kenya is one of only a few countries with a national Human Rights Institution - the Kenyan National Commission for Human Rights (KNCHR). The following study will demonstrate that KNCHR used its unique position to stimulate an interest in the UPR process among civil society groups. In addition, KNCHR exerted its influence on the government to ensure that the national report contained relevant and accurate accounts of human rights on the ground in Kenya. KNCHR also maintained pressure on the Kenyan government following the UPR to ensure that the government implemented the recommendations coming out of the UPR process. The KNCHR has also deemed it important to regularly report on the progress of the government in meeting its obligations.

\section{A. Background}

Kenya is a nation located on the east coast of the African continent, ${ }^{731}$ bordered by the Indian Ocean to the east, Somalia and Ethiopia to the North, South Sudan and Uganda to the west and Lake Victoria and Tanzania to the south. Kenya is a constitutional democracy led by a president with three branches: the legislature, executive and judiciary. ${ }^{732}$ Government activities are coordinated by the Prime Minister. ${ }^{733}$ Following independence in 1963

\footnotetext{
724 The plenary session can be viewed as a webcast on the website of the OHCHR at http:/ / www.unmultimedia.org/tv/webcast/2011/09/consideration-of-denmark-upr-reports-18th-plenary-meeting-18th-session-humanrights-council.html.

${ }^{725}$ Statement by the Danish Institute for Human Rights on the consideration of the UPR Report on Denmark on 21 September 2011, at http://www.upr-info.org/IMG/pdf/danish_institute_for_human_right_oral_denmark_2011.pdf.

${ }^{726} \mathrm{Id}$.

$727 \mathrm{Id}$.

728 Interview with Lis Dhundale, Program Manager, Danish Institute for Human Rights, February 7, 2012.

${ }^{729} \mathrm{Id}$.

${ }^{730} \mathrm{Id}$.

${ }^{731}$ National Report Submitted in Accordance with Paragraph 15 (a) of the Annex to Human Rights Council Resolution 5/1 - Kenya, UN Doc A/HRC/WG.6/8/KEN/1 4.

732 Id. at $\mathbb{7} 7$.

${ }^{733} \mathrm{Id}$.
} 
and until 2002, the country had been dominated by one political party. ${ }^{734}$ In recent years, Kenya suffered political turmoil resulting from post-election violence in 2007 and 2008. 735

In the United Nations, Kenya is part of the African bloc and is a member of the Commonwealth Nations. Kenya is a state party to the core human rights conventions with the exception of that for migrant workers. ${ }^{736}$ Kenya has incorporated the UN Convention on the Rights of the Child into its domestic law. ${ }^{737}$ Other instruments, such as CEDAW, ICESCR and ICERD have been "substantially domesticated through different legislations." 738

Kenya's universal periodic review took place May 6, 2010 in Geneva. The preparations by the government for the review were done within the Multi-Stakeholders National Advisory/Consultative Committee on Kenya's International Human Rights Obligations, under the coordination of the Ministry of Justice, National Cohesion and constitutional Affairs. ${ }^{739}$

\section{B. NHRI's Coordinate Civil Society Efforts}

\section{The Kenyan National Commission on Human Rights}

The Kenyan review provides a second case study of how National Human Rights Institutions (NHRIs) shape the issues that are raised in a review, the outcomes of the review and the implementation of recommendations following the review. The Kenyan National Commission on Human Rights (KNCHR) was established by parliamentary statute in 2002. ${ }^{740}$ The KNCHR is Kenya's NHRI. Its mandate is to "act as the chief agent of the government in ensuring the government's compliance with its obligations under the international treaties and the conventions on human rights." 741 The KNCHR is an A status NHRI, in accordance with the Paris Principles. ${ }^{742}$

The KNCHR attended government forums to discuss the UPR process while simultaneously carrying out its own initiative to reach civil society organizations. The KNCHR was "conscious from the beginning of the fact that the state report might not adequately address the concerns that KNCHR as well as other stakeholder's working on human rights issues had, and there was need for alternative means of bringing these issues before the Human Rights Council." 743 KNCHR envisioned the alternative as a process in which it would looks for ways to build capacity, coordinate reporting efforts and raise awareness through lobbying and publicity. ${ }^{744}$

The KNCHR began capacity building by briefing civil society on the UPR process. In October 2008, the KNCHR took advantage of the fact that the Ninth International Conference for NHRIS was to be held in Nairobi. The KNCHR arranged for a side event in which the mechanism would be introduced to civil society. ${ }^{745}$ The KNCHR wrote to all human rights actors in the country to inform them that the UPR would be taking place. ${ }^{746}$ Approximately 97 civil society organizations registered to be part of the process and the KNCHR would

\footnotetext{
$734 \mathrm{Id}$. at 96

${ }_{735}$ KenYAn NATIONAl COMmission FOR Human Rights, Accounting for Human Rights, supra note 610, at 3, 5, 33, $53,69,73$.

${ }^{736}$ National Report Submitted in Accordance with Paragraph 15 (a) of the Annex to Human Rights Council Resolution 5/1 - Kenya, I 28 UN Doc A/HRC/WG.6/8/KEN/1.

${ }_{737} \mathrm{Id}$. at $\mathrm{q} 30$.

$738 \mathrm{Id}$. at 933.

${ }^{739}$ DANISH InStiTUte FOR Human Rights, Universal Periodic Review First Cycle, supra note 609, at 79. See also Kenya's National Report 93.

${ }^{740}$ National Report Submitted in Accordance with Paragraph 15 (a) of the Annex to Human Rights Council Resolution 5/1 - Kenya, ๆ 19 UN Doc A/HRC/WG.6/8/KEN/1.

${ }^{741}$ KenYAn NATIONAL COMMission FOR Human RigHTS, Accounting for Human Rights, supra note 610 at 6, citing Section 16(1) (f) of The KNCHR Act.

${ }^{742}$ As of December 2011. See Chart of the Status of National Institutions Accredited by the International Coordinating Commission of National Institutions For the Promotion and Protection of Human Rights, available at http:/ / nhri.ohchr.org/EN/Documents/Chart\%20of\%20the\%20Status\%20of\%20NHRIs\%20(DIC\%202011).pdf.

743 DANISH INSTITUTE FOR HuMAN RigHTS, Universal Periodic Review First Cycle, supra note 609, at 80.

${ }^{744}$ Interview with Antonina Okuta, Senior Human Rights Official, Kenyan National Commission on Human Rights, 16 February, 2012

745 KENYAN NATIONAL COMMISSION FOR HUMAN RigHTS, Accounting for Human Rights, supra note 610, at 15.

746 Interview with Antonina Okuta, Senior Human Rights Official, Kenyan National Commission on Human Rights, 16 February, 2012
} 
undertake to train about the government report, the role of NHRIs and civil society in the review and about the format of the reports from stakeholders, and how to lobby other state delegations. ${ }^{747}$ While KNCHR was acting as a leader in the process, it did not act alone. In March 2009, the Kenya Stakeholders' Coalition for the Universal Periodic Review (KSC-UPR) with the goal of drawing up a joint stakeholder report for the Kenya UPR. ${ }^{748}$ The KSC-UPR would hold several sessions to draw up the report, but would also join in the capacity-building efforts. In May 2009, the KNCHR and KSC-UPR held the capacity-building workshop, drawing on the expertise and experiences of other countries, including South Africa and Brazil, which had already undergone a UPR. ${ }^{749}$ The workshop was designed to explain the step-by-step UPR process so that civil society organizations could actively participate in the Kenyan UPR. During the workshop, (which was facilitated by "resource persons from Kenya;, Rights and Democracy, European Office; Conectas, Brazil; the South African Human Rights commission; and Human Rights House Foundation, Norway"), 75057 members were taught :

the technical guidelines governing the UPR process;

how to prepare information and participate in the actual review and follow-up to the UPR;

good practices and experience of other states, including South Africa and Brazil; and

how to adopt a common strategy and action plan for the Kenya UPR.751

\section{Submission to UPR Process 752}

The final product of the KSC-UPR was a stakeholder submission to the OHCHR regarding the state of human rights in the country. Ninety-seven national and international organizations formed the coalition that drafted the report. ${ }^{753}$ The report, submitted on November 2, 2009, described the normative and institutional frame work for the promotion and protection of human rights in Kenya and made 52 recommendations regarding abuses, violations and human rights challenges in the nation. ${ }^{754}$ The recommendations covered themes such as the abuse of children in the criminal justice system, 755 working conditions for prison warders, 756 food insecurity, 757 inadequate water supply, ${ }^{758}$ high maternal and infant mortality rates, ${ }^{759}$ killing of older persons on allegations of witchcraft 760 and recognition of indigenous peoples. ${ }^{761}$ Some of the relevant recommendations were:

The State should immediately set up the Special Tribunal to investigate and deal with the human rights crimes that occurred immediately before, during and after the 2007 general elections in adherence to the principles of the Rome Statute. It should immediately operationalise a witness protection programme within this Special Tribunal. The State should enable the International Criminal Court to closely monitor the Kenyan situation with a view to finalizing preliminary investigations as a basis for prosecuting perpetrators of the post-election violence. ${ }^{762}$

The State should initiate a national awareness campaign on the rights of workers and corresponding employers' duties including the protection provided by the new Labour laws; introduce provisions to guarantee equal treatment and opportunities for informal sector workers; and urgently introduce amendments to the WIBA

\footnotetext{
${ }_{747} \mathrm{Id}$. The KNCHR informant recalls drawing heavily from the Brazilian experience during capacity-building workshops.

748 KenYAN NATIONAL COMMISSION FOR HumAn RigHTS, Accounting for Human Rights, supra note 610, at 15.

${ }^{749}$ Interview with Antonina Okuta, Senior Human Rights Official, Kenyan National Commission on Human Rights, 16 February, 2012

750 KeNYAN NATIONAL COMMISSION FOR HUMAN RigHTS, Accounting for Human Rights, supra note 610, at 20.

$751 \mathrm{Id}$.

752 KSC-UPR, Kenya Stakeholder Coalition for the Universal Periodic Review,

http://lib.ohchr.org/HRBodies/UPR/Documents/Session8/KE/KSC_UPR_KEN_S08_2010_KenyaStakeholdersCoalitionforUPR.pdf.

753 Interview with Antonina Okuta, Senior Human Rights Official, Kenyan National Commission on Human Rights, 16 February, 2012.

754 KSC-UPR, Kenya Stakeholder Coalition, supra note 723, at 1-10.

$755 \mathrm{Id}$. at $\mathrm{II} 3-4$.

$756 \mathrm{Id}$. at 9-10.

$757 \mathrm{Id}$. at 9 -13-14.

$758 \mathrm{Id}$. at 9 १ 15-16.

${ }^{759} \mathrm{Id}$. at 9 १ 25-26.

${ }^{760} \mathrm{Id}$. at 9 47-48.

${ }^{761} \mathrm{Id}$. at $\mathbb{9} 49-50$.

${ }^{762} \mathrm{Id}$. at 96. 
or a redrafted Bill on Work Injury Benefits to Parliament for enactment to ensure that work injury cases are not held in abeyance before the courts. ${ }^{763}$

The Government should, in its negotiations, deliberately ensure the protection of the right to health in the EPAs, in compliance with all international and regional health conventions including budgetary allocations as provided under the Abuja Declaration. It should also ensure that the EPAs contain provisions to protect infant industries by maintaining local subsidies or advocating for the removal of EU subsidies by a stipulated date. Lastly, the Government should speedily establish one central trade negotiation body to jointly work on COMESA, EAC and WTO agreements. ${ }^{764}$

\section{National Consultations and the National Report}

The KSC-UPR coalition was also interested in influencing the government's own report. The government had indicated its willingness to adopt a "consultative approach." 765 The government's national report contains a very cursory explanation of how the national consultation was conducted:

This report is a result of wide consultations within Government, the Kenya National Commission on Human Rights, other National Institutions, Non Governmental Organisations, Civil Society organizations and other stakeholders including academic and policy analysis institutions. ${ }^{766}$

The national report also referenced a validation process in which stakeholders such as the KSC-UPR and took part. ${ }^{767}$ The government did not make contact with the grassroots because it expressed the fear that it would run the risk of confrontation. ${ }^{768}$ The consultations were, therefore, carried out with civil society organizations. KSCUPR stated that many of its contributions from the consultations were not included in the government's report. ${ }^{769}$

The government's report largely acknowledged challenges without offering defenses or excuses. It reported that, in addition to the political violence, ${ }^{770}$ the country was suffering from other endemic social and political issues - unemployment, 771 bad governance, ${ }^{772}$ weak human rights institutions, ${ }^{773}$ a lack of constitutional provisions protecting human rights, ${ }^{774}$ lack of public awareness about human rights, ${ }^{775}$ corruption,, 776 child labor, 777 and poor prison conditions. ${ }^{778}$ The national report identified priorities and measures to tackle those problems. The government stated that poverty and inequality are dire problems that have exacerbated income disparity, access to education, health and land, as well as availability of basics such as clean water and shelter. ${ }^{779}$ The government stated that it was focusing its efforts on "universal primary education, improved access to basic health, expanded productive capacity in agricultural development...[in] arid and semi-arid areas, and upgrading the living conditions for urban dwellers that have suffered from poor urban infrastructure and social services mainly due to high urbanization rates." 780 The government also noted that one key national priority

\footnotetext{
${ }^{763} \mathrm{Id}$. at 18.

${ }^{764} \mathrm{Id}$. at 924.

771 Id. at 95.

$772 \mathrm{Id}$. at $\mathbb{9}$ 56-57.

$773 \mathrm{Id}$. at $\mathbb{9}$ - 58-59.

$774 \mathrm{Id}$. at 960 .

${ }_{775} \mathrm{Id}$. at 962.

$776 \mathrm{Id}$. at 163.

$777 \mathrm{Id}$. at $₫ \mathbb{9} 64-65$.

778 Id. at 66.

$779 \mathrm{Id}$. at $\mathbb{9}$ - 53-54.

$780 \mathrm{Id}$. at 88 .
}

765 KenYAN NATIONAL COMmissiOn FOR Human Rights, Accounting for Human Rights, supra note 610, at 21.

${ }^{766}$ National Report Submitted in Accordance with Paragraph 15 (a) of the Annex to Human Rights Council Resolution 5/1 - Kenya, UN Doc A/HRC/WG.6/8/KEN/1 ๆ 2.

${ }^{767}$ Id. ; See also KenYAN NATIONAL COMMISSION FOR HumAn RigHTS, Accounting for Human Rights, supra note 610, at 21.

768 Interview with Antonina Okuta, Senior Human Rights Official, Kenyan National Commission on Human Rights, 16 February, 2012.

769 KenYAn NATIONAL COMMISSION FOR Human RigHTS, Accounting for Human Rights, supra note 610, at 21.

770 National Report Submitted in Accordance with Paragraph 15 (a) of the Annex to Human Rights Council Resolution 5/1 - Kenya, UN Doc A/HRC/WG.6/8/KEN/1 ๆ 80-81. 
would be constitutional reform, which it deemed particularly necessary following the election violence. ${ }^{781}$ It further stated that tackling impunity, corruption and police violence were important goals. ${ }^{782}$ The government also highlighted the plight of minority groups that are living in arid regions; it acknowledged that the groups needed special protection and announced that a draft land policy was being circulated to address land acquisition, compensation and development. ${ }^{783}$

\section{OHCHR Compilations}

The Office of the High Commissioner for Human Rights (OHCHR) compilation demonstrated that Kenya has a rather broad range of international obligations, including reporting obligations pursuant to the ICERD, ICESCR, ICCPR, CEDAW, CAT, CRC, CRPD. ${ }^{784}$ Kenya is party to the Rome Statute of the International Criminal Court and to the ILO fundamental conventions. ${ }^{785}$ Regarding its constitutional and legislative framework, the United Nations Country Team criticized the Kenyan Bill of Rights for omitting economic, social and cultural rights and noted that the Constitution permits "discrimination on the grounds of personal status and citizenship." 786CAT and emphasized that the Immigration Act did not incorporate the concept of non-refoulement and CEDAW stated that Kenya had not yet incorporated a definition for discrimination into its Constitution and legislation. ${ }^{787}$

There were also concerns regarding Kenya's cooperation with human rights mechanisms. The country had never reported to CERD, its subsequent reports due to CESCR had not yet been filed, it owed a report to the HRC and CAT and was delinquent on the CRC reporting duties. ${ }^{788}$ It had also failed to submit initial reports to the CPRD. ${ }^{789}$ With respect to its cooperation with special procedures, the report noted that Kenya had not issued a standing invitation and had not agreed upon the timing of several requested visits, including those from the special rapporteur for the situation of human rights defenders (requested in 2003) and the independent expert on minority issues. ${ }^{790}$

The implementation of international human rights obligations in Kenya was also heavily criticized in several categories. For example, regarding equality and non-discrimination, the report cited the HRC's concern regarding "wife inheritance" and the CRC's concern that children born outside of wedlock were discriminated against as were children infected with HIV/AIDS. 791 In addition, the CESCR and the ILO Committee of Experts urged the Kenyan government to take measure regarding equal access to the regular labor market for women and the repeal of provisions in legislation that amounted to forced labor, respectively. ${ }^{792}$

The Summary of the stakeholder's submissions was equally negative. In addition to the recommendations made by KSC-UPR (discussed earlier), the stakeholder report also contained the content of other international and national stakeholders. A total of 19 organizations made submissions. ${ }^{793}$ The issues highlighted included controversies over entrenchment of Islamic Sharia law courts in certain districts, ${ }^{794}$ provisions in Kenyan law criminalizing sexual activity between "consenting adults of the same sex," 795 freedom of information and other

\footnotetext{
${ }^{781} \mathrm{Id}$. at $\boldsymbol{q}$ - 69-71.

$782 \mathrm{Id}$. at 9 १ 74-79.

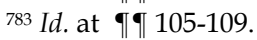

${ }^{784}$ Compilation Prepared by the Office of the High Commissioner for Human Rights in Accordance with Paragraph 15 (b) of the Annex to Human Rights Council Resolution 5/1 - Kenya, UN Doc A/HRC/WG.6/8/KEN/2, Section I. A.

${ }^{785} \mathrm{Id}$.

$786 \mathrm{Id}$. at 92.

${ }^{787} \mathrm{Id}$. at 9 5-6.

788 Id. at, Section II.A.1.

${ }^{789} \mathrm{Id}$.

${ }^{790} \mathrm{Id}$. at, Section II. A.2.

${ }^{791} \mathrm{Id}$. at 15-16.

${ }^{792} \mathrm{Id}$. at $\llbracket$ ฯ $48,51$.

${ }^{793}$ Summary Prepared by the Office of the High Commissioner for Human Rights in Accordance with Paragraph 15 (c) of the Annext to Human Rights Council Resolution 5/1 - Kenya, UN Doc A/HRC/WG.6/8/KEN/3.

${ }^{794} \mathrm{Id}$. at $\mathrm{I} 26$.

$795 \mathrm{Id}$. at 132.
} 
media and free speech issues, ${ }^{796}$ ill treatment of human rights defenders, ${ }^{797}$ the right to adequate housing, water and education, 798 and the rights of minorities and indigenous peoples. ${ }^{799}$

The overall picture being painted by the OHCHR was that of a nation burdened with the results of poverty, lack of education and a dearth of funds to address these problems. In addition, the reports showed a nation that was failing to meet its obligations to report to the treaty bodies. These reports also demonstrated the broad scope of human rights challenges facing Kenya. Those challenges ran the gamut from political rights, economic and social rights to labor and cultural heritage and community life.

While the reports regarding Kenya did paint a bleak picture, they did not differ substantially from the picture given by the government in its national report and the issues raised in the stakeholder submissions. The Kenyan UPR shows how pressure from civil society can result in the government acknowledgement of the view of the stakeholders. The result: initial agreement about the areas where more progress is needed. This lays the groundwork for future collaboration to improve in those areas.

\section{Media and Advocacy Campaigning in Preparation for the Interactive Dialogue}

The Coalition used the time immediately prior to the interactive dialogue and review of Kenya before the Council to launch an intense media campaign. The Coalition's starting point was an Advocacy charter which highlighted fifteen themes and made specific recommendations for action. The themes were drawn from the KSC-UPR reports, the national report and the treaty body and special procedures reports. ${ }^{800}$ The themes were:

- Justice for victims of post-election violence;

- Credibility challenges to the Truth Justice and Reconciliation commission (the body established to address past human rights violations;

- Insecurity due to extra-judicial killings and police brutality;

- Threats to human rights defenders;

- Infringement on freedom of expression and right to access information;

- Moratorium on the Death Penalty;

- Sexual Orientation/Gender Identity Discrimination;

- Gaps in the Protection of Rights for Persons with Disabilities;

- Lack of Legal Recognition for Minorities and Indigenous Peoples;

- Lack of Protection of Children in Criminal Justice System;

- Violations by Non-State Actors;

- $\quad$ Statelessness;

- Corruption in Education;

- $\quad \mathrm{HIV} /$ AIDS challenges; and

- Lapses in Environmental Protection. 801

Among the suggested recommendations were the establishment of a Special Tribunal to investigate and prosecute cases of crimes occurring before, during and after the 2007 general elections; 802 immediate

$796 \mathrm{Id}$. at 9 ฯ $34-40$.

797 Id. at 942 .

${ }^{798} \mathrm{Id}$. at 9 甲 $55,56,58,59$.

${ }^{799} \mathrm{Id}$. at 9 ๆ 60-67.

800 UN Human Rights Council - Universal Periodic Review Kenya's Human Rights Balance Sheet, available at http://www.upr-

info.org/IMG/pdf/Kenya_Advocacy_Charter.pdf.

${ }^{801} \mathrm{Id}$. at 1-10.

${ }^{802} \mathrm{Id}$. at 1 . 
investigations and prosecution of persons (including security agents) guilty of extra-judicial killings of human rights defenders; 803 enactment of the Freedom of Information Bill; and implementation of the Persons with Disabilities Act towards ensuring that at least $5 \%$ of employment opportunities are secured for persons with disabilities. ${ }^{804}$

Using the Coalition Advocacy Charter, the KSC-UPR posed questions and suggested recommendations that peer states could put to Kenya during the interactive dialogue. The KSC-UPR approached the government to express the importance of making voluntary commitments at the interactive dialogue. Among the officials consulted were "technocrats" in the Ministry of Justice, National Cohesion and Constitutional Affairs as well as the Minister of Justice himself. ${ }^{805}$ The KSC-UPR also contacted peer states within the UPR Working Group and the Council. By "assessing the extent to which specific states had engaged in the review of other states, and the sorts of issues which interested particular states [,] the coalition was able to target particular countries to carry their recommendations to the interactive dialogue. ${ }^{806}$ The KSC-UPR sought the support of national, regional and international NGOs in "leverage[ing] their formal and informal networks to influence the approaches of diplomats towards the Kenya review." 807 These NGOs also lent their accreditation to Kenyan NGOs so the latter would be able to participate in the interactive dialogue. ${ }^{808}$ These contacts also permitted the wide dissemination of the Advocacy Charter to permanent missions and state delegations and contact with journalists. ${ }^{809}$ The final front for its campaign was with the traditional print and broadcast media in Kenya. The Coalition was less happy with the outcome of these initiatives; however, it did place stories in newspapers, hold radio and television talk shows and disseminate publicity materials in April and May 2010.810

On April 13, 2010 both the Daily Nation and the Standard carried online articles regarding the upcoming UPR for Kenya. The Daily Nation reported that a KNCHR commissioner had requested that the government "do more to entrench enjoyment of human rights in the country." 811 That same commissioner was also quoted as saying that if Kenya made "voluntary commitments in Geneva, Kenyans will better enjoy their human rights." 812 The article also outlined the preparation for the review, explaining that the government filed a national report and that civil society organizations and the KNCHR had filed joint and individual reports. ${ }^{813}$ The article briefly summarized the positive aspects of human rights highlighted in the government's report as well as the challenges. ${ }^{814}$ It further explained that the KSC-UPR criticized the government in its response to post-election trials of suspects and the controversies surrounding the Truth Justice and Reconciliation Commission (TJRC). ${ }^{815}$ These two themes were also picked up in the article published in the Standard (online), which noted that the ISC-UPR had "recommended Kenya should fully co-operate with ICC prosecutor Luis Moreno-Ocampo in conducting investigations into the violence" and that the TJRC's amnesty and reparation programs had flaws. ${ }^{816}$

\footnotetext{
${ }^{803} \mathrm{Id}$. at 3 .

${ }^{804} \mathrm{Id}$. at 6.

805 KENYAN NATIONAL COMMISSION FOR HUMAN RIGHTS, Accounting for Human Rights, supra note 610, at 24.

${ }^{806} \mathrm{Id}$. at 25 .

${ }^{807} \mathrm{Id}$.

$808 \mathrm{Id}$.

${ }^{809} \mathrm{Id}$. at $25-26$.

${ }^{810} \mathrm{Id}$. at $26-27$.

811 SAMMY CHEBOI, Kenya to Give Rights Scorecard at http://www.nation.co.ke/News/Kenya\%20to\%20give\%20rights\%20scorecard/ /1056/898418/-/lv5f5lz/-/index.html.

$812 \mathrm{Id}$.

${ }^{813} \mathrm{Id}$.

${ }^{814} \mathrm{Id}$.

${ }^{815} \mathrm{Id}$.

816 Id.; PETER OPIYO, Chaos Trials, TJRC to Feature in Geneva at http:/ / www.standardmedia.co.ke/archives/news/InsidePage.php?id=2000007635\&cid=159\&story=Chaos\%20trials, \%20TJRC\%20to\%20featu re\%20in \%20Geneva.
} 
The KSC-UPR also held two side events in Geneva on May $4^{\text {th }}$ and $7^{\text {th }}$. The events were attended by "diplomats, civil society and others." 817

\section{Interactive Dialogue ${ }^{818}$}

The Kenyan UPR was of interest to many states. Prior to the interactive dialogue, Kenya received several advance questions ${ }^{819}$ from its peers in Belgium, the Czech Republic, Denmark, Ireland, Latvia, Norway, 820 Germany, ${ }^{821}$ the Netherlands, ${ }^{822}$ and Argentina. ${ }^{823}$ Belgium asked Kenya to commit to repealing laws that criminalized consensual sex between same sex adults; the Czech Republic asked six questions, including whether Kenya would accede to the Optional Protocol to the Convention against Torture and whether it would ensure that female genital mutilation was uprooted by investigating and punishing perpetrators; Latvia asked whether Kenya would give a standing invitation to the special procedures. The Netherlands submitted six questions including this one regarding corruption:

Kenya has considerable policy and legal frameworks in place to combat corruption, including the Kenya AntiCorruption Commission. Nevertheless, the Netherlands has received reports that corruption continues to hamper human-rights related reform programmes such as Free Primary Education and Kazi Kwa Vijana. Could the Government of Kenya indicate to what ex[t]ent initiatives to fight corruption have reduced corruption levels, and whether suspects in recent large corruption scandals will be prosecuted? How does the Government intend to tackle the perceived gap between policy and practice? ${ }^{824}$

The troika for Kenya consisted of Bangladesh, Egypt and Mexico. The delegation was headed by Mr. Mutula Kolonzo, the Minister for Justice, National Cohesion, and Constitutional Affairs. The government's presentation tended to highlight its multi-party democracy and the Constitution as well as various pieces of legislation in place to secure human rights. Kenya Vision 2030 - a long-term plan to develop the country- was also emphasized.

Fifty-five participants took the floor to make recommendations. ${ }^{825}$ Many recommendations dealt with the ratification of various human rights conventions and optional protocols. Algeria recommended ratification of the convention regarding migrant workers; Brazil urged the ratification of the convention against genocide; and Denmark asked Kenya to consider ratifying the Optional Protocol to the convention against torture. Several nations referred to the need for constitutional reforms (United Kingdom, Niger, Zimbabwe). Kenya was urged to strengthen the national institutions that protect human rights such as the National Commission on Human Rights (Indonesia, Botswana, Egypt, Malaysia). Themes that were present in the KSC-UPR joint submissions and Advocacy Campaign materials were raised by many of the nations that took the floor. Those themes included taking measures against corruption; investigation of post-electoral violence and cooperation with the ICC prosecution; halt the use of the death penalty; review of national legislation affecting freedom of expression; put policies in place to combat poverty; emphasize education of the girl child; work with the ILO at the national level to prevent child labor.

The author notes that an analysis of the discourse demonstrates the same use of diplomatic language found in the Danish review. But, there was also quite a bit of candid remarks and criticism of the Kenyan human rights situation, particularly with regard to the treatment of same-sex couples and with regard to the post-election violence and impunity for its perpetrators. Turkey, for example, complemented Kenya for its advancements,

817 Kenyan National COMmission fOR Human RigHTS, Accounting for Human Rights, supra note 610, at 27.

818 Unless otherwise noted, the information in this section is based on the interactive dialogue for Kenya held on May 6, 2010. The interactive dialogue is available on the OHCHR website in the video archives, available at

rtsp:// webcast.un.org/ondemand/conferences/unhrc/upr/8th/hrc100506am1-eng.rm?start=::\&end=:: Information regarding the interactive dialogue can also be found in the report of the working group. Report of the Working Group on the Universal Periodic Review Kenya, UN Doc A/HRC/15/8, 17 June 2010.

${ }^{819}$ Advance questions are available on the OHCHR website. They can be accessed by session or by country.

${ }^{820}$ Advanced Questions to Kenya, http://lib.ohchr.org/HRBodies/UPR/Documents/Session8/KE/kenya.pdf

${ }^{821}$ Advanced Questions to Kenya, Add. 1, http://lib.ohchr.org/HRBodies/UPR/Documents/Session8/KE/kenyaAdd.1.pdf

822 Advanced Questions to Kenya, Add. 2, http://lib.ohchr.org/HRBodies/UPR/Documents/Session8/KE/kenyaAdd.2.pdf

${ }_{823}$ Advanced Questions to Kenya, Add. 3, http://lib.ohchr.org/HRBodies/UPR/Documents/Session8/KE/kenyaAdd.3.pdf

${ }^{824}$ Advanced Questions to Kenya, Add. 2, http://lib.ohchr.org/HRBodies/UPR/Documents/Session8/KE/kenyaAdd.2.pdf.

${ }^{825}$ Report of the Working Group on the Universal Periodic Review Kenya, ๆ28 UN Doc A/HRC/15/8, 17 June 2010. 
including in its efforts toward Constitutional reform and in the establishment of a NHRI, but it duly noted that infant and maternal mortality rates were still elevated in Kenya and recommended that Kenya "[i]mprove access to reproductive health services for pregnant women. ${ }^{826}$ Germany raised concerns about internally displaced persons noting that there was a "lack of access to basic rights and services for hundreds...." 827

\section{Recommendations and Outcome 828}

A total of 150 recommendations were made to Kenya during the interactive dialogue. On May 10, 2010, the day that the Working Group adopted the report, Kenya accepted the vast majority of the recommendations (a total of 128). ${ }^{829}$ However, the delegation only agreed to consider the ratification of the Optional Protocol to the Convention Against Torture, CEDAW, the ICCPR CRC-SC, as well as the ratification of the Convention for the Protection from Enforced Disappearance and for the protection of Migrant Workers. Similarly, it only considered establishing a national mechanism to investigate and prosecute crimes committed during the following the 2007 elections. This deferral of approximately 15 recommendations provided fertile ground for KSC-UPR to lobby the government to accept more of the recommendations between the time of the adoption of the Working Group Report and the adoption of the Final Outcome report on September 22, 2010.830 The KNCHR and the government working group, MOJJCA had meeting from July 5 to July 8, 2010 in which it examined the question of the Optional Protocols to human rights conventions and what the Kenyan approach should be. ${ }^{831}$ At these meetings, they also started to devise an implementation plan. ${ }^{832}$ Kenya ended up accepting the recommendations that it agreed to consider at the plenary session before the Council.

Kenya initially rejected both the recommendations urging prohibition of the death penalty and the equal treatment of gays and lesbians, including the decriminalization of consensual sex between adults of the same sex. In the final outcome at the Human Rights Council plenary session, the only recommendation that Kenya would reject was the ones regarding same sex unions. It agreed to review its legislation on the death penalty. KSC-UPR and the KNCHR viewed their efforts to engage the Kenyan government between the adoption of the working group report and the final outcome largely fruitful.

Between the time of the interactive dialogue and the September adoption of final outcomes, Kenya had undertaken a referendum regarding modifications and reforms to the Constitution. The process engaged nearly $72 \%$ of the population and $69 \%$ of the population approved the changes. The government relied heavily upon the Constitution to show its willingness to implement the recommendations that it received. Some of the delegations that took the floor, and the NGOs that address the Council referenced the new Constitution and its Bill of Rights as a positive step in addressing human rights concerns in the country.

One very important part of the final outcomes came in the form of oral statements made at the plenary session. Kenyan civil society organizations, including the KSC-UPR participants, did not have the proper accreditation to speak before the Council. 833 Therefore, they relied on international partners with accreditation to speak on their behalf. At the plenary session on September 22, 2010, the KNCHR Commissioner, Lawrence Mute stated that Kenya had adopted a new Constitution which included a Bill of Rights with economic, social and cultural rights, but that the government had not agreed to abolish the death penalty. ${ }^{834}$

\footnotetext{
826 Id. at $930,101.92$.

${ }^{827} \mathrm{Id}$. at 973.

${ }^{828}$ Unless otherwise noted, the information in this section is based upon the final outcome report. Report of the Working Group on the Universal Periodic Review Kenya, UN Doc A/HRC/15/8, 17 June 2010

${ }^{829}$ KENYAN NATIONAL COMMISSION FOR HUMAN RigHTS, Accounting for Human Rights, supra note 610, at 32.

$830 \mathrm{Id}$.

${ }^{831} \mathrm{Id}$. at 28 .

$832 \mathrm{Id}$.

833 Only A status NHRIs and accredited NGOs are permitted to take the floor or otherwise participate in Council sessions.

834 KenYAn NATIONAl COMMISSION FOR HUMAN RigHTS, Accounting for Human Rights, supra note 610, at 52.
} 


\section{Follow-Up and implementation}

As mentioned above, the KSC-UPR and KNCHR had already engaged the government in June 2010 regarding a blueprint for implementation. It continued this process by adopting an advocacy document which laid out the responsible parties for each recommendation.

\section{Best Practices from the Danish and Kenyan UPRs}

The Danish and Kenyan UPR provide excellent examples of how a NHRI can mobilize civil society participation to positively influence the national consultation and the final recommendations. There are five best practices that arise from the analysis of these two NHRIs:

- Knowledge and awareness dissemination

- Coordination lead (drafting and submission of stakeholder reports)

- Liaison to government (national consultation/implementation)

- Baseline for human rights situation on the ground

- Lobby efforts/media campaigns

\section{A. Knowledge and awareness}

Three best practices are evident in raising awareness about the UPR process. KNCHR and DIHR were involved in training civil society in how to approach the UPR. They also made written materials explaining the process. Finally, KNCHR used other scheduled events to inform stakeholders about the process through the use of a side event.

DIHR and KNCHR both knew that the UPR was a new mechanism and that even the most sophisticated civil society organizations may not have heard of the process. NIHRs are in a unique position to know all civil society organizations in a country; hence they are the best placed to provide training and capacity-building for civil society. KNCHR solicited the help of other regional and international allies to help train local civil society. DIHR took the initiative to call together all civil society organizations that focused on human rights and hold a briefing about the UPR mechanism. These efforts resulted in a myriad of stakeholder submissions covering many human rights failings by the two respective governments. It also raised awareness in the civil society and at the grass roots level about the UPR.

Both DIHR and KNCHR made written materials available. These materials give the reader more information about the process and guide civil society organizations through the phases of the UPR and explain what the organization can do to impact the UPR process. Those materials were also made available on the website of the DIHR for future reference.

KNCHR also availed itself of another event (the meeting of NHRIs in Nairobi) to make the larger civil society aware of the UPR. Taking advantage of other gatherings and asking to hold a side event is a good practice that is both cost-effective and time effective. It permits the NIHR to attract maximum attention of interested parties without scheduling a separate event.

\section{B. Coordination lead}

While maximum participation from civil society is a priority for a successful UPR, it is important that the participating be organized with goals in mind. Often the NHRI is in a position to offer coordination to the small NGO groups. One common goal should be a joint stakeholder report. Such a joint effort carries a lot of weight in Geneva and is particularly useful in providing an alternative picture to the one painted in the national report.

The KNCHR and DIHR served as coordinators for the drafting of joint stakeholder report and also collaborated in the coordination of efforts to finalize and disseminate the report. This close collaboration with civil society resulted in heightened interest in the mechanism and pressure on the national government to take 
into consideration issues raised by these groups. Submissions by large numbers of stakeholders to the OHCHR were an indicator of the level of interest from civil society.

Coordination includes becoming a sounding board for ideas about what substantive human rights issues to highlight, the format of the reports and procedures for drawing up, reviewing and revising the report. This coordination requires personnel that can access word processing, edit and disseminate drafts, take comments and revise those drafts and get final approval before submitting the draft. The coordination also requires negotiating skills and the ability to build consensus. Often the NHRI is the only entity placed to offer all of these services.

\section{Liaison to government}

Both KNCHR and DIHR played key leadership roles in the national consultations. DIHR suggested the format of the town hall meetings and facilitated them. By leading the initiative for the consultations, the DIHR also ensured that the voice of civil society would be heard. From the point of view of the government, having a "neutral" intermediary ensured that the meetings were constructive and did not degenerate into a head-to-head confrontation between government officials and disgruntled advocates or members of the public. The KNCHR and its coalition pressured the government to write a report that reflected the reality on the ground. It also placed the government in contact with NGOs and other CSOs from Kenya in order to know what issues were important to civil society.

The role of liaison extends also to the post-review period during the time of implementation. The Denmark UPR experience teaches an invaluable lesson. Governments change. With the new government, there are possibilities that some of the rejected recommendations will be taken up. DIHR kept an open line of communication with the old and the new government. By doing so, it was in a position to challenge the new government to take a fresh look at the recommendations coming out of the UPR with an eye to making even more engagements and accepting even more recommendations.

The real challenge of the UPR is how to ensure that a government remains committed to its engagements after the review. DIHR would like to present the government with a blueprint of the recommendations. The blueprint would identify the agencies and ministries responsible for implementation. The blueprint would also have a timeline for implementation. Both DIHR and the government would collaborate in carrying out the blueprint. KNCHR was aggressive in putting together a document to guide the government in implementing its recommendations. Both models show that there is room for the NIHR to take the lead in this area. Moreover, implementation of recommendations is often only achieved by continuing pressure after the review in Geneva.

\section{Baseline for Human Rights}

Many nations have no point of comparison to determine if progress is being made in the field of human rights. The NIHR can use the UPR process as a way of creating a baseline for the state of human rights within the nation. This can be done by focusing on the structures (judicial, administrative and executive) in place to promote human rights, protect citizens and punish violations of human rights. The baseline report should also look at legislation and regulations currently in place. The report can also include the recommendations and outcomes from the UPR and the Treaty Bodies, together with any special procedure outcomes. ${ }^{835}$ DIHR planned to create such a report after its UPR. 836

\section{E. Lobbying and Media}

National Human Rights Institutions cannot always expect their recommendations and those of civil society stakeholders to be duly reflected in the national report. Instead, they must lobby the permanent delegations to get certain issues raised in the interactive dialogue. Before lobbying, DIHR examined the past UPRs to see which

\footnotetext{
835 The Australian NHRI has begun to put together such a study. See the draft as of June 2011 available at http:/ / www.ag.gov.au/Documents/Baseline\%20Study\%20-\%20National\%20Human\%20Rights\%20Action\%20Plan\%20\%20final\%20version\%20for\%20public\%20release \%20-\%2029\%20June \%202011.pdf

836 DANish InSTITUTE FOR HumAn RigHTS, Universal Periodic Review First Cycle, supra note 609, at 3.
} 
delegations had raised certain issues in the past and where interests converged, DIHR approached the ambassador to give him/her a copy of the DIHR recommendations. DIHR also held meetings or side events in Geneva as well as meetings in Copenhagen in which ambassadors were welcome to come. At the meetings, the DIHR submission to the OHCHR was made available as were fact sheets about the Danish UPR. These initiatives gave heightened awareness to the issues that the DIHR wanted to highlight at the interactive dialogue and review of Denmark.

KNCHR was aware of the need to lobby and it did so in the same way as DIHR. However, KNCHR was challenged by its own government who thought that its lobbying efforts were a betrayal. ${ }^{837} \mathrm{KNCHR}$ determined that such a challenge was unwarranted and resolved to continue to lobby other governments in the future in connection with the UPR. KNCHR concluded "it is not disloyal for a NHRI to lobby States to ask the right questions." 838 KNCHR further noted that effective advocacy campaigns lead to better recommendations. 839

\section{Conclusion}

National Human Rights Institutions play key roles in the national consultation, lead-up to the interactive dialogue, the discussion of recommendations to be accepted and rejected before the plenary of the Council and in the follow-up to implementation of recommendations. The experience of the Danish and Kenyan NHRIs give insight into the importance of close coordination with civil society and government to ensure that recommendations that have been accepted are implemented. Additionally, the NHRIs can also be key actors in helping the governments interface with civil society in the national consultation and preparation of the national report. These case studies can offer insight for other NHRIs that are currently being established and those already in existence. The strategies used by these NHRIs are certainly accessible to other similar institutions.

${ }^{837}$ Interview with Antonina Okuta, Senior Human Rights Official, Kenyan National Commission on Human Rights, 16 February, 2012

838 KENYAN NATIONAL COMMISSION FOR HUMAN RigHTS, Accounting for Human Rights, supra note 610, at 58.

${ }^{839} \mathrm{Id}$. 


\section{Chapter Eight:}

\section{The Role of Civil Society in the Universal Periodic Review}

\section{Introduction}

Non-governmental organizations (NGOs) and other civil society organizations (CSOs) play important roles in the UPR. On the international stage, these organizations can submit stakeholder reports to the Office of the High Commissioner for Human Rights (OHCHR) which are made available on the website of the OHCHR and are summarized in the stakeholder summary available for all countries to consider and use in connection with recommendations and official statements. The CSOs can also connect with international partners and diplomatic missions to influence the UPR interactive dialogue and recommendations. Accredited NGOs are also welcome to the plenary session during the final outcome of the UPR to give oral statements regarding the recommendations made to the nation under review. On the national front, CSOs can liaise with National Human Rights Institutions (NHRIs). Many NGOs have also opted to offer information during national consultations and to lobby the diplomatic missions within the country to raise certain issues during the interactive dialogue.

The multiple options for impacting the UPR means that the way in which NGOs have chosen to participate in the UPR differs widely. Therefore, for the purposes of this study two very different styles of advocacy are highlighted in the case studies. These two styles are models from which NGOs and CSOs can interact in the UPR. By studying these two very different models, one can also determine how the human rights discourse has changed at the national and international levels as a result of the new UPR mechanism.

This chapter focuses on the UPR of the United States of America (USA) and on the UPR strategies of Amnesty International (AI or Amnesty). Three factors were considered when choosing the two case studies: (1) innovative aspects of the interaction between the organizations and the UPR; (2) the broadness of the themes covered or communities affected by the organization's actions and (3) the availability of information about the process, including the willingness of CSO or NGO staff to be interviewed and to speak candidly about the process.

There is one additional element that is important to emphasize. The absence or presence of a National Human Rights Institution in a country may influence how the national consultation and how follow-up implementation is approached. It is not clear to the author whether the roles of NGOs and CSOs are modified or altered in the presence or absence of such institutions and there is no way of gauging such an effect for this research. However, I do include this brief mention as a way to inform the reader that NHRIs may change or alter the dynamics of NGOs and CSOs and this study does not take that into account.

The examination of the USA was chosen because it offers a unique model for NGO and CSO interventions in the national consultation. The uniqueness of the model lay in the use of listening sessions (the name given by the Department of State to the meetings held around the country during its national consultation). Listening sessions were organized at universities and other venues. The listening sessions brought together members of civil society, including NGOs, advocacy groups, think tanks and academics. The listening sessions were often full-day or even two-day events in which panel discussions and question/answer sessions were used to disseminate human rights concerns and discuss the plight of communities in the country. In some cases, site visits were also planned, giving additional human rights perspectives not generally available to government officials.

The USA listening sessions involved a total of 13, held in nearly one dozen cities around the continental United States, thereby encompassing a large number of regions and cities. The broad nature of the listening sessions lay not only in the geographic aspects, but also in the thematic aspects. The locations of the listening sessions (New York, California, Texas, New Mexico, Arizona, Michigan, Alabama, Illinois and the District of Columbia) ensured that practically every region of the US was covered and therefore the concerns of these regions were also evident in the listening sessions. Many regions have local concerns that differ from the concerns in other parts of the nation. The advocacy groups and CSOs in these regions brought their local concerns forward during the listening sessions. 
Two persons were interviewed regarding the USA Listening sessions and the texts of the summaries, programs and agenda for the events as well as the advertisements were closely analyzed for the content and meaning of the discourse. One informant organized the listening session held at the University of San Francisco School of Law and the second informant was involved in arrangements for the New York City listening session held at the Columbia University School of Law. There was also an audio CD of the NY Listening session. The key informants that were interviewed were chosen based on their proximity to the organization of the events.

Amnesty International is the second case study in this chapter. Amnesty is active both at the national level (through its national branches) and at the international (through it London-based secretariat) in the UPR. It has submitted stakeholder reports in the vast majority of the UPRs and regularly makes statements in the plenary sessions before the Council. Regarding the three selection criteria, AI's national branches employ approaches that make sense in their local contexts, as will be borne out by the discussion below of the special circumstances surrounding the Hungarian UPR. AI prioritizes issues of importance for the UPR and, will highlight one human rights issue, if necessary, in order to have maximum impact in a country's UPR. On the other hand, AI is also adept at identifying several issues which need attention and getting those issues before the delegations most likely to deliver speeches during the interactive dialogue.

A total of two persons were interviewed concerning Amnesty International's participating in UPRs and information from an e-mail was also used to describe how AI has approached the UPR. The key informants were suggested to me by the coordinator of UPR strategy at AI's secretariat in London. These two key informants were directly responsible for interacting with the national government or the Geneva mechanism. In many instances of the advocacy by AI, the informant was the only person responsible for the national advocacy during the UPR.

\section{UPR Listening Sessions in the USA: Case Study of CSO Strategies in the UPR}

\section{Listening sessions around the country}

The United States of America was reviewed before the Council on November 5, 2010.840 The USA's national report and the correlating national consultations were carried out by the United States Department of State (DOS). The DOS approached several civil society organizations, including universities, NGOs, think tanks and others with the idea of holding listening sessions regarding human rights. ${ }^{841}$ The listening sessions were completely organized and paid for by the respective local organizers as the DOS bore solely the costs related to travel to and from the sites of the listening sessions. ${ }^{842}$ In its national report, the United States of America stated that "[n]early a thousand people, representing a diversity of communities and viewpoints, and voicing a wide range of concerns, attended these gathering in New Orleans, Louisiana; New York, New York; El Paso, Texas; Albuquerque, New Mexico; Window Rock, Arizona; the San Francisco Bay Area; Detroit, Michigan; Chicago, Illinois; Birmingham, Alabama; and Washington, D.C." 843 The content of every listening session was summarized by the DOS and is available to the public on its website. ${ }^{844}$

The topics covered in the listening sessions were often focused on regional and local concerns. For example, the Albuquerque, New Mexico and Window Rock, Arizona listening session, held March 16-17, 2010 were largely dedicated to the issues of the Native Americans, including the Seminole Nation, the Lakota/Sioux, the Navajo

\footnotetext{
${ }^{840}$ National Report Submitted in Accordance with Paragraph 15 (a) of the Annex to Human Rights Council Resolution 5/1 - United States of America, UN Doc A/HRC/WG.6/9/USA/1.

${ }^{841}$ Interview with New York Listening Session Organizer, February 21, 2012; Interview with Amanda Solter, Research Assistant, University of San Francisco School of Law, February 15, 2012.

${ }^{842}$ Interview with Amanda Solter, Research Assistant, University of San Francisco School of Law, February 15, 2012; Interview with New York Listening Session Organizer, February 21, 2012

${ }^{843}$ National Report Submitted in Accordance with Paragraph 15 (a) of the Annex to Human Rights Council Resolution 5/1 - United States of America, ๆ I.B.8 UN Doc A/HRC/WG.6/9/USA/1.

844 The United States Department of State maintains summaries of the listening sessions on its website. The information regarding the listening sessions are taken from those summaries, available at http://www.state.gov/j/drl/upr/summaries/index.htm.
} 
and the Pueblo. ${ }^{845}$ Some of these indigenous peoples are sovereign nations, others have lived on reservations. The discussions with government officials from ten different federal agencies rallied around topics such as treaty rights, the right to land, sacred sites and surface and subsurface resources. ${ }^{846}$ In addition, the complexity of the human rights concerns surrounding native peoples was evident as many live in towns and regions that border the Mexican and Canadian nations and trans-border issues also arise. ${ }^{847} \mathrm{~A}$ second example of the local focus can be found in the civil society consultation held on April 22, 2010 in Birmingham, Alabama. ${ }^{848}$ At that event, the issues of Hurricane Katrina and the loss of land by African-Americans, two topics of particular interest in the South, were raised. ${ }^{849}$ The listening session in Birmingham was attended by representatives from six federal agencies: The Department of State, the Department of Justice, the Department of Education, the Equal Employment Opportunity Commission, the Department of Homeland Security and the Department of Agriculture. ${ }^{850}$ Some listening sessions were arranged around a singular topic. In Chicago, a listening session on February 18, 2010 was dedicated to issues of homeland security. 851 The session was attended by the Department of Homeland Security, the Department of State and the Department of Justice. ${ }^{852}$ Concerns were raised regarding targeting of Arab and Muslims for inspection at points of entry; imaging technology in airports; radicalization in communities and racial profiling. ${ }^{853}$ Similarly, a listening session held on April 28, 2010 in Washington, DC highlighted post-9/11 measures, including treatment of detainees at CIA facilities; prosecution of terrorism suspects; surveillance techniques and privacy rights following the September 11 attacks and racial profiling by police in the South Asian and Sikh communities. 854

\section{New York and San Francisco}

The remaining portion of this discussion will focus on the listening session held in New York City with occasional references to the Bay Area of California listening session, where appropriate. These two events are instructive in demonstrating how CSOs, NGOs and other stakeholders can use the national consultation as a platform to raise important issues and place government officials in direct contact with human rights violations. New York City employed a useful strategy - site visits to put officials in direct contact with the individuals who suffer the effects of human rights violations.

The February 26, 2010 consultation was held in New York City at Columbia University School of Law and its Human Rights Institute while the March 26, 2010 Bay area consultation was held at the University of San Francisco School of Law. 855 The New York City and San Francisco listening sessions were unique in that both were focused on nation-wide human rights challenges. 856

The listening session for New York City was arranged and carried out "collaboratively" and in "heavy consultation with other partners." 857 Those partnerships were part of the larger US Human Rights Network which

\footnotetext{
${ }^{845}$ Department OF State US, Civil Society Consultation for the U.S. Universal Periodic Review: Albuquerque, New Mexico and Window Rock, Arizona at http://www.state.gov/documents/organization/144253.pdf.

$846 \mathrm{Id}$.

${ }^{847} \mathrm{Id}$. at 5.

848 Department of State US, Civil Society Consultation for the U.S. Universal Periodic Review: Birmingham, Alabama at http://www.state.gov/documents/organization/144259.pdf.

${ }^{849} \mathrm{Id}$. at $4-5$.

${ }^{850} \mathrm{Id}$. at 2

851 Department of State US, Department of Homeland Security/Community Roundtable for the U.S. Universal Periodic Review: Chicago, Illinois at http://www.state.gov/documents/organization/144258.pdf.

$852 \mathrm{Id}$. at 1.

${ }^{853} \mathrm{Id}$. at 2.

${ }^{854}$ Department of State US, Civil Society Consultation for the U.S. Universal Periodic Review: Washington, DC April 28, 2010 at http://www.state.gov/documents/organization/144260.pdf.

${ }^{855}$ Department of State US, Civil Society Consultation for the U.S. Universal Periodic Review: San Francisco, California at http:/ / www.state.gov/documents/organization/144255.pdf.;DEPARTMENT OF STATE US, Civil Society Consultation for the U.S. Universal Periodic Review: New York, New York February 26, 2010 at http://www.state.gov/documents/organization/144251.pdf.

856 Interview with New York Listening Session Organizer, February 21, 2012 ;

Interview with Amanda Solter, Research Assistant, University of San Francisco School of Law, February 15, 2012.

${ }^{857}$ Interview with New York Listening Session Organizer, February 21, 2012.
} 
had set up a planning committee with the goal of involving civil society groups that had not been previously involved in the network's activities. ${ }^{858}$ While, the University of San Francisco also consulted with the US Human Rights Network and the DOS, the law faculty was responsible for the bulk of the preparations as well as for the decision-making about panelists and participants. 859

Both the New York and San Francisco listening sessions also had a pre-event. ${ }^{860}$ The New York event took place the previous night where approximately 15 participants were given training on how to frame their issues using human rights terminology and standards. ${ }^{861}$ They were told about the UPR process and given a packet of key recommendations to help them in identifying where their issues fit into international human rights standards. ${ }^{862}$ These participants later signed on to the stakeholder reports that were submitted to the OHCHR. ${ }^{863}$ The Bay Area community training event was a two-hour session and was held at the suggestion of the US Human Rights Network, but did not receive as many participants as the listening session itself, which had over 100 participants. 864

The New York City listening session on February $26^{\text {th }}$ began at 9 am and ended at 3:45 pm. ${ }^{865}$ Following introductory remarks, the following panels were held: Housing, Employment/Labor, Education, Health and Criminal Justice.866 Each panel was designed to last 20 to 25 minutes and there were five speakers sitting on most of the panels. ${ }^{867}$ The panel was followed by a time for feedback and discussion by members of the audience. ${ }^{868}$ There was also a one-hour open comment period built into the last part of the agenda for the day. 869 Participants were also urged to submit written statements which were collected at the end of the day and submitted to the DOS. Those statements are also available on the Human Rights Institute's website.

Three elements set the tone for the listening session in New York. First, was the introductory intervention by a professor who had served in the past in various positions that sought to protect "civil rights." The second was the persona of the government officials who were very open and welcoming of remarks. Finally, the background of the person who would be the moderator of the entire event made the panels more relevant to human rights concerns. These three elements are elaborated here.

The New York Listening session began with a speech delivered by Theodore Shaw, professor of law at Columbia University's School of Law. Prof. Shaw explained that the New York listening session would serve as a venue for expanding the often narrow rights discourse. Prof. Shaw stated that in the US, the term "civil rights" is the preferred term but the term is too small a paradigm. He explained that the US Supreme Court had given a narrow interpretation to certain civil rights, telling what could not be done. However, Prof. Shaw noted that the New York listening session would adopt a liberating human rights discourse that "allows us to rise above the limitations of US law." Shaw further expressed his desire that the groups present would continue to engage with each other to bring the US back into the human rights discourse in a meaningful way. Shaw also noted the wider understanding of human rights, which encompasses economic, social and cultural rights, including poverty, homelessness, the right to a living wage and protections against discrimination based on race, sexual identity and

\footnotetext{
$858 \mathrm{Id}$.

${ }^{859}$ Interview with Amanda Solter, Research Assistant, University of San Francisco School of Law, February 15, 2012.

${ }^{860}$ The New York pre-session and the listening session coincided with a major snow storm on the East Coast of the United States. Air and overland travel came to a standstill and some participants, including a government official and a panelist, could not attend the listening session. The attendance at the pre-session was also affected by the storm.

${ }^{861}$ Interview with New York Listening Session Organizer, February 21, 2012.

$862 \mathrm{Id}$.

${ }^{863} \mathrm{Id}$.

${ }^{864}$ Interview with Amanda Solter, Research Assistant, University of San Francisco School of Law, February 15, 2012.

865 Consultation Agenda, New York UPR Human Rights Consultation, February 26, 2010 available at

http://www.ushrnetwork.org/sites/default/files/New\%20York\%20UPR\%20Human\%20Rights\%20Consultation\%20Agenda\%20and\%20Dire ctions \%20-\%20Final.pdf.

$866 \mathrm{Id}$.

${ }^{867} \mathrm{Id}$.

${ }^{868} \mathrm{Id}$.

${ }^{869} \mathrm{Id}$.
} 
subordination of women. Shaw ended his intervention stating, "If the US Constitution doesn't cover economic rights, the Universal Declaration on Human Rights does and we need to lift that up." This speech was crucial in creating the anticipation that the event would be important in helping bring about a broader understanding of rights in the US - a move away from civil rights to a larger human rights agenda that includes economic and education rights.

Mr. Christopher Componova, Senior Advisor at the Bureau of Democracy, Human Rights and Labor at DOS took the lectern to explain the UPR process. Componova was eager to demonstrate that his speech was not the most important; instead, he was looking forward to hearing the concerns from the persons on the panel. He also emphasized that concerns should also be accompanied by solutions and he was especially keen on hearing suggested resolutions. Componova indicated that the DOS had a website and e-mail address where individuals and organizations could submit information and concerns. Componova's openness was echoed later by other government officials who encouraged participants to approach them informally during the breaks to further express concerns and report human rights violations or abuses.

The entire New York event ${ }^{870}$ was moderated by Rob Robinson, who himself had a compelling personal experience that he shared with the audience. At the time of the listening session, Mr. Robinson was affiliated with Picture the Homeless. From 2003 to 2005, Mr. Robinson had a bout with homelessness, was forced to sleep on park benches, or to live in rental trucks or on the beach in Miami, Florida. He also spent 10 months in a New York City homeless shelter. He gave very poignant details of his own life and that of other named victims of homelessness, foreclosure and similar rights violations. Throughout the panel, between panels and between speakers, Mr. Robinson highlighted the work of advocacy groups found in the audience. Mr. Robinson painted the picture of homelessness in New York City stating that there were 39,000 people living in homeless shelters and that there were 10-year waiting lists for subsidized housing when hundreds of units stood vacant.

The housing panel gives a flavor of how the issues were discussed. The panel was moderated by Mr. Robinson who introduced each speaker. The panelists were a mix of civil society representatives (Eric Tars, of the National Law Center on Homelessness and Poverty) and individuals who had joined a neighborhood group because of personal adversity in public housing (Anne Washington of the Community Voices Heard). There was also a panelist (Tyler Chase of L'Orage) who showed a video on forced evictions in Brooklyn during the lunch break. One panelist gave a list of three recommendations to DOS that should be in its report when covering shortages in public housing. Others pointed out violations that they believed DOS and other agencies should address.

During the event, international human rights standards were often invoked. One theme that continually arose during the panel on housing was the visit by the UN Special Rapporteur on Adequate Housing to the US and her report. Many of the panelists and organizations present had provided information and/or site visits to the rapporteur during her visit. In addition, the panelists often referred to international standards regarding adequate housing. In other panels (for example, the one on education and race), panelists and others referred to the CERD report for the US government in which the US was criticized for segregated schools and other conditions that led to disparate impact on communities of color.

The agencies that were present at the listening session were solicitous of additional comments and interaction. Ms. Jennifer Jones identified herself as a representative from the United States Department of Housing and Urban Development (HUD). Ms. Jones stated that she and the Secretary of HUD were well aware that HUD had failed to meet its obligations, but that the Obama Administration is committed to progress in housing. She also explained that the administration was in a tough spot when it came to the call for a demolition moratorium because some of the buildings were so substandard that the requirements for decent, safe and sanitary environment were not met. Ms. Jones invited people to approach her during the breaks. She stated, "I have taken copious notes. This is going back to the Secretary on Monday." (Other panels were ended with a similar

${ }^{870}$ The description of the New York Listening Session is based on the author's analysis of an audio CD of the entire day's panels and speakers. 
statement from federal agents stating that they took the issues seriously and were available for additional conversations during breaks and following the event.)

During the time that panels were held, video clips were also shown to the government officials and audience in an attempt to illustrate more vividly the plight of the homeless and of other people.

Not all of the participants were happy with the organization of the event. A number of speakers who took the microphone, including Mr. Robinson, expressed disappointment with the DOS consultation process. They believed the process was not transparent. No advertisement was permitted. ${ }^{871}$ Some believed that the process was not inclusive. Because the process was non-participatory and exclusionary, Mr. Robinson believed it was doomed to fail.

On February 26 and 27, the government officials were led on site visits to see the housing conditions in New York boroughs. ${ }^{872}$ The visits were arranged by the Urban Justice Center and the National Law Center on Homelessness and Poverty. The visits were to apartments in Harlem and to Albee Square Mall in Brooklyn. While in Harlem, residents "spoke about the high rents they paid despite the poor conditions of their living spaces." ${ }^{773}$ The government officials were led by Mr. Robinson to "Grant public-housing complex, near West 125th Street, where, up 20 floors and along a dingy, beige-tiled corridor, they met Jackson Marizan, 29." ${ }^{874}$ Mr. Marizan has two children and, at the time of the visit, was unemployed and living in a two-bedroom apartment. ${ }^{875}$ He said that he'd been "complaining about mold for over a year" and showed his "bathroom ceiling, speckled with spores." 876 Mr. Marizan also stated that his two daughters both have asthma. ${ }^{877}$

The visit to Albee Square was to demonstrate the effects of economic development on small businesses. 878 Albee Square Mall was torn down in 2004 to make way for a new development project which was "stalled." 879 The project received a $\$ 20$ million investment but there were no guarantees for living wages or jobs for workers displaced by the new project. 880

Written statements were also collected. ${ }^{881}$ The statements contained details about specific human rights situations of individuals in the New York area. A statement from Kristi Barnes of New York Jobs with Justice, indicated that although stimulus package money was being funneled to local projects, there was no guarantee that the developers and contractors had to pay prevailing wages. In addition, the statement makes reference to two economic development programs that subsidize businesses that don't create new jobs, or that cut jobs or pay only poverty wages. Jesus Rosa stated he was sixteen years old and has been arrested on two occasions. At the age of fifteen he was walking home from a party and stopped and arrested by police because he and his friend "fit the description of people that committed a crime." He was sent to Riker's Island where he was subjected to a strip search and placed in cells with other youth. The charges were later dropped, but he spent one month at Riker's Island. In his second arrest he was handcuffed to a chair for three days. The only time he was un-handcuffed was to attend court appearances and use the bathroom. The United Confederation of Taino People submitted a statement underlining the lack of formal recognition for the Taino (the indigenous peoples of Puerto Rico and the Caribbean) violates their rights as indigenous peoples. The statement also refers to lack of free exercise of religion

\footnotetext{
871 Interview with New York Listening Session Organizer, February 21, 2012.

872 US, Civil Society Consultation for the U.S. Universal Periodic Review: New York, New York February 26, 2010.

$873 \mathrm{Id}$. at 5.

${ }^{874}$ NATASHA LENNARD, The Human Rights of Home NY Times at http:/ / cityroom.blogs.nytimes.com/2010/03/01/the-human-rights-ofhome/?pagemode=print.

${ }^{875} \mathrm{Id}$.

$876 \mathrm{Id}$.

$877 \mathrm{Id}$.

878 US, Civil Society Consultation for the U.S. Universal Periodic Review: New York, New York February 26, 2010.

879 LENNARD, The Human Rights of Home, supra note 874.

$880 \mathrm{Id}$.

881 The author analyzed the written statements taken at the New York Listening Session and available at http://www.law.columbia.edu/center_program/human_rights/HRinUS/HRinUSProject. All descriptions in this paragraph are based on accounts found on the webpage.
} 
as well as desecration of sacred sites. Lastly, one written statement told the story of policing and criminal procedures against pregnant women and girls for unborn children or still births. The statement says that women lose custody of their children or have been "subjected to intrusive state scrutiny" based on their behavior during a pregnancy. Other statements covering situations involving American Indians (Native Americans) or public housing or other issues were also submitted.

\section{Best practices from listening sessions}

The listening sessions for the US review demonstrate that even though the national consultation is the government's prerogative, civil society can mold them to meet their own objectives. Three strategies used by US civil society are worth highlighting. First, the consultations can use a variety of tools to get the message about human rights conditions across to the government. Second, the consultations may be flexible in their focus. Finally, consultations should bring the government in contact with every-day realities.

\section{(a) The tool box}

The New York City listening session made use of many mediums to convey their messages. First, the listening sessions used interactive panels, where speakers addressed the audience, then the audience addressed them. This flexibility allowed for give and take from both sides. It also made for a very authentic presentation of human rights problems. The atmosphere was not sterile or devoid of emotion. Anger, ire, frustration and hopelessness were expressed and came across in many of the interventions. At the same time, hopefulness, readiness for action and optimism were present. Government officials were also actively participating by responding at the end of each panel presentation. Officials were not just note takers, but participants.

The panels and question/answers were also accompanied by very able moderation. Mr. Robinson also contributed to the narrative about human rights in the US by giving anecdotes and stories about real people and how their lives were affected by lack of housing or other societal ills. The use of narratives can impact the listening sessions and the government officials listening to those narratives.

Some persons who were unable to attend the listening session due to inclement weather joined the session by telephone. This was accidental (they were supposed to attend in person) but it highlights that technology such as telephones and Skype can also give opportunity to bring in voices from other parts of the country to weigh in on issues and to provide a narrative or an expert viewpoint.

Video clips and movies were shown at the listening session and are particularly helpful for painting a more vivid picture of what is happening in a nation. They can also offer a narrative that is compelling for demonstrating the impact of policies on human life. Images have a lasting impact and can be more effective than narratives or descriptive words.

Finally, the site visit was a worthy initiative that gave officials an inside look at issues that they wouldn't normally see in person. The visit to an apartment or to a development site also permits people who may be unable to attend the listening session an opportunity to make their voice heard. Additionally, if the government didn't want the sessions advertised to the general public, the site visit is a way to get the general public back in and involved.

\section{(b) Flexibility about topic and themes}

Every society has regional issues that are not prominent in every part of the nation. There are themes that seem to recur in certain pockets of the country. The listening sessions in the US permitted certain cities to focus on such regional themes, where necessary. The U of San Francisco's panel regarding Lesbian Gay Bi-sexual and Transgender (LGBT) issues was particularly compelling. ${ }^{882}$ California has long been the locale for advocacy on LGBT issues, so focusing on human rights challenges in this area by the U San Francisco made sense. New York, on the other hand, is a microcosm of many nation-wide human rights issues, so the listening session held in that

882 Interview with Amanda Solter, Research Assistant, University of San Francisco School of Law, February 15, 2012. 
city echoed the larger, national challenges. Singular topics were also permitted in the listening session in Chicago and Washington, DC. Some issues (homeland security and terrorism) are so pressing that having listening sessions that treat those topics is logical.

\section{(c) Go to the grassroots}

One informant said that the strength of the UPR was that the national consultation brought high-level government officials in contact with the grassroots, the every-day people in a society. ${ }^{883}$ While this may not have been the case with every national consultation held in the first cycle of the UPR the American listening sessions were certainly examples of this unexpected encounter. Some governments (Kenya) specifically wanted to avoid direct encounters with angry citizens. ${ }^{884}$ Others tried to limit the sessions to invitees only (US, in relation to the NY listening sessions), no outside public advertisements allowed. ${ }^{885}$ In the latter, there was still an encounter with the grassroots because the groups that were present represented individuals who were often discussed their own personal situations. The groups were literally composed of self-advocates. Many of the organizations present were represented by people who had galvanized around a particular cause that affected their own daily lives.

\section{Amnesty International: Case study of NGO strategies in the UPR}

\section{A. Background}

Amnesty International (AI or Amnesty), the independent and financially autonomous NGO found in over 150 countries, ${ }^{886}$ has been active in the UPR since its inception. AI's secretariat prepares stakeholder submissions and/or an intervention during the plenary session. AI also lobbies governments to accept recommendations that it has taken under further consideration following the adoption of the Working Group Report. In addition, AI uses its national chapters to influence the domestic consultations and preparation of the national report as well as the implementation of the recommendations accepted in the final outcome. The individuals interviewed two from national AI chapters and one from the Secretariat - described AI's UPR strategy from start to finish. Additionally, an e-mail communication with the Interim Director of International Advocacy describing the AI strategy for UPR interventions was also relied upon for this case study. The author also analyzed the texts of the Amnesty submissions, as well as the three reports (the government's submission, the OHCHR compilation and the OHCHR summary of stakeholder submissions) and the final outcomes for the UPRs for Hungary, the Netherlands, Timor Leste and Indonesia.

The AI Secretariat, in London, is well placed to submit stakeholder reports and to intervene at the Genevalevel during the plenary sessions. It has approximately 500 staff persons and is divided into both theme-based and regional-based research teams. ${ }^{887}$ The Secretariat prepares stakeholder reports for submission to the OHCHR in consultation with the geographical desks and the national chapters, the latter often assisting to prioritize the issues that should be highlighted in the report. 888 The Secretariat also conducts lobbying efforts to get the most important issues before the diplomats that participate in the interactive dialogue. 889

AI's advocacy, however, is not limited to the work done by its London-based Secretariat. The national chapters conduct important campaigns and direct AI's participating in the national consultation and its interaction with other NGOs in the country. The national chapters prioritize the issues that should be included in the stakeholder report and also seek to liaise with government in the preparation of the national report, though

\footnotetext{
${ }^{883} \mathrm{Id}$.

884 Interview with Antonina Okuta, Senior Human Rights Official, Kenyan National Commission on Human Rights, 16 February, 2012.

885 Interview with New York Listening Session Organizer, February 21, 2012 (the US government had expressly requested that no public advertisement of the event in New York be carried out); Interview with Amanda Solter, Research Assistant, University of San Francisco School of Law, February 15, 2012 (at the U San Francisco listening session, no public advertisement was carried out at the university).

886 See Amnesty International, http://www.amnesty.org/en/who-we-are/history

${ }^{887}$ Email correspondence with Marianne Lilliebjerg, Interim Director of International Advocacy, February 14, 2012.

888 Id.; Interview with Orsolya Jeney, AI Hungary, April 18, 2012; Interview with Gerbrig Klos, AI Netherlands, April 24, 2012.

889 Interview with Orsolya Jeney, AI Hungary, April 18, 2012.
} 
this latter collaboration is often limited. National chapters also mobilize to urge implementation of the engagements taken on by the government in the final outcome of the UPR.

\section{B. Hungarian UPR}

In some cases, the national chapters of AI are particularly interested in highlighting hot issues that concern the general public and they are responsible for pressuring the government to fully implement the recommendations. Hungary's UPR in May 2011 is one example of how a national chapter with a conviction that the UPR could be useful to impact a certain issue of importance within a country can lead out in the advocacy campaign. In Hungary's UPR in the first cycle, certain events gave the national chapter impetus to make the treatment of the Roma (Romani), the centerpiece of its UPR advocacy. The case of the Roma and their treatment had been pushed by the national office which deemed the discriminatory treatment one of its top campaigns in Hungary. ${ }^{890}$ The office insisted that the Roma be made the key issue in the AI documents filed with the OHCHR. 891 In November 2010, AI (Secretariat) submitted its stakeholder report, 892 centering on Hungary's Criminal Code and arguing that the code lacked specific reference to racially-motivated crimes as a form of "base motivation" or an aggravating circumstance, rendering it difficult to monitor racially motivated offenses. ${ }^{893}$ The report also explained that law enforcement officials lacked training on combating racially-motivated hate crimes, ${ }^{894}$ that there was a lack of data regarding hate crimes ${ }^{895}$ and that there were no specific procedures for investigating hate crimes in Hungary. ${ }^{896}$ These failures impacted the Roma (Romani) community, which was particularly affected by racially-motivated hate crimes within the country. AI's submission outlined a series of recommendations on non-discrimination measures, implementation of hate crime legislation, recording crimes committed against members of community and victim support, including the following:

To develop an action plan and take urgent measures to combat and prevent racist incidents and hate crimes;

To ensure that members of Romani community, as well as members of other vulnerable groups, are protected from violence and attacks; [...]

To develop and implement guidelines for police officers to investigate crimes against the community under Article 174/B of the Criminal Code and other hate crime offences;

To introduce a system of comprehensive monitoring of all incidents that may constitute hate crimes, in particular racist offences. The monitoring should cover all stages of proceedings, including complaints lodged, charges brought and convictions recorded; [...]

To ensure that victims of hate crimes have effective access to mechanisms of justice and to redress, including by ensuring their access to appropriate support and assistance at each stage of the criminal justice process and, where appropriate, after its completion. The support and assistance should also be provided in cases in which the perpetrators are not identified, prosecuted or convicted. 897

The decision in November 2010 to make the Roma human rights violations a central part of advocacy was fortuitous because, following the submission of the national government's report, Roma were again subject to racial harassment within the country. ${ }^{898}$ The threats to the community continued for six weeks. ${ }^{899}$ The treatment gained international media attention and AI Hungary held a huge demonstration in April 2011 to raise awareness of the events. ${ }^{900}$ The international awareness facilitated AI Hungary's campaign to recruit governments to speak

\footnotetext{
${ }^{890} \mathrm{Id}$.

${ }^{891} \mathrm{Id}$.

892 Hungary, Amnesty International Submission to the UN Universal Periodic Review 11th Session of the UPR Working Group, May 2011. (2010)., available at http://www.amnesty.org/en/library/asset/EUR27/003/2010/en/5d8aeb44-0f8f-490b-8f4e1a003b31d8ee/eur270032010en.pdf.

893 Id. at 1-2.

${ }^{894} \mathrm{Id}$. at 2-3.

${ }^{895} \mathrm{Id}$. at 3.

${ }_{896} \mathrm{Id}$. at 3-4.

${ }^{897} \mathrm{Id}$. at 4-5.

${ }^{898}$ Interview with Orsolya Jeney, AI Hungary, April 18, 2012.

${ }^{899} \mathrm{Id}$.

${ }_{900} \mathrm{Id}$.
} 
about the Roma during their intervention in the interactive dialogue because many governments were keen on criticizing Hungary. ${ }^{901}$ Some 90 recommendations were made regarding the Roma. ${ }^{902}$

$\mathrm{AI}^{\prime}$ s interaction with governments during the national consultation is also a key moment as the staff has the opportunity to make known its recommendation and positions on human rights issues so there were no surprises during the interactive dialogue. In the Hungarian UPR, the Ministry of Foreign Affairs led the efforts for the national consultation. AI Hungary did not consider the consultations to be broad or continuous; they involved approximately 12 or 13 NGOs. ${ }^{903}$ Instead, the consultations appeared to be "window dressing." 904 The consultations were held based on themes, NGOs were invited to attend. Speakers presented points and the shadow reports were shared. Despite these efforts, the Hungarian national report ${ }^{905}$ had few self-critical observations. To its credit, the national report did admit that the efforts to train police staff in handling of "racist prejudices" and communication with "victims and suspects belonging to minorities" were insufficient. 906 However, most of the report contained a laundry list of laws, legislation or Constitutional provisions. Little was said about measures to be taken to address inequalities. For example, regarding the disproportionate representation of Roma children in Hungarian children's homes, the report states, "In many cases the conduct of life of the parents is the reason of endangerment of the child. Since Roma children have more siblings (even 8-10), the placement of them into family-like care may be difficult. Age factor appear as another obstacle, since 13-14-15 year old children refuse to live with another family, once abandoned by their own family." No additional information or solutions are given in the report. Regarding hate crimes, the report notes that the Criminal Code "regulates several independent crimes in connection with hate crimes.[,,] Accordingly, any person who assaults another person for being part, whether in fact or under presumption, of a national, ethnic, racial or religious group, or of certain groups of the population, or compels him by applying coercion or duress to do, not to do, or to endure something, is punishable by imprisonment up to five years." 907 The report also cites the punishment for crimes committed with a "base motive or purpose." 908 What the report does not do is address the fact that there are no specific provisions for punishment of racially-motivated crimes and there are no statistics regarding racially-motivated crimes.

Perhaps the most important observation is that the national report did dedicate considerable space to the Roma. An analysis of the text relating to the Roma demonstrates a defensive posture from the government in that most of the space dedicated to the Roma is used to list programs put in place and funds disbursed to those programs. In many cases, the programs are not specifically designed to address the Roma, but are in place for individuals or communities with economic disadvantages. In addition, there is a consistent denial within the government report that unequal status of the Roma is due to ethnic origin. However, because the report made so many references to the Roma, the theme would have to be covered by the government and the states in the interactive dialogue.

Under the rubric for education, the national report acknowledges a lack of equality in access to quality education for certain groups, including Roma students; it simultaneously states that the difficulties faced by a "significant proportion of the Roma minority are not due mostly to their ethnic origin, but to their social and health-related status." ${ }^{09}$ With respect to employment, the report references the adoption in Parliament of the Decade of Roma Inclusion Program Strategic Plan in 2007 which tasks the "improvement of employment." 910 The government also stated that statistics showed the level of employment among Roma to be half that of the non-

\footnotetext{
$901 \mathrm{Id}$.

$902 \mathrm{Id}$.

$903 \mathrm{Id}$.

$904 \mathrm{Id}$.

${ }^{905}$ National Report Submitted in Accordance with Paragraph 15 (a) of the Annex to Human Rights Council Resolution 5/1 - Hungary, UN Doc A/HRC/WG.6/11/HUN/1 .

$906 \mathrm{Id}$. at 96.

907 Id. at 932.

908 Id. at 33.

$909 \mathrm{Id}$. at 916.

${ }^{910} \mathrm{Id}$. at 19. 
Roma population. ${ }^{911}$ The report averred that many programs had been initiated in the past to address labor market activities for "disadvantaged people, including the Roma," but explained that the programs are defined on the basis of "socio-economic disadvantages" rather than on the ethnic background of the participant. 912 The report included a chart detailing the millions of euros invested by the government through employment programs, but the exact share of the Roma in the programs were either unable to be determined or based only upon estimations. ${ }^{913}$ In the realm of education, the government touted several scholarship programs, cultural and intervention funds, as well as a mentoring program as examples of its commitment to promote progress in Roma education. ${ }^{914}$ The government also cited programs to promote health care among the Roma, including a mobile screening unit. 915

Following the events surrounding the treatment of Roma, AI had stepped up its media campaigning. 916 One key element was a media event to make other NGOs and the media aware of the UPR and of AI position on certain issues. ${ }^{917}$ AI contacted everyone on the NGO press list. ${ }^{918}$ Approximately 10 persons were in attendance, including 5 people from the Ministry of Foreign Affairs. ${ }^{19}$ Most journalists were from newspapers and admitted they had not known about the UPR. ${ }^{920}$ The UPR then received huge coverage in the written media in Hungary, including one television interview of Amnesty International in May 2011.921

In the interactive dialogue, the Hungarian delegation admitted that the situation for the Roma had deteriorated and that unemployment had worsened. The government also stated that it was in the process of developing a "Roma Programme."922 Of the 48 countries that took the floor, several mentioned the plight of the Roma, including India, which stated it was concerned about the "persistent discrimination against the Roma people with respect to education, health, employment and housing, and the disproportionately high levels of poverty among them." 923 The final recommendations made to Hungary included many references to the Roma community including Switzerland which exhorted Hungary to adopt a plan of action to prevent racist attacks against the Roma so that they could live in "safety and dignity." 924 Indonesia made multiple recommendations, including one that urged Hungary to "[w]ork with the Roma self-governments, NGOs and human rights organizations to implement measures to encourage Roma and other victims to report hate crimes and, when they do, to protect them from reprisals." 925

Hungary either accepted or agreed to consider the vast majority of the recommendations made to it. In its final outcome, it rejected recommendations that it become a party to the convention on migrant workers and it also rejected the Russian Federation's recommendation that it revoke the condition that minority groups have resided 100 years in the country before being granted minority status. ${ }^{926}$

Following the review, the Hungarian government created a Human Rights Working Group that is supposed to take on the task of implementing the recommendations that were accepted. While AI considers the creation of

$911 \mathrm{Id}$. at 939.

912 Id. at 41.

${ }^{913} \mathrm{Id}$. at 942.

914 Id. at $945-47$.

$915 \mathrm{Id}$. at 954.

916 Interview with Orsolya Jeney, AI Hungary, April 18, 2012.

917 Interview with Orsolya Jeney, AI Hungary, April 18, 2012.

$918 \mathrm{Id}$.

${ }^{919} \mathrm{Id}$.

${ }_{920} \mathrm{Id}$.

${ }^{921} \mathrm{Id}$.

922 Report of the Working Group on the Universal Periodic Review Hungary, ๆ 10 UN Doc A/HRC/18/17, 11 July 2011.

923 Id. at 30.

${ }_{924} \mathrm{Id}$. at 94.29.

${ }_{925} \mathrm{Id}$. at 94.86 .

${ }_{926} \mathrm{Id}$. at 9 96.6. 
the group a positive step, it is also waiting to see whether the group will work in a transparent manner and who they will appoint to be members of the group. ${ }^{927}$

\section{UPR in The Netherlands (second cycle)}

$\mathrm{AI}^{\prime}$ s participation in the review of the Netherlands (in the second cycle of the UPR) is also noteworthy. AI engaged other NGOs and the Dutch Equal Treatment Commission in an effort to increase civil society participation, as compared to the previous cycle. In addition, in preparing its advocacy, AI looked back at the recommendations made to the Netherlands and at what the Netherlands had engaged to do, in order to prepare a focused submission that highlighted a few important human rights issues.

While this inquiry is concerned with AI's initiatives in the second Dutch UPR, there are some points to note regarding the first cycle. The Netherlands was reviewed in the very first session of the first cycle of the UPR on April 15, 2008.928 Prior to the review, the government had held two consultations with approximately 20 NGOs and some other organizations, including the Dutch Equal Treatment Commission. ${ }^{929}$ The report itself had been drawn up with the joint participation of eight Dutch ministries. ${ }^{930}$ The total time to draft the document had been from December 2007 until the end of February 2008. ${ }^{931}$ An outline of the topics was introduced to the NGOs at the first consultation and the second consultation explained more in depth the content of the national report. ${ }^{932}$ The national report was not circulated during the consultations. ${ }^{933}$

Amnesty International's national chapter in the Netherlands was also active in the first review of that country before the Council. ${ }^{934}$ The AI national chapter acknowledges that in the first round there was less NGO participation than in the second cycle. 935 That fact is also borne out by the number of submissions by NGOS in the first cycle as compared to the second cycle. In the first cycle only five NGOS submitted reports to the OHCHR, 936 compared with 16 stakeholder submission for the May 2012 review. ${ }^{937}$ Nonetheless, it is also important to note that in both cycles stakeholders submitted joint stakeholder reports; therefore, the total number of CSOs participating in the review was much higher than the number of reports that were submitted. The government's own 2008 report ${ }^{938}$ stated, that [i]n preparing this report, the government consulted over 20 Dutch human rights organizations." 939 In its 2012 report, ${ }^{940}$ the government noted that its first meeting was attended by 20 representatives of "different organizations." 941 No figure was given for the number of attendees at the second meeting. ${ }^{942}$

In preparation for the second cycle, AI attended a session for NGOs, ombudsman and others in Madrid, where they were informed about the UPR and how to best interact with the mechanism. ${ }^{943}$ After that mid-2011

\footnotetext{
927 Interview with Gerbrig Klos, AI Netherlands, April 24, 2012.

${ }_{928}$ Report of the Working Group on the Universal Periodic Review The Netherlands, UN Doc A/HRC/8/31, 13 May 2008.

${ }_{929}$ Interview with Walter Oostelbos, Strategic Adviser Migration Policy Department, the Netherlands, April 6, 2012.

$930 \mathrm{Id}$.

$931 \mathrm{Id}$.

$932 \mathrm{Id}$.

${ }_{933} \mathrm{Id}$.

934 Interview with Gerbrig Klos, AI Netherlands, April 24, 2012.

$935 \mathrm{Id}$.

${ }^{936}$ Summary prepared by the Office of the High Commissioner for Human Rights in accordance with paragraph 15 (c) of the annex to Human Rights Council resolution 5/1 - The Netherlands, UN Doc. A/HRC/WG.6/1/NLD/3 (13 March 2008).

937 Summary prepared by the Office of the High Commissioner for Human Rights in accordance with paragraph 5 of the annex to Human Rights Council resolution 16/21 - The Netherlands, UN Doc. A/HRC/WG.6/13/NLD/3 (12 March 2012).

${ }_{938}$ National Report Submitted in Accordance with Paragraph 15 (a) of the Annex to Human Rights Council Resolution 5/1 - The Netherlands, UN Doc A/HRC/WG.6/1/NDL/1.

${ }^{939} \mathrm{Id}$. at 94.

${ }_{940}$ National Report Submitted in Accordance with Paragraph 5 of the Annex to Human Rights Council Resolution 16/21 - Netherlands, UN Doc A/HRC/WG.6/13/NDL/1.

${ }_{941} \mathrm{Id}$. at 94.

${ }_{942} \mathrm{Id}$.

${ }^{943}$ Interview with Gerbrig Klos, AI Netherlands, April 24, 2012.
} 
meeting in Madrid, AI also organized a meeting in the Netherlands for NGOs which explained the process. ${ }^{944}$ AI worked with the Equal Treatment Commission (which is on track to become the Netherlands' NHRI) to try to entice Dutch NGOs to agree to all emphasize two main points in the submissions: The need for more human rights education in the Netherlands and for a national action plan or strategy for human rights. The effort fell flat as NGOs had other items for their agenda. ${ }^{945}$ However, in terms of numbers, the effort was a success - more than 40 NGOs participated in the process. ${ }^{946}$ Amnesty's Dutch chapter decided that in its second cycle strategy, it would highlight a very small number of substantive human rights issues in its submission; namely, the criminalization of irregular migrants and ethnic profiling. ${ }^{947}$ In addition, it was emphasizing a national human rights plan and human rights education for the Netherlands. ${ }^{948}$

$\mathrm{AI}^{\prime} \mathrm{s} 2012$ submission 949 assessed the first review of the Netherlands in 2008, stating that the Netherlands has accepted recommendations concerning "migrants, refugees and asylum-seekers; racial discrimination; and human rights education." 950 The report further stated that many of the recommendations "have yet to be implemented." 951

The remainder of the report was dedicated to the main issues that it had agreed would be part of its advocacy in the second cycle. Regarding the issue of a national human rights action plan AI expressed its regret that "the Netherlands has shown no intention of developing a national action plan on human rights, to specify amongst other things guidelines for meaningful collaboration with human rights treaty bodies, directions for policy making, benchmarks for assessing progress and measure for evaluation. [...] Most ministries do not have a human rights focal point, a human rights agenda, or a structured approach to addressing human rights concerns raised by international human rights bodies and national or international civil society organizations." 952 The issue of immigration detention remained an area of concern for $\mathrm{AI}$ as detainees had been subject to frequent handcuffing, locking up in cells for up to 16 hours per day, and required to wear restraining trousers, and because detainees were often also vulnerable individuals (victims of torture, human trafficking, mentally ill, elderly or pregnant.) ${ }^{953} \mathrm{AI}$ stressed that the government's position to only act as a facilitator in countering discrimination is in "conflict with the obligation in international human rights standards to respect, protect and fulfill the principle of non-discrimination." 954 AI noted in particular that the limited approach signified that the government fails to address "concerns about discrimination by the authorities, such as ethnic profiling by police and discrimination in the juvenile justice system." 955 Finally, with respect to the criminalization of irregular entry and stay, AI repeated the stance of the OHCHR and the Special Rapporteur on the human rights of migrants in opposition to measures "imposing criminal sanctions solely in connection with irregular migration. "956 AI expressed its concern with two draft laws that, if enacted, would do just that. 957 AI's submission ended with nineteen different recommendations in the above-referenced areas, including the following:

Establish a national action plan for human rights;

Fulfill the state's obligation to provide human rights education to all school pupils.

$944 \mathrm{Id}$.

${ }_{945} \mathrm{Id}$.

$946 \mathrm{Id}$.

$947 \mathrm{Id}$.

$948 \mathrm{Id}$.

949 AMnESTY InTERNATIONAL, Netherlands: Protecting Human Rights at Home, Amnesty International Submission to the UN Universal Periodic Review, May-June 2012 (November 2011), http:// www.amnesty.org/pt-br/library/asset/EUR35/001/2011/en/6340b386-2521-4cd1-93602d08a6b98149/eur350012011en.pdf.

$950 \mathrm{Id}$. at 3.

$951 \mathrm{Id}$.

$952 \mathrm{Id}$. at 4.

${ }_{953} \mathrm{Id}$. at 5-6.

${ }_{954} \mathrm{Id}$. at 6.

$955 \mathrm{Id}$.

956 Id.

${ }_{957} \mathrm{Id}$. at 6. 
Ensure that the National Human Rights Institution is accessible to all individuals in the Kingdom of the Netherlands, including all parts of the overseas territories;

Review its asylum legislation and procedures to ensure that all asylum-seekers, including those whose claims are being assessed under the accelerated procedure, receive a full and fair individualized determination of their claim;

Introduce statutory provisions in law, policy and practice to prevent the detention of persons belonging to vulnerable groups;

Treat those detained for immigration purposes humanely and in line with the strictest international human rights standards;

Develop a national action plan to combat discrimination;

Address concerns of discrimination by the government such as ethnic profiling, in order to uphold the principle of non-discrimination; and

Refrain from criminalization of irregular entry or stay which may leave irregular migrants more vulnerable to human rights abuses.958

The government held two sessions - one in December 2011 and one in February 2012 to discuss the government's submission. ${ }^{959}$ AI welcomed the fact that in this second cycle, the government's report writing is being led by the Interior Ministry rather than the Ministry of Foreign Affairs. ${ }^{960}$ AI did bring along its report (submission) and the government was keen on conversing and hearing about the report. 961 The first government event was well attended and the atmosphere friendly as people met in a room around a table; however, the AI felt the second meeting was less conducive to discussion because there was no particular agenda and the meeting was held in an auditorium with the government at the table and the participants far away in the seats. 962 Stakeholders were disappointed that the government didn't take the initiative to agree to "voluntary commitments." $963 \mathrm{AI}$ Netherlands and the Dutch Equal Opportunity Commission hoped for some surprises, something new that the government could agree to, but would get no such concession. ${ }^{964}$

The government's report for the second cycle 965 discussed two of the points highlighted by AI: criminalization of illegal residence and human rights education and promotion. However, racial profiling and other non-discrimination issues raised in the AI submission, together with the restraints on detainees were not specifically addressed.966 Regarding criminalization of illegal residence, the government defended itself by stating that "[c]riminalising illegal residence is not an end in itself and that it is expected to have a deterrent effect on illegal immigrants or people planning to bring immigrants to the Netherlands illegally." 967 The government further explains that being an illegal resident is a "minor offence." 968 Furthermore, the report emphasizes that minor children "cannot be criminally liable for their illegal residence."* Finally, the government defended the second-category fine imposed for illegal residence by pointing out that it is usually much lower than the 3,800

958 Id. at 7-8.

${ }^{959}$ Interview with Gerbrig Klos, AI Netherlands, April 24, 2012.

${ }^{960} \mathrm{Id}$.

$961 \mathrm{Id}$.

$962 \mathrm{Id}$.

$963 \mathrm{Id}$.

$964 \mathrm{Id}$.

965 National Report Submitted in Accordance with Paragraph 5 of the Annex to Human Rights Council Resolution 16/21 - Netherlands, UN Doc A/HRC/WG.6/13/NDL/1.

966 One portion of the national report discussing asylum procedure did indicate that an "independent committee supervises the return process, including forced expulsion and the use of force. Every year it concludes that there is no systematic use of excessive force in the expulsion process. The committee also makes recommendations to further limit the need for the use of force in individual cases." Netherlands National Report (2012), at 107.

${ }_{967}$ National Report Submitted in Accordance with Paragraph 5 of the Annex to Human Rights Council Resolution 16/21 - Netherlands, $\{108$, UN Doc A/HRC/WG.6/13/NDL/1.

968 Id. at 109. 
euro maximum and further acknowledged that four months detention can also be imposed in cases involved illegal residence. ${ }^{969}$

The government's report also addressed the presence of human rights education in primary and secondary schools by acknowledged that human rights are part of the good citizenship education. ${ }^{970}$ The government acknowledged, however, that the human rights principles are only implicitly included in good citizenship education. ${ }^{971}$ It stated that the Education Council of the Netherlands will issue a report in Spring 2012 to find additional ways to teach citizenship and will addressed the relationship between human rights education and citizenship education. ${ }^{972}$

AI Netherlands also began to contact diplomatic missions to get the word out regarding its submission regarding the upcoming review. It sent its submission to diplomatic missions in the Hague. In the cover letter it expressed hope that the representative would raise their concerns at the interactive dialogue and it outlined the substantive concerns regarding criminalization of un-documented migration, racial profiling and the need for human rights education. AI also scheduled face-to-face talks with those embassies that wished to meet and presented their reasons why a recommendation was necessary. AI spoke with diplomats from the embassies of Spain, Australia, the United States of American, Iran, Iraq, Tunisia and others. AI Netherlands chose the embassies they contacted based on an analysis of the recommendations they had made in the past. ${ }^{973}$ Using the UPR-Info.org database of recommendations, they generated a report that showed the top 10 states that made recommendations. This was simply a list of the 10 countries that had made the most recommendations during the UPR process (Canada, Norway, France, Mexico, Brazil, Spain, United Kingdom, Algeria, Netherlands, Slovenia). The theory was that "active" states would be more likely to make recommendations than the inactive ones. The second category analyzed were the top five states that were most aggressive in making recommendations to the Netherlands in past cycle's review (Algeria, Egypt, Russia, Mexico, India). The rationale was that these states would be useful to approach since they seemed to take a particular interest in Dutch human rights. A third area of analysis was to look at the nations that were being reviewed in the same session as the Netherlands and see what human rights issues they had made recommendations to the Netherlands in the first cycle (Algeria, India, Brazil, Indonesia, UK, South Africa, Finland, Morocco, Ecuador, Tunisia, Philippines, Bahrain, Poland - the latter seven nations had made no recommendations to the Netherlands in the past). This tactic was used with the belief that those nations might be more inclined to prepare intensively for the session since they were under review and may be inclined to make recommendations. AI also compiled a list of countries that had made recommendations in the same general topic areas -i.e. asylum seekers/refugees (Mexico, Nigeria), migrants (Algeria, Egypt, Mexico, Nigeria, Peru, Turkey), racial discrimination (Algeria, Canada, Cuba, Egypt, Indonesia) as well as a list in the specific topic areas - i.e. ethnic profiling (Indonesia, Algeria, Brazil, Egypt, Canada, Syria, Greece, USA), immigration detention (Brazil, Mexico, Slovakia, Slovenia Switzerland) and criminalization of irregular stay (Mexico, Brazil, Guatemala). After the analysis, AI targeted those embassies. In particular, AI wanted to get in touch with Mexico and Brazil since those countries kept reappearing in each of the individual lists. Following its contacts with embassies, certain missions called and asked for more information. ${ }^{974}$ AI believes those countries were feeding information to their capitals. 975

AI also attended a pre-session for the $13^{\text {th }}$ session of the UPR. The pre-session was hosted by UPR-Info.org 976 and was held in Geneva on April 4, 2012. A pre-session is hosted by UPR-Info.org some two months before the

\footnotetext{
${ }^{969} \mathrm{Id}$. at 9110.

${ }_{970} \mathrm{Id}$. at 9 १ 111-114.

${ }^{971} \mathrm{Id}$. at 9 \ 111-112.

972 Id. at 9114.

973 In the remainder of this paragraph, the process to choose which embassies to approach is described. This is based on a confidential document made available to the author by Gerbrig Klos of AI Netherlands.

${ }_{974}$ Interview with Gerbrig Klos, AI Netherlands, April 24, 2012.

$975 \mathrm{Id}$.

976 UPR-Info.org is a non-governmental organization based in Geneva, Switzerland with the stated goal of "raising awareness and providing capacity-building tools to the different actors of the UPR process, such as United Nations Member States, NGOs, National Human Rights Institutions and civil society in general." http://www.upr-info.org/-About-us-.html.
} 
scheduled interactive dialogue/review of a country and seeks to bring together delegations from nations and $\mathrm{CSO}$ to discuss the human rights situation in a nation. AI Netherlands made a formal statement at the presession, emphasizing that the "development of an ambitious domestic human rights strategy" would "enhance the protection of human rights in the country." 977 AI further urged the introduction of "law, policy and practice to prevent the detention of children, pregnant women, the elderly and victims of torture and trafficking." $978 \mathrm{AI}$ recommended that the government change a recently introduced law that imposes administrative fines upon, and imprisons irregular migrants. ${ }^{979}$ Finally, AI stated that the Dutch's government's approach to tackle discrimination is insufficient, particularly as it regards racial discrimination. ${ }^{980}$ AI urged that the Netherlands develop a national plan of action to combat discrimination and that it address concerns of ethnic profiling by the police and "wider criminal justice sector." 981 UPR-Info.org reported that during the pre-session on the Netherlands, "significant attention was drawn to concerns about the rights of immigrants, migrant workers, and asylum seekers. NGOs urged the government of the Netherlands to improve the conditions of detention facilities, to take measures to limit excessive lengths of detention, and to consider alternatives for detention wherever possible." 982 Other issues were also discussed and the NGOs urged the Netherlands to adopt a national strategy to "mainstream human rights into its national and local governmental bodies and policies." 983 While at the presession, AI was able to meet with the representative from Brazil, one of the countries it identified as being friendly to the themes of the recommendations it would like to get before the Dutch UPR. ${ }^{984}$

AI's Dutch section has other plans for the time up until the May $31^{\text {st }}$ review of the Netherlands. It would like to have a side event and an event in the Hague showing the interactive dialogue, but these plans are still in the works. 985

\section{Best practices for NGOs in the UPR}

AI's advocacy in the Hungarian and Dutch reviews provides alternative examples of how to approach the UPR as an NGO. There are three strategies evident in AI's approach: prioritizing issues, tailoring recommendations to prioritized human rights issues and maintaining pressure on the government.

\section{Prioritization of human rights issues}

The UPR was set up to review the ensemble of human rights in a nation. However, AI recognizes the importance of prioritizing rather than attempting to list all of the rights challenges faced by a nation. This strategy is particularly effective for AI because it permits the organization to generate a set of clear recommendations that target the priority issue. As was seen in the case of the Hungarian UPR, choosing an issue that is in the spotlight can also lay the groundwork for later campaigns with embassies and diplomats because the issue will already be very familiar to the permanent missions and back at the capitals.

In prioritizing, two steps should be undertaken. First, one should identify the candidates to be given a priority and choose the one that can have the greatest impact at the moment. This can be done by considering the political situation. Is the government being pressured from other places, like the Hungarian government was being pressured by the European authorities to improve the Roma situation? Perhaps there is an issue that is being

\footnotetext{
977 AMNESTY INTERNATIONAL, Statement of Amnesty International delivered by Gerbrig Klos, Senior policy Officer Amnesty International Dutch section, http://www.naareenmensenrechteninstituut.nl/ul/cms/fck-uploaded/AmnestyInternationalStatementAmnestyNetherlandsApril42012.pdf.

978 Id.

${ }^{979} \mathrm{Id}$.

$980 \mathrm{Id}$.

${ }^{981} \mathrm{Id}$.

982 UPR-INFO.ORG, UPR Info Wraps up a Dynamic First Round of "Pre-Sessions, " http:/ / www.upr-info.org/+UPR-Info-wraps-up-a-dynamicfirst+.html.

${ }_{983} \mathrm{Id}$.

984 Interview with Gerbrig Klos, AI Netherlands, April 24, 2012.

985 Id. 
raised often in Geneva, like the establishment of national action plans. The Dutch AI chapter grabbed that topic and made it a priority, knowing it was also being advocated internationally.

A second step is to see whether interest in the topic chosen as a priority can be generated among other missions and diplomats. The Dutch chapter's research into the missions most likely to carry their recommendations to the floor of the Human Rights Council is an excellent example of the type of homework an NGO should do to make sure that its recommendations gain traction in Geneva.

\section{Tailored recommendations}

$\mathrm{AI}^{\prime}$ s recommendations are always on point and cover the issues that were chosen as priorities. The recommendations are well formulated and they propose specific action. For example, AI's recommendation to Hungary regarding policing hate crimes stated, "ensure that all police officers receive in-service training on the nature of hate crime and the role of the police in combating them." 986 This was specifically calling for in-house training and it specified what needed to be covered in the training.

The recommendations should also be related to the prioritized issues. In the example given, the recommendation is related to hate crimes. However, because the Roma were subjects of hate crimes and the police are not trained in identifying the crime as a hate crime, this recommendation is central to the Roma issue.

\section{Pressure}

The UPR is a peer review mechanism. Pressure is the name of the game. However, NGOs must know how to pressure other governments to apply pressure to fellow governments. This is not an easy task. AI has used several tools to maintain pressure on governments before, during and after the reviews - stakeholder submissions, lobbying of diplomatic representative, oral statements in the plenary session and press releases.

AI announces in advance its position regarding the UPR and which issues it will highlight in the report. This information is given to the government, but also to diplomats. The information is widely circulated and is also available on the AI website, among the OHCHR documents and is sent to the missions. Therefore, everyone, including the government knows what issues are targeted and what change in behavior AI would like to see.

By approaching missions and diplomats, AI ensures that its issues are raised on the floor of the Council during the interactive dialogue. Statements are made and recommendations are put forward only during the interactive dialogue. AI has no right to make statements at that time; therefore, it is important for it to keep the pressure on through is proxies in the permanent missions.

During the plenary session, when AI is allowed to take the floor and speak, it will highlight what it is happy with and what it is disappointed with. The speeches often also urge the government to reconsider its position on certain issues. By highlighting the bad, AI keep the government under pressure to consider accepting the recommendations it rejected at the next cycle. AI also released a press statement to keep the government under pressure even after the review. ${ }^{987} \mathrm{The}$ press release also makes the general public aware of what engagements were made by the government in its review.

\section{Conclusion}

Civil society organizations are key actors in the UPR. CSOs can drive the national consultation process thereby influencing the content of the national report. CSOs also have opportunities to lobby permanent delegations to get their issues into the interactive dialogue in Geneva. To effectively engage in the UPR, all groups, including NGOs, must also look for ways to pressure governments to implement the recommendations. This study has shown that devising cooperative strategies among

\footnotetext{
${ }^{986}$ AMNESTY INTERNATIONAL, Netherlands: Protecting Human Rights at Home, supra note 949, at 5.

${ }^{987}$ Email from Marianne Lilliebjerg, Interim Director of International Advocacy ( February 14, 2012) (on file with the author). 
NGOs is an effective way to ensure that ideas are heard and that governments take action to fulfill their responsibilities. 


\section{PART FOUR}

\section{TRANSFORMATION OF THE HUMAN RIGHTS DISCOURSE}

This dissertation opened by explaining the historical context to the creation of the UPR, including existing review mechanisms. It continued by comparing the types of accountability mechanisms in existence today at the international level and the particular significance of peer review as an accountability mechanism. The inquiry then turned to the UPR itself and how it is described in its founding documents and how it has been carried out in various states.

Part Four describes the findings of the case studies of UPR actors and comparative studies regarding the accountability mechanisms. Then, I make policy recommendations to strengthen the process. Finally, I draw conclusions about the UPR and anticipate the challenges the UPR process faces in the future.

\section{Research questions}

The main research question for this inquiry was: Does the Universal Periodic Review change the human rights discourse at the national and/or international level?

The answer to this question was approached by asking four additional sub-questions:

- Does a peer review mechanism change the human rights discourse at the international level?

- Does government participation in the UPR change human rights discourse nationally and/or internationally?

- Does the participation of National Human Rights Institutions in the UPR change human rights discourse nationally and/or internationally?

- Does the participation of civil society in the UPR change the human rights discourse nationally and/or internationally?

\section{Change in discourse}

This final portion of the dissertation discusses the finding concerning the changes brought to the human rights discourse by a peer review mechanism and by the participation of governments, national human rights institutions (NHRIs) and civil society organizations (CSOs). Based upon the case studies and observations of the UPR process, I describe my findings regarding the changes in the human rights discourse that the UPR has and potentially can continue to bring. To assess how a peer review mechanism and how governments, NHRIs and CSOs have brought changes to the human rights discourse, the inquiry examines four important elements which are described in detail below:

Participants in the human rights discourse;

The frequency and total number of encounters between the participants;

The manner in which the human rights discourse is carried out; and

The content of the human rights discourse.

Participants are the actors that are engaging in the UPR process in a country. The author holds the viewpoint that the human rights discourse benefits from a broadening of the participants and actors. Therefore, a positive advance would be a mechanism that increased the parties to the UPR process both within a nation's consultation process and at the level of the Council in Geneva.

The frequency of contact is also important for assessing how the human rights discourse has changed because continued contact suggests a dynamic character and on-going engagement by all participants. For example, a one-time national consultation occurring every four years is less desirable than a discourse that includes meetings following the UPR to assess the implementation process or progress on a particular right or issue. 
The manner in which the discourse is carried out can be evaluated by looking at the setting (venue) of the dialogues, meetings, or other encounters. Variety and flexibility seem preferable. For example, are the participants interacting in a variety of settings and venues - e.g. in person, by telephone, via e-mail, etc. Are the contacts recorded so that people can compare and assess previous positions or gains and progression? Is there a way to track what was done in the past and what needs to be done in the future to continue the discourse? Is the discourse devoid of over-politicized remarks or bloc voting?

The content of human rights discourse is equally significant because the UPR has an inherent goal of looking at the overall picture of a country's human rights record. Accordingly, the spectrum of human rights topics should be in the human rights discourse. In addition, the content should be universally applied so that all nations are subject to the same standards. The author believes that a viable discourse would be one in which all the actors become fluent in the framework of human rights, as understood in the international community, based on the core UN human rights conventions. In addition, discourse that incorporates the plight of individuals or groups within a nation is equally desirable.

\section{Constraints and limitations}

When summarizing findings, I found that the case study method introduces some restraints and limitations to the usability of the data gathered. Case studies describe a particular situation at a given point in time and are, therefore, a snapshot of reality of one particular country. The author acknowledges that case studies are generally not useful for drawing broad generalizations about the phenomena observed. My research describes the process of reporting the human rights situations in Kenya, the Netherlands, Denmark, the United States of America and Hungary during the first or second cycles of the UPR. These descriptions may not apply to UPR processes in other nations. Therefore, as a researcher, I was faced with the challenge of finding how my data is relevant and to what extent one can generalize or draw best practices from one particular process. I address this challenge by disclosing the limitations to the applicability of the findings and explaining how the finding can be validly used. A systematic study of many more national consultations and interactive dialogues over several UPR cycles is necessary to arrive at a conclusion that a permanent transformation has occurred.

The key informants interviewed for the case studies come from UPRs conducted in largely democratic states with an independent civil society. As a result, the findings are likely applicable to countries with similar democratic processes. More authoritarian regimes are not likely to have seen the same expansion in the human rights discourse expressed in my findings. Further research needs to be done to see if the human rights discourse in authoritarian regimes was either begun or expanded when conducted in the national consultations or following up on recommendations that were accepted in the process. This author suspects that even in very closed regimes, sending a delegation to Geneva to engage in the interactive dialogue and explain policies related to human rights in the language and terminology used in the UN Human Rights Council settings did require some additional engagement to at least perfunctorily consider the human rights picture in the nation.

Regarding the usefulness of the findings, there are two. First, the author stresses that the best practices highlighted in Part Three can be particularly helpful in encouraging nations to find ways to incorporate those best practices in their own national contexts leading to a more universal application of human rights promotion and protection in national policy-making. Therefore, the descriptions and analysis in the case studies can serve as models to other societies for ways to organize NGO participation, structure NHRI interaction and conduct government consultations with civil society. Second, even in authoritarian environments, the power of awarenessraising cannot be overstated. As more nations, institutions, civil society groups and citizens become aware of the UPR and of the explicit goals of the process, pressure can be brought to bear on governments to give more meaningful participation in future years. 


\section{Chapter Nine}

\section{Findings and Conclusions}

\section{The Creation of a Peer Review Mechanism Transforms Human Rights Discourse}

Immediately before the establishment of the UPR, the human rights discourse had as its main participants: the OHCHR Secretariat, thematic and special rapporteurs, experts sitting on the Treaty Bodies and the national governments, with a limited participation by NHRIs and NGOs who offered shadow reports, but were not direct participants. The main accountability holders were the experts, rapporteurs and treaty committee members. The Universal Periodic Review (UPR) has changed the accountability holders within the human rights discourse by introducing a peer review mechanism that emphasizes inter-governmental dialogue at the international level and, at the national level, a dialogue with civil society. It makes government one of the accountability holders and has the potential to permit civil society, national human rights institutions and (as in the case of the Netherlands) parliament to also play a prominent part in the process during national consultations and also at the time of implementation of recommendations.

The changes I describe regarding the national consultations and the follow-up to implementation of recommendations are possible in democratic nations where civil society groups are active and independent. In more authoritarian contexts, the human rights discourse is limited, if it exists at all; moreover, civil society is either absent or heavily dependent upon the government for aid and support. As a result, the observations that I make regarding national human rights discourse are valid for democratic societies, but are unlikely to have occurred in autocratic nations. The wider application of the findings to states that I have not studied is justifiable because the case studies of the US, Hungary, Kenya, the Netherlands and Denmark do show a coherency across the five countries in terms of structure of civil society, strategies and tactics used by civil society groups. This is also likely the case for other democratic societies not studied. In the countries where NHRIs are present, there is also a similar approach to contacts with government and civil society. One can presume that similar conditions exist in other nations with NHRIs. In addition, in terms of validity of findings regarding the human rights discourse, at a national level, the existence of civil society and democratic institutions lays the groundwork for the discourse in such a nation to have been modified as a result of the UPR. Moreover, even if such a change did not take place, the conditions are present for such changes to occur in future UPRs; therefore, the best practices discussed in my inquiry can also be useful in those nations where the human rights discourse was only marginally impacted by the UPR.

What is concluded regarding interactions at the international level, in Geneva, are valid for both autocratic and democratic societies alike. Those processes were undergone by autocratic and democratic nations alike. The scrutiny and pressure applied at that level and the modifications to the human rights discourse are universally applicable to all nations. 988

The relevant research sub-question was: Does a peer review mechanism change the human rights discourse at the international level? The four criteria to gauge the change were: the participants in the human rights discourse; the frequency and total number of encounters between the participants; the manner in which the human rights discourse is carried out; and the content of the human rights discourse.

Based upon the findings of the peer review discussion, this author posits that a new peer review mechanism for discusses human rights has changed the participants in the human rights discourse during the interactive dialogue by making states the center of the debate and excluding the direct participation of experts. Secondly, the

\footnotetext{
988 The author has viewed the interactive dialogues of many more than the five countries used in the case studies. While an exhaustive list is not possible, among those webcasts observed were: Gabon, Bahrain, Yemen, Ecuador, Switzerland, the Netherlands, Denmark, Timor Leste, Indonesia, the United States of America, Hungary, Kenya, Slovenia, France, and Australia. The author was present in Geneva for the reviews of Ireland, Haiti, Venezuela, and Syria. Accordingly, the findings regarding governments and the interactive dialogue in Geneva are also underpinned by the observations of these UPRs.
} 
total number of encounters at the international level in which states debate human rights with other states has also increased because the Working Group meets three times per year over a period of two weeks to assess the human rights records of peer states. This represents a more sustained dialogue regarding human rights issues. A third finding is that the discourse is open and available for public observation both during the actual sessions and for view on archived webcasts after the reviews. Finally, the human rights discourse has also been enriched as all nations have been assessed and required to respond regarding a large variety of human rights issues; thereby engaging even the most closed societies in a dialogue about the most fundamental rights. These findings are more closely analyzed in the discussion below.

\section{A. Peer Review Changes the Accountability Holders in the Human Rights Discourse}

Following its implementation, the UPR provided a new forum for governments to examine each other's human rights records. Such a forum was innovative because, at the Geneva level, during the interactive dialogue, only governments were scrutinizing and commenting on the human rights records of their fellow states. The UPR's interactive dialogue -- the 47-member Council and the state under review -- is novel in the sense that it offers governments a place to talk among themselves, rather than be questioned before experts and treaty-body members, about their human rights records and the challenges they face in the area of human rights. The UPR changes the accountability holders in the human rights discourse because, during the three-hour interactive dialogue, the accountability holders are the states themselves, as opposed to the Council, rapporteurs or treaty body members. The other participants - NHRIs and NGOs - are not admitted at this level. In general, this idea of peers holding peers accountable changes the participants of the human rights discourse. In the peer context at the international level, the participants in the human rights discourse are members of the governments only.

While the UPR's innovative interactive dialogue has made states themselves accountable to other states, it has also claimed one casualty - experts. The interactive dialogue does not envision an active role for experts in the UPR. Therefore, the human rights discourse has been modified by the UPR to exclude the voice of experts during the three-hour dialogue. Detractors of the UPR process point to the absence of experts as proof that the mechanism lacks authority. For example, one common assertion is that the UPR is an inter-governmental mechanism and cannot "be of any use in the case of those who are not really willing to participate...." 989 Philip Alston is particularly harsh in assessing monitoring mechanisms that rely on initial state reports as "cumbersome, technologically outmoded, expensive and generally unproductive." 990

This author takes the viewpoint that the nature and purpose of peer review as a cooperative process necessarily encourages improvements in human rights records. 911 As has been set forth in earlier chapters, the goals of peer review are to encourage compliance through pressure. The fact that all states submitted national reports and appeared with high-level delegations in the first cycle and continue to do so in the first session of the second cycle means that the countries have made a decision to cooperate with the mechanism. While it is theoretically true that at any given point, a state could refuse to cooperate, the reality of peer review suggests that such a choice would be seen as unacceptable by peer states that have chosen to participate in the reviews. (See discussion below regarding Israel's absence from its own second cycle review.) In addition, the national reports, as has been explained in earlier chapters, are only part of the way in which states are assessed; other voices have heavily influenced the interactive dialogue. Therefore, the interactive dialogue still bears the prints of experts and other stakeholders.

\footnotetext{
989 Olivier De Frouville, Building a Universal System for the Protection of Human Rights: The Way Forward, in New Challenges for the UN Human Rights Machinery: What Future for the UN Treaty Body System and the Human Rights Council Procedures? 241, 253 (M. Cherif \& Bassiouni, William A Schabas. eds. 2011).

The proposition that experts are excluded from the interactive dialogue does not mean that expert information is not available to inform the dialogue. To the contrary, experts' voices are "heard" in the two reports submitted and compiled by the OHCHR; namely, the stakeholder submissions and the OHCHR compilation of reports from UN agencies and bodies.

990 AlsTON, supra note 21, at 214.

${ }^{991}$ Dominguez Redondo asserts that, due to the legalistic nature or perception of human rights, "those in charge of human rights mechanisms, scholars and practitioners tend to neglect the potential value of cooperative approaches to human rights implementation and focus instead on the confrontation approaches to human rights implementation." DOMINGUEZ, REDONDO, supra note 71, at 13.
} 
There are positive considerations for limiting the participation of experts in the UPR. The absence of experts can render states more eager to participate in the interactive dialogue. This has not been the case with the treaty body dialogues, which some states perceive as confrontational, placing the state under review on the defensive. ${ }^{992}$ A second advantage is that the solutions and suggestions for improvements are inventions of the member states themselves. What could be better than for states who have experiences or who are experiencing similar situations to suggest ways to improve or tackle human rights concerns? Experts may not be needed in such a case. Finally, although experts do not participate directly in the interactive dialogue and in the other Geneva sessions, their voices are echoed in the documents provided by the OHCHR to the process. Therefore, they are not completely absent from the dialogue at the international level.

While experts may be absent from the discourse during the interactive dialogue, this absence is a bit overstated, as will be demonstrated by the diagrams and discussion below. At first blush, the UPR interactive dialogue, accountability appears to be structured in the following manner, with the groups closer to the state review wielding the most influence in the process and with no outside influence from non-state participants.

992 Interview with Bacre Ndiaye, UPR Division, Office of the High Commissioner for Human Rights, March 17, 2012; Interview with Amanda Solter, Research Assistant, University of San Francisco School of Law, February 15, 2012. 


\section{UPR Interactive Dialogue: An Erroneous Depiction}

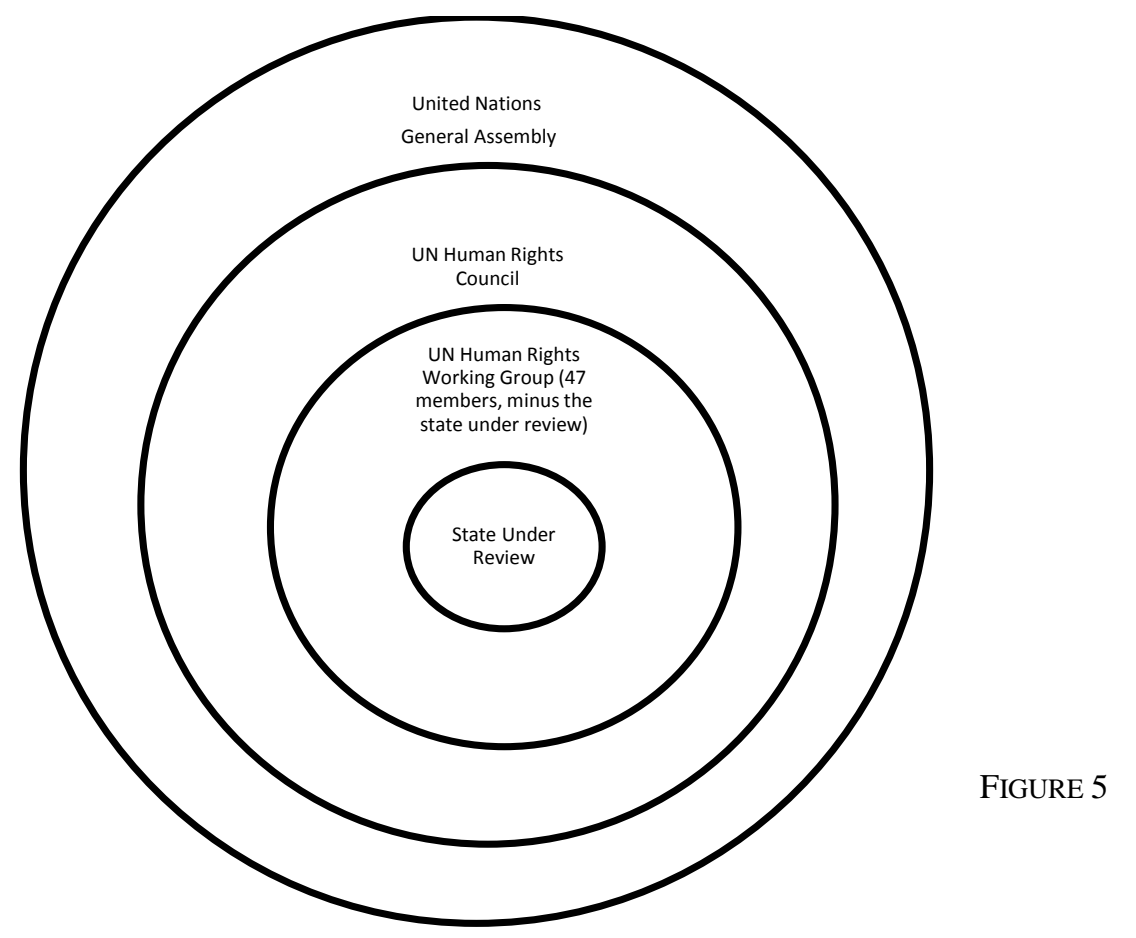

The diagram above depicts an interactive dialogue devoid of any groups other than states as accountability holders. However, that picture is only partially correct because, in democratic nations and to a lesser degree in autocratic regimes, the actual process is tinted and influenced by experts, NHRIs (if active in the state under review) and CSOs, as was demonstrated in the case study of the Netherlands, the United States of America, Hungary and Denmark. This influence comes from the way in which the national consultations and preparation of the national report are carried out. In all of the states mentioned, civil society organizations were proactive in bringing their concerns during the interactive dialogue. Many times, the cases of human rights violations evoked are based on meticulous studies of violations and fact-finding missions carried out by human rights experts within organizations such as Amnesty International or Justitia et Pax. In addition, the OHCHR compilation contains information from the expert bodies and special procedures. These reports are closely read by the delegations and thereby tint the interactive dialogue with the opinions and recommendations from the other processes. The case studies from the NHRIs and CSOs also demonstrate active lobbying from civil society or permanent representatives in Geneva and ambassadors in efforts to influence the topics raised during the interactive dialogue. For example, the Danish Institute for Human Rights has an extensive campaign, contacting the ambassadors in Copenhagen and the representatives in Geneva regarding issues such as children's rights. The informant from the Dutch National Human Rights Institution also indicated that it held a session in Den Haag for 20 ambassadors regarding the second review of the Netherlands and that it later confirmed that the United States of America brought up several of the Institution's talking points during the interactive dialogue, including asylum practices and the issue of women in the labor market. 993

As a result, the following diagram more accurately depicts the reality of the accountability holders in the interactive dialogue. The arrows illustrate a line of influence directly to either the Working Group or the state under review itself.

\footnotetext{
993 Interview with informant from Het College voor de Rechten van de Mens (the Dutch national human rights institution) on May 14, 2013. The United States expressed its concern regarding the denial of the majority of asylum requests by children outside of the country seeking to be reunited with parents and also evoked the "vulnerability of women in the labour market." 993 Report of the Working Group on the Universal Periodic Review - The Netherlands, U.N. Doc. A/HRC/21/15 (9 July 2012), ๆๆ I.B. 62.
} 


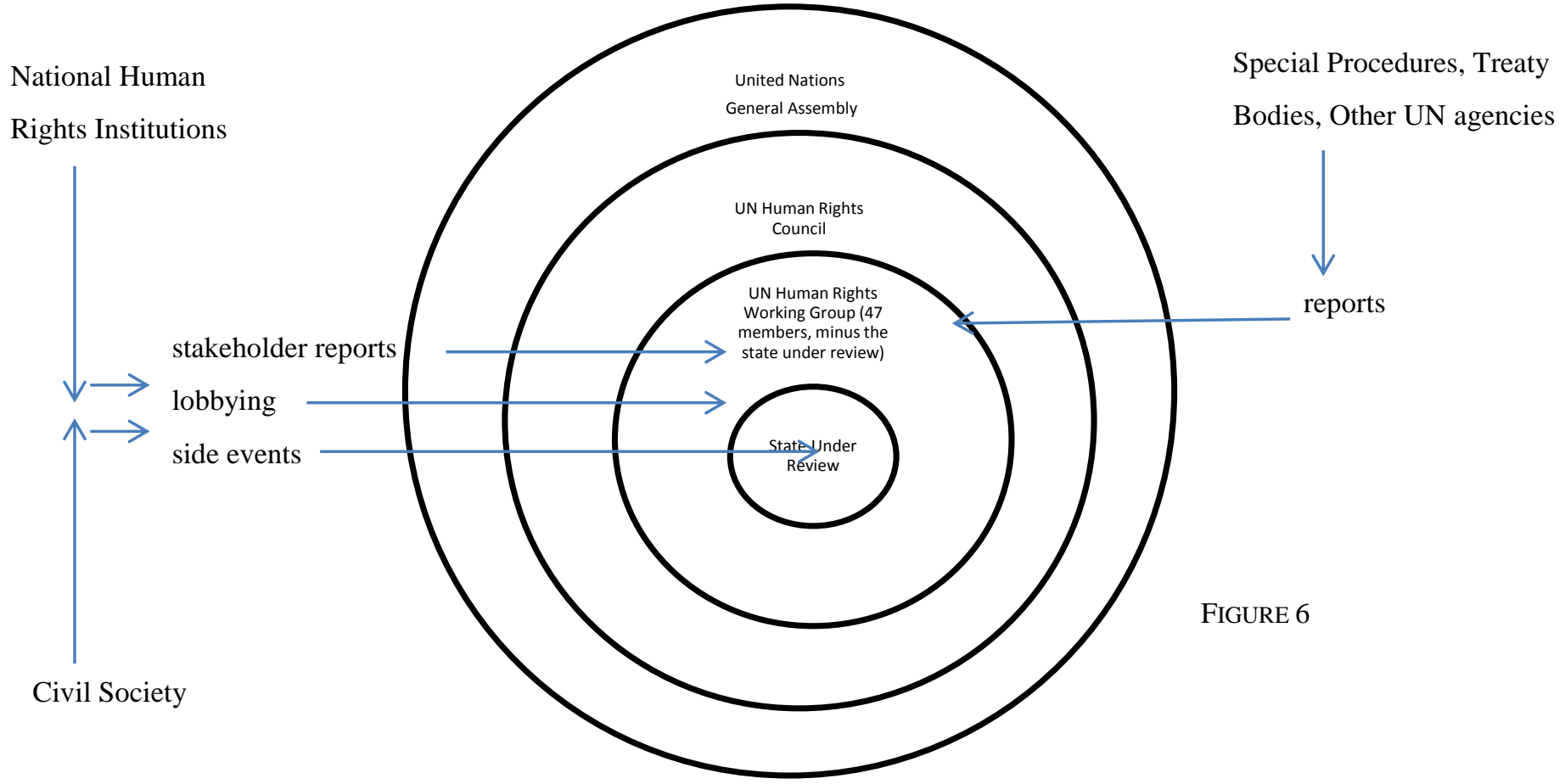

Currently, the UPR is the only forum for human rights discourse available exclusively to UN member states to periodically discuss their own human rights records with peers. (The procedure formerly known at 1503, which is a discussion among peer states, is a complaint mechanism, not a periodic review.) This forum is unique and should be viewed as another valuable forum where human rights can be evoked. The author is of the view that it is important to have human rights issues discussed, debated and argued in a variety of fora, with and without the direct involvement of experts. In the case of the UPR, it is important that member states discuss each other's records, opening up and giving more transparency to the human rights situations within their borders. It is equally important that the OHCHR, NHRIs, NGOs and others be privy to the discourse (even if only in a limited way) so that these organizations are equally aware of what the situation is and how the government's plan to approach the situation. The Working Group should also take advantage of the unique composition of the interactive dialogue (that is to say, the fact that only states are present) to find ways to enhance the cooperation and sharing of best practices, as discussed in more detail in the recommendations below. In summary, the peer to peer dialogue gives a new dimension to how human rights are discussed in Geneva. For the first time, both autocratic and democratic nations are evoking human rights issues of all types in a forum where any topic related to human rights can be evoked.

\section{B. Increased frequency and total number of encounters}

When a democratic nation conscientiously participates in the UPR process, the UPR has the potential to introduce an unprecedented opportunity for regular encounters between governments to discuss all matters affecting human rights. The total time and frequency of these encounters can increase. Using the Netherlands case study as an example, one sees that prior to the introduction of the UPR, no time was dedicated at the international level to the discussion of the total human rights record of a nation. Instead, the discussion took place in relation to treaty body reporting, which focused on the particular human rights topics in the treaty. That has changed. The UPR now requires governments, like the Netherlands, to defend their records for approximately four and-a-half hours (three hours, in the interactive dialogue, 30 minutes in the adoption of the report of the working group and one hour in the adoption of the final outcome) every four-and-a-half years. While a member state's review takes place only every four (now four and-a-half) years, the review of nations in Geneva occurs three times each year for two weeks each time. Therefore, the UPR has opened an opportunity for governments to discuss human rights for a total of six weeks each year. These encounters are held among 47 UN 
member states who discuss the human rights situations in nations for three hours during an interactive dialogue and for a half-hour during the adoption of the working group report. In addition, three times a year, states come before the plenary Council to discuss the final outcome of the review in a one-hour session. There is also significant time invested in pre-review and in the follow-up to the working group outcome. The additional time and frequency of encounters in Geneva meant that nations were engaged in the debate and discussions of human rights issues of all types for a longer time and this longer discourse also permitted nations to use the language of human rights and potentially inclined them towards a wider consideration of human rights in all policy-making.

The increase in time allotted for discourse on human rights also translates, in the case of nations where democratic political institutions divide power among ministries, to national policy making. This is because as permanent representatives are engaging in human rights discourse, they are also contacting their capitals (as the Dutch government did) in relaying back the criticisms and recommendations that other states have made regarding human rights policies. That communication sparks additional discussions regarding human rights at the ministerial levels in the nation (again, evident with the review of the Netherlands, when the ministries had to communicate back to Geneva which recommendations would be accepted or rejected). Assuming that most democratic (and even some autocratic) nations will want to dialogue with the capital prior to accepting and rejecting recommendations, one can see the potential for starting national conversations about the ensemble of human rights issues, even if those conversations are limited to the ministers in charge of policy-making.

The UPR has increased the amount of time dedicated to the discussion of human rights by governments. This increased focus means that the discourse is becoming more entrenched in the human rights machinery at the UN. Moreover, diplomatic representatives are dedicating resources and personnel to intervene in the working group and plenaries with speeches and written questions regarding the records of fellow governments. The work of the Kenyan and Danish human rights institutions and the AI civil society case study showed that diplomatic representatives are interfacing with civil society groups from around the world to determine what recommendations to make during the interactive dialogue. The overall effect of this increase in time dedicated to human rights discussion means more governments and international civil servants engaged in the language and discourse of human rights.

Even as the UPR has increased the total amount of time being dedicated to human rights issues, it has also increased the amount of encounters in which human rights are being discussed both in formal settings during the plenaries and working group and in informal contacts with civil society. More contact time with human rights means more sophisticated dialogue and more informed civil servants to add human rights to their professional dossiers. ${ }^{994}$ The stimulation in debate is not limited to Geneva, as states under review will also contact their capitals to get guidance about what recommendations to accept or reject, sparking debate at home in the various ministries in charge of human rights topics.

\section{Transparency of the peer review}

The way in which the human rights discourse is portrayed to the public in the peer review setting is equally altered due to the UPR. As was already stated, the UPR is among fellow governments. However, that it is done in an open manner and recorded for posterity is equally unique. The interactive dialogue, the adoption of the working group report and the final outcome are all webcast live on the OHCHR website and are later available in the archives of the same site. A press release is also issued at the end of a review. All written documents (including the national report and working group report) are also archived and made available to the public. The

994 The author acknowledges that the informant from the Dutch Ministry of the Interior did not believe that the national consultations resulted in increased contact with civil society because these contacts were already occurring. However, in nations where many of the core human rights treaties have not been ratified, the UPR has the potential for opening up discussions about rights that are not generally discussed at the ministerial level. The staffmember from the Dutch national human rights institution also expressed hope that the Dutch Human Rights Action Plan, currently being designed by the Dutch Ministry of the Interior, will provide for frequent contact with all ministries and the parliament to discuss human rights responsibilities emanating from the UPR and Treaty Body processes. The Program Officer from Justitia et Pax conceded that Dutch civil society had to reorganize itself in order to effectively participate in the national consultation during the second cycle review and in order to make joint submissions as stakeholders in that process. 
transparency of the peer review is in contrast with the way in which many treaty body reviews are done. ${ }^{995}$ This transparency makes it more accessible to other participants, including civil society. The Kenyan experience highlights the easy accessibility to press reports regarding upcoming reviews and the usefulness of media for spreading awareness of the outcomes of the review.

Permitting written and verbal statements by each government wishing to participate is also a feature of importance. The UPR encourages broad participation by states. In many of the reviews of the first cycle, including that of the United States in which 80 nations and observers took the floor. ${ }^{996}$ In the second cycle, Cuba's review took the record for the most participants taking the floor to speak: $102 .{ }^{997}$ Wider participation by the international community in the statements is significant because it shows a willingness to confront peers face-toface and openly identify areas in which one's homologue can improve human rights. Given the historical disfavor of inter-state complaints in other mechanisms, this boldness is unprecedented.

In the past, the human rights discourse was done through a summoning before a treaty body or through a site visit or report before the special procedures. But, a dialogue before peers was missing. By having permanent delegates formulate recommendations and comment on the records of other states, the discourse became more reflective and self-penetrating. Though many states choose not to address the questions or comments made in the interactive dialogue in their entirety, 998 the fact is that they must at least field some probing questions. This author observed the interactive dialogues for Ireland and Syria in October 2012. During those dialogues, each country was confronted with unpleasant realities evoked by other member states. Ireland was questioned closely regarding treatment of the travelers, while Syria was told in no uncertain terms by several nations that its leader should step down in the face of flagrant human rights violations. In addition, nations are often pushed to explain why they will not accept certain recommendations during the plenary session. The manner of the discourse is changed to one where reflective comments are given and governments are expected to rationalize their positions in front of fellow member states.

Transparency is not always welcome among those studying the mechanism. Because the transparency of the review has meant that the UPR process is easily accessible to the public and to civil society groups, many view the UPR as "eclipsing" the treaty body processes. Their argument is that the UPR was supposed to be designed to complement, rather than replace or eclipse, the other existing UN human rights monitoring and protection mechanisms, including the Treaty Bodies and the Special Procedures. Some wonder whether the UPR can ever complement the other procedures.

One commentator notes that "there is no real interaction between the UPR and the other mechanisms for the protection of human rights." 999 He further opines that "the UPR is overshadowing the work of the treaty bodies and of the special procedures. It is overshadowing it in the most immediate sense, through the media and the general public, who now tend to identify the UN human rights system with the UPR." 1000 Of particular offense to this commentator is the fact that the outcome document to the UPR is more widely read than the concluding observations of treaty body committees. ${ }^{1001}$ The commentator cites the example of Tunisia's UPR to show that the UPR document doesn't paint the same picture of Tunisian society as was painted in the Human Rights Committee

\footnotetext{
995 This has changed with the introduction of video at the Human Rights Committee.

996 International Service for Human Rights, UPR of the United States: No New Commitments, available at http://www.ishr.ch/archiveupr/942-upr-of-the-united-states-no-new-commitments.

997 UPR-Info.org Newsletter, May 2013, available at http://www.uprinfo.org/newsletter/archive.php? $x=130$ \&listID=1\&layoutID=3\&pagerows=15\&pagenum=1.

${ }^{998}$ FREEDMAN, supra note 22. Freedman notes that some states avoid scrutiny by ignoring issues altogether. "States often answered questions in clusters, thus allowing them to select questions. Some States allowed so many questions within each cluster that they avoided the majority of issues raised." Id. at 310 .

999 De FROUVILLE, supra note 989, at 250.

$1000 \mathrm{Id}$. at 251.

${ }^{1001} I d$.
} 
outcome document, stating that if you compare the two, you wouldn't know they were talking about the same country. ${ }^{1002}$

However, the allegation that the UPR does not complement the Treaty Bodies falls flat because the recommendations that have been generated in the first cycle include thousands of references to Treaty Bodies. Consider the following recommendations made to the Netherlands in the second cycle review:

98.14. Lift its reservations to articles 26 (c), 37 and 40 of the CRC (Uzbekistan);

98.15. Ratify the OP-ICESCR (Slovakia);

$[\ldots]$

98.60. Follow up on the CESCR recommendation to combat racism and xenophobia and to enforce effectively the legal prohibitions against discrimination in the enjoyment of economic, social and cultural rights (Turkey).1003

In fact, there are three trends evident - encouragement to ratify treaties and their optional protocols; reference to specific outcomes of treaty bodies and concurrent encouragement to comply with the outcome; and recommendations that do not specifically mention a treaty body outcome, but that call for the same result. Michael O'Flaherty - a member of the Human Rights Committee -- has even concluded that the UPR has come to serve as a sort of follow-up mechanism to Treaty Body outcomes. ${ }^{1004}$

There is no doubt that the UPR has achieved a level of cooperation in its first cycle that is not evident in the Treaty Body system. In the first full cycle of the UPR, all UN Member States fulfilled their duty to report. Due to the earthquake in Haiti, the Haitian UPR was postponed until the last session; nevertheless, the review took place. In contrast, the Treaty Bodies have experienced years of challenges regarding non-reporting and overdue reports. ${ }^{1005}$ These challenges are due to the weak procedural structure evident in the Treaty Bodies - most do not use a master calendar, stating the date that reports are due and the date when a state delegation must appear before the committee. Therefore, states have no definite engagements and many simply do not report or appear before the committees. Nonetheless, these achievements by the UPR should not be viewed as "overshadowing" treaty bodies. To the contrary, the UPR has been instrumental in reminding the states under review of their treaty body commitments. ${ }^{1006}$

The UPR process is, by nature, highly visible. As noted earlier, the UN has chosen to provide webcasts and to post all documents on an easily-accessed website. ${ }^{1007}$ Many treaty body committees do not enjoy such public awareness. Instead of viewing this contrast as negative, this author argues that by citing the treaty body, the UPR is giving new light and therefore more publicity to the treaty body. Perhaps readers of the UPR report will now refer to the treaty body to get more specifics about the outcomes for the state under review. The readership of treaty body outcomes as compared to UPR recommendations should not be a source of tension. Instead, one should appreciate the way in which the UPR process can make observers aware of other human rights mechanisms by the way the process cites the mechanisms in its recommendations.

\section{Enriched content of the human rights discourse}

The mandate of the UPR permits all human rights issues to be discussed. However, at the beginning of the process, there was no indication that states would have an incentive to expose all the aspects of their human rights violations and challenges. Following the first cycle, it is evident that nations haven't shied away from discussing some of the thornier human rights issues. The chart below looks at 15 issues that are leading topics in human

\footnotetext{
$1002 I d$.

${ }^{1003}$ Report of the Working Group on the Universal Periodic Review - The Netherlands, U.N. Doc. A/HRC/21/15 (9 July 2012), ๆ ๆ 98.14, 98.15 , 98.60. 
rights. Taking a sample of five nations reviewed in one of the four years of the first cycle, ${ }^{1008}$ the chart depicts the broad gamut of issues covered in the reviews and further demonstrates that most topics are the subject of at least one recommendation in each country's final report.

\begin{tabular}{|c|c|c|c|c|c|}
\hline Type of Human Right & $\begin{array}{l}\text { The Netherlands }{ }^{1009} \\
\text { (Apr. 2008) }\end{array}$ & $\begin{array}{l}\text { China }^{1010} \text { (Feb. } \\
\text { 2009) }\end{array}$ & $\begin{array}{l}\text { Jordan }{ }^{1011} \text { (Feb. } \\
\text { 2009) }\end{array}$ & $\begin{array}{l}\text { Madagascar }{ }^{1012} \\
\text { (Feb. 2010) }\end{array}$ & $\begin{array}{l}\text { United States of } \\
\text { America }{ }^{1013} \text { (Nov. } \\
\text { 2011) }\end{array}$ \\
\hline Torture & $\mathrm{x}$ & & $\mathrm{x}$ & $\mathrm{x}$ & $\mathrm{x}$ \\
\hline Enforced Disappearances & $\mathrm{x}$ & & & & $\mathrm{x}$ \\
\hline Women's Rights/Sexual Violence & $\mathrm{x}$ & $\mathrm{x}$ & $\mathrm{x}$ & $\mathrm{x}$ & $\mathrm{x}$ \\
\hline Racial Discrimination & $\mathrm{x}$ & & & $\mathrm{x}$ & $\mathrm{x}$ \\
\hline Economic, Social, Cultural Rights & $\mathrm{x}$ & $\mathrm{x}$ & $\mathrm{x}$ & $\mathrm{x}$ & $\mathrm{x}$ \\
\hline $\begin{array}{l}\text { Civil, Political Rights, including religious } \\
\text { freedoms }\end{array}$ & $\mathrm{x}$ & $\mathrm{x}$ & $\mathrm{x}$ & $\mathrm{x}$ & $\mathrm{x}$ \\
\hline Migrants & $\mathrm{x}$ & $\mathrm{x}$ & $\mathrm{x}$ & & $\mathrm{x}$ \\
\hline Disabilities & & $\mathrm{x}$ & $\mathrm{x}$ & & $\mathrm{x}$ \\
\hline Media/Press/Internet & $\mathrm{x}$ & $\mathrm{x}$ & & $\mathrm{x}$ & $\mathrm{x}$ \\
\hline Indigenous Peoples/Minorities & $\mathrm{x}$ & $\mathrm{x}$ & & & $\mathrm{x}$ \\
\hline Children & $\mathrm{x}$ & $\mathrm{x}$ & $\mathrm{x}$ & $\mathrm{x}$ & $\mathrm{x}$ \\
\hline
\end{tabular}

1008 One nation was chosen from each of the years, but two were chosen in 2009. The nations were chosen randomly, but the author attempted to include a Western nation, a nation in development, a nation where Islam is practiced and nations that differed in size.

1009 Report of the Working Group on the Universal Periodic Review - The Netherlands, U.N. Doc. A/HRC/8/31 (May 13, 2008).

${ }^{1010}$ Report of the Working Group on the Universal Periodic Review - China, U.N. Doc. A/HRC/11/25 (Mar. 3, 2009).

1011 Report of the Working Group on the Universal Periodic Review - Jordan, U.N. Doc. A/HRC/11/29 (Mar. 3, 2009).

1012 Report of the Working Group on the Universal Periodic Review - Madagascar, U.N. Doc. A/HRC/14/13 (Mar. 26, 2010).

1013 Report of the Working Group on the Universal Periodic Review - United States of America, U.N. Doc. A/HRC/16/11 (Jan. 4, 2011). 


\begin{tabular}{|c|c|c|c|c|c|}
\hline Detention/Prisons & & & $\mathrm{x}$ & $\mathrm{x}$ & \\
\hline Sexual Orientation & & & & $\mathrm{x}$ \\
\hline Trafficking & $\mathrm{x}$ & & & $\mathrm{x}$ & $\mathrm{x}$ \\
\hline $\begin{array}{l}\text { Ratification of Human Rights instruments, } \\
\text { including elimination of reservations }\end{array}$ & $\mathrm{x}$ & $\mathrm{x}$ & $\mathrm{x}$ & $\mathrm{x}$ & $\mathrm{x}$ \\
\hline
\end{tabular}

One glance at the chart shows that most of the issues are raised in the review of most of the states most of the time. Nonetheless, upon more careful review, it is evident that some obvious issues have not been raised with certain states. For example, one may ask why torture was not raised in the review of China. Therefore, in addition to showing the broad range of topics discussed during the reviews, the chart also demonstrates that it is possible to avoid being criticized on some key human rights issues, if you know how to play the game.

The fact that China and other autocratic states may have avoided questions on certain human rights topics shows a weakness in the modalities for composing the speakers list - a modality that has been modified for the second cycle. A related issue is that states have been accused of not answering written questions or questions posed during the interactive dialogue. ${ }^{1014}$ This tactic along with the strategy to load the speaker list with allies is widely viewed as a way to permit countries to avoid receiving harsh recommendations. Sweeney and Saito observed that beginning with the very first review, "a negative trend was established of 'friendly States' filling the speakers' list to compliment the State under review." 1015 During the first session of the first cycle, this was noted particularly with regard to the Bahrain and Tunisia reviews. ${ }^{1016}$

This author notes that even the nations accused of having stacked the speakers' list with friends (China, Iran) were still required to make changes or correct violations in their human rights records. For example, China accepted these recommendations:

Invite other Special Rapporteurs dealing with economic and social rights to visit the country (Saudi Arabia);

Step up cooperation with the special procedures (Latvia); Engage with the Human Rights Council's special procedure mandate holders on addressing human rights challenges (New Zealand). ${ }^{1017}$

Therefore, the tactic, in the author's view, was not successful. Moreover, with the reforms made to how the speaker list is drawn up, this is no longer an issue in the second cycle. The second cycle permits all states that want to speak the opportunity to do so, but decreases the total amount of time allotted to each speaker in accordance with time limitations.

This inquiry has, therefore, found that the introduction of a peer review mechanism into the UN Human Rights machinery has altered the human rights discourse by introducing new accountability holders governments themselves as well as civil society. Internationally, governments are holding other governments accountable for engaging to make improvements to their human rights situations. The UPR has laid the

\footnotetext{
1014 SWEENEY \& SAITO, supra note 484 , at 211 (“ [t]he prevailing practice of States under review was to answer questions in clusters. However, many States, including India, Brazil and Guatemala, allowed the clusters to be so large that the majority of issues were left unaddressed, intentionally or otherwise. Gabon, in the second session, was the first country to take all of the questions at the end rather than by clusters, and also avoided addressing many points. In comparative terms, such a la carte responsiveness would generally not be considered acceptable by the treaty bodies....") SWEENEY \& SAITO, supra note 484 , at 211.

1015 SWEENEY \& SAITO, supra note 484, at 210.

$1016 \mathrm{Id}$.

1017 Report of the Working Group on the Universal Periodic Review - China, U.N. Doc. A/HRC/11/25 (Mar. 3, 2009$)$ ) ), ๆ 9 9, 10.
} 
groundwork for the discussion of topics in human rights for several weeks each year by $47 \mathrm{UN}$ members. The reviews are recorded and available to the larger public. The issues that are discussed run the gamut of hot topics and sensitive themes that are of concern in localities around the world. In summary, this peer review mechanism has a great potential for implicating governments on a wide variety of human rights themes and engaging the international community in discussion of these topics.

\section{Governments in the Human Rights Discourse}

The relevant research sub-question regarding the governments and their role in the UPR was: Does government participation in the UPR transform human rights discourse nationally and/or internationally?

Again, the four criteria to be considered were: the participants in the human rights discourse; the frequency and total number of encounters between the participants; the manner in which the human rights discourse is carried out; and the content of the human rights discourse.

Based on the case study of the Netherlands and on the information from key informants regarding the national consultations in the United States of America, Kenya, Hungary and Denmark, this author finds that the UPR process has the potential to change the ways in which governments engage with civil society on the national level to address human rights violations and make human rights policy. By requiring a national consultation, the UPR opens up the potential for new initiatives to broaden the number of participants in the discourse, increase the frequency of discussions regarding human rights and innovate in the manner in which the discourse is carried out. In addition, because the UPR requires states to take responsibility for the ensemble of human rights issues, the content of the human rights discourse can potentially be present in all areas of policy-making within a nation. Internationally, particularly in the case of less democratic nations, the international dialogue is a forum where criticisms will be introduced to nations that may have avoided being self-critical in national reports. Additionally, the interactive dialogue will be the place where all nations, whether democratic or autocratic, will gather and use the language of human rights discourse to defend their human rights practices. This opportunity should not be overlooked.

\section{A. The National Consultation Brings New Participants, Increases Contacts and Changes the Manner in Which the Discourse is Carried Out}

The introduction of the national consultation gave governments the opportunity to innovate the way in which they glean information from civil society. The first possibility is to broaden the field of participants. In the United States listening sessions, each venue chosen offered an opportunity to focus on a regional human rights concern; for example, the Albuquerque and California venues emphasized regional concerns related to the right of indigenous peoples, the Washington, DC venue focused on national security issues and the New York City session was designed to cover economic, social and culture issues such as housing rights. The groups involved came from a wide spectrum and demonstrate that a national consultation can broaden the participants and widen the discussion of human rights by increasing the number of participants.

A second possibility for increased contact with government and civil society is also one positive fruit of the national consultation. In the Netherlands, the new national human rights institution will be directly collaborating with the Ministry of the Interior to elaborate a National Action Plan for human rights. The informant from the Dutch national human rights institution hopes that the plan will include space for more frequent meetings between the institution and the government, as well as with CSOs in order to be able to implement the ensemble of recommendations, views and observations coming out of the UPR and Treaty Body processes. ${ }^{1018}$ This author has also noted the heightened attention to national action plans for human rights referenced by states when making recommendations; for example, the Netherlands was urged by the Philippines, Norway, Argentina and Uzbekistan (among others) to develop a national action plan for human rights. ${ }^{1019}$ This call for national action

\footnotetext{
1018 Interview with informant from Het College voor de Rechten van de Mens (the Dutch national human rights institution) on May 14, 2013.

1019 Report of the Working Group on the Universal Periodic Review - The Netherlands, U.N. Doc. A/HRC/21/15 (9 July 2012).
} 
plans is in accordance with the OHCHR's own initiative to foment such plans since $2002 .{ }^{1020}$ Action plans can call for continued and frequent contact to discuss implementation of human rights policies, opening up new possibilities for human rights discourse on a variety of subjects.

The national consultation has also introduced the potential to change the manner in which human rights are discussed. As was shown in the Netherlands, governments could directly ask for information about how human rights were being respected or violated in Dutch society. This conversation involved the entire ensemble of human rights. It opened the door for criticism and praise about all of the diverse human rights recognized in the international community. The context was one of collaboration where the government was not imposing its view, instead it was listening to the civil society's viewpoints. On the other hand, civil society was not issuing a scathing report, lodging a complaint or accusing the government in litigation or under a complaint procedure, it was instead listing the problems or issues and asking that they be recognized as such.

The Danish townhall-style meetings and the listening sessions held in the United States of America are also models for how a national consultation can enhance the contents of the dialogue during contact between civil society and government officials. In both cases, officials were hearing directly from citizens and citizens groups about human rights violations and other concerns about the way human rights are respected or disrespected within a nation. In addition, this was the case in the United States of America where the New York listening session participants took government officials on a "tour" of housing units to give a sense of how people live in sub-human conditions. As the informant from the San Francisco listening session highlighted, this was an audience of grassroots stakeholders confronting influential members of government. The New York listening session informant remarked that a government official witnessed first-hand mold in an apartment in New York. Comments by the Columbia University Professor regarding the change from discussions about "civil rights" (which tend to be limited to civil and political rights enumerated in the U.S. Constitution) to debates about human rights also highlight the change that the UPR had in the U.S. discourse. This was echoed by the repeated references by civil society actors during the listening session in New York to rights from the UDHR, rather than those in the Constitution. Economic, social and cultural rights were at the forefront in the NY Listening Session. The site visits and video clips used in the New York City listening session were also a novel way to bring officials into contact with human rights realities. They demonstrate the potential for national consultations to enrich the human rights discourse.

\section{B. The Content of the Dialogue is Enriched as Governments Take on Responsibility for Overall Human Rights Situation}

The UPR permits a view of the overall human rights situation rather than of particular areas or themes in human rights. It is like a yearly physical at the doctor, where you get a view of your entire health picture. In the UPR, the government needs to be assessed for its total picture. One lesson learned in the Dutch UPR is that all societies have areas where improvement is crucial, even in societies widely viewed as compliant with human rights, personal freedom and individual dignity. In its UPR, the United States of America also openly acknowledged areas of weakness in issues relating to housing. The Kenyan national report was largely devoid of excuses for failings and fairly descriptive of the challenges that it met in the area of human rights following the election violence. The government of Hungary was sharply criticized for its handling of the Roma people.

Denmark faced harsh words because of its posture toward migrants and the use of profiling by police. Each of these countries is viewed as democratic, yet each was found to be deficient in the promotion and protection of certain human rights. This author believes that the UPR's focus on the total human rights picture has brought a new perspective to democratic nations who view themselves as largely compliant with international human rights standards.

The interesting perspective about the human rights discourse from the viewpoint of the government is that the participants, and therefore the accountability holders, shift depending on the forum. When the UPR is acting locally during the national consultation, the accountability holders are the civil society organizations, non-

${ }^{1020}$ OHCHR, Handbook on National Human Rights Plans of Action, August 29, 2009, available at http://www.ohchr.org/Documents/Publications/training10en.pdf. 
governmental organizations and national human rights institutions. But, at the interactive dialogue and adoption of the working group report, only the working group members (e.g. states) are permitted to take the floor. Therefore, internationally, the accountability holders are other states. Finally, in the final outcome, the nongovernmental organizations are allowed to participate along with the states. The shift for the accountability returns to the non-governmental organizations and national human rights institutions, who are again trying to press the state under review to take on more recommendations and commitments. The shifting of the accountability holders and participants makes the human rights discourse complex as states are trying to both defend their records, demonstrate concern for human rights issues at the national level and appear to be earnest about complying with their obligations internationally.

While one can argue that civil society has always been the accountability holder at the domestic level in democratic states; after the advent of the UPR, civil society has the potential to enhance the nature of its participation in the human rights discourse. Civil society could specify what behavior it wanted from the government then pressure the government to actually respect its engagements after the review. This was the case with the Netherlands where Justitia et Pax kept pressure on the government to address migrant detention conditions by meeting with the justice and interior ministers to explain what was occurring in detention facilities (based on the testimonial evidence provided by priests and other clergy ministering to detainees) and demanding the situations be addressed. ${ }^{1021}$ Rather than merely reporting back to the committee, Council or rapporteur, the civil society groups can keep a more constant pressure on the government to show progress during the time after the review. This makes the dialogue interesting because democratic states often try to admit that they have some challenges in the national report and in the interactive dialogue, but they also understand that if they accept recommendations, they will then be pressured to implement them domestically, so they tend to be conservative about what new engagements they will make. This was borne out by the experience of the Netherlands. The informant from the Ministry of the Interior explained that the Dutch government was eager to accommodate its civil society groups by asking for their input about what should go into the national report, so it gave additional space to issues like data privacy and the treatment of asylum seekers because these issues were most emphasized by CSOs during the national consultations. While the government had intended to appear open to CSO suggestions, it also made itself vulnerable to harsh criticism at the international level from its peers in Geneva because the asylum issue was a hot topic and the Dutch government was facing criticism from friends and foes alike on its controversial detention policies. In the end, it had to accept recommendations to change the detention policies. Nevertheless, even as the government was conceding on this point, CSOs were still sharply critical of the modifications in detention policies, noting that the changes were small and that an overhaul of the detention policy was necessary. In the end, by attempting to appease one group of accountability holders - Dutch civil society - the government actually did not achieve its goal and still faces pressure from civil society to take additional measures to protect asylum seekers and make broad reforms to detention policies.

In contrast, in an autocratic state, where civil society has a limited role, or no role, the author believes the tendency will be to gloss over human rights violations in the national report and during the government presentation at the interactive dialogue. Such was the view of the author when observing the review of Syria in October 2012 in Geneva. However, because the accountability holders shift from civil society to other peer states, at the interactive dialogue level, there is little room for avoiding critique. Therefore, in the interactive dialogue stage of Syria's UPR, the country underwent harsh criticism and even unprecedented speeches from the United States of America and Canada, among others, who called for the Syrian president to stand down and questioned the legitimacy of the Syrian regime. Based on this author's observation of the review, one can conclude that even in the most autocratic of states, it will be hard to avoid receiving hard-hitting recommendations and pressure will be applied internationally to such regimes to make changes in their human rights situations. ${ }^{1022}$

\footnotetext{
1021 Interview with Justitia et Pax Program Officer.

1022 Again, this is only at the international level. There is little leverage available to ensure that recommendations are accepted and implemented nationally.
} 


\section{One Challenge: Will Cooperation by Government Continue to be the Norm?}

In other parts of this chapter, I have lauded the UPR mechanism for achieving 100 percent cooperation in the first cycle. That achievement may not be the norm in the second and in future cycles. The fact that the UPR is an intergovernmental mechanism is significant in that countries may feel they unilaterally make decisions about their cooperation with the mechanism. Early in the second cycle, the UPR was faced with a challenge to its authority by the state of Israel.

Israel disassociated itself with the Human Rights Council on May 14, 2012, thereby also bringing into question whether it would appear at its own UPR. ${ }^{1023}$ Ambassador Aharon Leshno Yaar stated in a letter dated May 14, 2012, that Israel was suspending its relationship with the Council and the OHCHR because of the "ongoing, unrelenting singling out of Israel in the Human Rights Council, which has been persistent since its inception in 2006, continued through the review process, and exists to this day. The Council and the Office of the High Commissioner for Human Rights, respectively, have become a political tool and a convenient platform, cynically used to advance certain political aims, to bash and demonize Israel."1024 That decision led to its absence from its own review in the second cycle in January 2013.1025 The Working Group of the Council passed a resolution regretting Israel's decision, called on Israel to resume its cooperation with the UPR and postponed Israel's review until later in 2013, a decision that was acknowledged in a letter from the Ambassador Eviatar Manor, thanking the Polish Ambassador for his efforts in securing a delay in the Israeli UPR. ${ }^{1026}$ That decision was met with criticism:

Pakistan, on behalf of the Organisation of the Islamic Conference, expressed its fears and concerns that the absence of Israel will have consequences for the future of the mechanism. Gabon, on behalf of the African Group, was afraid that this situation will weaken the mechanism and create a precedent while Turkey explained that the "HRC risked of opening a breach in the system by allowing a non-cooperating country a delay and by setting a bad precedent". ${ }^{1027}$

The events surrounding Israel's UPR demonstrate a challenge to the authority of the mechanism. If states begin to determine whether or not they will appear for a review, the credibility of the mechanism will be called into question. It is too early to draw a conclusion about this challenge because as of the writing of this study, the new date for the review has not arrived.

\section{National Human Rights Institutions in the Human Rights Discourse}

National Human Rights Institutions have also been placed in a unique position to widen the number and caliber of participants in the human rights discourse at the national level. The findings in this section are relevant to democratic societies with independent civil society organizations and national human rights institutions. Currently, less than 70 countries have an accredited NHRI; therefore, the finding here are very limited. Nevertheless, the case for encouraging NHRIs is strengthened by this discussion because it illustrates the important role that NHRIs can have in promoting human rights policy changes.

The relevant research sub-question is: Does the participation of National Human Rights Institutions in the UPR change the human rights discourse nationally and/or internationally? The four criteria to gauge the change were: the participants in the human rights discourse; the frequency and total number of encounters between the participants; the manner in which the human rights discourse is carried out; and the content of the human rights discourse.

\footnotetext{
${ }^{1023}$ UPR-Info.org, Israel's Absence from its Own Review, http:/ / www.upr-info.org/spip.php?page=breve-print\&id_breve=1128. ${ }^{1024}$ Letter, dated May 142012 from Ambasssador Yaar, Permanent Representative, available at http://www.humanrightsvoices.org/assets/attachments/documents/10409IsraeliAmblettertoPdtofHRC_14May2012.pdf 
Based upon the case studies, this author finds that -- on the national level --the NHRIs, due to their unique placement as independent organizations interfacing between civil society and government, can help increase the number of civil society actors engaging with government on human rights issues. Active NHRIs can press for more meaningful national consultations and even host or organize such meetings. In countries where NHRIs are present, they can also determine the manner in which consultations and other meetings are held and develop engaging formats where governments will best be able to receive information about human rights issues and concerns. Finally, NHRIs broaden the content of the human rights discourse by raising issues and awareness about concerns that may not be on the radar of governments. Internationally, the NHRIs have influence through use of lobbying and organizing side events to get major issues in to the interactive dialogue. In the second cycle, the NHRIs will be the first to take the floor following the statement by governments in the plenary session and the adoption of the final report.

\section{A. National Human Rights Institutions Introduce New Participants to the Human Rights Discourse}

NHRIs have played a special role in reaching out to the advocates and civil society groups that promote human rights in the national context. Because the UPR encompasses such a broad mandate, even civil society groups whose advocacy work covers themes beyond the mandate of the treaties to which the country is a party have the opportunity to contribute to the UPR. This is significant because this author suspects that the number of civil society organizations who can potentially participate in the UPR far exceeds that of the treaty body process just based on the fact that there are more topics available to discuss. Therefore, in many democratic countries with independent civil society groups, new NGOs and CSOs can potentially become a part of the process in Geneva.

While the widening of the discourse participants is welcome, it does not come without its own challenges. Many of the organizations are not familiar with the language of human rights and therefore may not be capable of engaging in a sophisticated manner at the Geneva level. The informants from the New York and San Francisco listening sessions discussed in detail the plans to "train" civil society in the language of human rights so that they could frame their complaints in a way that most effectively used international human rights instruments. In addition, some NGO participation in the international discourse is restricted because they do not have the necessary accreditation to appear before the Council. The Kenyan experience demonstrates that such an obstacle can be surmounted when fellow accredited NGOs were willing to lend their resources and credentials to permit Kenyan stakeholders a voice in the proceedings.

A second widening of the human rights discourse participants takes place within the government. NHRIs often engage directly with the ministries that are involved in the preparation of the national report. Many governments choose to leave the report preparation to the ministries that are involved. Therefore, more ministries tend to be involved in the preparation of parts of the national report. NHRIs place themselves at the disposal of those ministries to discuss their viewpoints on issues that should be addressed in the report - such was the case in Kenya. New contacts and relationships evolve during this process and the NHRI can sensitize government officials to human rights issues and draw them into the human rights discourse. It also opens the door for later implementation of recommendations. For example, the Kenyan NHRI already had a blueprint in place for the implementation of recommendations by the various ministries.

\section{B. NHRIs Increase the frequency and total number of encounters with government}

NHRIs are in a position to push the government to take the national consultation and preparation of the national report seriously. Therefore, NHRIs position themselves to meet with government officials and to assist in the national consultation. This contact is often more extensive than contact made for Treaty Body issues because a large number of government ministries or agencies participate in the UPR.

The potential number of encounters between the NHRI and government is greatly increased because the NHRI wants to contact government agencies to disseminate its report and to make its position known on key issues. In addition, the government will want to ask the NHRIs assistance in making contact with the key civil 
society organizations and advocacy groups. All of this leads to additional meetings and opportunities for dialogue. The participants will necessarily be interacting and using the language of human rights to communicate their positions, strategies and/or criticisms. In addition, as mutual trust increases or decreases, the human rights discourse can be enriched or inhibited. During the implementation and post-review phase, the NHRI again can be a catalyst for stimulating additional discourse. Suggesting a blueprint for action or creating a working group to interface with government agencies can also lead to additional encounters and more frequent contact between the participants. The result is a more sensitized civil servant group and a greater understanding of the human rights themes and challenges. As government officials become more versed in these subjects.

NHRIs are equally well-placed to interface with civil society and can increase contacts with advocacy groups. ${ }^{1028}$ The frequency of these contacts can be particularly high during the time that stakeholder reports are being generated and during the lobbying campaigns to diplomatic missions. The increase in this type of activity due to the UPR is evident in the case studies of Denmark and Kenya and the result has been a capacitating of small and large NGOs alike in the inner process at Geneva and in the UPR in particular. In both countries, as discussed in Chapter Seven, the NHRI initiated a series of new training opportunities for local NGOs regarding the UPR and created and disseminated written materials to explain the process. The informant from the Dutch NHRI also indicated that their organization heavily lobbied permanent missions in Geneva and embassies in Den Haag to get items into the interactive dialogue, using both talking points from the NHRI submission and from the submission of civil society groups. ${ }^{1029}$ NGOs and other groups become more adept in framing their challenges and difficulties in the language of human rights. This is important as the human rights discourse in Geneva is often stilted and makes use of certain phrases and catchwords. Drafting a document or intervention that employs such phrases and incorporates the diplomatic wording found in many UN documents will enhance the chances that an idea is adopted or at least considered. During the post-review, NHRIs may also reach out again to NGOs to coordinate efforts to pressure the government to implement the recommendations. This effort can also change the discourse as NGOs and NHRIs plot strategies to pressure and keep recommendations in the media and in the forefront of government priorities. In such a case, the discourse turns from being rights-centered to being realization-centered. The participants will want to talk about how best to realize a right.

\section{NHRIs Influence the Manner in which Participants Take Part in the UPR}

NHRIs wield quite a large amount of power to influence the manner in which the UPR is conducted. The Danish case study shows that if some national governments do not dispose of the means or political will to independently contact civil society to arrange for consultations. In Denmark, the NHRI was solicited by the government and asked to make the arrangements for the national consultation. Accordingly, a government may approach the NHRI to conduct the national consultations. In such a case, the NHRI is in the position to determine how open or closed the consultation will be. The UPR has provided an instance for NHRIs to make the discourse on human rights more inclusive and transparent by widening the region where the discourse takes place (e.g. having consultations in different cities). The NHRIs can also determine the format of the consultation by arranging for a town hall type meeting or a panel discussion. NHRIs have the ability to influence all of these factors and in the various national jurisdictions, the way in which the consultations have been carried out has varied.

Similarly, the way in which NHRIs have chosen to include civil society in the preparation of stakeholder reports is also varied and demonstrates the influence that NHRIs wield. The Danish NHRI was sensitive to the feelings among civil society groups that the NHRI should not lead them, but that it should be a partnership and collaboration, 1030 a thought also echoed by the Dutch NHRI informant. ${ }^{1031}$ In the case of the Kenyan NHRI, civil society groups were heavily reliant upon the NHRI for guidance and expected the NHRI to take the lead. ${ }^{1032}$ Here

\footnotetext{
${ }^{1028}$ The author notes that the informant from the Dutch national human rights institution indicated that they have contacts with some 80 NGOs. In contrast, the government has only invited some 20 Dutch NGOs to national consultations in the first and second cycles of the UPR. ${ }^{1029}$ Interview with informant from Het College voor de Rechten van de Mens (the Dutch national human rights institution) on May 14, 2013.

${ }^{1030}$ Interview with Lis Dhundale, Program Manager, Danish Institute for Human Rights, February 7, 2012.

${ }^{1031}$ Interview with informant from Het College voor de Rechten van de Mens (the Dutch national human rights institution) on May $14,2013$.

1032 Interview with Antonina Okuta, Senior Human Rights Official, Kenyan National Commission on Human Rights, 16 February, 2012
} 
again, the human rights discourse is impacted when NHRIs choose to provide joint stakeholder submissions that carry significant weight among international actors who read the submissions and use them to formulate recommendations for the interactive dialogue. The human rights discourse is enriched as more and more civil actors provide anecdotes or statistics to explain how a human right is not realized within a nation. In addition, the persuasiveness of the document is based on how well the civil society actors have been trained in the language of human rights and in framing human right violations. This training is often provided by the NHRI. The discourse can also be diluted and stymied by submissions that are not well-written or that provide faulty data. Therefore, NHRIs have an ethical interest in ensuring that the members of civil society are trained in proper reporting techniques but also encouraged to use sound methodological techniques.

\section{NHRIs broaden the content of the human rights discourse to include important domestic issues}

Prior to the UPR, the human rights discourse was often dominated by what international actors in Geneva placed on the agenda. Certain buzzwords and hot button topics emerged and the national jurisdictions were criticized or praised depending upon whether they were perceived to be in compliance or not. That has changed. The human rights discourse is now also directed by national priorities. In the Danish UPR, the NHRI had already disseminated its document spelling out the main issues it viewed as important in human rights discourse in Denmark. As the Danish NHRI, it was positioned to decide what issues should be emphasized in stakeholder submissions. The Joint stakeholder submissions then complemented and further elaborated on the issues identified by the NHRI. It was a good practice because the Danish NHRI was familiar with the weaknesses in internal legal structures and policies and able to identify measures and laws that needed adjustment. Many times, the NHRI is the key player in promoting and protecting minority cultures, language and races in a society. International actors are simply not familiar with the domestic phenomenon to act include such concerns in the discourse. NHRIs can raise awareness and engage the right participants to bring these important domestic issues to the forefront of the dialogue. This alters the human rights discourse to place more weight on domestic concerns when talking about human rights. One example is during the Kenyan UPR when the issue surrounding the political violence following the elections and the impunity for its perpetrators became the subject of many interventions and recommendations during the interactive dialogue. The issue had been raised by the Kenyan Stakeholder Coalition and by Kenya's NHRI and became the main part of the human rights discourse during the Kenyan UPR in the first cycle.

One can summarize the contribution of NHRIs to the human rights discourse in the following ways. The NHRIs have broadened the types and numbers of civil society organizations, NGOs and advocacy groups that take part in the Geneva-based human rights discourse by adding groups with specialized human rights advocacy areas. More frequent contact is made between the NHRI and government ministries enriching the dialogue by increasing the number of ministries that have human rights in the dossier. NHRIs have also brought government into contact with civil society during the preparation of stakeholder reports and during the national consultation through very transparent processes that are often reported to the press and that have visible outcomes that are made available to the public. Finally, NHRIs have brought domestic issues into the forefront at the international level by identifying priorities that are highlighted in written documents and become the basis for recommendations and interventions in Geneva.

\section{Civil Society Organizations and the Human Rights Discourse}

Because the UPR covers the ensemble of human rights, many more civil society organizations (CSOs) can potentially participate in the process. The increased number of CSOs also means that even more issues can be articulated in the human rights discourse.

The relevant research question is: Does the participation of civil society in the UPR change the human rights discourse nationally and/or internationally? The four criteria to gauge the change were: the participants in the human rights discourse; the frequency and total number of encounters between the participants; the manner in which the human rights discourse is carried out; and the content of the human rights discourse. 
Based on the relevant case studies regarding civil society, this author finds that the UPR potentially opens up more opportunities for more CSOs to participate in national consultations, plenary sessions and implementation processes because any human right is fair game for discussion in the UPR. The UPR also potentially increases contact among CSOs, contact with governments and also with NHRIs, where present, to make for a more dynamic national human rights discourse. The manner in which the discourse is carried out can also potentially change, with more emphasis on media campaigns, site visits, video content and lobbying to bring awareness to government officials. While such mediums have been available and have been used in the past, the expanded content and the direct contact make this a new terrain for CSOs in the UPR. The content of the human rights discourse can also be influenced in democratic societies through agenda-setting by CSOs. In this way, the most urgent matters can be brought to the forefront for attention in the national report and at the interactive dialogue.

\section{A. Participation among civil society organizations has the potential to multiply in the UPR}

The U.S. and Hungary were the two case studies of countries with no NHRI present. The potential for the introduction of new civil society participants through the UPR is significant, particularly where a country has limited treaty body contact. In the U.S., where no NHRI has been establishes, there is very limited periodic reporting because the country is only a party to two of the core human rights treaties. Because the UPR covers many subjects beyond that of the ICCPR and CERD, groups such as the Centre on Housing Rights and Evictions or the Disability Rights Education and Defense Fund could make formal submissions to the OHCHR on housing and disability rights, respectively. No such participation would have been afforded in the treaty body process without making the tenuous connection between the human right at issue and one of the articles in the ICCPR and CERD. It is likely that this increased involvement could also be present in other democratic nations as they undergo UPR reviews, particularly where those nations have active civil societies that are aware of the UPR and are willing to interact with others in the submission of joint reports. The author has studied the civil society submissions in connection with the reviews in 2008 and 2012 of Bahrain, Ecuador and Switzerland. ${ }^{1033}$ In each case, the second review showed significant increases in the total number of NGOs submitting reports to the OHCHR. For example, Bahrain's first review in 2008 yielded only 12 submissions by NGOs; in 2012, 14 NGOs gave reports and four joint stakeholder reports were submitted. Ecuador witnessed a similar burst of interest in the second cycle - in the initial cycle 9 NGOs made submissions, but that number increased to 15, plus 5 joint stakeholder submissions. In Switzerland, a mere 5 NGOs submitted reports in 2008, by 2013 there were 3 individual NGO submissions, but 6 joint submissions, including one joint submission signed onto by 46 different NGOs.

Additionally, CSOs bring much more specific information and details to the human rights discourse. These organizations are often also grassroots organizations who hear complaints directly from their source or who advocate on behalf of victims and claimants. Their information enhances the human rights discourse with statistics, narratives, anecdotal data and historical information. The information is crucial to buttress claims of mistreatment, violations or failed realization of rights. The more diverse the types of CSOs that participate, the more broad the range of topics included in the submissions and in the plenary session interventions.

\section{B. Increased contact and coordination among CSOs and other CSOs, government}

Even in countries where NHRIs are not present, the human rights dialogue has been changed thanks to the role of CSOs. These groups often form larger networks that seek to impact the national consultation process or to submit stakeholder submissions. Such was the case in the UPR for the United States, where the US Human Rights Network played a coordinating role in the listening sessions. The organizations were able to have listening sessions attended by high-level members of government, giving them entry to the federal agencies responsible for human rights issues. Moreover, the CSOs sensitized the government officials to the issues that impact their own agencies thereby increasing the awareness of human rights within the government. The mix of CSOs in contact with each other for UPR review is also different due to the fact that all human rights groups have an incentive to

${ }^{1033}$ The author uses the database at www.UPR-Info.org to tally the total number of NGO submissions in each cycle. 
participate. New groups that may not have been part of the previous coalitions for treaty body reports or special rapporteur visits are potentially able to enter the discourse.

While the frequency of contact may vary, the fact that these organizations are in meeting to coordinate the drafting of stakeholder reports or to meet with government officials during the national consultation raises awareness about human rights themes at the grassroots level, as CSOs get the word out about the UPR. Similarly, government officials are sensitized about the ways in which policies and regulations impact the local community. Again, taking an example from the UPR for the United States, government officials were taken on a site visit to a neighborhood in Brooklyn that suffered negatively from federal programs designed to encourage urban renewal. By seeing the stymied project, officials witnessed first-hand how infusions of cash without requisite oversight and follow-up could lead to failure of a well-intentioned policy. The visit also sensitized officials to themes such as living wages. While the site visits may have been a one-time encounter, the visit did serve to introduce novel themes to the human rights discourse within US government agencies.

When civil society opens itself to exchanges involving new participants, the human rights discourse changes for the better as the participants find common ground and new ways to approach challenges. One fact of life in the area of economic, social and cultural rights is that many of the inequalities suffered in one sector are directly related to the injustices suffered in another sector. Often, these injustices are so intertwined that it does not make sense to treat them as separate problems. By having the housing advocates alongside the healthcare and racial justice advocates, the discourse is enriched by new synergies between and among groups fighting to improve life for citizens in all of these different sectors.

\section{Carrying out the discourse through pressure, media campaigns and lobbying}

Discourse need not be limited to panels and site visits. Civil society has also influenced the discourse in new ways during the UPR by informing the public about the review through the media, by creating video clips on human rights to show during side events or even by lobbying and pressuring diplomatic missions to make recommendations regarding a certain human rights violation.

Media campaigns broaden the human rights discourse further by bringing citizens into the dialogue. These citizens become more educated regarding topics in human rights and about the way in which human rights are monitored at the UN.

Pressure and lobbying have also been a trademark of CSO participation in the UPR. When AI approaches missions with its written stakeholder submissions and its recommendations, it does so with the hope to pressure the mission to make a statement that will translate into a solid recommendation in the final outcome. AI's agenda and priorities then become the priorities of that state, which in turn makes a recommendation, bringing everything back full circle to the country, who now must implement the recommendation (if it is accepted). This is a long and round-about way to again influence the national human rights dialogue. The exchanges between the CSO and the diplomatic mission offer another opportunity to introduce and sensitize international civil servants to the language of human rights.

\section{Influencing the content of the discourse through agenda-setting}

Civil society organizations have also impacted how the human rights discourse is carried out. All discourse is channeled by themes and hot debates. Often these themes arise due to the agenda of a certain powerful group who wish to influence how the discourse is set and what topics are pertinent for the discourse. In human rights, the agenda has often been set by the experts in the Treaty Bodies committees or the special rapporteurs. The Council has also set the agenda for what is important in the discourse. The introduction of the UPR has opened new avenues to civil society to influence the discourse. This is evident in the way that Amnesty International has approached the UPR in the national contexts. Both in the case of the Netherlands (second cycle) and Hungary, AI's national chapters prioritized the issues that they wanted to stress during the UPR. This effectively turned eyes in Geneva toward a specific set of human rights violations. In the case of the Hungarian UPR, the interactive 
dialogue was dominated by the Roma issue. The discourse in Geneva now mirrored the same debate that was taking place locally.

The UPR does not permit NGOs to make comments during the Geneva processes except in the plenary session. NGOs can submit reports, but "the Office of the High Commissioner for Human Rights (OHCHR) distills and summarizes their reports down to the strict limit of 10 pages for NGO material. Many NGOs have complained that the document prepared by the OHCHR ignored or did not include key issues. In addition, a number of countries have used points of order and other procedures to intimidate NGOs from making statements or to strike their comments from the record if the NGOs did not strictly reference comments in the report." 1034 Pointing to the reviews of Cuba, North Korea and China, two observers noted that the curtailed NGO participation "tainted the UPR and resulted in numerous farcical human rights reviews." 1035

The influence of NGOs is not always measured by participation in the Geneva-based meetings. Instead, the UPR has introduced new opportunities for NGOs and other civil society organizations (CSOs) to influence the UPR through the national consultations and during the implementation process. This dissertation has demonstrated that one of the most important innovations of the UPR comes with the national consultation, where NGOs and CSOs have the opportunity to pressure national governments to recognize human rights concerns and to reflect those concerns in the national report. These same organizations can lobby other governments to raise concerns during the interactive dialogue. As was seen in the case studies of the United States, Hungary and the Netherlands, NGOs and CSOs can often see their recommendations in the final reports of the countries under review through effective lobbying strategies.

While is it easy to point to states like Cuba, North Korea or China to highlight weaknesses in the UPR process, one must concede that it was important that these three nations participate in the process because it required them, at the Geneva level, to articulate human rights concepts and respond to questions, even if a reduced number of questions. For example, in the case of North Korea, this author notes that the country is a party to four core human rights treaties - the ICCPR, the CRC, CEDAW and ICESCR. ${ }^{1036}$ In its December 2009 review, there were a total of 12 stakeholders, including Amnesty International and Human Rights Watch, reporting on the human rights situation. ${ }^{1037}$ Amnesty International's submission called on North Korea to open its doors to civil society groups and criticized the nation for ignoring the right to food, practicing torture, restricting free movement, engaging in forced disappearances and limited free expression. ${ }^{1038}$ During the interactive dialogue, North Korea's intervention is really a summary of how many autocratic nations feel about the UPR and its processes; it expressed its dislike of the Council and its procedures, but contrasted that with its respect for the UPR mechanism:

5. The delegation of DPRK stated that it appreciated this opportunity to participate in the sixth session of the Working Group.. As is known, at the Human Rights Council and the General Assembly the human rights situation of DPRK has been singled out for discussion every year out of purposes and motives irrelevant to genuine human rights, resulting in the adoption of the unjust "resolutions". DPRK neither recognize nor accept such "resolutions", and categorically reject them as the extreme manifestation of politicization, selectivity and double standards in the area of human rights.

\footnotetext{
1034 Brett D. Schaefer, U.N. Human Rights Council Whitewash Argues Against U.S. Participation, THE CUTTING EDGE, APR. 13, 2009, at http://www.thecuttingedgenews.com/index.php?article=11247\&pageid=\&pagename=

1035 Brett D. Schaefer \& Steven Groves, The U.S. Universal Periodic Review: Flawed From the Start, WeBMEMO, AUG. 26, 2010, at http:// www.heritage.org/research/reports/2010/08/the-us-universal-periodic-review-flawed-from-the-start

1036 Compilation Prepared by the Office of the High Commissioner for Human Rights in Accordance with Paragraph 15 (b) of the Annex to Human Rights Council Resolution 5/1 - Democratic People's Republic of Korea, UN Doc. A/HRC/WG.6/6/PRK/2 (18 September 2009$)$, at 2. 1037 Summary Prepared by the Office of the High Commissioner for Human Rights in Accordance with Paragraph 15 (c) of the Annext to Human Rights Council Resolution 5/1 - Democratic People's Republic of Korea, UN Doc. A/HRC/WG.6/6/PRK/3 (28 August 2009), at 1. ${ }_{1038}$ Amnesty International, Democratic People's Republic of Korea Submission to the UN Universal Periodic Review Sixth session of the UPR Working Group of the Human Rights Council November - December 2009, available at http://lib.ohchr.org/HRBodies/UPR/Documents/Session6/KP/AI_PRK_UPR_S06_2009.pdf.
} 
6. However, DPRK has come to this session as it values the universal periodic review mechanism, which is impartially treating all United Nations Member States with different ideologies and systems, cultures and traditions. DPRK hopes that this session will serve as an excellent occasion for the international community to adopt a cooperative approach with a view to correctly understanding and impartially assessing the human rights ideas and policies DPRK people have chosen and the prevailing reality of the country. ${ }^{1039}$

Nonetheless, North Korea's statement regarding its own human rights record may be considered farcical by some; the country declared, "DPRK has consistently maintained the principle of prioritizing human rights and honouring the United Nations Charter and the international human rights instruments. Its history has been the history of struggle to safeguard genuine human rights of its people." ${ }^{1040}$ Despite this seemingly sardonic attempt at presenting a picture of a human rights paradise, other states seemingly took the interactive dialogue seriously. The following statements demonstrate attempts by three states to strike a conciliatory tone during the North Korean review, while still insisting that advances in human rights be made:

18. Brazil considered DPRK's participation in the UPR as an important step. It believes that through improved cooperation and genuine dialogue, including with Special Procedures, the UN and the international community would be able to assist the DPRK. Brazil asked about internal challenges to the promotion and protection of human rights and remained concerned about allegations of executions in political detention camps and the disparities in public distribution of food. Brazil hoped that DPRK authorities would reestablish full-fledged investigations on the abduction of Japanese nationals

19. Japan noted certain positive steps undertaken by DPRK such as engaging in dialogue with the Committee on the Rights of the Child and cooperating with UNICEF to improve health situation and quality education for children. Japan expressed its regret that DPRK did not fully respond to the various concerns of international community including punishment against those citizens expelled or returned from abroad, public executions, the abduction issue and the issue of detention facilities. Japan was also concerned about those who are suffering.

20. The Republic of Korea noted the recent positive efforts of DPRK to engage with the Committee on the Rights of the Child and to stipulate in the Constitution that the State shall respect and protect human rights. However, it remained concerned about the detention in political prison camps and violations of the freedoms of movement, expression, thought and religion; a huge gap between the recognition of human rights in legal codes and their actual implementation, and the situations of separated families, prisoners of war and abductees. It urged the Government to take all necessary measures at the grassroots level to uphold human rights and fundamental freedoms enshrined in the Constitution and domestic laws as well as in human rights treaties such as ICCPR, ICESCR, CEDAW and CRC, to which DPRK is a party. ${ }^{1041}$

This author notes that, as in the North Korea review, China and Cuba did face critical statements regarding their human rights situations during the interactive dialogue and each of the outcome documents for the reviews of these three nations does have recommendations that these three nations must implement to improve human rights. ${ }^{1042}$ Though, in the case of North Korea no recommendations were immediately agreed to, it is important to

1039 Report of the Working Group on the Universal Periodic Review Democratic People's Republic of Korea, Part I, ๆ $\mid 5-6$, UN Doc.

A/HRC/13/13 (Jan. 4, 2010). The author notes that the position taken by North Korea may also serve to highlight another challenge raised by UPR observers - that states that have a history of gross and consistent human rights violations can use the UPR process as a convenient way to avoid cooperation with investigations or inquiries by Special Procedures or other Council initiatives.

$1040 \mathrm{Id}$, at Part I, 97.

1041 Id. at Part I, $₫$ \18-20.

1042 Cuba accepted many recommendations, among them this one: Give importance and continue to provide human rights training for government officials at all levels, law enforcement personnel, police, the judiciary, including judges and lawyers (Jordan; Thailand), Report of 
keep in mind that the goal of the UPR process is not to lambaste non-compliance but to encourage efforts to improve the human rights situation. Iin the second cycle, the mechanism will need to find ways to aid nations like North Korea in accepting recommendations and making changes, however slowly they may occur.

\section{Summary of Findings}

The Universal Periodic Review has contributed a peer review mechanism to the international human rights machinery at the United Nations, enabling governments to discuss their human rights records before the UN Human Rights Council in an atmosphere of non-confrontation, mutual trust and cooperation. As member countries' records are reviewed the human rights discourse has been transformed to include input from grassroots, national participants as well as peer states. Nationally, during consultations, governments have been more engaged with civil society and in some cases high-level government officials have listened to the struggles of their citizens and seen first-hand what human rights violations translate into for everyday life. In some nations, national human rights institutions have brought new actors from civil society into the discourse of human rights and have introduced them to the mechanism and to the human rights framework; thereby training and capacitating new actors for the national and international arena. Civil society organizations have taken an interest in the mechanism and have brought their homologues aboard to learn about the international human rights framework, the language of rights and the advocacy and lobbying process to push for implementation of rights. Because the UPR covers the gamut of human rights, these civil society groups can raise issues on topics that go beyond the obligations under conventions and treaties. This author posits that these contributions to the human rights discourse can rightfully be described as transformative, in the countries where they have taken place, even as the mechanism itself is designed to complement existing human rights procedures with in the UN human rights machinery. This inquiry has shown that in the states studied, the UPR has been transformative in engaging both local, grassroots actors and peer UN Member States in the language or discourse of human rights in ways that are not possible in expert mechanisms or individual complaint procedures. Therefore, because of the transformative potential of the UPR on human rights discourse in UN Member States, it would be advisable to encourage similar processes in coming cycles in the UN Member States where national consultations were less effective, where the interactive dialogue did not suscitate meaningful recommendations or where the state under review did not accept recommendations or did not implement those recommendations it accepted.

\section{Improving the UPR process}

This inquiry has arrived at positive conclusions about the way in which the UPR has transformed human discourse in the national and international arenas. Nevertheless, the author equally acknowledges that the mechanism suffers from some apparent weaknesses. For example, during this researcher's observations of the interactive dialogue, it became evident that throughout the first cycle, the interactive dialogue had no particular focus and countries made random recommendations and repeated or contradicted the recommendations of fellow nations. The mechanism could benefit from a more focused interactive dialogue. The fact that the UPR introduces peer review into the mix of human rights monitoring machinery should also mean that the process adds to the human rights discourse in a unique way. One unique contribution would be the development of a forum for sharing best practices. Finally, the mechanism should also afford countries opportunities for meaningful exchange of those best practices.

In light of these observations, the following three improvements are suggested for the UPR process and discussed in depth below:

(1) Using expert mechanisms for focusing the review and interactive dialogue;

the Working Group on the Universal Periodic Review Cuba, Part 2, $\uparrow 10$, UN Doc. A/HRC/11/37 (Oct. 16, 2009); China also accepted recommendations, including recommendations to "Create conditions for an early ratification of the International Covenant on Civil and Political Rights (ICCPR) (Sweden); In accordance with its imperatives indicated by its national realities, to proceed to legislative, judicial and administrative reform as well as create conditions permitting the ratification, as soon as possible, of the ICCPR (Algeria); Analyse the possibility of ratifying/consider ratifying/ratify ICCPR (Argentina, Brazil, Austria);" Report of the Working Group on the Universal Periodic Review Cuba, Part 2, \1, UN Doc. A/HRC/11/25 (Mar. 3, 2009). 
(2) Making the three-hour review a way to share best practices; and

(3) Including recommendations that require site visits to nations to transfer policy and knowledge.

\section{A. Using the expert human rights mechanisms to inform the interactive dialogue}

The UPR was particularly adept at garnering the full compliance of UN Member States with the reporting requirement in its first cycle. This is in stark contrast to the Treaty Bodies, which have suffered from nonreporting and under reporting. It seems that the Treaty Bodies may wish to use their resources and expertise to inform the UPR. In other words, the Treaty Bodies can act as the agenda-setters for the UPR process by identifying one or two aspects of their individual subject matter that must be addressed by the state under review. This could be modeled on the OECD model, where the Secretariat develops a questionnaire to guide the national report and the examination itself is "chaired" by two member states. ${ }^{1043}$ The Treaty bodies could make their recommendations to the UPR process during the same time as the national report is being developed. These issues can then be the focus of the interactive dialogue and three-hour review.

By using the Treaty Bodies in this way, two weaknesses of the UPR can be addressed: the lack of a focused interactive dialogue and the need for more expert participation in the UPR. Two other issues would need to be considered: whether the Treaty Bodies would need to revamp the way they approach periodic reporting. Perhaps the Treaty Bodies would consider only receiving periodic reporting on the issues that they find most in need of attention so as to allow the UPR national report to be the core report for all UN Human Rights machinery. One additional possibility would be to adopt a practice similar to the ILO's procedure for addressing nations that are habitually non-compliant by having them appear before the Conference Committee. In the case of the UPR, the Treaty Bodies could be the forum where non-compliant countries appear to explain their inability to comply with the treaties they have ratified. In such a manner, the UPR would have a stronger process for addressing violations. In tandem with this suggestion would be a second related process where those nations who have signed a treaty, but failed to ratify it, explain before the Treaty Body members what steps they are taking to ratify and the obstacles the keep them from successfully doing so (echoing the ILO process where countries are still required to report on non-ratified instruments.)

When Treaty Bodies have informed the UPR of the one or two issues most in need of attention in a state under review, the interactive dialogue could be directed toward assisting the country to find ways to improve the situation within its borders. This would, in turn, require the interactive dialogue to be modified so as to become a place where best practices are shared. That is the subject of the next suggestion for improvement.

\section{B. Sharing best practices in the interactive dialogue}

The interactive dialogue is a three-hour process. In the first and second cycles, it has largely been dominated by two-minute statements by permanent missions, often covering the same subjects and repeating questions or recommendations. Since the UPR is the only opportunity for states to speak face-to-face, it would be useful if the three-hour dialogue could also include a time for best practices to be shared. Again, calling to mind the goals of peer review, one must remember that non-confrontational dialogue is only one of the goals. Other worthy objectives include: policy convergence, regulating policies and improving national policy making. These goals should also be highlighted in future cycles by tailing the interactive dialogue to bring such goals into focus.

If the Treaty Bodies have identified the issues that need attention, countries that have managed to address similar issues may briefly share the experiences from their own countries. The sharing of best practices serves to aid the country in identifying ways to tackle a challenging issue. In addition, it permits policy transfer and sharing of knowledge - two of the phenomena that occur in peer review settings. The knowledge transfer and sharing could be done on site in countries where a successful policy has been established, much like is done in the

\footnotetext{
${ }^{1043}$ Even if the OECD model were not copied, there are other ways to refocus the dialogue. For example, the Treaty Bodies could more resemble the Committee of Experts at the ILO. That Committee drives the dialogue with the State Party by identifying the issues that must be explained in the dialogue. Such a role would be useful in the UPR process because it would offer more focus and also require the country under review to give more specifics about the issues raised. The GRECO model of preparing questionnaires to be answered by the state under review and identifying themes for each round of reviews may also be a way to ensure that the interactive dialogue is more focused.
} 
Open Method of Coordination program in the EU.1044Eventually, with more sharing and implementation of such policies, the UPR can help nations achieve a convergence of policies and practices concerning human rights. This author already sees one such phenomenon occurring with the call of national action plans on human rights. If this practice continues and countries do continue to establish such plans, a time will come when the practice of having a coordinated and coherent plan to consider human rights at all levels of policy-making will exist in all UN Member States - such a result would be laudable.

Again, sharing best practices does not go far enough, the country must receive specific recommendations to approach those nations that can share in a more in-depth way the measures they took to deal with the problem. This is discussed in the next section.

\section{Recommendations to visit and exchange best practices and transfer knowledge and policies}

The discussion in Part Two regarding the Open Methods of Coordination used in the European Union demonstrated that peer review works when best practices are shared and visits are made to countries to observe how measures are implemented and policies put into practice. The UPR also needs to encourage such visits and sharing of best practices. Policy transfer and knowledge transfer can lead to capacitation of nations where human rights challenges are still unresolved.

In its final outcome, the Working Group of the Council should consider making some recommendations for site visits to particular countries to look at specific programs or action plans that tackle human rights challenges and issues. During the visits, the officials responsible should be available to discuss how the plans and policies were implemented. The visits should include the sites where the policies are carried out and ideally can also involve speaking with the people directly affected by the policies.

These visits require resources. As a result, the author also recommends that the Voluntary Fund be used to facilitate such visits for the countries which may have difficulties in raising the funds to travel. In addition, if a country has practices worth sharing, but is unable to afford the costs of hosting a visit, the Voluntary Fund should equally be available for such purposes.

\section{No formal requirement to report follow-up}

During the first cycle of the UPR, the follow-up procedures were not formally specified. One observer noted that Iran was asked to "take measures to prevent excessive use of force by security forces, guarantee freedom of expression, and limit capital punishment and torture," but there are no repercussions if Iran fails to comply. ${ }^{1045}$

This criticism is partially true. The modalities for the UPR do not have a specific format for reporting progress. However, the UPR was designed with the idea that the second cycle would be a follow-up to the first cycle and that countries would need to give an accounting for the progress made regarding the initial recommendations of the first cycle. To date, the second cycle has served to call countries into account regarding the recommendations they accepted from the first cycle.

In addition, several countries, including the Netherlands, Bahrain and others have opted to report during the interim period regarding the implementation of recommendations. Countries such as Denmark, Kenya, Australia and New Zealand have entrusted the monitoring of progress to the National Human Rights Institutions present in the country.

The advantage to having no formal requirement is to allow a certain flexibility in what is done in the interim between reporting periods. Some countries, like the Netherlands and Bahrain, have chosen to give written progress reports to the Human Rights Council, others have permitted national institutions to guide the process.

\footnotetext{
1044 The author has in mind the Open Method of Coordination discussed in Chapter Four. That model included site visits to other countries to hear the officials discuss and demonstrate how certain successful policies were put into place.

1045 Justin Shore, Universal Periodic Review: Problems and Potential, THE HUMAN RIGHTS BRIEF, APR. 6, 2010, at

http://hrbrief.org/2010/04/universal-periodic-review-problems-and-potential/.
} 
More important than a formal requirement is an ability to appreciate that different states may choose different means to measure the progress of implementation.

\section{Conclusion}

This inquiry has assessed the way in which the human rights discourse has been altered by the introduction of the Universal Periodic Review mechanism by asking the research question: Does the Universal Periodic Review change the human rights discourse nationally and/or internationally?

The findings of my research demonstrate that the UPR has changed the international human rights discourse by offering a new forum for discussion of human rights records of nations by peer states. In addition, the UPR has changed the national human rights discourse through the national consultation, which encourages greater opportunities for cooperation between governments, civil society and national human rights institutions. This is borne out by the experiences in the five nations of the case studies - The Netherlands, Denmark, Kenya, Hungary, and the United States of America. In those studies, it was shown that there are more actors from civil society, more frequency of contact between civil society and government. The manner of the discourse is modified as states find unique ways to consult - through townhall meetings or listening sessions. The content of human rights discoursed is enriched because all aspects of human rights are under scrutiny in the UPR.

My research had the following sub-questions:

- Does a peer review mechanism change the human rights discourse at the international level?

- Does government participation in the UPR change human rights discourse nationally and/or internationally?

- Does the participation of National Human Rights Institutions in the UPR change human rights discourse nationally and/or internationally?

- Does the participation of civil society in the UPR change the human rights discourse nationally and/or internationally?

Regarding the introduction of a peer review mechanism the study finds that peer review introduces a nonconfrontational process for giving critiques of human rights policies in the state under review while also sharing suggestions for improvement and best practices. Governments have new potential to engage with civil society in unique ways as a result of the national consultations and, in nations with NHRIs, new partnerships could emerge as NHRIs oversee and encourage implementation of recommendations from the UPR.

With respect to the government's participation, particularly as regards the national consultation, this inquiry finds a broadening of the subject matter and content of dialogue between governments, civil society and human rights institutions at the domestic level. There is potential for an enhanced level of cooperation and interaction among these groups has also been observed. In addition, governments like the Netherlands, Bahrain and others have been responsive to reporting on the progress of implementation of recommendations.

Both NHRIs and CSOs have also been found to have contributed to the increase in civil society participants as well as in the frequency of meetings with other CSOs or with government agencies responsible for human rights (though the Netherlands ministries do not see such a change in their experience). This author has also found that the UPR has changed the manner in which CSOs interacting with each other, as the UPR has offered new opportunities for joint stakeholder reports and collaboration in lobbying governments together with NHRIs, if present. The content of the human rights discourse now includes discussion of peer pressure in a peer review mechanism, rights discourse that cover the entire gamut of human rights and further strategizing for soft governance tactics such as NGOs meeting with government agencies to ask about progress on recommendations accepted or, in the case of NHRIs, drafting blueprints to force the government to identify the ministries responsible for implementation. 
What can be said to conclude this study of the UPR? First, I note that the UPR has appeared to have largely avoided the politicization that weighed down proceedings under the old Commission. Overall, in the first cycle, all of the countries were reviewed and all were subject to the same human rights standards. Countries were questioned about their rights by friends and foes alike. Even when we look at autocratic nations such as North Korea, Cuba, Iran or China, we see that the interactive dialogue included critical remarks and recommendations were accepted by most of these nations (except North Korea, which postponed its notice regarding which recommendations it would accept) to make changes in human rights policies. This is an important achievement that should not be overlooked because it highlights the potential for the longevity of the mechanism and the potential for meaningful improvements in the domestic human rights picture of all nations.

Secondly, this UPR has surpassed the old Commission mechanisms in two respects. The Commission machinery was only able to periodically review the human rights records of countries if the country ratified a human rights treaty. The UPR changes the content of the human rights discourse by permitting countries to be reviewed on the ensemble of human rights issues, regardless of whether they have ratified a relevant treaty, much like the ILO regime. For example, North Korea was criticized regarding its lack of free speech even though it is not a party to the ICCPR and the United States of America's housing policies were scrutinized though it has never ratified the ICESCR. In addition, the UPR does not have to rely on an individual complaint through the former 1503 procedure to consider the rights records of states. The UPR surpasses the 1503 procedure because it is done in the open, rather than behind closed doors, and it is not initiated through a complaint, but is conducted every 4.5 years on a periodic basis.

Thirdly, I acknowledge that most of the information gathered has related to the first cycle and the views of actors in that time frame. The second cycle is widely viewed by observants and participants of the UPR as the time when conclusions can be drawn regarding the ability of the UPR mechanism to truly assess progress. This is an area open for future scholarship. The second cycle will be the opportunity for nations to explain what steps they have taken to implement the recommendations accepted in the first cycle. Therefore, we can take a look at the first session of the second cycle to find some of the challenges that the second cycle will bring.

On March 16, 2012, the Human Rights Council held a general debate regarding the achievements and challenges of the UPR. During the debate states emphasized the need to follow-up on the recommendations received by reviewed States during the first cycle." 1046 Following the $13^{\text {th }}$ session and first round of reviews of the second cycle, the Council's general debate during the $20^{\text {th }}$ session was peppered with criticism for failure to address implementation of recommendations from the first cycle.

The Republic of Korea regretted that the focus of the first session in the second cycle was not the recommendations made in the first cycle nor the assessment of the effectiveness of the implementation of accepted recommendations. Consequently, the Republic of Korea expressed its anticipation that the focus on implementation be maintained, ensuring that recommendations made do improve the human rights situation on the ground and encouraged all States to maintain their commitments through concrete actions towards implementation. Austria called for a clear focus on implementation, for previously made recommendations to receive continued attention in the second cycle and to analyze and assess progress made on the implementation of recommendations. Moreover, UPR Info emphasized the failure of States in the 13th Session to address recommendations made in the 1st Session in a satisfactory manner highlighting that only $16 \%$ of 2008 recommendations were followed up by similar or additional recommendations in the 13th session. ${ }^{1047}$

\footnotetext{
1046 International Service for Human Rights, Council Debate on UPR: Raising the Bar for the Second Cycle at http://www.ishr.ch/uprnews/1282-council-holds-debate-on-upr-states-call-for-follow-up-to-recommendations.

${ }_{1047}$ UPR-Info.org, General Debate on the UPR Discusses Lack of Focus on Implementation and Reprisals Against Human Rights Defenders at http://www.upr-info.org/+General-debate-on-the-UPR+.html
} 
Fourteen states were reviewed in the first session of the second cycle. Observers note that the session was attended by all states scheduled for review and high level delegations were sent to Geneva. ${ }^{1048}$ Many states did assess the implementation of recommendations. ${ }^{1049}$ However, as noted above, the reviewing states did not follow up on the recommendations they had made in the previous cycle. ${ }^{1050}$ This is particularly disturbing because it suggests that recommendations will continue to accumulate through the review cycles without any real attempt to ensure that states are taking the proper steps to implement them.

Indonesia's review provides an example of how recommendations accepted in the first cycle were still awaiting implementation at the time of the second review. Some examples include recommendations regarding rights of the child such as the "Optional Protocol to the Convention on the Rights of the child on involvement of children in armed conflict" ${ }^{1051}$ When Slovenia made a recommendation to ratify the Optional Protocol, Indonesia accepted the recommendation in the final outcome for the second cycle review. ${ }^{1052}$

These additional anecdotes are examples of the challenges faced by the mechanism. Full participation and cooperation is not always guaranteed, as evidenced by the refusal of Israel to participate in its own peer review. The Working Group will need to consider whether to have a procedure for states that do not satisfactorily carry out their duties under the mechanism. Perhaps the GRECO procedures for such unsatisfactory performance can serve as a guide. Peer governments will also need to step up to challenge those flagging in zeal to keep cooperating with the mechanism. In addition, the process of reform must be viewed as an on-going method of continuous improvement. Flexibility will be key in ensuring the life of the review process.

The second session of the second cycle, held from April 22nd until May 3, 2013, saw other practices that represented challenges to the validity of the process. Uzbekistan and Russia rejected certain recommendations characterizing them as facually incorrect or politically motivated.

The challenges arising in the second cycle highlight the fact that the future of the UPR is still tenuous. It is a mechanism that relies on cooperation of the Member States. While politicization has not been eliminated from the UPR, it has enjoyed less polemic behavior than that of the Council - at least in the first cycle. This author asserts that the UPR will fare well if it continues to identify ways to strengthen its role in the human rights machinery. It will need to remain relevant by offering a forum for exchange of best practices and by identifying policies that can be harmonized across states. In addition, resources should always be made available to the OHCHR to continue the important role of data gathering and archiving of documents and webcasts.

This author is positive about the future of the mechanism because she believes human rights are poised to gain greater footing in the national policy-making culture. As civil society demands better and more effective promotion and protection of human rights by governments, this mechanism will enjoy the international support and attention it deserves. States will also gain better credibility and loftier reputations when they are perceived as compliant with the goals and objectives of the Universal Periodic Review. In addition, local societies will become ever more fluent in the discourse of human rights. This latter point will also strengthen the promotion and protection of human rights in local societies.

\footnotetext{
1048 UPR-Info.org, Newsletter 31 (May-June 2012) at http:/ / www.uprinfo.org/newsletter/archive.php? $x=106 \&$ listID=1\&layoutID=3\&pagerows=15\&pagenum=1 ${ }^{1049} \mathrm{Id}$.

$1050 \mathrm{Id}$.

1051 INTERNATIONAL SERVICE FOR HUMAN RIGHTS, Positive Steps Eclipsed by Matters of Grave Concern at http://www.ishr.ch/upr-news/1305-uprof-indonesia-positive-steps-eclipsed-by-matters-of-grave-concern

1052 Report of the Working Group on the Universal Periodic Review Indonesia, ๆ 108.4 UN Doc A/HRC/21/7, 5 July 2012.
} 


\section{ANNEX I - Interviews}

Name

Civil Servant**

Civil Servant ${ }^{* *}$

Civil Servant $2^{* *}$

Lis Dhundalee

Florence Elie

Martin Futtrup

ILO official $^{*}$

Jakob de Jonge

Orsolya Jeney

Gerbrig Klos

Bacre Waly Ndiaye

NYC Listening Session Organizer*

Antonina Okuta

Walter Oostelbos

Amanda Solter

Wendy van der Tol

Ugandan NGO official ${ }^{* *}$

\section{Affiliation}

Dutch Ministry of the Interior

Dutch Ministry of Foreign Affairs

Dutch Ministry of Foreign Affairs

Program Manager, Danish Institute for Human Rights

Protectrice

Office de la Protection du Citoyen et de la Citoyenne, Haiti

Legal Adviser, Danish Institute for Human Rights

International Labour Organization

Justitia et Pax (The Netherlands)

Amnesty International Hungary

Amnesty International (The Netherlands)

Director, UPR Division, OHCHR

\section{Coordinator}

Senior Human Rights Officer Kenyan Nat'l Comm'n on Human Rights

Strategic Adviser Migration Policy (Netherlands)

Research Assistant, U San Francisco Law School

Staffmember, Het College voor de Rechten van de Mens

Coordinator

\section{Interview Date}

April 10, 2013

September 6, 2012

April 25, 2013

February 7, 2012

March, 17, 2012

February 7, 2012

June 28, 2011

April 9, 2013

April 18, 2012

April 24, 2012 and April 8, 2013

March 17, 2012

February 21, 2012

February 16, 2012

$$
\text { April 6, } 2012
$$

February 15, 2012

$$
\text { May 14, } 2013
$$

March 20, 2012

\section{Type of Interview}

Landline telephone

Landline Telephone

Landline Telephone

Skype to landline telephone

In Person

Skype to landline telephone In Person Maastricht, the Netherlands

Landline telephone

$$
\text { Skype }
$$

Landline telephone

In Person

Skype to landline telephone

Skype with video

Skype to landline telephone

Skype with video

Landline telephone

In Person, Turku, Finland

* denotes anonymity requested by interviewee

** denotes anonymity granted at the discretion of the author for ethical reasons 


\title{
Annex II - Interview Questions
}

\section{INTERVIEW QUESTIONS: LISTENING SESSIONS IN USA'S UNIVERSAL PERIODIC REVIEW}

\author{
Role of the University of San Francisco School of Law in the United State of America's \\ Universal Periodic Review
}

USE OF INFORMATION:

Check the box to indicate the interviewees' preference regarding the use of the information from the telephone interview (choose from one of two options below):

The information given in this questionnaire CAN be attributed to me by name. (You will be permitted to review and approve the information prior to its dissemination and publication.)

This information is given on the condition of complete anonymity. (Your name will not be used in the dissemination and publication of the information given in the questionnaire.)

\section{QUESTIONS:}

1. Give your full name, your official title and explain your role in the listening session held at the U of San Francisco.

2. Who took the first initiative to propose that a listening session be held at U San Francisco?

3. Who was involved in determining what individuals and civil society groups would be invited to the listening session?

4. How where the themes to be raised in the listening session chosen?

5. What goals did the planning committee have regarding how they hoped the information and issues raised in the listening session would be used by the State Department?

6. Describe the listening sessions and format. (Please explain whether there were visual aids, handouts or other ways in which the information given by the panelists were expressed.)

7. Did you follow up with the State Department to see how the issues were being included in the national report? If so, what steps were taken?

8. Was a stakeholder report submitted? If not, explain why not?

9. Did you or members of your team go to or watch the webcast of the review in Geneva? If so, indicate whether you thought your issues were adequately expressed during the interactive dialogue.

10. Have you read the final recommendations? If so, do you believe your issues were adequately represented in the final recommendations? Were they accepted by the government?

11. Have you/will you follow up to see how the recommendations are being implemented by the government?

12. What were the contributions of the listening session to the way civil society organizations defend human rights? 


\section{Annex III - Propositions}

1. The Universal periodic Review mechanism is the leading UN process for bringing attention to the human rights records of UN Member States.

2. The national consultation phase of the Universal Periodic Review process should be promoted in side events in Geneva to spread best practices for governments when interfacing with their grassroots constituents to get a picture of how human rights are realized by citizens.

3. The interactive dialogue of the Universal Periodic Review should also include more pointed questioning regarding violations or failure to implement recommendations with the expectation that the state under review will have to give a satisfactory explanation.

4. Future research regarding the Universal Periodic Review should focus on whether states properly implemented recommendations from the first cycle of the Universal Periodic Review.

5. Human rights, basic rights owed to all human beings, must be promoted and protected through a variety of processes, but the Universal Periodic Review should be the flagship process of the UN human rights machinery because it involves all human rights and obligations.

6. Human rights organizations benefit from critical analyses of the United Nations Human Rights machinery and institutions, including dissertations that analyze the governance aspects.

7. While substantive research regarding human rights policies are needed, the procedural and institutional roots of human rights should not be ignored because poor processes impact the ability to make substantive changes.

8. More interdisciplinary approaches to research are needed in the field of human rights to broaden the way human rights violations are addressed, pure doctrinal analysis of human rights norms is of little value for correcting violations.

9. International education is the key to sharing research, teaching methods and the spread of new ideas within academia; therefore, universities should develop joint degree programs for the study of human rights. 


\section{BIBLIOGRAPHY}

Abebe, Allehone Mulugeta, Of Shaming and Bargaining: African States and the Universal Periodic Review of the United Nations Human Rights Council, 9 Human Rights Law Review (2009).

Alston, Philip. Reconceiving the UN Human Rights Regime: Challenges Confronting the New UN Human Rights Council, 7 Melbourne Journal of International Law 185 (2006).

Amnesty, International, Netherlands: Protecting Human Rights at Home, Amnesty International Submission to the UN Universal Periodic Review, May-June 2012.

Dutch section. Statement of Amnesty International delivered by Gerbrig Klos, Senior policy Officer Amnesty International

BENZ, ARTHUR, Accountable Multilevel Governance by the Open Method of Coordination, 13 European Law Journal (2007).

BERNAZ, NADIA, Reforming the UN Human Rights Protection Procedures: A Legal Perspective on the Establishment of the Universal Periodic Review Mechanism, in New Institutions for Human Rights Protection: The Collected Courses of the Academy of European Law (Kevin Boyle ed. 2009).

Black's LaW Dictionary, (Bryan A. Garner ed., West Thomson Reuters 9th ed.).

BOEREFIN, InEKe, The Reporting Procedure Under the Covenant on Civil and Political Rights (Intersentia. 1999).

Burall, Simon \& Neligan, CARoline, The Accountability of International Organizations, GPPi Research Paper Series No. 21.

Claire Callejon, Developments at the Human Rights Council in 2007: A Reflection of its Ambivalence, 8 Hum. Rts. L. Rev. 323 (2008).

Chayes, Abram \& Chayes, Antonia Handler, The New Sovereignty (Harvard University Press. 1995).

CHebor, SAmmy, Kenya to Give Rights Scorecard, http://www.nation.co.ke/News/Kenya\%20to\%20give\%20rights\%20scorecard/-/1056/898418/-/lv5f5lz//index.html.

Chukwumerije, Okezie, Peer Review and the Promotion of Good Governance in Africa, 32 North Carolina Journal of International Law and Commercial Regulation (2006).

Cisneros de AlEnCAR, ANTONIO M., Cooperation Between the Universal and Inter-American Human Rights Systems in the Framework of the Universal Periodic Review Mechanism 7 Sur International Journal on Human Rights 13 (2010), at 171-183.

Cochrane, LeAnNe \& Kathryn MCNeilly, The United Kingdom, the United Nations Human Rights Council and the First Cycle of the Universal Periodic Review, 17 International Journal of Human Rights 1 (2012), at 152-177.

COMley, Blair, Peer Review in the Context of Regional Integration Australian Government Treasury, http://www.treasury.gov.au/documents/1268/PDF/02_Peer_review.pdf.

COnZelmann, Thomas, Reporting and Peer Review in the Implementation of International Rules: What Role for Non-State Actors?, in The Ashgate Research Companion to Non-State Actors (Bob Reinalda ed. 2011).

CoOmans, Fons; Grunfeld Fred \& Kamminga, Menno T., Methods of Human Rights Research (Intersentia 2009). Beyond the Carrot and the Stick: State Reporting Procedures in the World Trade Organization and the Organization for Economic Cooperation and Development, in International Organizations and Implementation (Jutta Joachim ed. 2008).

CURRY-SUMNER, IAN ET AL., Research Skills Instruction for Lawyers (Ars Aequi Libri. 2010). 
Danish Institute for Human Rights, Universal Periodic Review First Cycle: Reporting Methodologies from the Position of the State, Civil Society and National Human Rights Institutions,

http://idsn.org/fileadmin/user_folder/pdf/New_files/UN/UPR_First_Cycle_DIHR_.pdf.

Davies, Martin Brett, Doing a Successful Research Project, 209-228 ( Palgrave Macmillan 2007).

De la Vega, COnStance. \& Lewis, TAMARA, Peer Review in the Mix: How the UPR Transforms Human Rights Discourse, in New Challenges for the UN Human Rights Machinery: What Future for the UN Treaty Body System and the Human Rights Council Procedures? Bassiouni, M. Cherif \& Schabas, William A. eds. (Intersentia 2011).

Dominguez Redondo, Elvira, The Universal Periodic Review of the UN Human Rights Council: An Assessment of the First Session, 7 Chinese Journal of International Law (2008).

The Universal Periodic Review - Is There Life Beyond Naming and Shaming in Human Rights Implementation?, available at http:// papers.ssrn.com/sol3/papers.cfm?abstract_id=2111607.

DopHEIDE, T., Universal Periodic Review, Het grote mensenrechtenexamen van de VN, 33 NJCM-Bulletin 6 (2008), at 891-901.

Engle Merry, SAlly Anthropology and Activism: Researching Human Rights Across Porous Boundaries, 28 PoLAR 240(2005). New Legal Realism and the Ethnography of Transnational Law, 31 Law \& Social Inquiry 974(2006).

FAirclough, Norman, Language and Power (Pearson Education, 2001)

FLICK, UWE, Designing Qualitative Research (Sage Publications Ltd. 2007).

Freedman, R. New Mechanisms of the UN Human Rights Council, 29 Netherlands Quarterly of Human Rights (2011).

GAER, Felice D.,.A Voice Not an Echo: Universal Periodic Review and the UN Treaty Body System, 7 Human Rights Law Review (2007).

FORSYTHE, DAVID, Human Rights in International Relations (Cambridge University Press, 2012).

Gordon, Neve \& Berkovitch, Nitza, Human Rights Discourse in Domestic Settings: How Does it Emerge?, 55 Pol. Sci. Studies 243, 243-246 (2007).

GERrING, JOHN, Case Study Research: Principles and Practices (Cambridge Press, 2007).

GROENENDIJK, NiCO, The EU and OECD Benchmarking and Peer Review Compared (European Union Centre of Excellence 2009).

GUILMETTE, JEAN H \& RUDNER, MARTIN, The OECD Approach and it Relevance to the Management of the Dnieper River Basin, The International Development Research Centre (2000).

Hamilton, Neil W., The Ethics of Peer Review in the Academic and Legal Professions, South Texas Law Review (2001).

Harrington, JoAnna, Canada, the United Nations Human Rights Council, and Universal Periodic Review, 18 Constitutional Forum 79 (2009) at 79-93.

CHRIS HART, Doing a Literature Search: A Comprehensive Guide for the Social Sciences (Sage Publications, 2003)

HELFER, LAURENCE R., Understanding Change in International Organizations: Globalization and Innovation in the ILO, 59 Vanderbilt Law Review (April 2006).

JacobSSOn, Kerstin, Between Deliberation and Discipline: Soft Governance in EU Employment Policy, in Soft Law in Governance and Regulation: An Interdisciplinary Analysis (Ulrika Morth ed. 2004).

Kanbur, RaVI, The African Peer Review Mechanism (APRM): An Assessment of Concept and Design. (2004), http://www.arts.cornell.edu/poverty/kanbur/APRM.pdf.

Kenyan National COMmission for Human Rights, Accounting for Human Rights Protection Under the UPR: The Difference Kenya's Stakeholders Made, (September 2011).

KSC-UPR, Kenya Stakeholder Coalition for the Universal Periodic Review, http://lib.ohchr.org/HRBodies/UPR/Documents/Session8/KE/KSC_UPR_KEN_S08_2010_KenyaStakeholdersCoa litionforUPR.pdf. 
Keohane, Robert O. \& Grant, Ruth W., Accountability and Abuses of Power in World Politics, 99 American Political Science Review (2005).

KeOHAne, Robert O., Exploring the Governance Agenda of Corporate Reponsibility: Complex Accountability and Power in Global Governance: Issues for Global Business, 8 Corporate Governance 361(2008).

KILDAL, NANNA, Perspectives on Policy Transfer: The Case of the OECD at http://www.ub.uib.no/elpub/rokkan/N/N13-03.pdf.

Killander, Magnus, The African Peer Review Mechanism and Human Rights: The First Reviews and the Way Forward, 30 Human Rights Quarterly (2008).

KIRCHMEIER, FELIX, Inaugural Session of the United Nations Human Rights Council Geneva 19 to 30 June 2006, Friedrich Ebert Stiftung (July 2006).

LANDMAN, Todd, Studying Human Rights (Routledge,

LAWSON, RicK, How to Maintain and Improve Mutual Trust Amongst EU Member States in Police and Judicial Cooperation in Criminal Matters? Lessons from the Functioning of Monitoring Mechanisms in the Council of Europe (Dane, Marlen and Klip, Andre eds., Celsus Legal Publishers.).

LEECH, BeTH L., Interview Methods in Political Science, 35 Political Science \& Politics 663(2002).

Lehtonen, MARKKu, Deliberative Democracy, Participation, and OECD Peer Reviews of Environmental Policies, 27 American Journal of Evaluation (2006).

(2005). OECD Environmental Performance Review Programme: Accountability (f)or Learning?, 11 Evaluation

LENNARD, NATASHA, The Human Rights of Home NY Times, http:/ / cityroom.blogs.nytimes.com/2010/03/01/thehuman-rights-of-home/?pagemode=print.

LILLIEBJERG, MARIANNE, Interim, Email ( February 14, 2012).

LOMBARDi,DOMEnICO \& WoOds, NGaIRE, The Politics of Influence: An Analysis of IMF Surveillance, 15 Review of International Political Economy.

Macdonald, Roderick A., Metaphors of Multiplicity: Civil Society, Regimes, and Legal Pluralism, 15 Arizona Journal of International \& Comparative Law 69(1998).

MARCUSSEN, MARTIN, OECD Governance Through Soft Law, in Soft Law in Governance and Regulation (Ulrika Morth ed. 2004).

MARTENS, KERSTIN ET AL. Introduction: The OECD as an Actor in International Politics, in Mechanisms of OECD Governance (Kerstin Martens ed. 2011).

MAXWELL, JosePH A.Designing a Qualitative Study, in The Handbook of Applied Social Research Methods (Leonard \& Rog Bickman, Debra ed. 2008).

MCMAHON, EDWARD \& MARTA ASCHERIO, Analysis of Recommendations of the Universal Periodic Review Sessions IVI, Friedrich Ebert Stiftung (October 2010).

McMaHOn, EdWARD, The Universal Periodic Review: A Work in Progress, An Evaluation of the First Cycle of the New UPR Mechanism of the United Nations Human Rights Council, Friedrich Ebert Stiftung (September 2012).

Milman-Sivan, Faina, The Virtuous Cycle: A New Paradigm for Democratizing Global Governance Through Deliberation, 30 Comparative Labor Law \& Policy Journal (2008-09).

MomAnI, BEssma, Assessing the Utility of, and Measuring Learning from, Canada's IMF Article IV Consultations, 39 Canadian Journal of Political Science (2006).

NOWAK, MANFRED, Introduction to the International Human Rights Regime (Martinus Nijhoff Publishers. 2003).

OPIYO, PETER, Chaos Trials, TJRC to Feature in Geneva at http:/ / www.standardmedia.co.ke/archives/news/InsidePage.php?id=2000007635\&cid=159\&story $=$ Chaos $\% 20$ trials, \%20TJRC $\% 20$ to $\% 20$ feature $\% 20$ in $\% 20$ Geneva. 
Organization of Economic Cooperation and Development, Peer Review: Merits and Approaches in a Trade and Competition Context. (2002),

http:/ / www.oecd.org/officialdocuments/displaydocumentpdf?cote=com/td/daffe/comp(2002)4/final\&doclangua ge $=$ en.

, Practical Modalities of Peer Review in a Multilateral Framework on Competition (2003),

http:/ / www.oecd.org/officialdocuments/displaydocumentpdf?cote=com/daffe/td(2002)82/final\&doclanguage=en

Issues for Trade and Competition in the Global Context: A Synthesis (2003),

http:// www.oecd.org/officialdocuments/publicdisplaydocumentpdf/?cote=CCNM/GF/COMP/TR(2003)3\&docLa nguage $=$ En.

O'Flaherty, M ichael \& Tsai, PeI-Lun, Periodic Reporting: The Backbone of the UN Treaty Body Review Procedures, in New Challenges for the UN Human Rights Machinery: What Future for the UN Treaty Body System and the Human Rights Council Procedures? (Bassiouni, M. Cherif \& Schabas William A. eds., Intersentia 2011).

PAGAnI, FABrizIO, Peer Review: A Tool for Co-operation and Change, An Analysis of an OECD Working Method (2002

Patrick \& Chapman McNeill, Steve, Research Methods (Routledge Third ed. 2005).

PAULY, LOUIS W., IMF Surveillance and the Legacy of Bretton Woods (2006)

PRECKEL, KIRA \& Rosaline Willi, The Role of Civil Society in the Universal Periodic Review: Human Dignity, in Your Hands? in European Yearbook on Human Rights, (Wolfgang Benedek, Florence BenoitRohmer, Wolfram Karl, Manfred Nowak, eds., 2012), at 417-432.

Radaelli, Claudio M., The Open Method of Coordination: A New Governance Architecture for the European Union? Swedish Institute for European Policy Studies, 2003.

RATHgEBer, THEODOR, The HRC Universal Periodic Review: A Preliminary Assessment, Friedrich Ebert Stiftung (July 2008).

RuHL, J.B. \& SAlzMan, James, In Defense of Regulatory Peer Review, 38 Environmental Law Reporter News and Analysis (2008).

In Defense of Regulatory Peer Review, 84 WASH. U. L. REV. 1, 12 (2006).

SABEL, CHARLES F.\& ZEITLIN, JONATHAN, Learning from Difference: The New Architecture of Experimentalist Governance in the European Union, European Governance Papers (EUROGOV) No. 2-07-02, 2007.

SCHAFER, ARMIN, A New Form of Governance? Comparing the Open Method of Co-ordination to Multilateral Surveillance by the IMF and the OECD, 13 Journal of European Public Policy (2006).

ScotT, Alister, Peer Review and the Relevance of Science, 39 Futures (2007).

Seale, Clive, The Quality of Qualitative Research (Sage Publications, 1999).

SEN, PERnA, Universal Periodic Review of Human Rights: Towards Best Practice (Commonwealth Secretariat, 2009).

Secretariat, 2011).

Universal Periodic Review: Lessons, Hopes and Expectations (Commonwealth

Smith, RHONA K.M., Equality of 'Nations Large and Small': Testing the Theory of the Universal Periodic Review in the Asia-Pacific, 2 Asia-Pacific Journal on Human Rights and the Law (2011), at 36-54.

The Pacific Island States: Themes Emerging from the United Nations Human Rights Council's Inaugural Universal Periodic Review? 13 Melbourne Journal of International Law 1 (2012), at 1-26.

SweEney, Gareth \& SAITO, Yuri An NGO Assessment of the New Mechanisms of the UN Human Rights Council, 9 Human Rights Law Review (2009).

Travers, MAx, Qualitative Research Through Case Studies (Sage Publication

United NATIONS, RePOrT OF THE SeCRetary General, In Larger Freedom: Towards Development, Security and Human Rights for All (2005). 
Yearbook of the United Nations 2005: Sixtieth Anniversary Edition - Towards Development, Security and Human Rights for All (UN Dep't of Public Information ed. 2008).

Working With the United Nations Human Rights Programme: A Handbook for Civil Society (2008).

United States Department of State, Civil Society Consultation for the U.S. Universal Periodic Review: Albuquerque, New Mexico and Window Rock, Arizona at http://www.state.gov/documents/organization/144253.pdf.

Civil Society Consultation for the U.S. Universal Periodic Review: Birmingham, Alabama at http://www.state.gov/documents/organization/144259.pdf.

Department of Homeland Security/Community Roundtable for the U.S. Universal Periodic Review:

Chicago, Illinois at http://www.state.gov/documents/organization/144258.pdf.

, Civil Society Consultation for the U.S. Universal Periodic Review: Washington, DC April 28, 2010 at

http://www.state.gov/documents/organization/144260.pdf.

, Civil Society Consultation for the U.S. Universal Periodic Review: San Francisco, California at http://www.state.gov/documents/organization/144255.pdf.

Civil Society Consultation for the U.S. Universal Periodic Review: New York, New York February 26, 2010 at http://www.state.gov/documents/organization/144251.pdf.

van Hoof, G.J.H. \& DE Vey Mestdagh, Mechanisms of International Supervision (P. Van Dijk ed., Kluwer 1984).

VerRest, P.A.M. \& T. DopheIDE, De evaluatie van Nederland in het kader van de Universal Periodic Review, 6 Justiele Verkenningen (Oct. 2012), at 11-21.

VON KEYSERLINGK, GISELA, Fifth Session of the UN Human Rights Council, Friedrich Ebert Stiftung, (June 2007 No. 6).

VengoecheA-Barrios, JulianA, The Universal Periodic Review: A New Hope for International Human Rights Law or A Reformulation of Errors of the Past? 12 Revista Colombiana de Derecho Internacional (2008), at 101-116.

Virelli, LouIS J.Scientific Peer Review and Administrative Legitimacy, 61 Administrative Law Review 723(2009).

Washington, Monica J., The Practice of Peer Review in the International Nuclear Safety Regime, 72 New York University Law Review (1997).

YEBOAH, NANA, The Establishment of the Human Rights Council, in Managing Change at the United Nations, 83 (Center for UN Reform Education 2008), available at http://www.centerforunreform.org/node/308.

\section{Treaties}

Universal Declaration of Human Rights, Article 1, http://www.un.org/en/documents/udhr/index.shtml.

INTERNATIONAL COVENANT ON Civil AND POLITICAL Rights, http://www2.ohchr.org/english/law/ccpr.htm.

INTERNATIONAL COVENANT ON ECONOMIC SOCIAL AND CULTURAL RigHTS,

http://www2.ohchr.org/english/law/cescr.htm.

CHARTER OF THE United NATIONS, Chapter 1 (Article 1).

\section{UN Documents}

Advanced Questions to Kenya, Add. 2 at

http://lib.ohchr.org/HRBodies/UPR/Documents/Session8/KE/kenyaAdd.2.pdf.

Compilation Prepared by the Office of the High Commissioner for Human Rights in Accordance with Paragraph 15

(b) of the Annex to Human Rights Council Resolution 5/1 - Kenya, UN Doc A/HRC/WG.6/8/KEN/2

Compilation Prepared by the Office of the High Commissioner for Human Rights in Accordance with Paragraph 15

(b) of the Annex to Human Rights Council Resolution 5/1 - Denmark, UN Doc A/HRC/WG.6/11/DNK/2

Consultation Agenda, New York UPR Human Rights Consultation, February 26, 2010 
Human Rights Council Res. 5/1, Rep. of the Human Rights Council, 5th Sess., 11-18 June 2007, UN GAOR, 62nd Sess., Supp No. 53, A/62/53/, at 48 (18 June 2007)

HRC Res 16/21, UN Doc A/HRC/RES/16/21, 21 March 2011

HRC Res 17/119, UN Doc /HRC/DEC/17/119, 17 June 2011

Human Rights Council, Decision 6/102 Follow-up to Human Rights Council resolution 5/1, (27 September 2007)

National Report Submitted in Accordance With Paragraph 15(a) of the Annex to Human Rights Council Resolution 5/1 Denmark, UN Doc. A/HRC/WG.6/11/DNK/1

National Report Submitted in Accordance with Paragraph 15 (a) of the Annex to Human Rights Council Resolution 5/1 - The Netherlands, UN Doc A/HRC/WG.6/1/NDL/1

National Report Submitted in Accordance with Paragraph 5 of the Annex to Human Rights Council Resolution 16/21 - Netherlands, UN Doc A/HRC/WG.6/13/NDL/1

National Report Submitted in Accordance with Paragraph 15 (a) of the Annex to Human Rights Council Resolution 5/1 - Kenya, UN Doc A/HRC/WG.6/8/KEN/1

National Report Submitted in Accordance with Paragraph 15 (a) of the Annex to Human Rights Council Resolution 5/1 - United States of America, UN Doc A/HRC/WG.6/9/USA/1

Hungary, Amnesty International Submission to the UN Universal Periodic Review 11th Session of the UPR Working Group, May 2011. (2010).

National Report Submitted in Accordance with Paragraph 15 (a) of the Annex to Human Rights Council Resolution 5/1 - Hungary, UN Doc A/HRC/WG.6/11/HUN/1

Paris Principles Relating to the Status and Functioning of National Institutions for the Protection and Promotion of Human Rights, annex to UNGA Res. 48/134 UN Doc A/RES/48/134 (20 December 1993)

Report of the Working Group on the Universal Periodic Review Hungary, UN Doc A/HRC/18/17, 11 July 2011

Report of the Working Group on the Universal Periodic Review The Netherlands, UN Doc A/HRC/8/31, 13 May 2008

Report of the Working Group on the Universal Periodic Review - Denmark, UN Doc A/HRC/18/4

Report of the Working Group on the Universal Periodic Review Kenya, UN Doc A/HRC/15/8, 17 June 2010

Report of the Working Group on the Universal Periodic Review -- Denmark, Addendum, Views on Conclusions and/or Recommendations, Voluntary Commitments and Replies Presented by the State Under Review, UN Doc A/HRC/18/4/Add.1

Report of the Working Group on the Universal Periodic Review Timor-Leste, UN Doc A/HRC/19/17, 3 January 2012

Submission by the Danish Institute for Human Rights to the Universal Periodic Review of Denmark 2nd May 2011, 11th Session of the Working Group Under the UN Human Rights Council

Summary prepared by the Office of the High Commissioner for Human Rights in accordance with paragraph 15 (c) of the annex to Human Rights Council resolution 5/1 - The Netherlands, UN Doc. A/HRC/WG.6/1/NLD/3 (13 March 2008).

Summary prepared by the Office of the High Commissioner for Human Rights in accordance with paragraph 5 of the annex to Human Rights Council resolution 16/21 - The Netherlands, UN Doc. A/HRC/WG.6/13/NLD/3 (12 March 2012).

Summary Prepared by the Office of the High Commissioner for Human Rights in Accordance with Paragraph 15 (c) of the Annext to Human Rights Council Resolution 5/1 - Kenya, UN Doc A/HRC/WG.6/8/KEN/3

Summary Prepared by the Office of the High Commissioner for Human Rights in Accordance with Paragraph 15 (c) of the Annext to Human Rights Council Resolution 5/1 - Denmark, UN Doc A/HRC/WG.6/11/DNK/3

UN Human Rights Council - Universal Periodic Review Kenya's Human Rights Balance Sheet

UNGA Res 60/251, 15 March 2006 


\section{Websites}

Australian Human Rights Commission, About The Australian Human Rights Commission.

Australian Human Rights Commission, The Australian Human Rights Commission's Complaint Process at http://www.hreoc.gov.au/complaints_information/complaints_flyers/complaints_process_flyer.html.

Australian Human Rights COMMISsion, Annual Report 2009-2010 at http://www.hreoc.gov.au/pdf/about/publications/annual_reports/2009_2010/AHRC2009_2010_complete.pdf.

City of Pittsburgh Citizens Police Review Board, City of Pittsburgh, at http://www.city.pittsburgh.pa.us/cprb/.

COUNCIL OF EUROPE, What is GRECO?, at

http://www.coe.int/t/dghl/monitoring/greco/general/3.\%20What\%20is\%20GRECO_en.asp.

COUNCIL OF EUROPE, Statute of the GRECO, at

http://www.coe.int/t/dghl/monitoring/greco/documents/statute_en.asp.

COUNCIL OF EUROPE, How Does GRECO Work?, at

http://www.coe.int/t/dghl/monitoring/greco/general/4.\%20How $\% 20$ does $\% 20$ GRECO $\% 20$ work_en.asp.

COUNCIL OF EUROPE, GRECO Rules of Procedure, at

http://www.coe.int/t/dghl/monitoring/greco/documents/Greco(2010)9_RulesOfProcedure_EN.pdf.

COUNCIL OF EUROPE, GRECO Evaluations, at

http://www.coe.int/t/dghl/monitoring/greco/evaluations/index_en.asp.

EuROPEAN COMMISSION, Operational Guide - Peer Reviews at http://www.peer-review-social-inclusion.eu/peerreviews.

Lisbon European Council 23 and 24 March 2000 Presidency Conclusions. (2000).

European Commission).

Operational Guide - Peer Reviews (Social Affairs and Inclusion DG Employment ed.,

DANISH InSTITUTE FOR HumAn RigHTS, Who We Are: The Mandate of Danish Institute for Human Rights,

http:// www.oecd.org/officialdocuments/publicdisplaydocumentpdf/?cote=CCNM/GF/COMP/TR(2003)3\&docLa $\underline{\text { nguage }=\text { En }}$

DIHR's Mandate, http://www.humanrights.dk/who+we+are/dihr's+mandate

INTERNATIONAL LABOUR ORGANIZATION, About the ILO: Origins \& History, at http://www.ilo.org/global/About_the_ILO/Origins_and_history/lang--en/index.htm.

ILO CONSTITUTION, at http://www.ilo.org/ilolex/english/constq.htm.

INTERNATIONAL LABOUR ORGANIZATION, About the ILO: Tripartism.

INTERNATIONAL LABOUR OFFICE, Handbook of Procedures Relating to International Labour Conventions and Recommendations at http://www.ilo.org/wcmsp5/groups/public/---ed_norm/---normes/documents/publication/wcms_087791.pdf.

INTERNATIONAL MONETARy FUnD, About the IMF: Cooperation and Reconstruction (1944-71).

IMF InDEPENDENT Evaluation OfFICE, The IMF's Multilateral Surveillance: Issues Paper for an Evaluation by the Independent Evaluation Office (IEO) at http://www.imf.org/External/NP/ieo/2005/ms/eng/092305.pdf.

IMF, IMF Surveillance -- The 2007 Decision on Bilateral Surveillance(2011), at http://www.imf.org/external/np/exr/facts/surv07.htm.

INTERNATIONAL MONETARy FUnD, IMF Surveillance(2011), at http://www.imf.org/external/np/exr/facts/surv.htm.

INTERNATIONAL MONETARY FUnD, Surveillance at http://www.imf.org/external/about/econsurv.htm.

IMF LeGAL DEPARTMENT, The Fund's Mandate -- The Legal Framework(2010), at

http://www.imf.org/external/np/pp/eng/2010/022210.pdf.

INTERNATIONAL MONETARY Fund, Articles of Agreement of the IMF. 
International Monetary Fund, IMF Executive Board Concludes 2009 Article IV Consultation with the Kingdom of the Netherlands - Netherlands Public Information Notice (PIN) No. 10/17; February 2, 2010 at

http://www.imf.org/external/np/sec/pn/2010/pn1017.htm.

NEPAD, African Peer Review Mechanism, The New Partnership for Africa's Development(2011), http://www.nepad.org/economicandcorporategovernance/african-peer-review-mechanism/about.

New York City Civilian Complaint Review Board, City of New York Police Department, at http://www.nyc.gov/html/ccrb/pdf/English.pdf.

New York City Civilian Complaint Review BoARd, CCRB Case Profiles, at http://www.nyc.gov/html/ccrb/html/profiles.html.

New York City CiviLIAN COMPLAint Review BOARD, http://www.icac.nsw.gov.au/documents/doc_download/2213new-york-police-department-preventing-crime-and-corruption\#P345_52509.

OfFice of ECONOMic COOPERATION AND DeVElopment, Peer Review in Economic Surveys: the Role of the EDRC, http://www.oecd.org/document/23/0,3746,en_21571361_37949547_37970135_1_1_1_1,00.html.

OfFice Of THE High COMMISSIONER FOR Human Rights, First Session of the Universal Periodic Review, at http://www.ohchr.org/EN/NEWSEVENTS/Pages/UPR_1stSsession.aspx

Office of the High COMmissioner FOR Human Rights, The United Nations Human Rights System: How to Make It Work for You at http://www.un-ngls.org/IMG/pdf/Final_logo.pdf.

OfFice of the High COMmissioner for Human Rights United NATIONS Human Rights, Complaint Procedure, at http://www.ohchr.org/EN/HRBodies/HRC/Pages/Complaint.aspx.

OfFice of the High COMmissioner for Human Rights United Nations Human Rights, Special Procedures of the Human Rights Council: Introduction, at http://www.ohchr.org/EN/HRBodies/SP/Pages/Welcomepage.aspx.

OfFice of the High Commissioner for Human Rights United Nations Human Rights, Communications, http://www.ohchr.org/EN/HRBodies/SP/Pages/Communications.aspx.

ORGANIZATION OF ECONOMIC CO-OPERATION AND DEVELOPMENT, Examples of Peer Review, OECD, http://www.oecd.org/document/8/0,3746,en_21571361_37949547_37970056_1_1_1_1,00.html.

UPR-INFO.ORG, UPR Info Wraps up a Dynamic First Round of "Pre-Sessions" at http://www.upr-info.org/+UPR-Infowraps-up-a-dynamic-first+.html. 


\section{Curriculum Vitae}

Tamara Nicolle Lewis Arredondo is a native of Minnesota, USA. She studied International Relations at the Edmund A. Walsh School of Foreign Service at Georgetown University in Washington, D.C. where she earned a Bachelor of Science in Foreign Service. Thereafter, she studied law at Columbia University School of Law in New York City. Following admission to the New York Bar, she practiced law in the area of corporate, finance and banking at Kaye, Scholer, Fierman, Hays \& Handler. Miss Lewis left the practice of law and dedicated several years to teaching at the primary and secondary school levels in New York and New Jersey. She returned to the field of law in 2001, joining a racial discrimination project at the Office of the Monitor in St. Paul, Minnesota.

In 2007, Lewis won the prestigious Fulbright Fellowship to learn Arabic in Sana'a, Yemen and to complete an LL.M. degree at Utrecht University in the Netherlands. She graduated summa cum laude and wrote her master's thesis on "Fair Trial Guarantees of the Iraqi High Tribunal." Miss Lewis completed this doctoral dissertation as a lecturer and researcher at Maastricht University Faculty of Law in the Netherlands. 